\title{
Hemolysis, microcirculatory changes and organ injury induced by cardiovascular surgery
}

Citation for published version (APA):

Hanssen, S. J. P. (2011). Hemolysis, microcirculatory changes and organ injury induced by cardiovascular surgery. [Doctoral Thesis, Maastricht University]. Datawyse / Universitaire Pers Maastricht. https://doi.org/10.26481/dis.20110930sh

Document status and date:

Published: 01/01/2011

DOI:

10.26481/dis.20110930sh

Document Version:

Publisher's PDF, also known as Version of record

\section{Please check the document version of this publication:}

- A submitted manuscript is the version of the article upon submission and before peer-review. There can be important differences between the submitted version and the official published version of record.

People interested in the research are advised to contact the author for the final version of the publication, or visit the DOI to the publisher's website.

- The final author version and the galley proof are versions of the publication after peer review.

- The final published version features the final layout of the paper including the volume, issue and page numbers.

Link to publication

\footnotetext{
General rights rights.

- You may freely distribute the URL identifying the publication in the public portal. please follow below link for the End User Agreement:

www.umlib.nl/taverne-license

Take down policy

If you believe that this document breaches copyright please contact us at:

repository@maastrichtuniversity.nl

providing details and we will investigate your claim.
}

Copyright and moral rights for the publications made accessible in the public portal are retained by the authors and/or other copyright owners and it is a condition of accessing publications that users recognise and abide by the legal requirements associated with these

- Users may download and print one copy of any publication from the public portal for the purpose of private study or research.

- You may not further distribute the material or use it for any profit-making activity or commercial gain

If the publication is distributed under the terms of Article $25 \mathrm{fa}$ of the Dutch Copyright Act, indicated by the "Taverne" license above, 
Hemolysis, Microcirculatory Changes

and Organ Injury Induced

by Cardiovascular Surgery 


\section{iutfim}

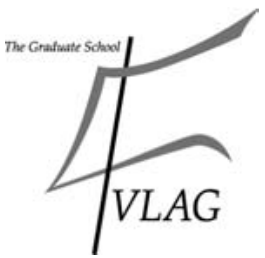

The studies presented in this thesis were performed within the Cardiovascular Research Institute Maastricht (CARIM) an institute under the Dutch University Education Act (WWO) and the Nutrition and Toxicology Research Institute Maastricht (NUTRIM), which participates in the Graduate School VLAG (Food Technology, Agro-biotechnology, Nutrition and Health Sciences), accredited by the Royal Netherlands Academy of Arts and Sciences (KNAW).

The publication of this thesis was financially supported by Profileringsfonds MUMC'.

\section{S.J.P. Hanssen, Maastricht 2011}

ISBN: 9789461590732

Cover illustration: Geertjan van Zonneveld

Design and lay-out: Carolin Hanssen

Publisher and print: Datawyse | Universitaire Pers Maastricht 


\title{
Hemolysis, Microcirculatory Changes and Organ Injury Induced by Cardiovascular Surgery
}

\author{
PROEFSCHRIFT \\ ter verkrijging van de graad van doctor aan de Universiteit Maastricht, \\ op gezag van de Rector Magnificus, Prof. mr. G.P.M.F. Mols, \\ volgens het besluit van het College van Decanen, \\ in het openbaar te verdedigen \\ op vrijdag 30 september 2011 om 14:00 uur \\ door \\ Sebastiaan Jozef Philomena Hanssen
}

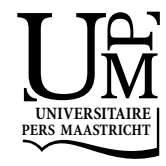




\section{Promotores}

Prof. dr. W.A. Buurman

Prof. dr. M.J.H.M. Jacobs

\section{Beoordelingscommissie}

Prof. dr. J.G. Maessen (voorzitter)

Prof. dr. R. Autschbach (Universitätsklinikum der RWTH Aachen, Deutschland)

Prof. dr. M.J.A.P. Daemen

Prof. dr. C.D.A. Stehouwer

Prof. dr. J.L. Waltenberger (Universitätsklinikum Münster, Deutschland) 


\section{Content}

$\begin{array}{lll}\text { Chapter } 1 \text { General Introduction } & 7\end{array}$

Chapter 2 Visceral Injury and Systemic Inflammation in Patients 15

Undergoing Extracorporeal Circulation During Aortic Surgery

Chapter 3 Elevated Plasma Arginase-1 Does Not Affect Plasma Arginine in 33 Patients Undergoing Liver Resection

Chapter 4 Cardiovascular Surgery and Organ Damage; Time to Reconsider the Role of Hemolysis

Chapter 5 Hemolysis Compromises NO-Dependent Vasodilatory

Responses in Patients Undergoing Major Cardiovascular

Surgery

Chapter 6 Circulating Free Hemoglobin Results in Impaired Intestinal

Microcirculation and Epithelial Cell injury

Chapter 7 NO-Ventilation Attenuates the Deleterious Effects of Cell-Free Hemoglobin on Microcirculatory Blood Flow and Injury in the Kidney

Chapter 8 Summary and Discussion

Samenvatting

Zusammenfassung

Dankwoord / Danksagung

151

Curriculum Vitae

Scientific Publications

Color Figures 
<smiles>C=C=C</smiles> 
Chapter 1

\section{General Introduction}




\section{Introduction}

The following section provides background information on the topics discussed in the different chapters, as well as the aims of this thesis.

\section{Cardiovascular Surgery}

Cardiovascular surgery with extracorporeal circulation to preserve organ perfusion is associated with high postoperative morbidity and mortality, especially in patients undergoing complex procedures. Patients undergoing combined coronary artery bypass grafting (CABG) and valve surgery, Bentall procedures, and open repair of thoracic aortic aneurysms (TAA) and thoracoabdominal aortic aneurysms (TAAA) are at high risk for developing major complications like gastrointestinal injury and acute kidney injury, ${ }^{1-6}$ pulmonary dysfunction, ${ }^{7,8}$ sepsis and multiple organ failure. ${ }^{9}$

TAA and TAAA are highly lethal disorders for which open surgical repair is the only solution that ensures long-term durability and survival. Evidence for this can be drawn from the fact that the number needed to treat (the number of patients who need to be treated to prevent one adverse outcome) is only two. ${ }^{10}$ However, it is a complex intervention which challenges not only the patient's cardiovascular system, but also the pulmonary, neurological, hematological, and immune system. Hence, it is not surprising that this intervention is associated with a high incidence of severe complications, often leading to respiratory failure, renal failure, neurological deficits or even death. Substantial refinements in the preoperative optimization of the patient's condition, anesthetic and surgical techniques, as well as postoperative care have reduced mortality and morbidity over the past decades. ${ }^{11,12}$ However, there are still major complications to be acknowledged.

\section{Visceral Injury around Cardiovascular Surgery}

The extracorporeal circulation technique is implemented in open TAA repair to provide (retrograde) distal aortic perfusion via the femoral artery. In case of open TAAA repair involving the origin of visceral arteries, extracorporeal circulation with distal aortic perfusion is combined with selective organ perfusion catheters to directly provide the designated visceral arteries with blood. ${ }^{5,12}$ The rationale behind this is the reduction of ischemic injury of visceral organs, in particular the highly susceptible intestines and kidneys. ${ }^{13,14}$

The advantages of visceral protection notwithstanding extracorporeal circulation during cardiac surgery is associated with loss of intestinal barrier function seen as endotoxin translocation, indicating visceral injury. ${ }^{15-17}$ Moreover, recent publica- 
tions suggest extracorporeal circulation with antegrade aortic flow to result in a poorly understood state of 'functional' hypoperfusion of visceral organs, which is related to visceral injury and the induction of SIRS. ${ }^{18-20}$

Three possible mechanisms of visceral injury after cardiovascular surgery have been described and discussed by scholars so far: (i) ischemia/reperfusion and hypoperfusion injury to the visceral organs as a result of redistribution of blood flow and increased oxygen demand, (ii) inflammatory mediated endothelial dysfunction and priming, and (iii) increased mesenteric vascular resistance. ${ }^{20-22}$

In this thesis hemolysis, in particular the release of cell-free oxyhemoglobin and its interference in nitric oxide-dependent microcirculatory blood flow is proposed as a further and novel cause of visceral injury around cardiovascular surgery.

\section{Hemolysis and Visceral Microcirculatory Blood Flow around Cardiovascular Surgery}

Hemolysis during cardiovascular surgery is considered an unavoidable, but not specifically harmful side-effect. Three potential causes for hemolysis exist within the field of cardiovascular surgery. Extracorporeal circulation (ECC) is an inevitable part of open cardiac and TAA or TAAA surgery which is known to result in hemolysis. ${ }^{23,24}$ This type of surgery is also associated with considerable blood loss, leading to massive transfusion requirements. Hemolysis during the storage of red blood cells intended for transfusion, as well as the use of 'older' red blood cells are both factors associated with increased mortality rates in patients undergoing massive allogeneic transfusion (i.e. receiving ABO-compatible red blood cells). ${ }^{25,}{ }^{26}$ Allogeneic transfusion requirements may be reduced by application of cell-salvage devices during cardiovascular surgery, when shed blood from the operation field is processed in order to retrieve autologous red blood cells. However, such devices and procedures lead to injury of red blood cells intended for autologous transfusion. ${ }^{27}$

Recently, intravascular hemolysis has been associated with disturbances in endothelial nitric oxide (NO) metabolism, the key system in regulating vascular tone and microcirculatory blood flow. ${ }^{28,29}$ First, oxyhemoglobin released from injured erythrocytes $(\mathrm{FHb})$ reduces NO bioavailability by scavenging NO. ${ }^{28}$ Oxyhemoglobin in its ferrous form binds $\mathrm{NO}$ to generate ferric hemoglobin, also known as methemoglobin, and bioinactive nitrate $\left(\mathrm{HbFe}^{2+}-\mathrm{O}_{2}+\mathrm{NO} \rightarrow \mathrm{HbFe}^{3+}+\mathrm{NO}_{3}{ }^{-}\right)$. Second, arginase-1 released from hemolytic erythrocytes has been suggested to decrease NO production by depletion of plasma arginine, the precursor for NO synthesis, with a concomitant increase of plasma ornithine, the product of arginase-1 activity. ${ }^{30}$ Both $\mathrm{FHb}$ and arginase-1 may impair NO bioavailability resulting in a compromised microcirculation. 
Indeed, evidence is building up that hemolysis is an important factor in the pathogenesis of compromised microcirculation, hampering tissue perfusion and inducing organ injury in chronic hereditary or acquired hemolytic diseases such as sickle cell disease and falciparum malaria infection. ${ }^{30-32}$ Therefore, hemolysis is proposed to be more than an innocent bystander effect during acute hemolytic challenges such as cardiovascular surgery.

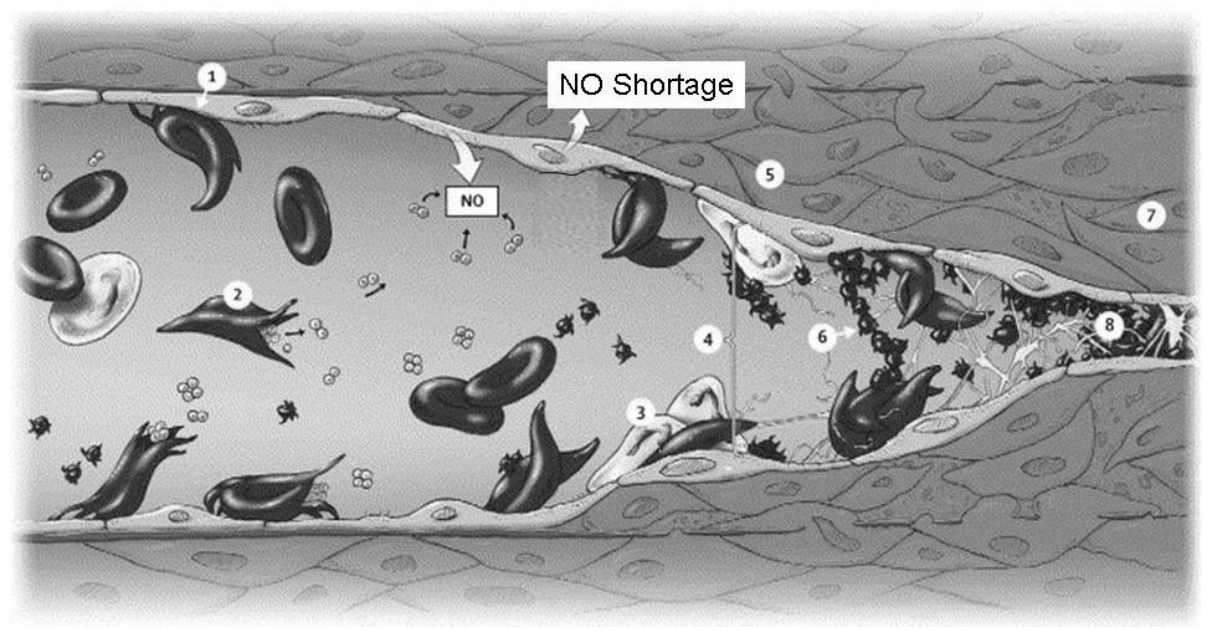

Figure 1.1 The damaged erythrocyte is pre-eminent in the development of disturbed tissue microcirculation as a result of abnormal adherence to the vascular endothelium (1) and hemolysis (2). These factors result in a proinflammatory state manifested, in part, by leucocyte adhesion (3) and platelet aggregation (6). As soon as scavenging of NO by FHb leads to increased vasomotor tone (4) luminal narrowing occurs (5) and results in disturbed tissue perfusion (8) with concomitant tissue injury (7). (Modified after Switzer et al. $^{33}$ ). See page 167 for color figure.

\section{Aims of This Thesis}

The first aim was to evaluate to what extent visceral organ injury and inflammation was present in patients undergoing open TAAA repair (Chapter 2). This evaluation was followed by a study of the putative relevance of arginase-1 release in major abdominal surgery (Chapter $\mathbf{3}$ ). Recent evidence suggests hemolysis and concomitant release of $\mathrm{FHb}$ to be important factors in the pathogenesis of compromised microcirculation in hereditary and acquired hemolytic disorders. Hemolysis around cardiovascular surgery is undervalued and its possible effects and therapies are reviewed in Chapter 4. The effect of hemolysis on NO-dependent blood flow in TAAA patients was measured using forearm blood flow measurements perioperatively (Chapter 5). Given the data on compromised forearm blood flow during high levels of circulating $\mathrm{FHb}$, the individual effect of $\mathrm{FHb}$ on gut microcirculatory blood 
flow and gut mucosal epithelial cell integrity was evaluated next using a selfdeveloped animal study of intravascular hemolysis / model of elevated circulating levels of FHb (Chapter 6). Kidney injury, microcirculatory blood flow and oxygenation, as well as NO-ventilation as a therapeutic agent during elevated circulating levels of FHb, were evaluated in a second animal study (Chapter 7). Finally, a discussion of the work and the results are presented in Chapter 8. 


\section{References}

1. Achouh PE, Madsen K, Miller CC, 3rd, et al. Gastrointestinal complications after descending thoracic and thoracoabdominal aortic repairs: a 14-year experience. J Vasc Surg 2006; 44:442-6.

2. Conlon PJ, Stafford-Smith M, White WD, et al. Acute renal failure following cardiac surgery. Nephrol Dial Transplant 1999; 14:1158-62.

3. Grayson $A D$, Khater $M$, Jackson $M$, Fox MA. Valvular heart operation is an independent risk factor for acute renal failure. Ann Thorac Surg 2003; 75:1829-35.

4. Provenchere S, Plantefeve G, Hufnagel G, et al. Renal dysfunction after cardiac surgery with normothermic cardiopulmonary bypass: incidence, risk factors, and effect on clinical outcome. Anesth Analg 2003; 96:1258-64, table of contents.

5. Jacobs MJ, de Mol BA, Legemate DA, et al. Retrograde aortic and selective organ perfusion during thoracoabdominal aortic aneurysm repair. Eur J Vasc Endovasc Surg 1997; 14:360-6.

6. Andersson LG, Ekroth R, Bratteby LE, et al. Acute renal failure after coronary surgery--a study of incidence and risk factors in 2009 consecutive patients. Thorac Cardiovasc Surg 1993; 41:237-41.

7. Coselli JS, LeMaire SA, Conklin LD, et al. Morbidity and mortality after extent II thoracoabdominal aortic aneurysm repair. Ann Thorac Surg 2002; 73:1107-15; discussion 1115-6.

8. Rectenwald JE, Huber TS, Martin TD, et al. Functional outcome after thoracoabdominal aortic aneurysm repair. J Vasc Surg 2002; 35:640-7.

9. Kieffer E, Chiche L, Godet G, et al. Type IV thoracoabdominal aneurysm repair: predictors of postoperative mortality, spinal cord injury, and acute intestinal ischemia. Ann Vasc Surg 2008; 22:822-8.

10. Miller CC, 3rd, Porat EE, Estrera AL, et al. Number needed to treat: analyzing of the effectiveness of thoracoabdominal aortic repair. Eur J Vasc Endovasc Surg 2004; 28:154-7.

11. Chiesa R, Melissano G, Civilini E, et al. Ten years experience of thoracic and thoracoabdominal aortic aneurysm surgical repair: lessons learned. Ann Vasc Surg 2004; 18:514-20.

12. Jacobs MJ, Mommertz G, Koeppel TA, et al. Surgical repair of thoracoabdominal aortic aneurysms. J Cardiovasc Surg (Torino) 2007; 48:49-58.

13. Takala J. Determinants of splanchnic blood flow. Br J Anaesth 1996; 77:50-8.

14. Schepens MA, Heijmen RH, Ranschaert W, et al. Thoracoabdominal aortic aneurysm repair: results of conventional open surgery. Eur J Vasc Endovasc Surg 2009; 37:640-5.

15. Ohri SK, Somasundaram S, Koak Y, et al. The effect of intestinal hypoperfusion on intestinal absorption and permeability during cardiopulmonary bypass. Gastroenterology 1994; 106:318-23.

16. Riddington DW, Venkatesh $\mathrm{B}$, Boivin $\mathrm{CM}$, et al. Intestinal permeability, gastric intramucosal pH, and systemic endotoxemia in patients undergoing cardiopulmonary bypass. Jama 1996; 275:1007-12.

17. Rossi M, Sganga G, Mazzone M, et al. Cardiopulmonary bypass in man: role of the intestine in a selflimiting inflammatory response with demonstrable bacterial translocation. Ann Thorac Surg 2004; 77:612-8.

18. Sato K, Sogawa M, Namura O, Hayashi J. Deterioration of body oxygen metabolism by vasodilator and/or vasoconstrictor administration during cardiopulmonary bypass. Asaio J 2006; 52:96-9.

19. Holmes JHT, Lieberman JM, Probert CB, et al. Elevated intestinal fatty acid binding protein and gastrointestinal complications following cardiopulmonary bypass: a preliminary analysis. J Surg Res 2001; 100:192-6.

20. Morariu AM, Loef BG, Aarts LP, et al. Dexamethasone: benefit and prejudice for patients undergoing on-pump coronary artery bypass grafting: a study on myocardial, pulmonary, renal, intestinal, and hepatic injury. Chest 2005; 128:2677-87.

21. Tao W, Zwischenberger JB, Nguyen TT, et al. Gut mucosal ischemia during normothermic cardiopulmonary bypass results from blood flow redistribution and increased oxygen demand. J Thorac Cardiovasc Surg 1995; 110:819-28.

22. Ohri SK, Velissaris T. Gastrointestinal dysfunction following cardiac surgery. Perfusion 2006; 21:21523. 
23. Fransen EJ, Ganushchak YM, Vijay V, et al. Evaluation of a new condensed extra-corporeal circuit for cardiac surgery: a prospective randomized clinical pilot study. Perfusion 2005; 20:91-9.

24. Maruyama $O$, Numata $Y$, Nishida $M$, et al. Hemolysis caused by surface roughness under shear flow. J Artif Organs 2005; 8:228-36.

25. Karkouti K, Wijeysundera DN, Yau TM, et al. The independent association of massive blood loss with mortality in cardiac surgery. Transfusion 2004; 44:1453-62.

26. Koch CG, Li L, Sessler DI, et al. Duration of red-cell storage and complications after cardiac surgery. $\mathrm{N}$ Engl J Med 2008; 358:1229-39.

27. Serrick CJ, Scholz M, Melo A, et al. Quality of red blood cells using autotransfusion devices: a comparative analysis. J Extra Corpor Technol 2003; 35:28-34.

28. Rother RP, Bell L, Hillmen P, Gladwin MT. The clinical sequelae of intravascular hemolysis and extracellular plasma hemoglobin: a novel mechanism of human disease. Jama 2005; 293:1653-62.

29. Villagra J, Shiva S, Hunter LA, et al. Platelet activation in patients with sickle disease, hemolysisassociated pulmonary hypertension, and nitric oxide scavenging by cell-free hemoglobin. Blood 2007; 110:2166-72.

30. Morris CR, Kato GJ, Poljakovic M, et al. Dysregulated arginine metabolism, hemolysis-associated pulmonary hypertension, and mortality in sickle cell disease. Jama 2005; 294:81-90.

31. Yeo TW, Lampah DA, Gitawati R, et al. Impaired nitric oxide bioavailability and L-arginine reversible endothelial dysfunction in adults with falciparum malaria. J Exp Med 2007; 204:2693-704.

32. Ataga $\mathrm{KI}$, Moore CG, Hillery CA, et al. Coagulation activation and inflammation in sickle cell diseaseassociated pulmonary hypertension. Haematologica 2008; 93:20-6.

33. Switzer JA, Hess DC, Nichols FT, Adams RJ. Pathophysiology and treatment of stroke in sickle-cell disease: present and future. Lancet Neurol 2006; 5:501-12. 
<smiles>C=C=C</smiles> 


\section{Chapter 2 Visceral Injury and Systemic Inflammation in Patients Undergoing Extracorporeal Circulation During Aortic Surgery}

Sebastiaan J. Hanssen, Joep P. Derikx, Iris C. Vermeulen Windsant, John H. Heijmans, Thomas A. Koeppel, Geert W. Schurink, Wim A. Buurman, Michael J. Jacobs

Annals of Surgery, Volume 248, July 2008, Pages $117-125$. 


\section{Abstract}

Objectives Visceral injury and inflammation are evaluated in patients undergoing extracorporeal circulation (ECC) either with distal aortic perfusion (DAP) during thoracic aortic aneurysm (TAA) repair or DAP and selective organ perfusion (DAP \& SP) during thoracoabdominal aortic aneurysm (TAAA) repair.

Summary Background Data Visceral hypoperfusion and subsequent visceral injury, mainly to the gut, have been implicated as central events in the development of systemic inflammatory response syndrome (SIRS) and organ dysfunction after major surgery. Patients undergoing DAP or DAP \& SP are exposed to artificial visceral perfusion, potentially leading to the development of intestinal injury and systemic inflammation.

Methods To assess visceral injury arteriovenous differences in Fatty Acid Binding Proteins were measured for the gut (I-FABP and L-FABP) and left kidney (L-FABP) along with systemic plasma concentrations. Systemic ALT was used as liver injury marker. Plasma IL-6 and IL-8 denoted systemic inflammation.

Results During ECC systemic I-FABP and L-FABP levels increased in both groups, representing intestinal injury. Significantly elevated levels of I-FABP $(P<0.001)$ and L-FABP $(P<0.001$ ) were found in the DAP \& SP group, after ECC was stopped and normal circulation restored. Liver and renal tubular cell injury was not detected. Significant increases in systemic IL-6 and IL- 8 values were measured only in patients undergoing DAP \& SP. Additionally, the extent of intestinal injury correlated positively with systemic inflammation.

Conclusions This study shows the development of intestinal mucosal injury during ECC with DAP or DAP \& SP, indicative of insufficient intestinal perfusion. Intestinal injury was associated with a systemic pro-inflammatory response. 


\section{Introduction}

Open surgical repair of thoracic aortic aneurysms (TAA) and thoracoabdominal aortic aneurysms (TAAA) are extensive, complex procedures that are associated with significant post-operative morbidity and mortality. Post-operative complications include respiratory failure, renal and liver dysfunction, spinal cord injury, and gastrointestinal complications. ${ }^{1-3}$

Experimental studies of major surgery and trauma suggest that intestinal injury and hypoperfusion of visceral organs lead to initiation of a systemic proinflammatory response. ${ }^{4,5}$ Therefore, visceral protection during aortic surgery is warranted. ${ }^{6,7}$

The extracorporeal circulation (ECC) technique has been implemented in open TAA repair to provide (retrograde) distal aortic perfusion (DAP) via the femoral artery. In case of TAAA repair involving the origin of visceral arteries, ECC with DAP is combined with selective organ perfusion catheters (DAP \& SP) to provide designated visceral arteries directly with blood. ${ }^{8,9}$ The rationale behind DAP and DAP \& $\mathrm{SP}$ is to reduce ischemic injury of visceral organs, in particular the highly susceptible intestinal mucosa. ${ }^{10}$

The advantages of visceral protection notwithstanding, ECC during cardiac surgery provides antegrade aortic perfusion of visceral organs and is still associated with loss of intestinal barrier function seen as endotoxin translocation, indicating intestinal mucosal injury. ${ }^{11-13}$ The development of intestinal organ injury during antegrade aortic perfusion is strongly associated with gastrointestinal complications and mortality. ${ }^{14,15}$ Moreover, recent publications suggest ECC with antegrade aortic flow to result in a poorly understood state of 'functional' hypoperfusion of visceral organs, which is related to visceral injury and the induction of SIRS. ${ }^{14,16,17}$

The quantification of (subclinical) visceral injury during open TAA / TAAA repair could provide valuable information on the perfusion adequacy of ECC with either DAP or DAP \& SP. Therefore, in this study we measured intestinal and renal release of fatty acid binding proteins, small cytosolic proteins that leak from injured cells into the circulation, and systemic plasma ALT to evaluate liver injury. The proinflammatory cytokines IL-6 and IL- 8 were measured to assess systemic inflammation. The aim of the present study was to investigate the development of visceral injury in patients undergoing either DAP or DAP \& SP, and to evaluate the relation of visceral injury to the systemic inflammatory response in these patients. 


\section{Methods}

\section{Patient Population}

Patients that underwent elective open TAA or TAAA repair between January 2006 and April 2007 at the University Hospital Maastricht or the University Hospital Aachen were included in the study. The study was approved by the local Institutional Review Board of both institutes, and written informed consent was obtained from every patient.

Pre-operative clinical data were prospectively collected from the patient's medical record. Crawford's classification was used to specify TAAA type. ${ }^{18}$

\section{Surgical Procedure}

For all patients the same anesthetic protocol was used. The following anesthetic and surgical procedure has been described previously in detail. ${ }^{9,}{ }^{19}$ Collapse of the left lung in all patients except type IV TAAA was enabled by either a double-lumen endotracheal tube or a selective left main bronchial blocker. Induction of anesthesia was achieved with etomidate and sufentanil, and maintained with sufentanil and ketamine. All patients were placed in a left helical position, and thoracotomy or thoracolaparotomy through the sixth intercostal space (eighth intercostal in patients with TAAA type IV aneurysms) was performed.

After heparinization, $(0.5 \mathrm{mg} / \mathrm{kg})$, for all patients ECC with DAP was established after cannulation of the left pulmonary vein and the femoral artery, connected to a centrifugal pump. Alternatively, the femoral vein was cannulated with a long cannula placed in the vena cava inferior close to the right atrium; in all cases an oxygenator was part of the ECC. For DAP \& SP, a 4-branched tubing system was connected to the ECC and 4 catheters with inflatable tips and flow probes were used for selective perfusion of the celiac axis, the superior mesenteric artery and both renal arteries.

Typically, the aortic reconstruction was done from proximal to distal. During proximal cross-clamping, transsection of the aorta, and completion of the proximal anastomosis, DAP was maintained at a mean pressure of $60 \mathrm{mmHg}$ or higher. After abdominal aortotomy, all four selective perfusion catheters were installed in patients undergoing TAAA repair. In ten patients $(N=10)$ we evaluated directly after insertion the mean blood flow through each individual SP catheter (Table 2.1). In general, the celiac axis, superior mesenteric artery and the right renal artery were anastomosed simultaneously as an island in the aortic graft. Just before finishing the anastomosis, the perfusion catheters were removed, indicating that ischemic time is limited to the timeframes of insertion and removal of the catheters. In most cases, the left renal artery was treated with a selective graft using selective perfusion dur- 
ing end-to-end anastomosis. After completion of the anastomosis, the tip of the catheter was withdrawn into the graft, and perfusion continued, until implantation into the aortic tube graft was accomplished.

\section{Blood Sampling}

Peripheral arterial blood was drawn at set time-points (Figure 2.1) from the radial artery pre-operatively (Pre-op), while creating access to the aorta, but before clamping the aorta and ECC was initiated (Cannulation), during ECC just before ending DAP or DAP \& SP (ECC), 15 minutes after the proximal aortic cross clamp was removed and reperfusion ( $R$ ) initiated ( $15 \mathrm{~min} R$ ), at 2 hours, 6 hours and 10 hours in the reperfusion phase ( 2 hrs R, 6 hrs R and $10 \mathrm{hrs} R$ ), as well as at day 1 and 2 postoperatively (Day 1 and Day 2). Whole blood was collected in EDTA vacutainers (Becton Dickinson, Franklin Lakes, NJ) and immediately put on ice. Blood was centrifuged and plasma was stored in aliquots at $-20^{\circ} \mathrm{C}$ until further analysis.

To enable venous blood sampling from the intestines and left kidney in eight patients ( $\mathrm{N}=8$ ) undergoing DAP \& SP, a $16 \mathrm{G}$ single lumen central venous catheter kit was used to cannulate the portal vein (Terumo Corporation, Tokyo, Japan), and a $18 \mathrm{G}$ intravenous catheter (Venflon, Becton Dickinson, Franklin Lakes, NJ) was used to cannulate the left renal vein prior to starting ECC. This enabled us to sample specific arterial and venous blood from the gut and the left kidney in order to calculate organ release and consumption of plasma proteins. Blood was taken from these cannulas before ECC, during ECC with DAP \& SP when a sample was taken from the arterial line of the ECC as well, and at 15 minutes reperfusion (Figure 2.1).

\section{Measurements}

\section{Visceral Organ Injury}

Fatty acid binding proteins (FABP) are small cytosolic proteins (15 kDa) that are abundantly expressed in visceral tissue and can be used as sensitive plasma markers to detect early cellular injury. ${ }^{20-22}$ Two types of FABP, intestinal-type FABP (I-FABP) and liver-type (L-FABP), are expressed at the tips of the villi of intestinal mucosal epithelial cells. I-FABP is only present in intestinal mucosal cells; in contrast, L-FABP is also expressed in hepatocytes, and to a lesser extent in renal tubular cells, and increased plasma levels could therefore represent hepatocyte or renal tubular cell injury as well. ${ }^{23}$ In order to evaluate hepatocellular injury systemic common liver injury marker ALT was measured. Furthermore, to study renal tubular cell injury as cause of elevated circulating L-FABP levels, the arteriovenous concentration difference for the left kidney ([arterial concentration] - [venous concentration] / [arterial concentration] $\times 100 \%)$ of L-FABP was calculated in eight patients $(\mathrm{N}=8)$ undergoing DAP \& SP. 


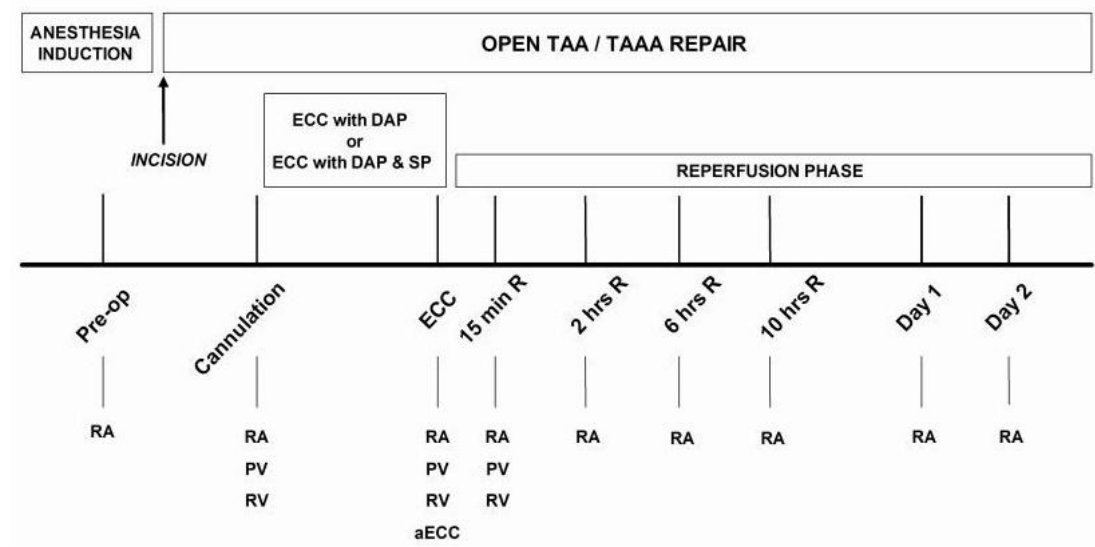

Figure 2.1. Timeline of blood sampling. At given time-points blood was drawn from the radial artery line and arterial line of the extracorporeal circulation (ECC). Patients undergoing open TAA repair received ECC with distal aortic perfusion (DAP - group), while ECC with DAP and selective organ perfusion was used in patients undergoing open TAAA repair (DAP \& SP - group).

In order to enable simultaneous arterial and venous organ blood sampling, in eight patients receiving ECC with DAP \& SP, a venous catheter was inserted in the portal vein, as well as the left renal vein. This allowed specific calculation of arteriovenous concentration differences for the gut as well as the left kidney.

TAA, Thoracic Aortic Aneurysm; TAAA, Thoracoabdominal Aortic Aneurysm; ECC, extracorporeal circulation; DAP, distal aortic perfusion; SP, selective organ perfusion R, Reperfusion; RA, radial artery; PV, portal vein; RV, renal vein; aECC, arterial line of ECC.

Plasma I-FABP and L-FABP levels were analyzed using Enzyme Linked Immuno Sorbent Assays (ELISA). These commercially available ELISA kits were kindly provided by Hycult biotechnology (Uden, the Netherlands) and were used according to manufacture guidelines. The detection limit was $41 \mathrm{pg} / \mathrm{mL}$ for I-FABP and $102 \mathrm{pg} / \mathrm{mL}$ for LFABP.

\section{Systemic Inflammatory Response}

The plasma levels of the cytokines IL- 6 and IL- 8 were assayed to determine the systemic inflammatory response following TAA / TAAA repair. IL-6 and IL-8 are commonly used as general inflammatory markers, amongst others produced by stimulated monocytes and activated endothelium, and considered key players in the development of SIRS after major trauma and surgical stress. ${ }^{17,24,25}$

IL-6 and IL-8 ELISA techniques have been described elsewhere. ${ }^{26}$ Briefly, 96-well plates (Greiner Bio-One, Kremsmünster, Austria) were coated overnight $\left(4^{\circ} \mathrm{C}\right)$ with the appropriate antibodies. Monoclonal antibodies 5E1 and 3E3 were used as coating for IL-6 and IL-8, respectively. Free sites were blocked with $1 \%$ bovine serum albumin in PBS. 
Samples and standard dilution series were incubated for 2 hours. Human recombinant IL- 6 and IL- 8 were used for standard titration curves. Washing buffer contained $0.1 \%$ Tween-20. Biotinylated anti-human IL- 6 and IL-8 were developed in our own laboratory and used as detection antibodies. Finally, 3,3', 5,5'-tetramethylbenzidine (TMB) was used as a substrate and the reaction was stopped by adding $1 \mathrm{M} \mathrm{H}_{2} \mathrm{SO}_{4}$. Plasma samples were analyzed in the same run spectrophotometrically $(450 \mathrm{~nm})$ using an automated ELISA reader. The detection limits for the assays were $12.3 \mathrm{pg} / \mathrm{mL}$ (IL-6) and $46.0 \mathrm{pg} / \mathrm{mL}$ (IL-8).

\section{Statistical Analysis}

All data are expressed as mean \pm standard error of the mean (SEM). KolmogorovSmirnov test was used to test for Gaussian distribution. Student's T-test for independent-samples and Chi-square test, followed by Fisher's exact test when needed, were used to test differences between pre-operative patient characteristics. Changes in parameters over time were tested using repeated measures ANOVA, followed by paired Student's T-tests versus Pre-op values with post-hoc Bonferroni correction, if significant differences were found. In the same way changes in arteriovenous concentrations differences of plasma proteins were tested, with values measured during cannulation as reference. To characterize the total amount of intestinal injury and systemic inflammation during the study period, area under the curve (AUC) for I-FABP and L-FABP, as well as IL-6 and IL-8 was calculated for each patient. To assess association between intestinal mucosal cell injury and inflammation Spearman correlation analysis between $\mathrm{AUC}_{\mathrm{I}-\mathrm{FABP}}, \mathrm{AUC}_{\mathrm{L}-\mathrm{FABP}}, \mathrm{AUC}_{\mathrm{IL}-6}$, and $\mathrm{AUC}_{\mathrm{IL}-8}$ was performed. Mann Whitney $U$ test was used to calculate differences in AUC for each parameter between both patient groups. Statistical calculations were made using SPSS 15.0 for Windows (SPSS, Inc., Chicago, IL), and GraphPad Prism software (GraphPad Software, Inc. San Diego, CA). A P-value < 0.05 was considered to indicate statistical significance.

\section{Results}

\section{Patient Characteristics and Intra-Operative Data}

Thirty consecutive patients that underwent TAA $(\mathrm{N}=8)$ or TAAA $(\mathrm{N}=22)$ repair were included in the study. Table 2.1 shows pre-operative clinical data of patients undergoing ECC with DAP (TAA patients) or DAP \& SP (TAAA patients). No significant differences in pre-existing co-morbidities were present in the two patient groups studied, except for the co-existence of an aortic dissection (DAP $\mathrm{N}=4 / 8$ versus 
DAP \& SP N = 2 / 22, P = 0.033). Nevertheless, aortic dissection did not influence the surgical approach to repair the aneurysm.

Aorta cross-clamp time (ACC), total ECC time and total operation time were noted during all procedures. ACC and total ECC time did not differ significantly between both groups. However, a significant difference in total operation time was found, reflecting the operative complexity of patients undergoing TAAA repair (DAP 326 (17) minutes, and DAP \& SP 399 (15) minutes, $P=0.015)$.

Table 2.1. Characteristics of patients undergoing open TAA / TAAA repair

\begin{tabular}{|c|c|c|c|}
\hline & ECC with DAP & ECC with DAP \& SP & P-value \\
\hline Total procedures (N) & 8 & 22 & \\
\hline TAA & 8 & - & \\
\hline TAAA $^{*}$ & - & 22 & \\
\hline TAAA II & - & 3 & \\
\hline TAAA III & - & 9 & \\
\hline TAAA IV & - & 10 & \\
\hline Male (N) & 4 & 11 & 1.000 \\
\hline Dissection & 4 & 2 & 0.033 \\
\hline Mean age (yr) & $60.0(3.4)$ & $63.5(2.7)$ & 0.483 \\
\hline $\mathrm{BMI}^{* *}\left(\mathrm{~kg} / \mathrm{m}^{2}\right)$ & $26.9(1.2)$ & $23.9(0.8)$ & 0.058 \\
\hline Diabetes & - & 2 & 1.000 \\
\hline Hypertension & 5 & 17 & 0.643 \\
\hline Smoked & 4 & 19 & 0.395 \\
\hline Hypercholesterolemia & 1 & 11 & 0.099 \\
\hline Chronic renal failure & - & 2 & 1.000 \\
\hline $\mathrm{CAD}^{\wedge}$ & 1 & 2 & 1.000 \\
\hline $\mathrm{COPD}^{\wedge \wedge}$ & - & 5 & 0.280 \\
\hline $\mathrm{ACC}^{\#}$ time (min) & $86(9)$ & $86(7)$ & 0.986 \\
\hline ECC time ( $\mathrm{min}$ ) & $131(36)$ & $142(9)$ & 0.677 \\
\hline \multicolumn{4}{|l|}{ Flow SP catheter ${ }^{\dagger}(\mathrm{mL} / \mathrm{min})$} \\
\hline Celiac axis & - & $202.0(33.2)$ & \\
\hline Superior mesenteric artery & - & $311.6(30.4)$ & \\
\hline Left renal artery & - & $212.6(33.3)$ & \\
\hline Right renal artery & - & $186.4(27.7)$ & \\
\hline Total operation time (min) & $326(17)$ & $399(15)$ & 0.015 \\
\hline
\end{tabular}

Classification according to Crawford..$^{18 * *} \mathrm{BMI}$, body mass index; ${ }^{*} \mathrm{CAD}$, coronary artery disease; COPD, chronic obstructive pulmonary disease. "ACC, aorta cross clamp; Continues variables are expressed as mean (SEM). ${ }^{\dagger}$ Flow in SP catheter was measured in ten $(\mathrm{N}=10)$ patients undergoing ECC with DAP \& SP.

\section{Extracorporeal Circulation and Intestinal Mucosal Injury}

Pre-operative I-FABP levels (DAP 326.8 (84.8) pg/mL, and DAP \& SP 411.7 (82.4) $\mathrm{pg} / \mathrm{mL}$, Figure $2.2 \mathrm{~A}$ ) were comparable to the values measured in a healthy population, ${ }^{27}$ demonstrating the absence of intestinal mucosal cell injury. Manipulation of visceral organs to create access to the aorta, did not lead to elevated circulating IFABP levels. In contrast, during ECC I-FABP levels increased in both groups repre- 
senting the development of intestinal mucosal injury which was supported by statistically significant repeated measures ANOVA in both groups (DAP, $P<0.05$; DAP \& $\mathrm{SP}, \mathrm{P}<0.0001$, data not shown). Shortly after artificial circulation was terminated and normal circulation was restored, plasma I-FABP levels increased further (DAP 763.9 (200.7) pg/mL, P > 0.05; DAP \& SP 2351.0 (378.1) pg/mL, P < 0.001) and remained elevated for six hours. The release of I-FABP in patients undergoing DAP \& SP was clearly more pronounced than in patients undergoing DAP, indicating more intestinal injury in the DAP \& SP group. Total AUC of systemically measured I-FABP was calculated for both groups and revealed significantly more I-FABP release in the DAP \& SP patient group ( $P<0.05$, data not shown).

Intestinal mucosal cell injury leads next to I-FABP release to L-FABP release, although, plasma L-FABP increase can also be caused by liver and renal tubular cell injury. L-FABP plasma levels showed a similar pattern as I-FABP, potentially supporting intestinal injury (Figure 2.2B). The total calculated $A U C_{L-F A B P}$ was significantly higher in patients undergoing DAP \& SP $(P<0.01$, data not shown).

To ascertain the intestinal origin of the released I-FABP and L-FABP during and shortly after ECC, the arteriovenous concentration differences were measured in eight patients $(N=8)$ undergoing DAP \& SP (Figure 2.3A). In line with the systemic measurements, before starting ECC there was no fractional increase in I-FABP indicating the absence of I-FABP release (+ $0.3(1.8) \%)$. However, during ECC with DAP \& SP a significant release of I-FABP was found $(+53.5(11.2) \%, P<0.001)$, which still occurred at 15 minutes after ECC had been stopped $(+28.0$ (3.3) \%, P < 0.05). Similar to the I-FABP release reported above, no detectable L-FABP release from the gut was found before starting ECC with DAP \& SP (+ 1.9 (2.8) \%). During ECC with DAP \& $\mathrm{SP}, \mathrm{L}-\mathrm{FABP}$ release from the intestinal mucosa increased significantly $(+103.0$ (17.5) $\%, P<0.001$ ) and release of L-FABP, specifically indicating intestinal injury, was still statistically significant shortly after ECC perfusion was terminated and normal circulation was restored (+ 51.5 (13.9) \%, P < 0.05).

Since L-FABP is next to the gut also expressed in liver and kidneys, we studied hepatocellular and renal tubular cell injury. To exclude liver injury, ALT was measured at three different time-points (Figure 2.3B); ALT, a cytosolic enzyme mainly expressed in the liver, was not elevated in the early reperfusion phase or at postoperative day 1 . These data support the intestinal origin of L-FABP release during open TAA / TAAA repair. 


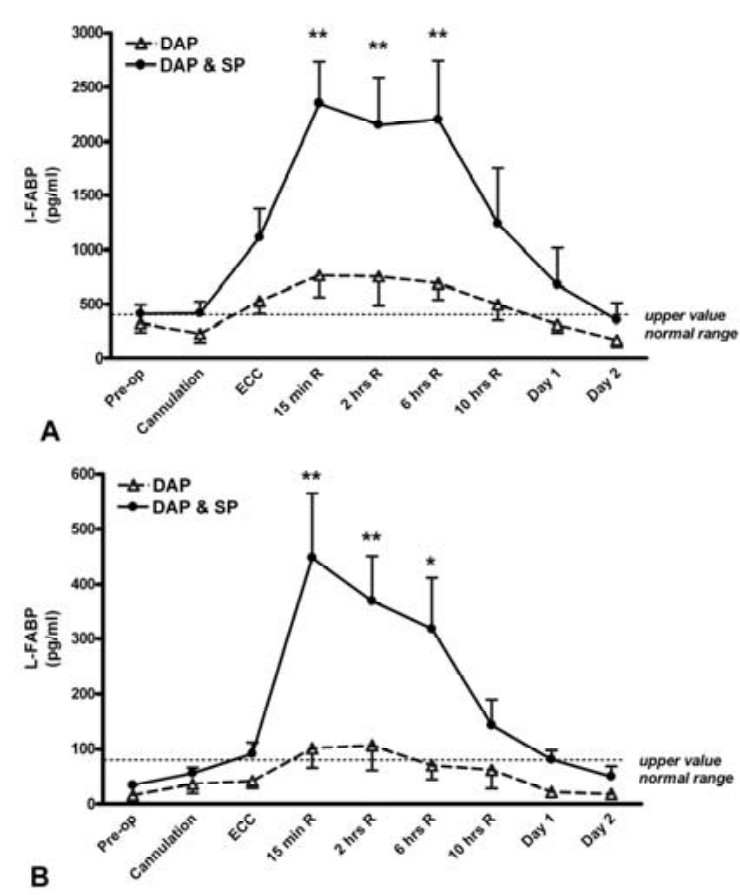

Figure 2.2. Elevated plasma I-FABP and L-FABP levels in patients undergoing DAP or DAP \& SP. (A) Highest values for I-FABP, reflecting intestinal injury, were found during reperfusion for both groups. (B) Systemic plasma L-FABP values measured in both patient groups mimicked IFABP release, potentially representing intestinal injury. Values are presented as mean \pm SEM and are compared to pre-operative values. Data were analyzed using paired Student's T-tests with post-hoc Bonferroni correction. * $\mathrm{P}<0.01 ; * *$ $P<0.001$

Potentially, renal tubular cell injury also results in elevated plasma L-FABP concentrations. Therefore, to evaluate release from injured renal tubular cells, we measured arteriovenous concentration differences of L-FABP for the left kidney from the same eight patients as reported above. The calculated mean arteriovenous concentration difference before going on ECC was - 21.5 (4.0) \%. During ECC with DAP \& SP (- $27.6(6.0) \%)$ and after ECC, when the patients were on normal visceral circulation again (- $22.8(4.4) \%)$, arteriovenous concentration differences were not significantly altered compared to values before ECC, indicating an absence of release from injured renal tubular cells (data not shown).

To analyze correlations between intestinal organ injury markers I-FABP and L$F A B P$, the total $A U C_{1-F A B P}$ and $A U C_{L-F A B P}$, of all patients undergoing $E C C(N=30)$ were correlated (Figure 2.5). A strong positive correlation was found between $A U C_{1-F A B P}$ and $\operatorname{AUC}_{\text {L-FABP }}(r=0.70, P<0.0001)$.

Taken together, the circulating plasma levels of both I-FABP and L-FABP were elevated during ECC and a further increase was observed in the early phase of restored normal circulation in patients undergoing open TAA / TAAA repair. This indicates intestinal injury, with release of these proteins being more prominent when ECC with DAP \& SP was used. 


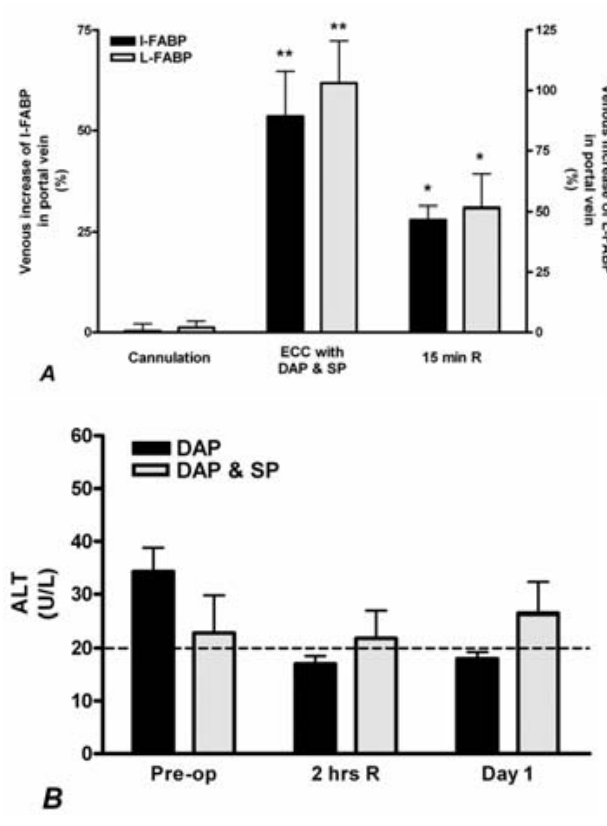

Figure 2.3. Intestinal I-FABP and intestinal L-FABP release was evaluated using arterio-venous concentration differences in eight patients undergoing ECC with DAP \& SP. Arterial blood from the radial artery (or the arterial line of the ECC) and the portal vein were simultaneously sampled and intestinal I-FABP and L-FABP release was calculated using the following formula: venous concentration minus arterial concentration divided by arterial concentration $\times 100 \%$. (A) Significant release of I-FABP and L-FABP from the gut was observed during ECC and directly in the reperfusion phase when normal visceral circulation was restored. (B) Circulating concentrations $A L T$, a specific liver enzyme was measured preoperatively, at 2 hours reperfusion and at day 1 postoperatively. ALT levels showed no significant increase at the given time points, indicating no significant liver injury. Values are shown as mean \pm SEM and compared to pre-operative values (or values found during cannulation) using paired Student's T-tests with post-hoc Bonferroni correction. * $\mathrm{P}<0.05 ; * * \mathrm{P}<0.001$

\section{Systemic Inflammatory Response and Extracorporeal Circulation during TAA / TAAA repair}

Circulating pro-inflammatory cytokines IL-6 and IL-8 were measured in order to evaluate the inflammatory response associated with TAA / TAAA repair. Plasma concentrations of IL- 6 before ECC started were not significantly different from baseline values (Figure 2.4A). Although changes in plasma IL-6 levels were observed in both patient groups, the mean IL- 6 values measured in the DAP patients group were not statistically significantly altered during the studied period (ANOVA P $>0.05$, data not shown). During visceral perfusion using ECC combined with DAP \& SP plasma IL6 levels increased significantly, indicating the development of a systemic inflammatory response (ANOVA P $<0.0001$, data not shown). Release of IL-6 continued until peak-values were reached 2 hours after reperfusion (DAP \& SP 295.7 (62.7) pg/mL, $P<0.001$ ), whereas after 6 hours reperfusion and later plasma values lowered, but remained elevated until day 2 post-operative. 

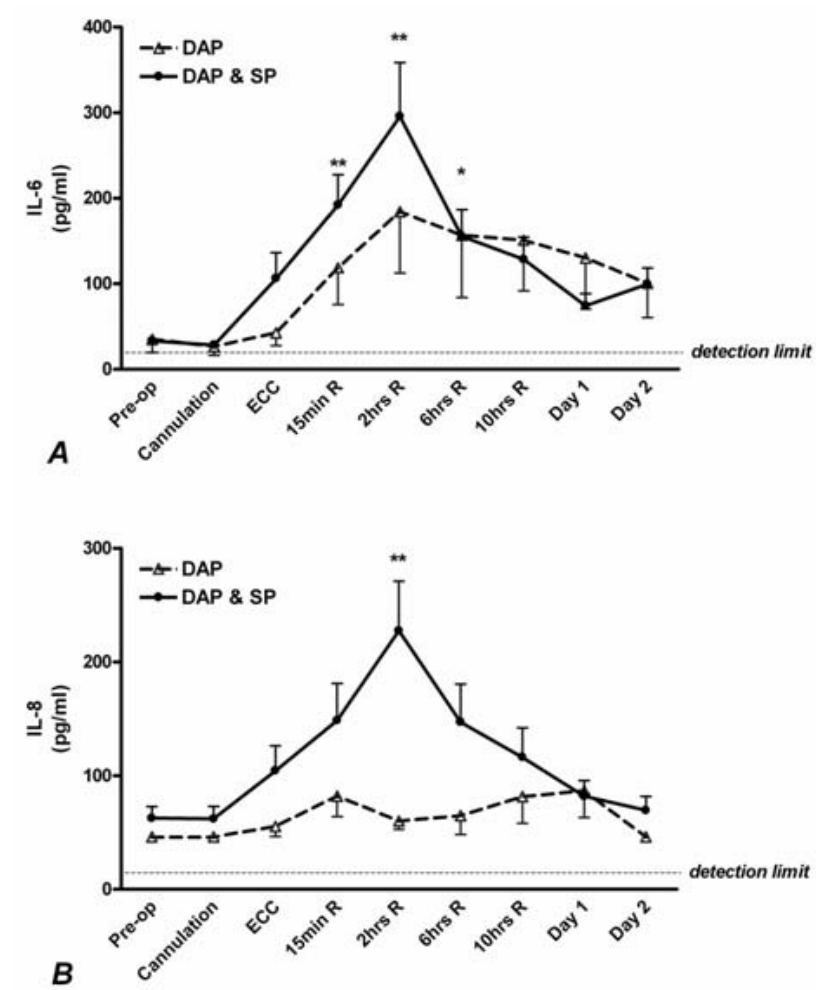

Figure 2.4. The systemic inflammatory response is initiated during ECC. (A) Increased levels of the proinflammatory cytokine IL-6 are found in patients receiving DAP (TAA patients) or DAP \& SP (TAAA patients) during artificial visceral perfusion using ECC. Peak values were reached at 2 hours reperfusion $\left(\begin{array}{lll}2 \mathrm{hrs} & \mathrm{R}\end{array}\right) . \quad$ (B) Marked IL-8 release in patients receiving DAP \& SP. After initial release during ECC combined with DAP \& SP, peak plasma values for patients undergoing TAAA repair were found at 2 hours reperfusion ( $2 \mathrm{hrs} \mathrm{R}$ ). Values are mean \pm SEM and compared to pre-operative values using paired Student's T-tests with post-hoc Bonferroni correction. * $\mathrm{P}<0.05$; ** $\mathrm{P}<$ 0.001

The pro-inflammatory cytokine IL-8, a strong neutrophil attractant, was detectable in pre-operatively taken blood samples from five out of twenty-two patients who underwent DAP \& SP (Figure 2.4B). Initially, plasma IL-8 curves mimicked IL-6 kinetics, starting to increase during the reperfusion phase in both groups. However, further increase in plasma IL-8 levels in patients who underwent ECC with DAP was relatively small (ANOVA P $>0.05$, data not shown), whereas increase in plasma IL-8 was significant in patients who underwent ECC with DAP \& SP (ANOVA P $<0.0001$, data not shown), with peak values found at 2 hours reperfusion $(227.4(43.5) \mathrm{pg} / \mathrm{mL}$, $\mathrm{P}<0.05)$, indicating a strong pro-inflammatory, chemotactic response in these patients. At postoperative day 2, plasma IL-8 had almost disappeared, being nondetectable in patients who underwent DAP, and only detectable in plasma from four out of twenty-two patients who underwent DAP \& SP.

The increase of IL- 6 and IL- 8 observed during TAA / TAAA repair, indicates the development of a systemic inflammatory response after DAP or DAP \& SP; IL-8 release was significant in patients undergoing DAP \& SP only, signifying a strong systemic neutrophil attractive response in this patient group. 


\section{Intestinal Injury and Systemic Inflammation in Patients Undergoing Extracorporeal Circulation}

To investigate whether intestinal injury was related to the systemic inflammatory response, correlations of $A \cup C_{\mathrm{I}-\mathrm{FABP}}$ with $A \cup \mathrm{C}_{\mathrm{IL}-6}$ and $A \cup \mathrm{C}_{\mathrm{IL}-8}$ (Figure 2.5) were analyzed in all patients undergoing ECC $(\mathrm{N}=30)$. $A \cup C_{\text {I-FABP }}$ correlated significantly with both $\mathrm{AUC}_{\mathrm{IL}-6}(r=0.64, \mathrm{P}<0.001)$ and $\mathrm{AUC}_{\mathrm{IL}-8}(r=0.54, \mathrm{P}<0.01)$, indicating an association between the extent of intestinal organ injury and systemic inflammation, underlining the need for intestinal organ protection during TAA / TAAA repair.

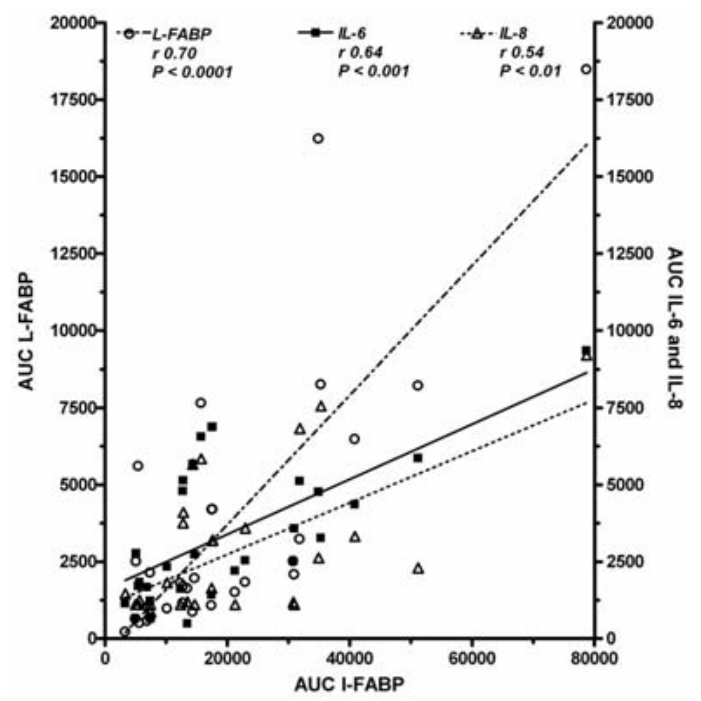

Figure 2.5. Association between intestinal mucosal cell injury and systemic inflammation in patients undergoing open TAA / TAAA repair. Patient's total AUCs of I-FABP, L-FABP, IL-6 and IL-8 were measured from pre-operative up until day 2 postoperative. Data are matched observations, and degree of correlation is represented by Spearman $r$. Visceral injury, denoted by $A \cup C_{1}$. FABP, strongly correlated with $A_{U} C_{L-F A B P}$, $\mathrm{AUC}_{\mathrm{IL}-6}$, and $A \cup C_{\mathrm{IL}-8}$. These data suggest intestinal injury to play a significant role in systemic inflammation in patients undergoing open TAA / TAAA repair.

\section{Discussion}

In this study intestinal mucosal cell injury, but not hepatic or renal tubular cell injury, occurred in patients undergoing elective open TAA or TAAA repair, despite artificial visceral perfusion using ECC with either DAP (TAA patients) or ECC with DAP \& SP (TAAA patients). The extent of intestinal injury and pro-inflammatory reaction was more pronounced in patients undergoing DAP \& SP. Furthermore, intestinal injury correlated positively with markers of systemic inflammation.

Visceral perfusion by means of ECC is used to ensure volume and pressure controlled blood flow to abdominal organs, preventing the deleterious effects of intestinal injury. ${ }^{3}$ ECC with antegrade aortic perfusion is a well-known technique used in cardiac surgery and acknowledged to induce intestinal injury. ${ }^{11}$ Holmes et al. showed elevated urine I-FABP levels following CABG surgery and suggested that intestinal mucosal injury plays a role in inducing a complicated post-operative course. ${ }^{14}$ The use of ECC with either DAP or DAP \& SP in patients undergoing open 
TAA / TAAA repair was first described in the 1980s, and these techniques have since been further refined. ${ }^{28,}{ }^{29}$ We described our first experiences with ECC and DAP or DAP \& SP in the mid-90s, and both were considered safe techniques to prevent postoperative renal injury, assessed by urine output and serum creatinine following TAA / TAAA repair, and possibly intestinal injury, by subjective observation of the intestines and intestinal motility peri- and post-operatively. ${ }^{8,19}$

In the present study, the development of injury to visceral organs was investigated using measurements of plasma I-FABP and L-FABP for intestinal, ALT for hepatic, and L-FABP for renal tubular injury. Our data show development of intestinal injury during artificial perfusion of the viscera using ECC, and shortly thereafter when normal perfusion to the viscera was restored. ECC with DAP caused elevated plasma levels of I-FABP and L-FABP, and ECC with DAP \& SP led to significantly elevated circulating I-FABP and L-FABP levels, despite the intended protective effect of artificial visceral perfusion in patients undergoing open TAA / TAAA repair. The arteriovenous concentration differences over the intestines demonstrate significant release of I-FABP and L-FABP in patients undergoing ECC with DAP \& SP. During reperfusion the systemic plasma concentration of both I-FABP and L-FABP initially further increased, suggesting either continued wash-out of these proteins from the injured gut mucosa or sustained hypoperfusion injury leading to continued enhanced release of both proteins. These data are in line with low flow states in patients with hypovolemic or cardiogenic shock and inherent blood flow redistribution towards the heart and central nervous system at the expense of visceral organs. The intestinal mucosal epithelial cells are due to the specific anatomy of the small intestinal villus more susceptible to visceral hypoperfusion than hepatocytes or renal epithelial cells. In particular the cells at the tip of the villus, which contain I-FABP and L-FABP, are due to the sympathetic innervation of the arterioles and vascular anatomy of the villus, most vulnerable to hypoperfusion. ${ }^{10,11}$

Total intestinal injury seen during ECC was assessed by $A_{U} C_{\text {I-FABP }}$, and correlated positively with the $\mathrm{AUC}_{\mathrm{IL}-6}$ and $\mathrm{AUC}_{\mathrm{IL}-8}$, suggesting an association between the extent of intestinal mucosal injury and the extent of systemic inflammation. Morariu et al. studied the alleged protective use of dexamethasone on the inflammatory response and intestinal injury after CABG surgery with the use of antegrade aortic perfusion. ${ }^{17}$ Even though the inflammatory response was attenuated by dexamethasone, no effect on intestinal injury markers was seen, hereby suggesting the inflammatory response to be a result and not so much a cause of intestinal injury.

Pharmacological approaches to reduce visceral hypoperfusion and its sequelae can be directed at either improvement of perfusion or reduction of ischemic injury. Increasing microcirculatory blood flow, especially in the intestines, by pharmacological intervention (e.g. ACE-inhibitors, ET-receptor antagonists or catecholamine therapy) has been shown beneficial in animal studies. ${ }^{30-32}$ Furthermore, also antioxidant therapy (e.g. nitroxide, ascorbic acid or mannitol) has been shown effective 
in reducing ischemic injury to the intestines in animals. ${ }^{33,}{ }^{34}$ Future studies are needed to evaluate such interventions in the human setting.

The difference in extent of intestinal injury that was observed between DAP during open TAA repair and DAP \& SP during open TAAA repair is not easily clarified. Aortic cross clamp times or total perfusion times were similar between the groups. The most likely explanation for the difference in intestinal injury is a more prominent hypoperfusion of the intestines during ECC with DAP \& SP. Idu et al. showed in a pig model a significant decrease in blood flow per minute to the cranial mesenteric artery when clamping the aorta and perfusion was taken over with ECC and selective organ perfusion. ${ }^{35}$ Also, Leijdekkers et al. calculated that the flow to visceral organs during ECC with DAP \& SP is limited and insufficient to maintain tissue perfusion due to the internal diameter in SP catheters used in patients undergoing open TAAA repair. ${ }^{36}$ The flow administered through the selective organ perfusion catheter system during aortic clamping may be too low in our patients, creating an absolute state of 'functional' hypoperfusion to the intestines. It is of interest, however, that during the reperfusion phase especially in the DAP \& SP group the intestinal injury further increases. This suggests that during ECC a process has been initiated that results in ongoing increased intestinal mucosal cell injury, potentially through a prolonged 'functional' hypoperfusion. The mechanisms leading to visceral hypoperfusion during and after ECC in patients undergoing open TAA / TAAA repair remain to be resolved. Such information will be instrumental in developing strategies to prevent the intestinal injury and subsequent systemic inflammatory response induced by ECC with DAP or DAP \& SP.

\section{Conclusion}

Increased plasma I-FABP and L-FABP levels, representative of intestinal injury, and elevated plasma IL- 6 and IL-8 concentrations, indicative of systemic inflammation, were observed in patients undergoing open TAA / TAAA repair, despite ECC with either DAP or DAP \& SP. Our data show that intestinal injury precedes the development of a systemic inflammatory response and correlates positively with the extent of systemic inflammation, supporting the hypothesis that intestinal tissue injury is involved in the development and extent of a systemic inflammatory response.

\section{Acknowledgements}

The authors wish to thank dr. Maarten G. Snoeijs (Department of Surgery, Maastricht University Medical Center, the Netherlands) for critical review of the manuscript and Willemieke Balkema and Juliane van Driel (both University Hospital Aachen, Germany) for laboratory assistance. 


\section{References}

1. Rectenwald JE, Huber TS, Martin TD, et al. Functional outcome after thoracoabdominal aortic aneurysm repair. J Vasc Surg 2002; 35:640-7.

2. Gloviczki P. Surgical repair of thoracoabdominal aneurysms: patient selection, techniques and results. Cardiovasc Surg 2002; 10:434-41.

3. Achouh PE, Madsen K, Miller CC, 3rd, et al. Gastrointestinal complications after descending thoracic and thoracoabdominal aortic repairs: a 14-year experience. J Vasc Surg 2006; 44:442-6.

4. Fink MP. Gastrointestinal mucosal injury in experimental models of shock, trauma, and sepsis. Crit Care Med 1991; 19:627-41.

5. Moore FA. The role of the gastrointestinal tract in postinjury multiple organ failure. Am J Surg 1999; 178:449-53.

6. MacArthur RG, Carter SA, Coselli JS, LeMaire SA. Organ protection during thoracoabdominal aortic surgery: rationale for a multimodality approach. Semin Cardiothorac Vasc Anesth 2005; 9:143-9.

7. Welborn MB, Oldenburg HS, Hess PJ, et al. The relationship between visceral ischemia, proinflammatory cytokines, and organ injury in patients undergoing thoracoabdominal aortic aneurysm repair. Crit Care Med 2000; 28:3191-7.

8. Jacobs MJ, de Mol BA, Legemate DA, et al. Retrograde aortic and selective organ perfusion during thoracoabdominal aortic aneurysm repair. Eur J Vasc Endovasc Surg 1997; 14:360-6.

9. Jacobs MJ, Mommertz G, Koeppel TA, et al. Surgical repair of thoracoabdominal aortic aneurysms. J Cardiovasc Surg (Torino) 2007; 48:49-58.

10. Takala J. Determinants of splanchnic blood flow. Br J Anaesth 1996; 77:50-8.

11. Ohri SK, Somasundaram S, Koak Y, et al. The effect of intestinal hypoperfusion on intestinal absorption and permeability during cardiopulmonary bypass. Gastroenterology 1994; 106:318-23.

12. Riddington $\mathrm{DW}$, Venkatesh $\mathrm{B}$, Boivin $\mathrm{CM}$, et al. Intestinal permeability, gastric intramucosal $\mathrm{pH}$, and systemic endotoxemia in patients undergoing cardiopulmonary bypass. Jama 1996; 275:1007-12.

13. Rossi M, Sganga G, Mazzone M, et al. Cardiopulmonary bypass in man: role of the intestine in a selflimiting inflammatory response with demonstrable bacterial translocation. Ann Thorac Surg 2004; 77:612-8.

14. Holmes JHT, Lieberman JM, Probert CB, et al. Elevated intestinal fatty acid binding protein and gastrointestinal complications following cardiopulmonary bypass: a preliminary analysis. J Surg Res 2001; 100:192-6.

15. Bolcal $C$, Iyem $H$, Sargin $M$, et al. Gastrointestinal complications after cardiopulmonary bypass: Sixteen years of experience. Can J Gastroenterol 2005; 19:613-7.

16. Sato K, Sogawa M, Namura O, Hayashi J. Deterioration of body oxygen metabolism by vasodilator and/or vasoconstrictor administration during cardiopulmonary bypass. Asaio J 2006; 52:96-9.

17. Morariu AM, Loef BG, Aarts LP, et al. Dexamethasone: benefit and prejudice for patients undergoing on-pump coronary artery bypass grafting: a study on myocardial, pulmonary, renal, intestinal, and hepatic injury. Chest 2005; 128:2677-87.

18. Crawford ES. Thoraco-abdominal and abdominal aortic aneurysms involving renal, superior mesenteric, celiac arteries. Ann Surg 1974; 179:763-72.

19. Jacobs MJ, Eijsman L, Meylaerts SA, et al. Reduced renal failure following thoracoabdominal aortic aneurysm repair by selective perfusion. Eur J Cardiothorac Surg 1998; 14:201-5.

20. Lieberman JM, Sacchettini J, Marks C, Marks WH. Human intestinal fatty acid binding protein: report of an assay with studies in normal volunteers and intestinal ischemia. Surgery 1997; 121:335-42.

21. Niewold TA, Meinen M, van der Meulen J. Plasma intestinal fatty acid binding protein (I-FABP) concentrations increase following intestinal ischemia in pigs. Res Vet Sci 2004; 77:89-91.

22. Pelsers MM, Namiot Z, Kisielewski W, et al. Intestinal-type and liver-type fatty acid-binding protein in the intestine. Tissue distribution and clinical utility. Clin Biochem 2003; 36:529-35.

23. Pelsers MM, Hermens WT, Glatz JF. Fatty acid-binding proteins as plasma markers of tissue injury. Clin Chim Acta 2005; 352:15-35. 
24. Ytting $\mathrm{H}$, Christensen IJ, Basse L, et al. Influence of major surgery on the mannan-binding lectin pathway of innate immunity. Clin Exp Immunol 2006; 144:239-46.

25. Fiane $A E$, Videm $V$, Lingaas PS, et al. Mechanism of complement activation and its role in the inflammatory response after thoracoabdominal aortic aneurysm repair. Circulation 2003; 108:849-56.

26. Dentener MA, Bazil V, Von Asmuth EJ, et al. Involvement of CD14 in lipopolysaccharide-induced tumor necrosis factor-alpha, IL-6 and IL-8 release by human monocytes and alveolar macrophages. J Immunol 1993; 150:2885-91.

27. Derikx JP, Poeze M, van Bijnen AA, et al. Evidence for intestinal and liver epithelial cell injury in the early phase of sepsis. Shock 2007; 28:544-8.

28. Laschinger JC, Cunningham JN, Jr., Nathan IM, et al. Experimental and clinical assessment of the adequacy of partial bypass in maintenance of spinal cord blood flow during operations on the thoracic aorta. Ann Thorac Surg 1983; 36:417-26.

29. Kazui T, Yamada O, Ito T, et al. Total graft replacement of the thoracoabdominal aorta with reconstruction of visceral branches, intercostal and lumbar arteries in expanding chronic dissecting aneurysms of the thoracoabdominal aorta. Nippon Kyobu Geka Gakkai Zasshi 1989; 37:1436-40.

30. Bailey RW, Bulkley GB, Hamilton SR, et al. Pathogenesis of nonocclusive ischemic colitis. Ann Surg 1986; 203:590-9.

31. Krejci V, Hiltebrand LB, Erni D, Sigurdsson GH. Endothelin receptor antagonist bosentan improves microcirculatory blood flow in splanchnic organs in septic shock. Crit Care Med 2003; 31:203-10.

32. Sautner $T$, Wessely $C$, Riegler $M$, et al. Early effects of catecholamine therapy on mucosal integrity, intestinal blood flow, and oxygen metabolism in porcine endotoxin shock. Ann Surg 1998; 228:23948.

33. Gunel E, Caglayan F, Caglayan O, et al. Treatment of intestinal reperfusion injury using antioxidative agents. J Pediatr Surg 1998; 33:1536-9.

34. Udassin R, Haskel Y, Samuni A. Nitroxide radical attenuates ischaemia/reperfusion injury to the rat small intestine. Gut 1998; 42:623-7.

35. Idu MM, Heintjes RJ, Scholten EW, et al. Visceral and renal tissue oxygenation during supraceliac aortic crossclamping and left heart bypass with selective organ perfusion. Eur J Vasc Endovasc Surg 2004; 27:138-44.

36. Leijdekkers VJ, Wirds JW, Vahl AC, et al. The visceral perfusion system and distal bypass during thoracoabdominal aneurysm surgery: an alternative for physiological blood flow? Cardiovasc Surg 1999; 7:219-24. 
<smiles>C=C=C</smiles> 


\section{Chapter 3 Elevated Plasma Arginase-1 Does Not Affect Plasma Arginine in Patients Undergoing Liver Resection}

Marcel C. van de Poll, Sebastiaan J. Hanssen, Maaike Berbée, Nicolaas E. Deutz, Diethardt Monbaliu, Wim A. Buurman, Cornelis H. Dejong 


\section{Abstract}

Introduction Arginine is an important substrate in health and disease. It is a commonly held view that arginase-1 release from injured erythrocytes and hepatocytes leads to arginine breakdown; however, the true relationship between plasma arginase-1 concentration and activity has remained unaddressed.

Methods In the present study, blood was sampled from patients undergoing liver resection, a known cause of hepatocyte injury and arginase-1 release, to determine arginase-1, arginine and ornithine plasma levels. Arginase activity was assessed in vitro by measuring changes in arginine and ornithine plasma levels during incubation of plasma and whole-blood samples at $37^{\circ} \mathrm{C}$.

Results Arginase- 1 plasma levels increased 8-10-fold during liver resection, whereas arginine and ornithine levels remained unchanged. In accordance with these in vivo findings, arginine and ornithine levels remained unchanged in plasma incubated at $37^{\circ} \mathrm{C}$ irrespective of the arginase- 1 concentration. In contrast, arginine plasma levels in whole blood decreased significantly during incubation, with ornithine increasing stoichiometrically. These changes were irrespective of arginase-1 plasma levels and were explained by arginase activity present in intact erythrocytes. Next, plasma samples with 1000-fold normal arginase-1 concentrations were obtained from patients undergoing cadaveric liver transplantation. A significant decrease in arginine plasma levels occurred in vivo and in vitro.

Conclusions In contrast with commonly held views, moderately increased arginase1 plasma levels do not affect plasma arginine. Very high plasma arginase-1 levels are required to induce potential clinically relevant effects. 


\section{Introduction}

The amino acid arginine is an important substrate for protein synthesis and for the production of agmatine and creatine. ${ }^{1}$ It is best known, however, as the precursor for the imunoregulatory and vasoactive molecule nitric oxide (NO), although the conversion to NO represents only $1 \%$ of arginine plasma flux. ${ }^{2}$ Quantitatively, arginine plasma flux is determined by arginine intake, endogenous arginine synthesis and protein breakdown on one side and protein synthesis and arginine catabolism by the enzyme arginase on the other side. ${ }^{3}$ Arginase converts arginine to urea and ornithine and arginase activity accounts for $10 \%$ of total plasma arginine turnover. ${ }^{4}$ Arginase exists in two isoforms with only $58 \%$ sequence identity. ${ }^{5}$ Arginase- 1 is a cytosolic protein, predominantly found in the liver and to a lesser extent in erythrocytes. $^{6}$ Arginase-2 is located in mitochondria and more ubiquitously present, ${ }^{5}$ amongst others in the kidneys and the spleen but not in mature erythrocytes. ${ }^{6-7}$ Hepatic arginase-1 activity serves urea synthesis and nitrogen homeostasis. In the liver ornithine is recycled to citrulline and back to arginine. Due to compartmentalization of this urea cycle, plasma arginine is not a substrate for hepatic arginase-1. ${ }^{8,9}$ Ornithine generated outside the urea cycle can be converted to proline, an important constituent of collagen, and to the polyamines, which are important for cell proliferation. ${ }^{1}$ Changes in protein turnover, arginine intake or arginase activity can affect arginine plasma levels. ${ }^{3}$ Arginine deficiency may result in microcirculatory disturbances, pulmonary and systemic hypertension, ${ }^{10-11}$ disturbed collagen synthesis and wound healing, ${ }^{12}$ impaired immune function ${ }^{13,14}$ and in onset postoperative infections. ${ }^{15}$ Injury to arginase-1 expressing cells such as hepatocytes and erythrocytes leads to arginase-1 release into the circulation and increased arginase-1 plasma levels. ${ }^{10,11,16-19}$ It is generally believed that such an increase leads to plasma arginine breakdown compromising arginine availability, potentially leading to microcirculatory dysfunction ${ }^{10,11}$ and immune suppression. ${ }^{19,}{ }^{20}$ Alternatively, regarding its effect on cell proliferation, arginine depletion by exogenous arginase may become a promising anti-cancer treatment. ${ }^{21}$ The true relation between the concentration of arginase-1 in plasma and its actual activity however, has never been verified. Aim of this study was to investigate the effects of arginase-1 release on arginine plasma levels, using liver surgery (resection and transplantation) as a model of hepatocyte injury and arginase- 1 release and to establish the potential significance of circulating arginase-1 for arginine metabolism. 


\section{Methods}

\section{Patients}

Patients undergoing liver resection for secondary malignancies in an otherwise normal liver ( $\mathrm{N}=16$, Table 3.1 ) were studied. A routinely placed peripheral arterial catheter was used for blood sampling. Informed consent was obtained from every participant and the research protocol was approved by the Institutional Medical Ethical Committee.

\section{Arginase-1 protein release and indices of in vivo arginase enzyme activity during liver resection}

Arginase-1 release and its effect on arginine and ornithine levels were studied in vivo in 10 patients undergoing hepatectomy with intermittent hepatic inflow occlusion (Pringle manoeuvre). ${ }^{22}$ Arterial blood was sampled pre-operatively, before liver transection, before and after each event of an intermittent Pringle manoeuvre $(2 \mathrm{x}$ 15 minutes ischemia and 5 minutes reperfusion) and 90 minutes postoperatively. Blood was collected in pre-chilled heparinized vacuum tubes (Becton, Dickinson \& Co., Franklin Lakes, NJ), immediately placed on ice and processed as described below.

Table 3.1. Patient characteristics - liver resection

\begin{tabular}{lll}
\hline & In vivo study $(\mathbf{N}=\mathbf{1 0})$ & In vitro study $(\mathbf{N}=\mathbf{6})$ \\
\hline Surgical trauma & $\begin{array}{l}\text { Liver resection with intermittent } \\
\text { Pringle manoeuvre }\end{array}$ & $\begin{array}{l}\text { Liver mobilization / manipulation } \\
\text { prior to liver resection }\end{array}$ \\
Gender (M/F) & $5 / 5$ & $3 / 3$ \\
Age (years) & $50(33-75)$ & $54(36-74)$ \\
Colorectal liver metastases / & $8 / 2$ & $6 / 0$ \\
Other liver metastases & & \\
AST (IU/L) & $23(7-37)$ & $34(8-59)$ \\
LDH (IU/L) & $360(295-490)$ & $387(351-422)$ \\
Creatinine $(\mu \mathrm{mol} / \mathrm{I})$ & $103(67-118)$ & $93(56-106)$ \\
\hline
\end{tabular}

\section{In vitro arginase enzyme activity in whole blood and plasma after liver manipulation}

To study the effect of plasma arginase activity, separate from other processes regulating arginine levels in vivo, plasma samples with varying arginase-1 levels were incubated. In addition arginase activity was assessed in corresponding whole blood samples. Arterial blood was obtained from 6 patients undergoing liver resection, 
pre-operatively and after liver manipulation (before liver transection), when based upon prior experience peak arginase-1 concentrations were already expected. ${ }^{23}$

\section{Pre-incubation blood processing}

Blood was collected in two $4 \mathrm{~mL}$ heparin tubes (BD). One tube was centrifuged $(4,000 \times \mathrm{G}$, room temperature, $5 \mathrm{~min})$ to obtain plasma. The plasma was removed and transferred to clean tubes for incubation. The whole blood samples were incubated without any further processing.

\section{Incubation}

Incubations were performed immediately after sampling. Plasma and whole blood samples were divided over three aliquots per fraction that were incubated for 0,20 or 40 minutes at $37^{\circ} \mathrm{C}$. Thereafter, samples were placed on ice and processed immediately as described below. Arginase-1, arginine, ornithine and other amino acid concentrations were measured as described below. Arginase activity was expressed as the increment of ornithine concentration per minute. Since kinetic assays like these do not discriminate between the activities of different iso-enzymes the term arginase activity will be used without further specification when referring to the data of this assay.

\section{Arginase-1 protein release and plasma arginase enzyme activity after liver transplantation}

Roth et al. described a decrease of plasma arginine levels from $\pm 100 \mu \mathrm{mol} / \mathrm{l}$ to \pm 4 $\mu \mathrm{mol} / \mathrm{I}$ within 30 minutes following cadaveric liver transplantation, ${ }^{16}$ which was ascribed to arginase release from the graft and overwhelming plasma arginase activity. Ethical permission was granted to include 4 patients undergoing cadaveric liver transplantation at the University Hospital, Leuven, Belgium (Table 3.2) as optimal positive control to the present study. Arterial blood was drawn in heparin tubes (BD) pre-operatively, at the end of the anhepatic phase, and 3, 20 and 60 minutes following reperfusion of the graft. Whole blood was centrifuged at $4,000 \times \mathrm{G}$ for 5 minutes. Argininase-1, arginine, ornithine, and other amino acid concentrations were measured in all samples. Plasma obtained three minutes following reperfusion was incubated at $37^{\circ} \mathrm{C}$ for $25-40$ (mean 30) minutes to assess plasma arginase activity as described above. 
Table 3.2. Patient characteristics - liver transplantation

\begin{tabular}{|c|c|c|c|c|c|c|c|c|c|c|}
\hline & $M / F$ & Age & indication & $\begin{array}{c}\text { Cold } \\
\text { ischemia }\end{array}$ & $\begin{array}{l}\text { AST } \\
\text { Pre }\end{array}$ & $\begin{array}{l}\text { AST } \\
\text { 3' rep }\end{array}$ & $\begin{array}{l}\text { LDH } \\
\text { Pre }\end{array}$ & $\begin{array}{l}\text { LDH } \\
\text { 3' rep }\end{array}$ & $\begin{array}{l}\text { Creat } \\
\text { Pre }\end{array}$ & $\begin{array}{l}\text { Creat } \\
\text { 3' rep }\end{array}$ \\
\hline 1 & $\mathrm{~F}$ & 23 & Acute Budd-Chiari & $10: 51$ & 1956 & 1786 & 2417 & 4680 & 410 & 318 \\
\hline 2 & $M$ & 55 & $\begin{array}{c}\text { Alcoholic } \\
\text { cirrhosis + HCC }\end{array}$ & $8: 57$ & 40 & 479 & 274 & 1544 & 62 & 61 \\
\hline 3 & $M$ & 61 & Alcoholic cirrhosis & $11: 26$ & 71 & 458 & 572 & 1582 & 62 & 68 \\
\hline 4 & M & 73 & $\begin{array}{c}\text { Hepatitis C } \\
\text { cirrhosis + HCC }\end{array}$ & $12: 29$ & 68 & 290 & 329 & 855 & 21 & 98 \\
\hline
\end{tabular}

Gender, Age (years), Indication for liver transplantation, Cold ischemia time (hours:min) and AST (IU/L), $\mathrm{LDH}(\mathrm{IU} / \mathrm{L})$ and creatinine $(\mu \mathrm{M})$ levels preoperative and 3 minutes after reperfusion

\section{Relation between arginase activity and arginase-1 concentration in plasma Plasma arginase activity at physiological arginine concentration}

Aliquots of a plasma sample from one liver transplant recipient, obtained immediately following reperfusion (arginase-1 concentration $25 \mu \mathrm{g} / \mathrm{mL}$ ) were merged with aliquots of a plasma sample obtained from a healthy subject (arginase-1 concentration below detection limit $(10 \mathrm{ng} / \mathrm{ml})$. By this means an arginase- 1 dilution curve ranging from $25 \mu \mathrm{g} / \mathrm{ml}$ to $195 \mathrm{ng} / \mathrm{ml}$ was created. Before merging, phosphate buffered saline (PBS, $\mathrm{pH} 7.4$ ) containing $85 \mathrm{mmol} / \mathrm{l}$ arginine was added to the "healthy" plasma aliquots. The volume of arginine-enriched PBS added to each aliquot was adjusted so that the final arginine concentration after merging equaled $85 \mu \mathrm{mol} / \mathrm{l}$ in each sample. Accordingly, plasma samples were created containing varying arginase- 1 and equal arginine concentrations, the maximum concentration of PBS in these samples was $<0.1 \%$. All samples were immediately incubated at $37^{\circ} \mathrm{C}$ for 0,5 or 30 minutes.

\section{Plasma arginase activity at above- $\mathrm{Km}$ arginine concentration}

In a similar fashion as described above, plasma aliquots containing various concentrations of arginase-1 and $20 \mathrm{mmol} / \mathrm{l}$ arginine were created. However, in this case arginine was directly dissolved in the "healthy" plasma aliquots to avoid dilution of the plasma with PBS. Eventually plasma samples were created containing 15,000 , 1,500 or $150 \mathrm{ng} / \mathrm{ml}$ arginase- 1 with $20 \mathrm{mmol} / \mathrm{l}$ arginine. These samples were immediately incubated at $37^{\circ} \mathrm{C}$ for 0,5 or 30 minutes.

\section{Arginase-1 concentration in erythrocytes}

Blood was obtained from five healthy volunteers in vacuum tubes containing EDTA (Becton, Dickinson \& Co.). To remove plasma and mononuclear cells a previously described protocol was applied using a separation fluid (Lymphoprep 1.077, Axis- 
Shield, PoC AS, Oslo, Norway). ${ }^{24}$ One $\mathrm{ml}$ of packed erythrocytes was added to $74 \mathrm{ml}$ distilled water and gently shaken for 10 min to induce $100 \%$ haemolysis. ${ }^{25}$ The homogenate was centrifuged $(4,000 \mathrm{rpm}, \mathrm{RT}, 15 \mathrm{~min})$ and the supernatant was assayed for arginase-1.

\section{Post-incubation sample processing and laboratory analysis}

Whole blood samples were centrifuged $\left(4,000 \mathrm{rpm}, 4^{\circ} \mathrm{C}, 5 \mathrm{~min}\right)$ to obtain plasma. One hundred $\mu \mathrm{L}$ plasma was deproteinized with $8 \mathrm{mg}$ sulphosalicylic acid and stored at $-80^{\circ} \mathrm{C}$, the remainder was stored untreated $\left(-80^{\circ} \mathrm{C}\right)$. Amino acid levels were analyzed in SSA deproteinized samples by high performance liquid chromatography as described before. ${ }^{26}$ Arginase- 1 concentrations were measured in untreated samples using enzyme-linked immunosorbent assay (ELISA) ${ }^{27}$ (kindly provided by Hycult biotechnology, Uden, the Netherlands). The detection limit of this assay is $10 \mathrm{ng} / \mathrm{mL}$ arginase-1.

\section{Statistics}

Changes in amino acid and arginase-1 concentrations in vivo and in vitro were tested using a paired t-test or 1-way ANOVA for repeated measures when more than two serial observations were available. Statistical calculations were made using Prism 4.0 for Windows (GraphPad Software Inc. San Diego, CA). Results are expressed as mean (SEM), patient characteristics as median (range). A P-value $<0.05$ was considered to indicate statistical significance.

\section{Results}

\section{Effects of liver manipulation and warm ischemia}

As expected, mean (SEM) arginase-1 plasma levels increased significantly during liver manipulation (8-fold), before hepatic inflow occlusion (Figure 3.1A). Despite this, plasma concentrations of arginine and ornithine remained unchanged during the same period (Figure 3.1B). 

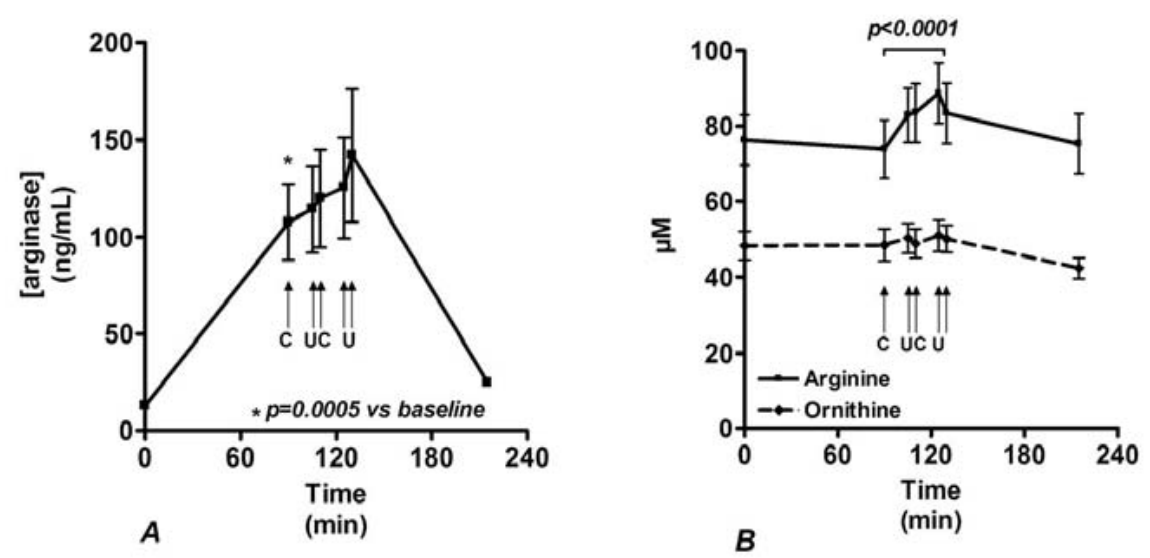

Figure 3.1. Arterial arginase-1 (A) and arginine and ornithine (B) concentrations were measured in 10 patients undergoing partial hepatectomy with intermittent Pringle manoeuvre (15' clamping, 5' reperfusion; clamping (C)/unclamping (U) indicated by arrows). Arginase-1 levels increased from the start of the procedure $(P=0.0005)$, without affecting arginine levels $(P=0.43)$. A significant increase of arginine levels was observed during hepatic pedicle clamping $(P<0.0001)$, most likely due to abolishment of hepatic amino acid clearance. Data are mean (SEM).

During inflow occlusion no further significant changes of arginase-1 plasma levels were observed (Figure 3.1A). At the same time plasma levels of arginine (and most other amino acids, data not shown) increased. Ornithine concentrations remained unchanged (Figure 3.1B). Ninety minutes postoperatively, mean arginase-1 plasma concentration was declined to $17 \%$ of the last measured intraoperative value. From this, an arginase-1 plasma half life of less than 1 hour was calculated.

\section{In vitro arginase activity}

Blood was sampled from 6 patients undergoing liver resection pre-operatively and after liver manipulation. Pre-operative arterial arginase-1 plasma levels were 18.1 (8.0) $\mathrm{ng} / \mathrm{ml}$. In line with abovementioned data, arginase-1 plasma levels increased significantly during liver manipulation (10-fold to $184(54) \mathrm{ng} / \mathrm{mL}$ ), without affecting arginine and ornithine levels in vivo ( $P=0.72$ and $P=0.16$ respectively) (Figure 3.2). 


\section{Plasma}
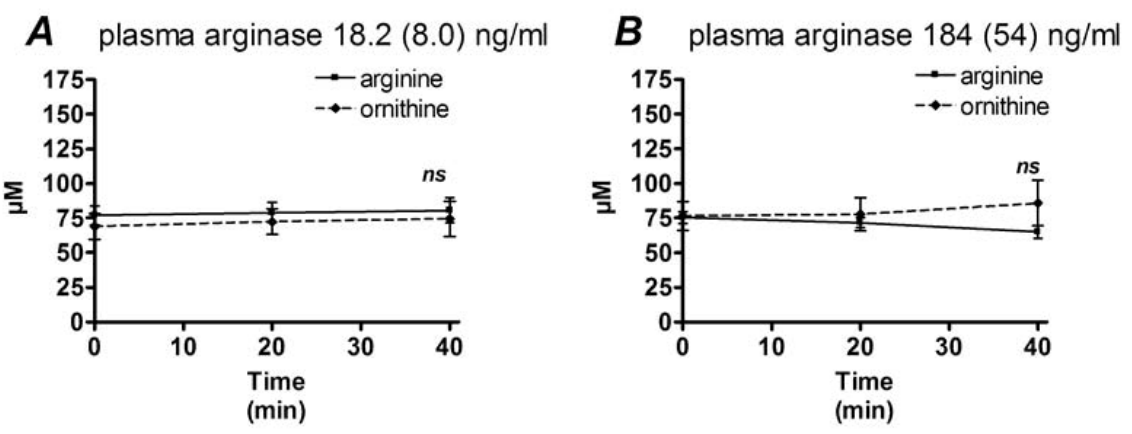

\section{Whole blood}
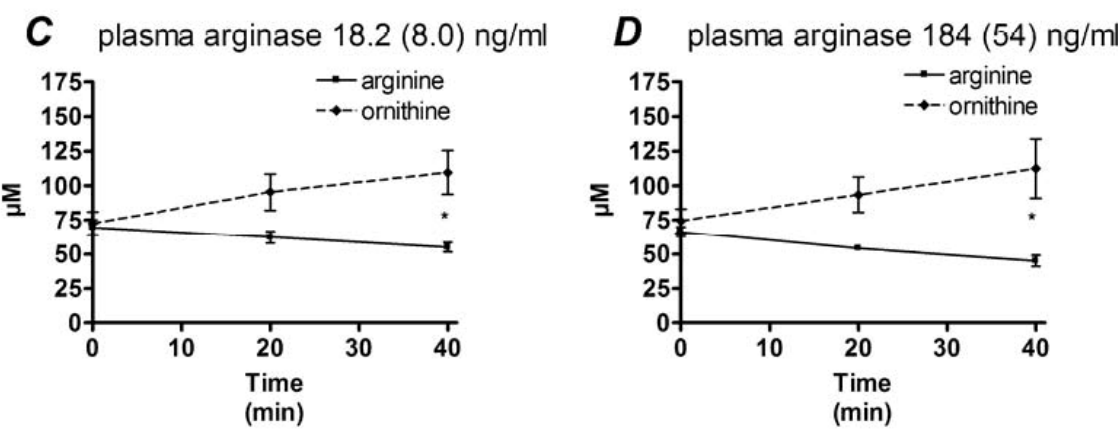

Figure 3.2. Blood was drawn from 6 patients undergoing liver resection immediately before surgery (A, C) and after liver manipulation (B, D). Mean (SEM) preoperative arginase-1 plasma concentration was 18.2 (8.0) $\mathrm{ng} / \mathrm{mL}$, which increased to $184(54) \mathrm{ng} / \mathrm{mL}$ following liver manipulation (10-fold increase, $P=0.028$ ), without affecting arginine and ornithine levels in vivo $(P=0.72$ and $P=0.16$, respectively). Plasma, whole blood and erythrocytes suspended in PBS $+80 \mu \mathrm{mol} / \mathrm{l}$ arginine obtained before and during surgery were incubated for 0,20 , and 40 minutes at $37^{\circ} \mathrm{C}$. No significant changes in arginine and ornithine concentration were found in plasma (A, B) irrespective of the amount of arginase- 1 in the samples. Arginine concentrations in whole blood (C, D) decreased significantly. Decreasing arginine levels were accompanied by stoichiometric increases of ornithine levels in all cases, indicating arginase activity. The amount of extracellular arginase-1 in the incubated whole blood samples did not influence the amount of ornithine formed. * $\mathrm{P}<0.001$

\section{Plasma}

Incubation of pre-operatively collected plasma samples for 40 minutes at $37^{\circ} \mathrm{C}$ did not lead to changes in arginine and ornithine concentration ( $P=0.26$; Figure 3.2A). In accordance with in vivo findings, no significant changes in arginine and ornithine concentrations were observed during incubation of plasma samples containing a $10-$ fold increased arginase-1 concentration ( $P=0.33$; Figure 3.2B). Plasma concentrations of other amino acids were not affected by in vitro incubation (Table 3.3). 
Table 3.3. Changes in plasma amino acid concentrations during incubation of plasma

\begin{tabular}{|c|c|c|c|}
\hline & $\begin{array}{c}\text { concentration } \\
(\mu \mathrm{mol} / \mathrm{l})\end{array}$ & $\begin{array}{l}\text { absolute increase } \\
(\mu \mathrm{mol} / \mathrm{I}) \mathrm{P} \text {-value }\end{array}$ & $\begin{array}{c}\text { relative increase } \\
\text { (\%) P-value }\end{array}$ \\
\hline Glutamate & $114(9.3)$ & $2.3(2.9) 0.451$ & $3.0(3.1) 0.350$ \\
\hline Asparagine & $68(11.7)$ & $4.3(2.2) 0.083$ & $4.6(2.8) 0.130$ \\
\hline Serine & $137(14.3)$ & $2.6(2.7) 0.355$ & $1.3(1.8) 0.481$ \\
\hline Glutamine & 626 (52.9) & 11.6 (12.5) 0.372 & $1.7(2.3) 0.481$ \\
\hline Histidine & $188(105.1)$ & $0.6(5.3) 0.915$ & $-5.7(9.8) 0.573$ \\
\hline Glycine & $329(40.3)$ & $9.8(8.7) 0.287$ & 8.8 (12.5) 0.496 \\
\hline Threonine & 155 (18.9) & $0.5(4.4) 0.911$ & $-1.3(2.8) 0.653$ \\
\hline Citrulline & $40(2.7)$ & $0.7(1.0) 0.526$ & $1.3(2.3) 0.582$ \\
\hline Alanine & $404(38.5)$ & 12.8 (8.3) 0.148 & $3.2(2.2) 0.187$ \\
\hline Taurine & $61(7.5)$ & $2.1(1.2) 0.113$ & $10.2(8.2) 0.237$ \\
\hline$\alpha$-amino butyric acid & $17(1.3)$ & $0.7(0.4) 0.136$ & $3.7(2.3) 0.140$ \\
\hline Tyrosine & $84(15.6)$ & $6.6(5.4) 0.246$ & $5.1(4.4) 0.272$ \\
\hline Valine & $156(12.0)$ & $7.5(5.1) 0.173$ & $3.2(2.7) 0.273$ \\
\hline Methionine & $38(11.1)$ & $1.5(0.8) 0.098$ & $2.8(2.3) 0.265$ \\
\hline Isoleucine & $52(3.5)$ & $2.3(1.5) 0.157$ & $3.5(2.6) 0.207$ \\
\hline Phenylalanine & $68(11.5$ & $2.0(1.2) 0.122$ & $2.2(1.7) 0.213$ \\
\hline Tryptophane & $51(7.5)$ & $1.3(1.3) 0.370$ & 3.7 (3.1) 0.251 \\
\hline Leucine & $101(8.5)$ & $4.3(2.2) 0.075$ & $3.2(2.0) 0.134$ \\
\hline Lysine & $212(19.0)$ & $8.0(5.8) 0.193$ & $2.8(2.6) 0.313$ \\
\hline$\Sigma$ AA & $3073(291.4)$ & $90.3(61.7) 0.171$ & $2.3(2.0) 0.283$ \\
\hline$\Sigma$ Arginine \& Ornithine & $161(10.0)$ & 4.8 (3.7) 0.219 & $1.7(2.1) 0.424$ \\
\hline
\end{tabular}

Pooled data of all plasma incubation experiments. Plasma was obtained from patients undergoing liver resection before liver manipulation $(N=6)$, after liver manipulation $(N=6)$ and after liver transplantation $(N=4)$. Arterial concentrations before incubation are given as well as absolute $(\mu \mathrm{mol} / \mathrm{l})$ and relative $(\%)$ increases at the end of the incubation (mean $\mathbf{3 7 . 5}$ minutes). Results were similar for all three experiments except for changes in arginine and ornithine concentrations in plasma obtained after liver transplantation. Changes in arginine and ornithine concentrations during the various experiments are presented in Figures 3.2 and 3.3C. The sum of arginine and ornithine concentrations remained unchanged during all experiments. Data are presented as mean (SEM), absolute and relative changes were tested vs. zero by a one-sample t-test. $\Sigma \mathrm{AA}=$ sum of all amino acids, $\Sigma$ Arginine $\&$ Ornithine $=$ sum of arginine and ornithine concentrations.

\section{Whole blood}

Arginase-1 plasma levels in incubated whole blood remained stable (data not shown), ruling out a potential increase of arginase activity due to hemolysis. After 40 minutes of incubation a significant decrease of arginine concentrations with a concomitant increase of ornithine concentrations was found in plasma of all whole blood samples, irrespective of the amount of arginase- 1 in the plasma (Figure 3.2C, D). These highly significant changes were not found for other amino acids (Table 3.4). 
Table 3.4. Changes in plasma amino acid concentrations during incubation of whole blood

\begin{tabular}{|c|c|c|c|}
\hline & $\begin{array}{c}\text { concentration } \\
(\mu \mathrm{mol} / \mathrm{l})\end{array}$ & $\begin{array}{l}\text { absolute increase } \\
(\mu \mathrm{mol} / \mathrm{l}) \text { P-value }\end{array}$ & $\begin{array}{c}\text { relative increase } \\
\text { (\%) P-value }\end{array}$ \\
\hline Glutamate & $109(6.8)$ & $9.6(4.7) 0.078$ & $8.3(4.0) 0.077$ \\
\hline Asparagine & $43(2.0)$ & $3.8(1.7) 0.066$ & $7.7(3.8) 0.079$ \\
\hline Serine & $118(10.7)$ & $3.6(5.3) 0.514$ & $1.7(4.4) 0.711$ \\
\hline Glutamine & $527(9.3)$ & $3.1(23.6) 0.898$ & $0.5(4.5) 0.924$ \\
\hline Histidine & $61(13.7)$ & $6.3(4.4) 0.196$ & $6.6(5.2) 0.247$ \\
\hline Glycine & $305(53.0)$ & $45.9(41.8) 0.308$ & $55.4(41.3) 0.221$ \\
\hline Threonine & $117(9.5)$ & $4.1(5.0) 0.433$ & $2.0(4.8) 0.692$ \\
\hline Citrulline & 39 (3.0) & 1.0 (1.1) 0.394 & $2.2(2.7) 0.437$ \\
\hline Arginine & $68(3.1)$ & $-18.3(2.2)<0.001$ & $-26.7(3.1)<0.001$ \\
\hline Alanine & $321(26.0)$ & 28.4 (14.6) 0.094 & $9.3(4.2) 0.062$ \\
\hline Taurine & $58(5.3)$ & -1.4 (10.9) 0.903 & $3.2(16.3) 0.850$ \\
\hline$\alpha$-amino butyric acid & $14(0.8)$ & $1.3(0.5) 0.049$ & $8.4(3.4) 0.043$ \\
\hline Tyrosine & 49 (2.9) & $2.1(1.7) 0.239$ & $3.5(3.3) 0.327$ \\
\hline Valine & $148(11.0)$ & $9.3(5.3) 0.127$ & $5.0(3.2) 0.161$ \\
\hline Methionine & $16(0.9)$ & $0.5(0.5) 0.351$ & $2.3(3.0) 0.473$ \\
\hline Isoleucine & $46(3.6)$ & 2.9 (1.6) 0.111 & $4.6(3.3) 0.209$ \\
\hline Phenylalanine & $43(2.6)$ & 1.9 (1.3) 0.201 & $4.0(3.0) 0.214$ \\
\hline Tryptophane & $34(4.0)$ & $2.1(2.3) 0.391$ & $7.8(8.7) 0.401$ \\
\hline Leucine & $85(7.4)$ & $7.3(2.9) 0.042$ & $7.1(2.9) 0.045$ \\
\hline Ornithine & $73(5.9)$ & $37.6(7.5)<0.001$ & $45.1(5.8)<0.001$ \\
\hline Lysine & $167(14.1)$ & 19.0 (11.2) 0.132 & $10.0(5.2) 0.094$ \\
\hline$\Sigma$ AA & 2445 (111.6) & $172.1(105.1) 0.145$ & $6.9(4.3) 0.153$ \\
\hline$\Sigma$ Arginine \& Ornithine & $145(8.5)$ & $19.3(7.4) 0.024$ & 12.0 (4.1) 0.015 \\
\hline
\end{tabular}

Pooled data of all whole blood incubation experiments. Whole blood was obtained from patient undergoing liver resection before liver manipulation $(N=6)$ and after liver manipulation $(N=6)$. Arterial concentrations before incubation are given as well as absolute $(\mu \mathrm{mol} / \mathrm{I})$ and relative $(\%)$ increases at the end of the incubation (mean 37.5 minutes). Results were similar for both experiments. Data are presented as mean (SEM), absolute and relative changes were tested vs. zero by a one-sample t-test. $\Sigma A A=$ sum of all amino acids, $\Sigma$ Arginine \& Ornithine = sum of arginine and ornithine concentrations.

\section{Plasma arginase activity after liver transplantation In vivo arginase-1 levels and indices of arginase activity}

After reperfusion, plasma arginase-1 levels increased steeply to 1000 -fold normal values (Figure 3.3A). In addition we observed a rapid decline of plasma arginine levels with a concomitant increase in the plasma levels of ornithine (Figure 3.3A). 


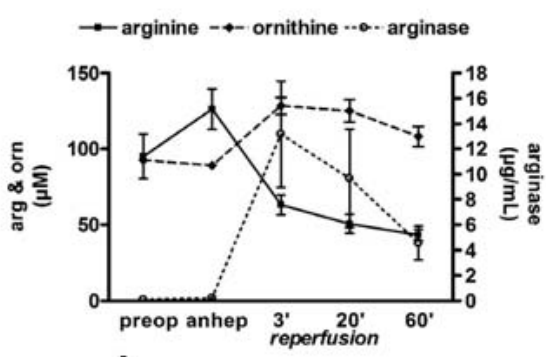

A
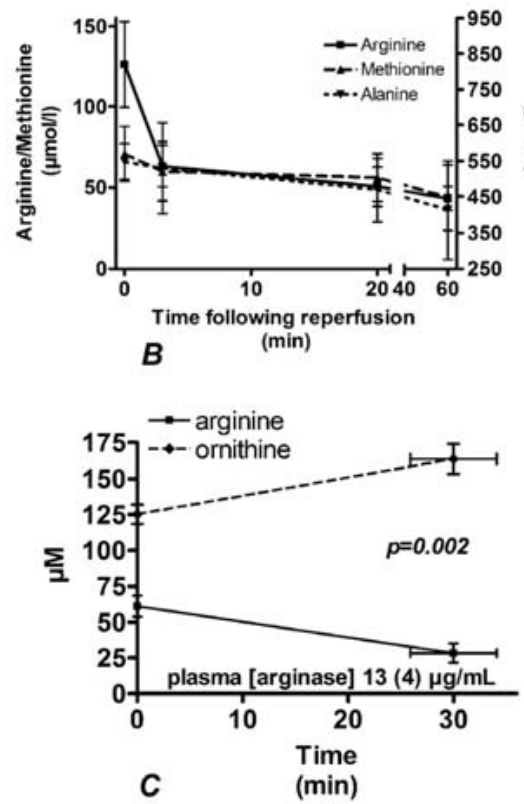

Figure 3.3. (A) Arterial arginase-1, arginine and ornithine concentrations were measured in 4 patients undergoing cadaveric liver transplantation. Preoperative arginase-1 levels were elevated above reference values, reflecting underlying liver disease eventually necessitating liver transplantation. Immediately following reperfusion a large increase of plasma arginase- 1 levels occurred $(P=0.008)$. This was accompanied by a sharp decrease of arginine $(P<0.0001)$ and concomitant increase of ornithine levels $(P=$ 0.0003). (B) The decline in plasma arginine levels was most outspoken in the first three minutes, where after arginine levels remained relatively stable. (C) Incubation of plasma samples drawn 3 minutes following reperfusion of the liver graft (containing a mean (SEM) arginase-1 concentration of $13(4.2) \mu \mathrm{g} / \mathrm{mL}$ ) led to a significant decrease of arginine levels with a concomitant increase of ornithine levels $(P=0.002)$, proving plasma arginase activity.

A one-phase exponential decay curve fitted along the mean arginase-1 concentrations 3,20 , and 60 minutes post reperfusion, resulted in a calculated plasma half life of approximately 40 minutes. Within 3 minutes following reperfusion in vivo arginine plasma levels were relatively stabilized (Figure 3.3B). Plasma concentrations of other amino acids that depend on the liver for their plasma clearance such as alanine and methionine also declined following reperfusion of the liver, although not as steeply as arginine concentrations (Figure 3.3B).

\section{In vitro arginase activity after liver transplantation}

Incubation of plasma sampled 3 minutes following liver transplantation (arginase-1 $13.2(4.2 \mu \mathrm{g} / \mathrm{ml})$ at $37^{\circ} \mathrm{C}$ for 30 minutes) resulted in a significant decrease of plasma 
arginine concentration (from 61.1 (7.4) to 28.4 (6.7) $\mu \mathrm{mol} / \mathrm{l}$ ). This was accompanied by a similar increase of ornithine concentration (from 125.2 (6.6) to 163.7 (10.4) $\mu \mathrm{mol} / \mathrm{l})(\mathrm{p}=0.002$ ) (Figure 3.3C). Other amino acids remained unaffected (Table 3.3).

\section{Relation between arginase enzyme activity and arginase-1 protein concentration in plasma}

\section{Plasma arginase activity at physiological arginine concentration}

Plasma samples containing different arginase- 1 levels were incubated for 5 and 30 minutes at $37^{\circ} \mathrm{C}$ in the presence of $85 \mu \mathrm{mol} / \mathrm{l}$ arginine. At this arginine concentration the relation between arginase- 1 concentration and arginase activity appeared to be non-linear, with a lower specific activity (activity per unit of enzyme) at higher arginase-1 concentrations. Below an arginase-1 concentration of $1.6 \mu \mathrm{g} / \mathrm{ml}$ however, there was in fact a linear relationship between arginase-1 concentration and arginase activity $\left(r^{2}=0.99\right)$ (Figure $\left.3.4 \mathrm{~A}\right)$. After 30 minutes of incubation with an initial arginine concentration of $85 \mu \mathrm{mol} / \mathrm{l}$, arginine plasma levels decreased dependent on the arginase-1 level. At arginase- 1 levels below $2 \mu \mathrm{g} / \mathrm{ml}$ and an initial arginine concentration of $85 \mu \mathrm{mol} / \mathrm{l}$, arginine levels decreased less than $10 \%$ within 30 minutes (Figure 3.4B).

\section{Plasma arginase activity at above-Km arginine concentration}

Plasma with varying amounts of arginase- 1 was incubated in the presence of 20 $\mathrm{mmol} / \mathrm{l}$ arginine, which is well above the $\mathrm{Km}$ for arginase-1. This resulted in an enduring linear ornithine formation. (Figure 3.4C), showing that the intrinsic activity of the enzyme in isolated plasma was preserved during in vitro incubation.

\section{Arginase-1 concentration in erythrocytes}

Erythrocyte arginase-1 concentration, measured by ELISA was 17.0 (1.1) $\mu \mathrm{g}$ per ml red blood cells. 

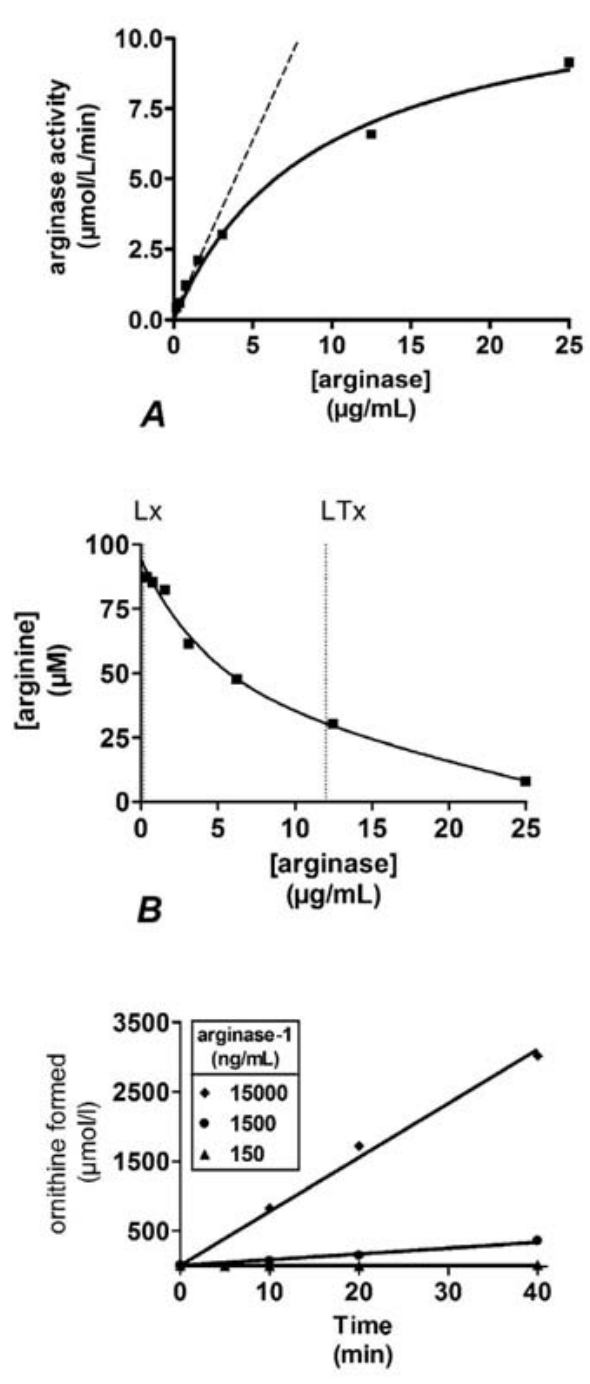

C
Figure 3.4. Plasma samples with varying arginase1 concentrations were created by mixing plasma from a liver transplant recipient ([arginase-1] 25 $\mu \mathrm{g} / \mathrm{mL}$ ) and from a healthy volunteer ([arginase1] below $10 \mathrm{ng} / \mathrm{mL}$ ). Starting arginine levels were adjusted by adding arginine and samples were incubated at $37^{\circ} \mathrm{C}$. (A) Plasma samples were incubated for 5 minutes in the presence of 85 $\mu \mathrm{mol} / \mathrm{l}$ arginine, which approximates the normal arginine concentration in human plasma. The data show that arginase activity was related to arginase-1 concentration; however, the formation of ornithine at the highest arginase- 1 concentrations was rapidly limited by decreasing substrate availability. The dashed line indicates the theoretical relation between arginase-1 concentration and arginase activity at a constant arginine concentration of $85 \mu \mathrm{mol} / \mathrm{l}$. (B) Plasma samples with varying concentrations of arginase1 were incubated in the presence of $85 \mu \mathrm{mol} / \mathrm{I}$ arginine for 20 minutes. During this period arginine plasma levels decreased dependent on the arginase-1 plasma level. At arginase-1 levels below 2,000 ng/ml, the decrease of arginine levels in 20 minutes was below $10 \%$. Below an arginine plasma level of $50 \mu \mathrm{mol} / \mathrm{l}$, arginase activity rapidly becomes limited by substrate availability. Lx indicates mean arginase1 levels reached during liver resection, LTx indicates mean arginase-1 levels reached after liver transplantation. (C) Plasma samples with varying concentrations of arginase-1 were incubated in the presence of $20 \mathrm{mmol} / \mathrm{l}$ arginine, which maintained substrate availability above $\mathrm{Km}$ values during the incubation. In this experiment the ornithine formation rate remained unchanged showing that the intrinsic activity of the enzyme was maintained during the incubations.

\section{Discussion}

Increased plasma arginase- 1 activity is frequently named as a cause of low arginine plasma levels in patients with hepatocellular or erythrocyte injury. ${ }^{10,11,16,17,20,28,29}$ This could be clinically relevant since low arginine levels may induce immunological and microcirculatory dysfunction. ${ }^{14,30,31}$ The results from the present study, however, show that a potentially relevant effect of plasma arginase- 1 on arginine me- 
tabolism only occurs when very high arginase- 1 concentrations are reached. We were able to study the relation between plasma arginase- 1 levels and plasma arginase activity by the application of a recently developed ELISA ${ }^{27}$ that allows exact quantification of the arginase- 1 concentration in plasma. Arginase- 1 was released from the liver into the plasma in patients undergoing liver resection, leading to an 8fold increase of circulating arginase-1, without affecting arginine and ornithine plasma levels. These data show no evidence for increased arginase activity despite increased arginase-1 plasma levels. From these data alone, however, it cannot be ruled out that actual arginase activity was compensated by other mechanisms regulating plasma arginine and ornithine levels. Plasma arginine levels are regulated in vivo by protein breakdown and endogenous arginine synthesis. The latter occurs in the kidney where citrulline, derived from intestinal glutamine metabolism becomes converted to arginine. ${ }^{9,} 32$ We have demonstrated recently that endogenous arginine synthesis remains unchanged during liver surgery. ${ }^{32}$ Quantitatively, arginine clearance is primarily determined by protein synthesis. This is illustrated by the increased plasma levels of arginine and most other amino acids during hepatic inflow occlusion, reflecting abolishment of hepatic protein synthesis. Ornithine concentrations remained unchanged, which is in line with the absence of physiological hepatic ornithine uptake. ${ }^{9}$

To study plasma arginase activity isolated from in vivo regulatory mechanisms, plasma and whole blood samples were incubated in vitro. In agreement with the in vivo data no significant changes in arginine and ornithine concentrations were found during incubation of plasma samples with a mean arginase- 1 concentration of $185 \mathrm{ng} / \mathrm{ml}$. To explore whether plasma arginase activity was dependent on factors present in whole blood but not in plasma, whole blood samples were incubated at $37^{\circ} \mathrm{C}$ for 40 minutes. A significant increase of ornithine was found, accompanied by a similar decrease of arginine. No changes were found in the plasma concentrations of other amino acids such as glutamate, an ornithine precursor or citrulline, an arginine product. This strongly suggests that the observed changes actually specifically reflect arginase activity. Whole blood arginase activity however was not related to the arginase- 1 plasma concentration, which underlines that plasma arginase-1 does not affect plasma arginine levels. More likely whole blood arginase activity occurs in the cellular fraction (erythrocytes and/or leucocytes). Several studies have reported arginase activity in plasma in clinical settings, which seemingly conflicts with our data. Roth et al. showed that liver transplantation leads to an immediate decrease of plasma arginine to virtually zero with a stoichiometric increase of plasma ornithine, which is highly indicative for arginase activity. ${ }^{11,16}$ We were able to reproduce these data, although the decrease of arginine levels was not as outspoken as described by Roth et al. Moreover plasma concentrations of other amino acids such as methionine and alanine decreased as well, reflecting restoration of liver function. Nonetheless, the specific steep decline of arginine in the first three minutes follow- 
ing reperfusion and the simultaneous increase of ornithine levels is in fact highly indicative for arginase activity. Arginase-1 plasma levels were 100-fold higher after liver transplantation than during liver resection and 1000 -fold higher than normal reference values. In vitro assessment of plasma obtained 3 minutes following transplantation revealed specific and stoichiometric changes in arginine and ornithine concentration that were related to arginase-1 concentration. Arginase activity per $\mu \mathrm{g}$ arginase-1 (specific activity) appeared to decline at increasing arginase-1 concentrations. This is probably due to the high initial reaction velocity at high arginase-1 concentrations, leading to rapid decline of arginine concentration and arginase activity. In samples with an arginase-1 concentration $<1.5 \mu \mathrm{g} / \mathrm{ml}$ arginine depletion did not occur. At these low enzyme concentrations there was a linear relation between plasma arginase-1 concentration and arginase activity. Moreover incubation of plasma samples with $20 \mathrm{mmol} / \mathrm{l}$ arginine (above $\mathrm{Km}$ ) showed that the intrinsic activity of the enzyme was preserved during incubation. Theoretically, the activity of arginase-1 at low enzyme and/or substrate concentrations may be limited by endogenous arginase inhibition. The most potent endogenous arginase inhibitor known is $\mathrm{N}-\omega$-hydroxyarginine (NOHA), an intermediate of NO synthesis. However, regarding the high NOHA concentrations required to cause arginase inhibition $(\text { IC50 } \approx 400 \mu \mathrm{M})^{33}$ it appears unlikely that any of the presently known arginase inhibitors affected the present results. Due to limited availability of methods to quantify arginase (-1 and -2 ) protein content in biological samples, various semi quantitative arginase activity assays, relying on supraphysiological $\mathrm{pH}$ and arginine concentrations have been developed. ${ }^{20,34}$ The wide-spread use of such biochemical assays has led to the interchangeable use of the terms arginase activity and arginase concentration. The in vitro experiments in the current study were designed to study arginase activity under physiological conditions rather than to quantify plasma levels of arginase. The data show that detection of arginase activity in a plasma sample under optimal biochemical conditions does not necessarily imply that arginase is active in plasma under physiological conditions. Currently, there is growing interest in the role of arginine and arginase in hemolytic anaemia. ${ }^{10,34}$ In a recent publication it was reported that hemolytic patients with sickle cell anaemia had reduced arginine levels and a 5-fold increase in plasma arginase activity, measured by a semi quantitative assay. ${ }^{10}$ In the same study it was found that erythrocyte arginase activity was similarly increased. Another recent study reported a 14-fold increase in erythrocyte arginase activity in sickle cell disease, measured semi quantitatively. ${ }^{34}$ In the light of our current data, which show that a considerable amount of plasma arginine catabolism is performed by arginase- 1 within the intact erythrocyte, it can be speculated that increased arginase activity in the blood of sickle cell patients should be ascribed to increased arginase activity in the cellular fraction rather than to increased arginase levels in plasma. Finally, it has been suggested that increased circulating arginase concentrations disturb arginine metabolism following blood trans- 
fusion due to hemolysis of stored erythrocytes. ${ }^{20}$ We found that normal erythrocytes contain $17 \mu \mathrm{g}$ arginase-1 per $\mathrm{ml}$ cells. Therefore one unit of red blood cell concentrate $(300 \mathrm{ml})$ contains $5.1 \mathrm{mg}$ arginase-1. Considering a distribution volume of $3 \mathrm{~L}$ (plasma volume) for these erythrocytes after transfusion, one unit of packed red blood cells can increase arginase- 1 plasma levels with $1.7 \mu \mathrm{g} / \mathrm{mL}$ in the extreme situation of $100 \%$ hemolysis of the transfused erythrocytes. This theoretical example shows that plasma arginase -1 activity during blood transfusion will not likely affect arginine metabolism substantially. This assumption is further confirmed by clinical observations in patients receiving massive blood transfusion during thoracoabdominal aorta surgery, showing moderate changes in plasma arginase-1 concentrations but no changes in plasma arginine concentrations (Chapter 5). In conclusion, increased plasma levels of arginase-1 occurring during liver resection do not lead to arginine breakdown. The threshold beyond which the plasma level of arginase-1 significantly affects plasma arginine concentration is probably rarely reached in clinical practice, with the exceptions of liver transplantation.

\section{Acknowledgements}

The authors would like to thank dr. Jan Rozing (Department of Biochemistry, Maastricht University, the Netherlands), dr. Wout H. Lamers (Department of Anatomy and Embryology, Maastricht University, the Netherlands) and dr. Alfred J. Meijer (Department of Biochemistry, University of Amsterdam, the Netherlands) for fruitful discussions. 


\section{References}

1. Wu G, Morris SM, Jr. Arginine metabolism: nitric oxide and beyond. Biochem J 1998; 336:1-17.

2. Castillo L, Beaumier L, Ajami AM, Young VR. Whole body nitric oxide synthesis in healthy men determined from [15N] arginine-to-[15N] citrulline labeling. Proc Natl Acad Sci USA 1996; 93:11460-5.

3. Castillo L, Chapman TE, Sanchez $M$, et al. Plasma arginine and citrulline kinetics in adults given adequate and arginine-free diets. Proc Natl Acad Sci USA 1993; 90:7749-53.

4. Castillo L, Sanchez M, Vogt J, et al. Plasma arginine, citrulline, and ornithine kinetics in adults, with observations on nitric oxide synthesis. Am J Physiol 1995; 268:E360-7.

5. Morris SM, Jr., Bhamidipati D, Kepka-Lenhart D. Human type II arginase: sequence analysis and tissue-specific expression. Gene 1997; 193:157-61.

6. Kim PS, Iyer RK, Lu KV, et al. Expression of the liver form of arginase in erythrocytes. Mol Genet Metab 2002; 76:100-10.

7. Grody WW, Argyle C, Kern RM, et al. Differential expression of the two human arginase genes in hyperargininemia. Enzymatic, pathologic, and molecular analysis. J Clin Invest 1989; 83:602-9.

8. Cheung CW, Cohen NS, Raijman L. Channeling of urea cycle intermediates in situ in permeabilized hepatocytes. J Biol Chem 1989; 264:4038-44.

9. van de Poll MC, Siroen MP, van Leeuwen PA, et al. Interorgan amino acid exchange in humans: consequences for arginine and citrulline metabolism. Am J Clin Nutr 2007; 85:167-72.

10. Morris CR, Kato GJ, Poljakovic M, et al. Dysregulated arginine metabolism, hemolysis-associated pulmonary hypertension, and mortality in sickle cell disease. JAMA 2005; 294:81-90.

11. Langle $F$, Steininger R, Roth $R$, et al. L-arginine deficiency and hemodynamic changes as a result of arginase efflux following orthotopic liver transplantation. Transplant Proc 1995; 27:2872-3.

12. Debats IB, Booi D, Deutz NE, et al. Infected Chronic Wounds Show Different Local and Systemic Arginine Conversion Compared With Acute Wounds. J Surg Res 2006; 134:205-14.

13. Luiking YC, Poeze $M$, Dejong $\mathrm{CH}$, et al. Sepsis: an arginine deficiency state? Crit Care Med 2004; 32:2135-45.

14. Makarenkova VP, Bansal V, Matta BM, et al. CD11b+/Gr-1+ myeloid suppressor cells cause $T$ cell dysfunction after traumatic stress. J Immunol 2006; 176:2085-94.

15. Braga M, Gianotti L, Vignali A, Carlo VD. Preoperative oral arginine and $n-3$ fatty acid supplementation improves the immunometabolic host response and outcome after colorectal resection for cancer. Surgery 2002; 132:805-14.

16. Roth E, Steininger R, Winkler S, et al. L-arginine deficiency after liver transplantation as an effect of arginase efflux from the graft. Transplantation 1994; 57:665-9.

17. Cheng PN, Leung YC, Lo WH, et al. Remission of hepatocellular carcinoma with arginine depletion induced by systemic release of endogenous hepatic arginase due to transhepatic arterial embolisation, augmented by high-dose insulin: arginase as a potential drug candidate for hepatocellular carcinoma. Cancer Lett 2005; 224:67-80.

18. Cacciatore L, Antoniello S, Valentino B, De Ritis F. Arginase activity, arginine and ornithine of plasma in experimental liver damage. Enzyme 1974; 17:269-75.

19. Houdijk AP, Teerlink T, Visser JJ, et al. Arginine deficiency in bile duct-ligated rats after surgery: the role of plasma arginase and gut endotoxin restriction. Gastroenterology 1997; 113:1375-83.

20. Prins HA, Houdijk AP, Nijveldt RJ, et al. Arginase release from red blood cells: possible link in transfusion induced immune suppression? Shock 2001; 16:113-5.

21. Wheatley DN. Controlling cancer by restricting arginine availability--argininecatabolizing enzymes as anticancer agents. Anticancer Drugs 2004; 15:825-33.

22. Patel A, van de Poll MC, Greve JW, et al. Early stress protein gene expression in a human model of ischemic preconditioning. Transplantation 2004; 78:1479-87.

23. van de Poll MC, Derikx JPM, Buurman WA, et al. Liver manipulation causes hepatocyte injury and precedes systemic inflammation in patients undergoing liver resection. World J Surg. 2007; 31:20338. 
24. Boyum A, Lovhaug D, Tresland L, Nordlie EM. Separation of leucocytes: improved cell purity by fine adjustments of gradient medium density and osmolality. Scand J Immunol 1991; 34:697-712.

25. Krzyzaniak JF, Raymond DM, Yalkowsky SH. Lysis of human red blood cells: Effect of contact time on water induced hemolysis. PDA J Pharm Sci Technol 1996; 50:223-6.

26. van Eijk HM, Rooyakkers DR, Deutz NE. Rapid routine determination of amino acids in plasma by high-performance liquid chromatography with a 2-3 microns Spherisorb ODS II column. J Chromatogr 1993; 620:143-8.

27. Ikemoto $M$, Tsunekawa $S$, Awane $M$, et al. A useful ELISA system for human liver-type arginase, and its utility in diagnosis of liver diseases. Clin Biochem 2001; 34:455-61.

28. Morris CR, Poljakovic M, Lavrisha L, et al. Decreased arginine bioavailability and increased serum arginase activity in asthma. Am J Respir Crit Care Med 2004; 170:148-53.

29. Rother RP, Bell L, Hillmen P, Gladwin MT. The clinical sequelae of intravascular hemolysis and extracellular plasma hemoglobin: a novel mechanism of human disease. JAMA 2005; 293:1653-62.

30. de Jonge WJ, Kwikkers KL, te Velde AA, et al. Arginine deficiency affects early $B$ cell maturation and lymphoid organ development in transgenic mice. J Clin Invest 2002; 110:1539-48.

31. Luiking YC, Poeze M, Ramsay G, Deutz NE. The role of arginine in infection and sepsis. JPEN J Parenter Enteral Nutr 2005; 29:S70-4.

32. van de Poll MC, Ligthart-Melis GC, Boelens PG, et al. Intestinal and hepatic metabolism of glutamine and citrulline in humans. J Physiol 2007; 581:819-827.

33. Tenu JP, Lepoivre M, Moali C, et al. Effects of the new arginase inhibitor N(omega)-hydroxy-nor-Larginine on NO synthase activity in murine macrophages. Nitric Oxide 1999; 3:427-38.

34. Iyamu EW, Cecil R, Parkin L, et al. Modulation of erythrocyte arginase activity in sickle cell disease patients during hydroxyurea therapy. Br J Haematol 2005; 131:389-94. 
<smiles>C=C=C</smiles> 
Chapter 4 Cardiovascular Surgery and Organ Damage; Time to Reconsider the Role of Hemolysis

Sebastiaan J. Hanssen*, Iris C. Vermeulen Windsant*, Wim A. Buurman, Michael J. Jacobs

* These authors contributed equally to this review

Journal of Thoracic and Cardiovascular Surgery, Volume 142, July 2011, Pages 1-11. 


\section{Abstract}

Cardiovascular surgery with cardiopulmonary bypass is associated with postoperative organ injury which severely affects patient morbidity and mortality. Multiple cardiopulmonary bypass related mechanisms have been linked to the development of tissue damage including hypoperfusion, ischemia/reperfusion and induction of a pro-inflammatory response. Hemolysis, resulting in increased plasma free hemoglobin concentrations is considered an inevitable, but relatively harmless side-effect of cardiopulmonary bypass. Recently, however, evidence is mounting that plasma free hemoglobin scavenges intravascular nitric oxide, thereby attenuating its bioavailability. A significant reduction in nitric oxide, the most important endogenous vasodilator, impairs tissue perfusion and induces organ injury development. Moreover, urinary free hemoglobin contributes to renal damage specifically by catalyzation of reactive oxygen species formation. In this review, the effects of increased free hemoglobin levels on nitric oxide metabolism are discussed. Additionally, we review the role of free hemoglobin in organ injury development, potential sources of free hemoglobin during cardiovascular surgery, as well as therapeutic options to attenuate the consequences of hemolysis. We propose that hemolysis is more than an innocent bystander effect of cardiopulmonary bypass assisted surgery. Therapeutic interventions attenuating the effects of hemolysis seem crucial in the reduction of postoperative morbidity and mortality after cardiovascular surgery. 


\section{Introduction}

Cardiovascular surgery with extracorporeal circulation is associated with considerable postoperative morbidity and mortality, especially in patients undergoing complex procedures like combined coronary artery bypass grafting (CABG) and valve surgery, Bentall procedures, and open repair of thoracic and thoracoabdominal aortic aneurysms. These patients are at high risk for developing major complications such as acute kidney injury, ${ }^{1-6}$ pulmonary dysfunction, ${ }^{7,8}$ sepsis, and multiple organ failure. ${ }^{9}$

The pathophysiology underlying these complications has been extensively studied in order to develop specific prevention and treatment strategies. The cardiopulmonary bypass (CPB) circuit has been associated with the development of tissue damage due to insufficient oxygen delivery through hemodilution, ${ }^{10}$ ischemia/reperfusion, ${ }^{11}$ and hypoperfusion. ${ }^{12,13}$ Cardiotomy suction during CPB has been shown to be a source of lipid microemboli forming small vascular occlusions in several tissues, including brain, kidney, spleen and muscle. ${ }^{14,15}$ Furthermore, the nonendothelial surface of the CPB-system initiates a pro-inflammatory response which deteriorates cellular function, for instance the function of renal tubular cells. ${ }^{16,17}$ Indeed, the use of a mini-cardiopulmonary bypass system, reducing the proinflammatory contact surface area and hemodilution, attenuates the release of intestinal and renal tissue damage markers as compared to a normal CPB circuit in cardiac surgery patients. ${ }^{18}$ Similarly, the incidence of liver injury and kidney injury is significantly reduced in patients undergoing CABG without CPB (off-pump) in comparison with on-pump CABG. ${ }^{19,}{ }^{20}$ Nevertheless, although off-pump surgery has gained popularity world-wide, CPB-assisted surgery is still widely used. To reduce CPB-related morbidity and mortality, successful efforts have been made to increase CPB biocompatibility and flow performance. Unfortunately, this has not led to a significantly decreased incidence of organ dysfunction after cardiovascular surgery. ${ }^{21}$ This underscores the need for further clarification of underlying pathophysiological mechanisms of tissue damage and dysfunction in this setting. ${ }^{21}$

A common consequence of CPB is hemolysis, considered an inevitable, but relatively harmless phenomenon. Hemolysis is principally caused by mechanical shear stress within the perfusion circuit and results in the release of hemoglobin into the circulation. $^{22,23}$ The role of this cell-free plasma hemoglobin (FHb) in the development of organ injury has gained increasing interest since a direct relation between hemolysis, impaired vascular function, decreased organ perfusion, and organ dysfunction has been reproducibly shown in experimental animal models and in chronic hemolytic diseases in men. ${ }^{24,25}$ Most recently, Meyer et al. showed that FHb due to hemodialysis-induced hemolysis impaired vascular function in patients, indicating a role for $\mathrm{FHb}$ in the development of microcirculatory dysfunction during acute and transient hemolysis. ${ }^{26,27}$ Moreover, the results of Meyer et al. substanti- 
ate our recent findings that acute hemolysis during major aortic surgery was independently associated with proximal renal tubular damage and postoperative acute kidney injury. ${ }^{28}$ Therefore, we propose hemolysis to be an important, but generally unrecognized, contributor to the development of organ injury during surgical procedures associated with hemolysis, such as cardiovascular surgery.

The interfering role of $\mathrm{FHb}$ in intravascular nitric oxide (NO) metabolism is believed to play a critical role in the development of microcirculatory impairment, organ damage, and organ dysfunction. ${ }^{24}$ Therefore, in this review we will discuss a) the effects of $\mathrm{FHb}$ on intravascular nitric oxide bioavailability, b) the role of $\mathrm{FHb}$ in the induction of microcirculatory dysfunction and organ damage, c) the potential sources of $\mathrm{FHb}$ during cardiovascular surgery, and d) therapeutic options to attenuate the consequences of hemolysis during CPB-assisted surgery.

\section{Increased plasma free hemoglobin due to hemolysis reduces intravascular nitric oxide bioavailability}

Upon intravascular destruction of red blood cells (RBC), FHb enters the circulation. $\mathrm{FHb}$ gets bound to either haptoglobin or is oxidized to methemoglobin. The hemoglobin-haptoglobin complex is rapidly cleared from the circulation through endocytosis by the surface scavenger receptor CD163 expressed on monocytes and tissue macrophages. This way, haptoglobin prevents accumulation of plasma FHb under physiological circumstances. ${ }^{29}$ This effect was illustrated in patients undergoing cardiac surgery in whom intravenous administration of haptoglobin significantly reduced circulating $\mathrm{FHb}$ levels. ${ }^{30}$ Free heme, another by-product of hemolysis, is released during oxidation of free hemoglobin and is scavenged by circulating hemopexin. Subsequently, heme-oxygenase ( $\mathrm{HO}$ )-1, activated due to reduced microcirculation, degrades heme to carbon monoxide, biliverdin, and iron mainly in the liver and spleen. ${ }^{31}$ This cytoprotective induction of $\mathrm{HO}-1$ by the microvasculature has been shown to modulate inflammation in patients after cardiac surgery with $\mathrm{CPB}$, which may benefit patient recovery postoperatively; ${ }^{32}$ furthermore, the induction of HO-1 inhibits vascular inflammation and vaso-occlusion in transgenic sickle mice. ${ }^{32,33}$ Since both haptoglobin and hemopexin are not recycled after clearance of hemoglobin-haptoglobin or heme-hemopexin complexes, excessive RBC lysis rapidly exhausts their storage pools. This results in enhanced levels of $\mathrm{FHb}$ and free heme, both harmful products. First of all, free heme is able to react with endogenous hydrogen peroxide, thereby forming toxic free radicals which are involved in the induction of pro-oxidant damage. ${ }^{34}$ Secondly, oxygenated $\mathrm{FHb}$ has been shown to be a potent scavenger of $\mathrm{NO}$, the most important endogenous vasodilator. The fast $(6-8$ $x 10^{7} \mathrm{~mol} / \mathrm{L} / \mathrm{s}$ ) and irreversible reaction of oxygenated $\mathrm{FHb}$ with NO results in conversion of $\mathrm{FHb}$ to methemoglobin and conversion of $\mathrm{NO}$ to nitrate. Circulating $\mathrm{FHb}$ is 
also present in a deoxygenated form. Such deoxygenated $\mathrm{FHb}$ also scavenges NO, forming nitrosyl- $\mathrm{Hb}$, but this reaction is slower $\left(10^{7} \mathrm{~mol} / \mathrm{L} / \mathrm{s}\right)$ and reversible. ${ }^{24,29}$ As a result, hemolysis significantly impairs NO-bioavailability, potentially inducing microcirculatory dysfunction. ${ }^{35,36}$ In vivo, FHb associated NO-scavenging was correlated to systemic vasoconstriction and a reduction in renal function in a canine hemolysis model. ${ }^{25}$ In patients with chronic high FHb levels due to sickle cell disease, forearm blood flow responses were reduced by $80 \%$ after infusion of the nitric oxide donor sodium nitroprusside, compared to patients with below average FHb levels. ${ }^{24}$ Thirdly, hemolysis also results in release of arginase-1, an enzyme that converts Larginine, the substrate for NO synthesis, to ornithine. ${ }^{37}$ This way, hemolysis causes not only scavenging of NO, but also, theoretically, prevents new NO formation. In practice, however, we showed that arginase- 1 release during surgery with CPB does not affect the arginine-ornithine ratio (unpublished data). This implies that arginase levels during this type of surgery are not high enough to affect arginine levels and attenuate NO-synthesis. $^{38}$

\section{Cell free hemoglobin contributes to microcirculatory dysfunction through NO-scavenging, potentially inducing hypoxic tissue damage}

The role of hemolysis in organ damage development was already described in the mid nineteen seventies. ${ }^{24,} 39$ These studies focused on acute kidney injury, since glomerularly filtered urinary $\mathrm{FHb}$, instead of plasma $\mathrm{FHb}$, was considered the culprit of organ injury induction. Therefore, at that time, only the kidney was believed to be at risk for $\mathrm{FHb}$ induced damage. Two mechanisms were proposed to underlie the association between hemolysis and renal tissue damage development. First, urine $\mathrm{FHb}$-derived free iron and heme catalyze the generation of reactive oxygen species which damage the renal tubular epithelium. ${ }^{40}$ Indeed, administration of the iron scavenger deferoxamine attenuated glomerular and tubular dysfunction induced by intravenous $\mathrm{FHb}$ administration in rats. ${ }^{41}$ Similarly, a reduced intravascular iron scavenging capacity - reflected by low plasma ferritin concentrations - was associated with acute kidney injury after human cardiovascular surgery. ${ }^{42}$ Second, intratubular $\mathrm{FHb}$ precipitation and heme cast formation in the acidic ultrafiltrate was considered to obstruct the tubular lumen, reducing glomerular filtration. ${ }^{40,43}$ Subsequent prevention of cast formation by urine alkalanization reduced tubular injury and glomerular dysfunction after intravenous $\mathrm{FHb}$ infusion in rats. ${ }^{40}$

The discovery of NO-scavenging properties of circulating plasma $\mathrm{FHb}$ by the group of Gladwin provided a complementary explanation for hemolysis-induced organ injury. ${ }^{24}$ For the first time, circulating $\mathrm{FHb}$ was recognized as a key player in the pathophysiology of complications in patients with chronic hemolytic disorders, such as sickle cell disease and malaria infection. ${ }^{24}$ Furthermore, the reported ad- 
verse effects associated with administration of hemoglobin based oxygen carriers which basically consist of $\mathrm{FHb}$ - could be explained by intravascular NO-scavenging through $\mathrm{FHb}^{44}$ The negative effects of increased plasma $\mathrm{FHb}$ have been confirmed by many studies since 2002 , in both animals and patients. For example, hemolysis induced by water infusion or direct intravascular $\mathrm{FHb}$ administration in dogs was associated with a significant increase in plasma NO consumption and simultaneously enhanced systemic vascular resistance. These effects were attenuated by NOinhalation (which converts plasma FHb into the less bioactive molecule methemoglobin in the pulmonary circulation), supporting a causal role for NO-scavenging by $\mathrm{FHb}^{25}$ In humans, fore-arm blood flow responses to intra-arterial infusion of sodium nitroprusside, a NO-donor, were negatively correlated to plasma FHb levels in sickle cell patients. ${ }^{24,25}$

The potential role of plasma $\mathrm{FHb}$ in organ injury development is further supported by our observation that plasma $\mathrm{FHb}$ levels are significantly associated with renal proximal tubular damage during CPB-assisted major aortic surgery. ${ }^{26}$ Moreover peak plasma $\mathrm{FHb}$ levels significantly predicted postoperative acute kidney injury. We could not detect $\mathrm{FHb}$ in urine samples during the perioperative period, indicating that urine $\mathrm{FHb}$ is not a major contributor to renal tubular injury development in this setting. ${ }^{26}$ Also, fore-arm blood flow responses after infusion of sodium nitroprusside at the time of peak plasma $\mathrm{FHb}$ concentrations were significantly reduced, as compared to the response measured when FHb-levels were normalized. This observation further underscores a potential causal role of FHb-induced tissue perfusion impairment during surgery (unpublished data). In addition, we have shown that $\mathrm{FHb}$ induces intestinal microcirculatory dysfunction and tissue integrity loss in a rat hemolysis model. ${ }^{45}$

\section{Sources of circulating free hemoglobin during cardiovascular surgery with cardiopulmonary bypass}

Hemolysis can principally be attributed to three sources during cardiovascular surgery; (i) the CPB, (ii) the cell saver system, and (iii) (massive) red blood cell transfusion.

\section{Cardiopulmonary bypass}

Cardiopulmonary bypass inflicts (sub)lethal RBC damage through turbulence and shear stress within the pump, tubes, connectors, cannula, reservoirs, and the oxygenator. ${ }^{23}$ Blood-air contact, blood-nonendothelial surface contact, wall impact forces, use of positive and negative pressures to assist venous drainage, and the use of an integrated cardiotomy suction reservoir all contribute to intraoperative hemo- 


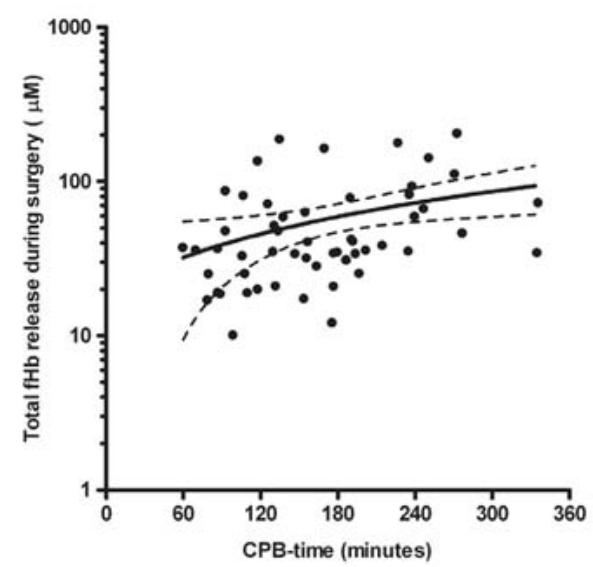

Figure 4.1. Association between cardiopulmonary bypass time and extent of hemolysis. A correlation-analysis between cardiopulmonary bypass time and total free hemoglobin release (defined as the area under the curve) was performed in fifty-four patients ( $N=54$ ) undergoing open surgical repair of thoracoabdominal aortic aneurysms with cardiopulmonary bypass. A significant correlation (Pearson $r=0.33, P<$ $0.05)$ was found between cardiopulmonary bypass time and plasma free hemoglobin release.

$\mathrm{CPB}$, cardiopulmonary bypass; FHb, free hemoglobin

lysis. $^{23,46,47}$ Next to CPB-composition, CPB-duration is considered to influence the degree of hemolysis, with longer CPB-times resulting in increased RBC-lysis. ${ }^{48}$ In support of this phenomenon, we found a positive and statistically significant correlation between total $\mathrm{FHb}$ release in the perioperative period and CPB-time in a group of 54 patients undergoing CPB-assisted major aortic surgery (Figure 4.1). Next to direct red blood cell lysis, the CPB-system induces sub-lethal RBC-injury. ${ }^{49,50}$ Such sub-lethally damaged RBCs are more prone to lysis in vivo. ${ }^{23,51}$ Delayed lysis of sublethally damaged RBCs could explain the continuing increase of plasma $\mathrm{FHb}$ after cessation of CPB (Figure 4.2).

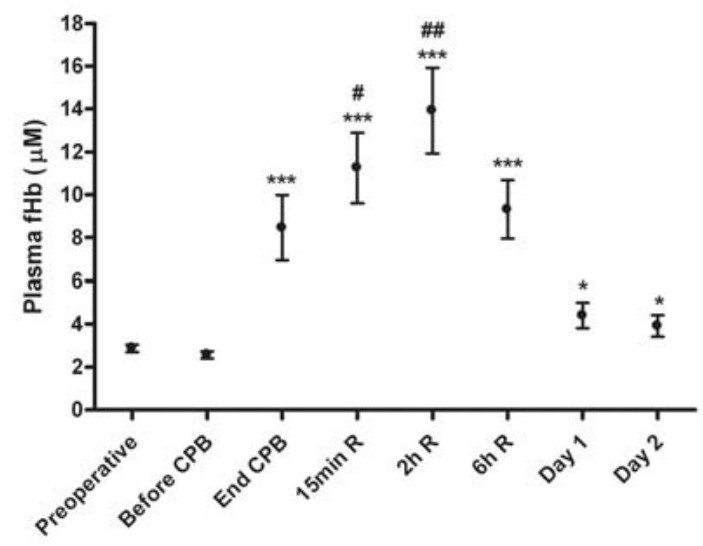

Figure 4.2. Hemolysis during open surgical repair of thoracoabdominal aortic aneurysms with cardiopulmonary bypass. Plasma free hemoglobin levels increased during surgery and continued to increase significantly in the early postoperative period. This indicates ongoing lysis of red blood cells after cardiopulmonary bypass has stopped.

* / *** $\mathrm{P}<0.05$ / 0.001 compared to preoperative levels. ${ }^{\# / \# \# ~} \mathrm{P}<0.05 / 0.01$ compared to end-CPB-levels.

$\mathrm{CPB}$, cardiopulmonary bypass; $\mathrm{FHb}$, free hemoglobin; $R$, reperfusion

\section{Cell saver}

Cell salvage devices are additional sources of $\mathrm{FHb}^{52,53}$ Washing and transfusion of damaged autologous shed blood could contribute to increased plasma FHb levels. 
Although modern cell saver systems are able to remove the major part of $\mathrm{FHb}$ during washing, they do not select between intact and damaged RBCs which are prone to lysis in vivo. ${ }^{54}$ This way, autologous blood transfusion could contribute to increased plasma FHb levels during surgery.

\section{Red blood cell transfusion}

A last potential source of $\mathrm{FHb}$ are stored RBC-concentrates. Storage of erythrocytes results in irreversible morphological changes like reduced membrane deformability and oxygen binding and delivery capacity, in addition to increased adhesiveness, aggregability, and accumulation of pro-inflammatory substances. ${ }^{55}$ These changes are considered to underlie the relation between RBC transfusion and adverse outcome, a phenomenon causing debate about the pros and cons of allogenic RBC administration. Additionally, storage duration of blood products appears to be a critical factor of transfusion-related morbidity and mortality. Transfusion of "old" blood (stored $>14$ days) was associated with a significantly higher mortality rate in patients undergoing cardiac surgery, compared to patients receiving RBCs stored for 14 days or less. Transfusion of "older" blood was also significantly related to prolonged ventilatory support, increased incidence of renal failure, septicemia or sepsis, and multiple organ failure. ${ }^{55}$ In line, RBC transfusion was the most reliable predictor of adverse outcome in 11.963 patients undergoing isolated CABG, with postoperative morbidity and mortality being dose-dependently related to RBC transfusion. ${ }^{56}$ We propose that high FHb concentrations due to RBC lysis in stored blood contribute to post-transfusion morbidity and mortality by inducing microcirculatory dysfunction through NO-scavenging. In addition, the shear stress imposed on less viable RBCs within the transfusate, might cause an additional increase of $\mathrm{FHb}$ during and after infusion. To study the degree of direct hemolysis of packed RBCs, we measured $\mathrm{FHb}$ levels by derivate spectrophotometry ${ }^{57}$ in samples from sixty randomly collected and transfused packed RBC units $(330 \mathrm{~mL} / \mathrm{U})$. $\mathrm{FHb}$ in the packed RBC supernatant levels averaged $36 \pm 2 \mu \mathrm{M}$ (mean \pm SEM), indicating severe hemolysis. Moreover, storage time and FHb levels were significantly correlated (Figure 4.3).

This means that transfusion of especially aged packed RBCs can result in an additional increase in circulating $\mathrm{FHb}$ in patients undergoing cardiovascular surgery with CPB. Recently, it was reported that packed RBC transfusion indeed contributed to systemic $\mathrm{FHb}$ levels with $7.5 \mu \mathrm{M}$ increase per transfused unit. ${ }^{58}$ Importantly, the supernatant of the packed RBC, which contains the $\mathrm{FHb}$ molecules was indeed able to consume NO, with a strong correlation between $\mathrm{FHb}$ levels and NOconsumption. ${ }^{58}$ The contributing effect of RBC transfusion to circulating plasma $\mathrm{FHb}$ concentrations may thus be considerable. The median transfusion requirement in a large cohort of cardiac surgery patients was found to be 2 packed RBC units, ${ }^{55}$ and 10 units for patients undergoing open repair for thoracoabdominal aortic aneu- 


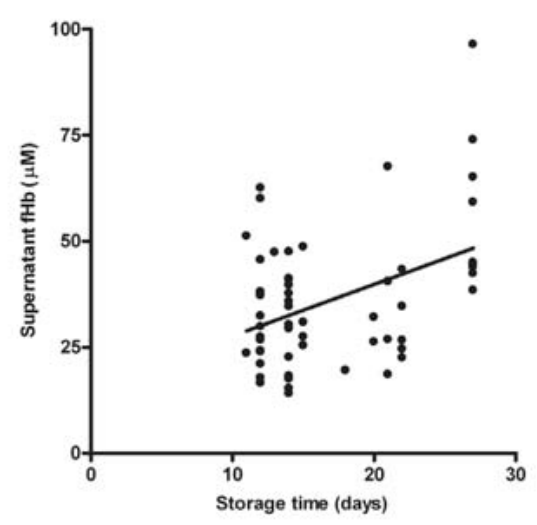

Figure 4.3. Association between storage time and free hemoglobin levels in packed red blood cell transfusion bags. A significant correlation (Pearson $r=0.43, P<0.001$ ) was found between packed red blood cell storage time and free hemoglobin concentration in packed red blood cell transfusion bags ( $N=60$ ) used for transfusion during cardiovascular surgery. These data indicate that prolonged storage time results in more red blood cell injury with concomitant more free hemoglobin being transfused into the patient. FHb, free hemoglobin

rysms, respectively. ${ }^{28}$ Transfusion of 2 or 10 packed cells could increase plasma FHblevels with $15 \mu \mathrm{M}$ and $75 \mu \mathrm{M}$, respectively. These levels are in sharp contrast to the plasma $\mathrm{FHb}$ levels of $0.1-0.2 \mu \mathrm{M}$ in normal healthy volunteers. ${ }^{24,58}$ Next to direct $\mathrm{FHb}$ administration via packed RBC transfusion, systemic $\mathrm{FHb}$ concentrations could additionally increase due to delayed lysis of sub-lethally damaged RBCs.

Lastly, another consequence of RBC storage is that so-called S-nitrosylated hemoglobin (SNO-Hb; NO bound to intracellular hemoglobin) is rapidly depleted. RBCs containing SNO-Hb are believed to contribute to vasodilation under hypoxic conditions through release of NO. Indeed, the capacity of RBCs to induce vasodilation significantly diminished parallel to SNO-Hb depletion. Reconstitution of SNO-Hb by exposure to aqueous NO restored the vasodilatory capacity of transfused RBCs and improved cardiac blood flow in dogs. ${ }^{59}$

\section{Therapeutic options to attenuate the adverse effects of FHb-mediated NO- scavenging}

The discovery of the NO-scavenging capacity of circulating FHb opened a new field of study on therapeutic options in diseases characterized by chronic hemolysis, such as sickle cell disease and malaria. ${ }^{60}$ In this paragraph, we present therapies that we consider to be of value for patients suffering from acute hemolytic episodes as occur during cardiovascular surgery (Table 4.1).

The direct (intravascular) therapeutic use of NO itself is greatly impeded by its extremely short half life of $0.05-1.8 \mathrm{msec}$. in vivo. ${ }^{61}$ Therefore, either inactivation of $\mathrm{FHb}$, or enhancement of the $\mathrm{NO}$ (-donor) pool, have potential in reducing the incidence and severity of complications of hemolytic diseases. We mainly focus on three potential therapeutic interventions (Figure 4.4); NO-inhalation, nitrite supplementation, and haptoglobin administration as we consider these therapeutic 
options to be most clinically relevant at this point in time. In addition, we will discuss three more experimental therapies: arginine and citrulline supplementation, CO-inhalation, and endothelin receptor blockade. For a more complete discussion of therapeutic options in chronic hemolytic disease we would like to refer to Kato et al. $^{60}$ and Lundberg et al. ${ }^{62}$

\section{NO-inhalation}

Intravascular conversion of plasma $\mathrm{FHb}$ into a less bioactive molecule is an interesting option to reduce the adverse consequences of increased $\mathrm{FHb}$ concentrations. $\mathrm{NO}$ gas inhalation results in pulmonary oxidation of $\mathrm{FHb}$ into methemoglobin, which does not scavenge NO, reducing NO consumption in plasma. In a canine hemolysis model, NO-inhalation attenuated the pulmonary and systemic vasoconstrictor effects of $\mathrm{FHb}^{25}$ In patients with sickle cell disease, NO-inhalation of 80ppm for 1.5 hours reduced pain during vaso-occlusive crisis, diminished plasma NO-consumption and increased methemoglobin levels, indicating oxidation of $\mathrm{FHb}^{24}$ Moreover, inhalation of $80 \mathrm{ppm}$ NO for 4 hours in children with sickle cell disease was not associated with any toxic side-effects such as hypotension, clinically significant decreases in $\mathrm{SpO}_{2}$, significant increases in methemoglobin, or toxic concentrations of $\mathrm{NO}_{2}{ }^{63}$ Even continuous NO-inhalation at $40 \mathrm{ppm}$ for 3.2 days in a patient with sickle cell disease with multi-organ involvement was not associated with adverse side-effects and markedly improved her clinical state. ${ }^{64}$ Lastly, mixing of up to 20 ppm NO gas with normal ventilation gas showed therapeutic potential in adult patients with cardiac surgery associated pulmonary hypertension by reducing right ventricular afterload and prevention of right ventricular failure. ${ }^{65,66}$ Next to FHb oxidation, NOgas inhalation also results in the formation of relatively stable NO-species in the lung. Longer intravascular half-times of these NO-carriers, such as nitrite, enable transport of NO in the blood, mediating extra pulmonary effects of NO-gas inhalation. $^{67,68}$ In conclusion, we consider NO-inhalation a promising and potentially easy applicable, therapeutic option to attenuate the adverse effects of FHb-mediated NO-scavenging during cardiovascular surgery. Ideally, the dose of NO-inhalation could even be adjusted based on intraoperative $\mathrm{FHb}$ measurements, which are already routinely performed at our institution. 
Table 4.1. Potential therapeutic options to reduce hemolysis-associated morbidity in patients undergoing cardiovascular surgery

\begin{tabular}{|c|c|c|c|}
\hline Therapy & Main therapeutic mechanisms & Feasibility & References \\
\hline NO-inhalation & $\begin{array}{l}\text { - Oxidates and inactivates } \mathrm{FHb} \text { in } \\
\text { the pulmonary circulation reduc- } \\
\text { ing NO-scavenging. } \\
\text { - Stimulates intrapulmonary } \\
\text { formation of NO-donors; en- } \\
\text { hancing NO bio-availability. }\end{array}$ & $\begin{array}{l}\text { - NO-inhalation al- } \\
\text { ready applied in } \\
\text { sickle cell patients } \\
\text { and patients who } \\
\text { underwent cardiac } \\
\text { surgery. } \\
\text { - Exact dose and } \\
\text { duration of inhala- } \\
\text { tion needs to be } \\
\text { studied. }\end{array}$ & $\begin{array}{l}\text { Reiter et al. }{ }^{24}, \\
\text { Minneci et al. }{ }^{25} \text {, } \\
\text { Kato et al. }{ }^{60}, \\
\text { Cannon et al. }{ }^{67}\end{array}$ \\
\hline $\begin{array}{l}\text { Nitrite } \\
\text { supplementation } \\
\text { (oral, intravenously, } \\
\text { by inhalation) }\end{array}$ & $\begin{array}{l}\text { - NO-donor during reduction, } \\
\text { especially during hypoxia and } \\
\text { low pH. } \\
\text { - Mediates cytoprotection } \\
\text { through hypoxic vasodilation } \\
\text { and decreased formation of re- } \\
\text { active oxygen species. } \\
\text { - Oxides FHb, hereby reducing } \\
\text { NO-scavenging. }\end{array}$ & $\begin{array}{l}\text { - Nitrite successfully } \\
\text { used in experimental } \\
\text { setting with sickle } \\
\text { cell patients. } \\
\text { - Exact dose, duration, } \\
\text { and way of admini- } \\
\text { stration needs to be } \\
\text { assessed. }\end{array}$ & $\begin{array}{l}\text { Lundberg et al. }{ }^{62} \text {, } \\
\text { Shiva et al. }{ }^{69}, \\
\text { Piknova et al. }{ }^{71}, \\
\text { Minnecci et al. }{ }^{76}\end{array}$ \\
\hline $\begin{array}{l}\text { Haptoglobin } \\
\text { administration }\end{array}$ & $\begin{array}{l}\text { - Natural FHb scavenger. } \\
\text { - Accelerates FHb uptake by } \\
\text { monocytes/macrophages and } \\
\text { hepatic degradation. } \\
\text { - Limits renal filtration of FHb. }\end{array}$ & $\begin{array}{l}\text { - Costs currently limit } \\
\text { clinical applicability. } \\
\text { - Moreover, haptoglo- } \\
\text { bin potentially does } \\
\text { not limit NO- } \\
\text { scavenging by FHb. }\end{array}$ & $\begin{array}{l}\text { Tanaka et al. }{ }^{30}, \\
\text { Lim et al. }{ }^{81}, \\
\text { Azarov et al. }{ }^{82}, \\
\text { Boretti et al. }{ }^{83}\end{array}$ \\
\hline $\begin{array}{l}\text { Arginine and } \\
\text { citrulline } \\
\text { supplementation }\end{array}$ & $\begin{array}{l}\text { Enhances substrate delivery for } \\
\text { NO-formation through the nitric } \\
\text { oxide synthases. }\end{array}$ & $\begin{array}{l}\text { - Arginine used ex- } \\
\text { perimentally in } 10 \\
\text { patients with sickle } \\
\text { cell disease. } \\
\text { - Dose and duration of } \\
\text { arginine and citrul- } \\
\text { line administration } \\
\text { unknown. }\end{array}$ & $\begin{array}{l}\text { Morris et al. }{ }^{86}, \\
\text { Luiking et al. }^{88}\end{array}$ \\
\hline $\begin{array}{l}\text { Carbon monoxide } \\
\text { inhalation }\end{array}$ & $\begin{array}{l}\text { - Regulates vascular tone and } \\
\text { induces vasodilation at low } \\
\text { doses. } \\
\text { - Reduces the pro-inflammatory } \\
\text { response. } \\
\text { - Relatively inert and does not } \\
\text { form reactive oxygen species. }\end{array}$ & $\begin{array}{l}\text { - No human data on } \\
\text { applicability in the } \\
\text { setting of cardiovas- } \\
\text { cular surgery. }\end{array}$ & Belcher et al. $^{33}$ \\
\hline $\begin{array}{l}\text { Endothelin receptor } \\
\text { blockade }\end{array}$ & $\begin{array}{l}\text { - Limits endothelin-1 induced } \\
\text { vasoconstriction. }\end{array}$ & $\begin{array}{l}\text { - Only tested in a } \\
\text { mouse sickle cell } \\
\text { model. }\end{array}$ & Sabaa et al. ${ }^{90}$ \\
\hline
\end{tabular}




\section{Nitrite supplementation}

Another promising candidate for therapeutic use is the anion nitrite $\left(\mathrm{NO}_{2}{ }^{-}\right)$, long believed to be merely an inert oxidation product of NO. Recent studies, however, provided evidence for the existence of multiple nitrite reducing pathways in which nitrite is converted back to NO, making nitrite an important NO-donor. ${ }^{62,69,70}$ Furthermore, nitrite is able to oxidize $\mathrm{FHb}$ in plasma, potentially limiting its capacity to scavenge NO. ${ }^{71}$ The enzymatic and non-enzymatic pathways of nitrite reduction include (free) deoxyhemoglobin and deoxymyoglobin, xanthine oxidoreductase, protons, ascorbate, and polyphenols. ${ }^{62}$ The process of NO-reduction is most efficient at low oxygen tension and low $\mathrm{pH}$ and thus occurs, preferably, during hypoxia and/or anoxia. ${ }^{70,72,73}$ This is of particular importance since NOS-activity is greatly limited at low-oxygen tensions. ${ }^{74}$ In adult patients suffering from sickle cell anemia, infusion of $0.4,4$, and $40 \mu \mathrm{M}$ nitrite into the brachial artery led to a dose-dependent increase in fore-arm blood flow up to $77 \%{ }^{75}$ In a canine hemolysis model, sodium nitrite increased blood flow in a similar way. ${ }^{76}$ Next to promoting vasodilation, nitrite has been shown to exert potent cytoprotection in the liver, heart, and brain in several animal models of ischemia-reperfusion. ${ }^{77}$ The way by which nitrite mediates cytoprotection in this setting is as yet unresolved but believed to be dual. First, nitrite enables hypoxic vasodilation as stated above. Second, nitrite is able to nitrosate complex I of the mitochondrial electron transport chain, inhibiting its activity and decreasing the formation of reactive oxygen species in the reperfusion phase. ${ }^{69}$ Considering these properties of nitrite, it has been suggested to have therapeutic value in various diseases, such as sickle cell disease, stroke, myocardial infarction, and organ transplantation. Nevertheless, the optimal nitrite dose for human systemic administration has not yet been clarified. Interestingly, the effect of nitrite may be greater at low plasma concentrations ( $<200 \mathrm{nM})$ and is lost at high plasma levels exceeding $1000 \mu \mathrm{M} .^{78,79}$ Furthermore, it was reported that the reaction between oxy $\mathrm{FHb}$ (in contrast to deoxy $\mathrm{FHb}$ ) and nitrite could initiate an autocatalytic free radical chain leading to unwanted oxidative damage. ${ }^{80}$ Piknova et al. addressed this issue and concluded that free radical formation in plasma during the reaction of pharmacological doses of nitrite (up to $120 \mu \mathrm{M}$ ) with clinically relevant levels of $\mathrm{FHb}(30 \mu \mathrm{M})$, would be highly unlikely. ${ }^{71}$ In conclusion, we consider nitrite to have potential in patients undergoing cardiovascular surgery to prevent and treat hemolysis-associated morbidity. Nevertheless, the optimal dose and application must be further studied. 


\section{Haptoglobin administration}

Administration of haptoglobin, being the physiological FHb scavenger, appears to be a logical choice in reducing $\mathrm{FHb}$ concentrations. Haptoglobin targets $\mathrm{FHb}$ for degradation in the liver, monocytes and macrophages. Furthermore, haptoglobin prevents glomerular filtration of $\mathrm{FHb}$, reducing $\mathrm{FHb}$-induced kidney damage. Increased $\mathrm{FHb}$ levels during cardiac surgery have been associated with total depletion of haptoglobin, ${ }^{30}$ enhancing the NO-scavenging capacity of plasma. Indeed, haptoglobin knock-out mice were more sensitive to the adverse effects of phenylhydrazineinduced hemolysis. ${ }^{81}$ Renal DNA damage was significantly higher and glomerular filtration function (reflected by poorer renal clearance of ${ }^{3} \mathrm{H}$-inulin) was significantly lower in haptoglobin knock-out mice compared to haptoglobin +/+ mice. Interestingly, administration of vasodilators restored glomerular filtration, implicating renal vasoconstriction to be the major contributor to hemolysis-induced acute kidney injury. This supports NO-scavenging by plasma $\mathrm{FHb}$. In addition, haptoglobin administration in patients undergoing cardiac surgery with plasma FHb levels surpassing $2.3 \mu \mathrm{M}$, was associated with a reduction of renal tubular damage. ${ }^{30}$ Nevertheless, this positive effect of haptoglobin was attributed to a decrease in urine $\mathrm{FHb}$ levels and a subsequent attenuation of oxidative renal damage.

Haptoglobin administration is an interesting therapeutic option, but its clinical application might be limited. First, it has been recently found that, in vitro, the hemoglobin - haptoglobin complex still potently scavenges NO at the same rate as $\mathrm{FHb}$. Although binding of $\mathrm{FHb}$ to haptoglobin increases the rate of uptake by monocytes and macrophages by 2 -fold (hereby disabling NO-scavenging), it is questionable whether this increased uptake would affect NO-bioavailability. ${ }^{82}$ Second, the costs involved in retrieving or producing the amounts of haptoglobin necessary for clinical application currently limits wide-spread implementation. Recently, Boretti et al. made use of the fact that the haptoglobin promoter gene contains glucocorticoid-responsive elements. Administration of $4 \mathrm{mg} / \mathrm{kg}$ prednisone twice daily for three days increased plasma haptoglobin levels 6-fold in dogs. ${ }^{83}$ Importantly, the glucocorticoid stimulation of haptoglobin synthesis prevented the $\mathrm{FHb}$-induced increase in mean arterial pressure in dogs after $\mathrm{FHb}$ infusion, most probably due to scavenging of $\mathrm{FHb}$ by haptoglobin. ${ }^{83}$ This sheds new light on the longstanding debate whether corticosteroid administration during cardiac and cardiovascular surgery is useful. ${ }^{84,85}$ In summary, haptoglobin could be useful to reduce kidney damage due to intratubular FHb toxicity. The effect on NO-scavenging may, however, be limited. 


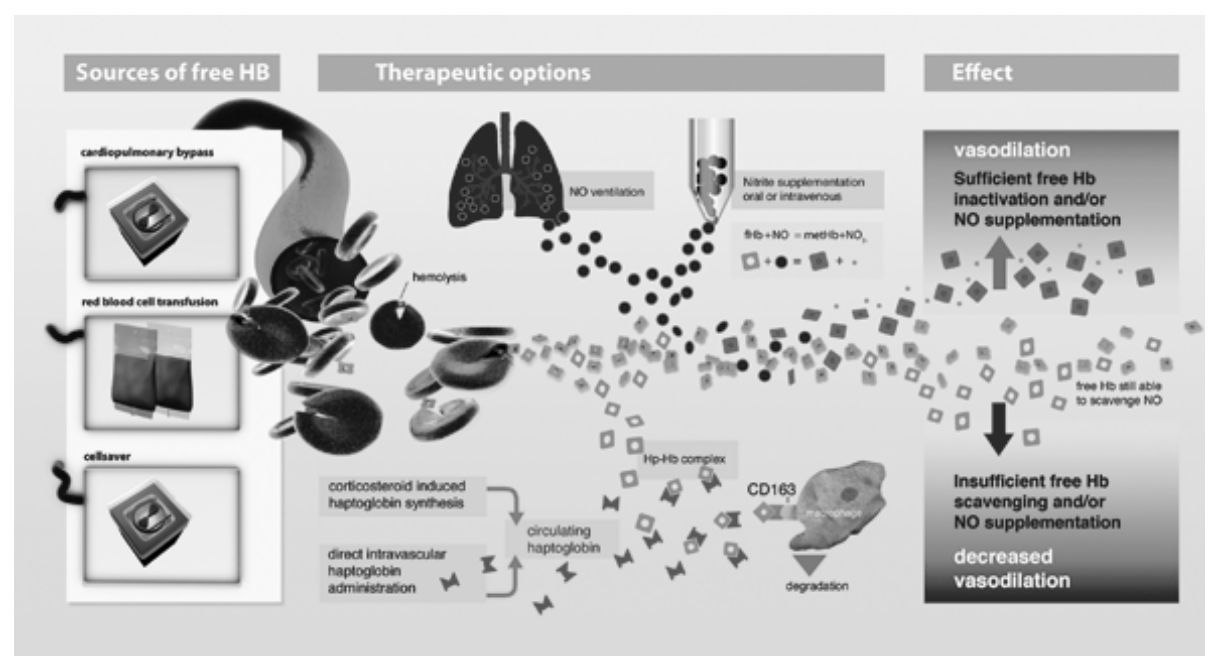

Figure 4.4. Potential sources and effects of plasma free hemoglobin during cardiovascular surgery with cardiopulmonary bypass, and therapeutic options to attenuate hemolysis-induced organ damage.

Intravascular hemolysis during cardiovascular surgery can be attributed to the cardiopulmonary bypass, transfusion of red blood cells, and cell-saver use (left). Lysis of red blood cells results in increased circulating plasma free hemoglobin (FHb) levels (orange squares). Under physiological circumstances, $\mathrm{FHb}$ is rapidly cleared by the $\mathrm{FHb}$ scavenger haptoglobin. Haptoglobin-hemoglobin complexes bind to CD-163 expressed by monocytes and macrophages, initiating endocytosis and degradation (middle, bottom). Haptoglobin is not recycled so excessive hemolysis depletes haptoglobin storages rapidly. Non-scavenged $\mathrm{FHb}$ potently binds circulating nitric oxide (NO), thereby limiting its bioavailability. This way, high $\mathrm{FHb}$ levels increase the NO-scavenging capacity of blood, causing impaired vasodilation due to vascular NOshortage. Decreased vasodilation contributes to impaired tissue perfusion and development of organ damage and organ dysfunction (right, bottom).

The adverse effects of $\mathrm{FHb}$ may be counteracted by either increasing haptoglobin levels to support $\mathrm{FHb}$ scavenging, or enhancing the NO(-donor) pool to increase NO-bioavailability. Haptoglobin can be administered intravenously or haptoglobin synthesis may be up-regulated through corticosteroid administration (center, bottom). The NO(-donor) pool could be increased by oral or intravenous nitrite administration which is oxidized to NO under low oxygen tension and/or low $\mathrm{pH}$. NO-inhalation inactivates $\mathrm{FHb}$ in the pulmonary circulation (or oxygenator in the cardiopulmonary bypass circuit) by transforming $\mathrm{FHb}$ to bioinactive methemoglobin (center, top). This way, scavenging and inactivation of $\mathrm{FHb}$, and supplementation of NO prevents the adverse effects of plasma FHb during cardiovascular surgery (right, top).

$\mathrm{Hp}-\mathrm{Hb}$-complex, haptoglobin-hemoglobin complex; FHb, free hemoglobin; NO, nitric oxide; metHb, methemoglobin. See page 168 for color figure.

\section{Other potential therapies}

We consider NO-inhalation and nitrite supplementation to be promising therapeutic interventions since they can be used successfully in the acute setting of cardiovascular surgery. Notwithstanding, several other therapeutic modalities may be of value in patients at risk for acute hemolytic episodes. 


\section{Arginine and citrulline supplementation}

L-arginine is the natural nitrogen donor for NO-synthesis and arginine supplementation enhances NO-formation. Arginine therapy at a dose of $0.1 \mathrm{~g} / \mathrm{kg}$ three times a day for 5 days in 10 adult patients with sickle cell anemia and pulmonary hypertension resulted in a significant decrease (15.2\%) of pulmonary arterial systolic pressures implicating vasodilation. ${ }^{86,87}$

Another interesting approach would be administration of citrulline, a substrate for de novo arginine synthesis. It has been suggested that in case of high arginase-1 levels, as occur during hemolysis, citrulline supplementation might restore the intracellular arginine balance and promote nitric oxide production. ${ }^{88}$

However, it remains unknown whether, and to what extent, arginine or citrulline supplementation is beneficial in patients with acute hemolysis during cardiovascular surgery.

\section{Carbon monoxide inhalation}

Carbon monoxide ( $\mathrm{CO}$ ) is produced during breakdown of the heme-ring of $\mathrm{FHb}$ which is mediated by HO-1. Inhaled CO, at low doses up to $250 \mathrm{ppm}$, has been shown to reduce vaso-occlusion in a mouse sickle cell model. CO even mimics some of the functions of NO like inhibition of platelet aggregation and activation, regulation of vascular tone, and reduction of a pro-inflammatory response. ${ }^{33} \mathrm{CO}$ is relatively inert in contrast to NO, which is able to react with intravascular reactive oxygen species forming the highly reactive peroxynitrite (ONOO'). ${ }^{89}$ Therefore, CO has been proposed to be even more effective in hemolytic disease than NO, but this has not been substantiated by human studies.

\section{Endothelin receptor blockade}

Endothelin-1 is a very potent vasoconstrictor and its secretion which is repressed by NO. A diminished NO-bioavailability due to hemolysis counterbalances this negative feed-back, resulting in enhanced endothelin-1 levels and vasoconstriction. A mouse sickle cell model provided evidence for beneficial effects of endothelin receptor blockade on renal blood flow, inflammation, and vascular congestion in the lungs and kidneys. ${ }^{90}$ Reduction of inflammation would be an additional positive effect in patients subjected to cardiopulmonary bypass, which induces a pro-inflammatory response. Nevertheless, further research is essential to find out whether short term endothelin receptor blockage is beneficial in this setting, since it is very different compared to sickle cell anemia.

In conclusion, there are several promising therapeutic interventions to attenuate the adverse effects of increased plasma $\mathrm{FHb}$ levels in patients suffering from acute hemolytic disease, including patients undergoing surgery with cardiopulmon- 
ary bypass, trauma patients, and patients necessitating long-term extracorporeal support for instance extracorporeal membranous oxygenation (ECMO) or hemodialysis. $^{91,92}$

\section{Hemolysis-induced organ injury in cardiovascular surgery; summary and future perspectives}

As evaluated in this review, hemolysis during cardiopulmonary bypass harbors a latent adverse effect. The NO-scavenging effect of plasma FHb contributes to deleterious effects of CPB, such as hypoperfusion and ischemia/reperfusion, thereby further hampering tissue perfusion and resulting in organ injury and dysfunction. These findings shed new light on the pathophysiology and preventive measures of organ injury during on-pump cardiovascular surgery (Figure 4.4).

\section{Conclusion}

Evidence is mounting that enhanced circulating levels of plasma FHb are detrimental, not only in chronic hemolytic diseases, but also in the acute setting of cardiovascular surgery. FHb-induced perturbations in microcirculatory blood flow and subsequent hypoperfusion or even ischemic damage, complemented by urine $\mathrm{FHb}$ induced oxidative stress to renal tissue cells, should be acknowledged as an important risk factor for organ injury development in patients undergoing cardiovascular surgery. Patients undergoing such procedures are at increased risk for developing post-operative organ injury with worse patient outcome. Circulating FHb appears to be an important determinant in organ injury development which offers a new therapeutic opportunity to reduce post-operative morbidity and mortality in patients. Interventional studies using NO-inhalation, nitrite administration or haptoglobin suppletion should be performed to establish the causal role between plasma FHb, NO-bioavailability, and organ injury in this particular setting. ${ }^{25,30,93,94}$ Furthermore, such interventional studies will provide valuable information for improvement of patient outcome. Lastly, the role of $\mathrm{FHb}$ in organ injury development is not only of importance for patients undergoing cardiovascular surgery but also for other patient groups at risk for hemolysis such as trauma patients, hemodialysis patients, and patients requiring long-term extracorporeal oxygenation or extracorporeal life-support. 


\section{References}

1. Andersson LG, Ekroth R, Bratteby LE, et al. Acute renal failure after coronary surgery--a study of incidence and risk factors in 2009 consecutive patients. Thorac Cardiovasc Surg 1993; 41:237-41.

2. Conlon PJ, Stafford-Smith M, White WD, et al. Acute renal failure following cardiac surgery. Nephrol Dial Transplant 1999; 14:1158-62.

3. Grayson $A D$, Khater $M$, Jackson $M$, Fox MA. Valvular heart operation is an independent risk factor for acute renal failure. Ann Thorac Surg 2003; 75:1829-35.

4. Provenchere S, Plantefeve G, Hufnagel G, et al. Renal dysfunction after cardiac surgery with normothermic cardiopulmonary bypass: incidence, risk factors, and effect on clinical outcome. Anesth Analg 2003; 96:1258-64.

5. Achouh PE, Madsen K, Miller CC, 3rd, et al. Gastrointestinal complications after descending thoracic and thoracoabdominal aortic repairs: a 14-year experience. J Vasc Surg 2006; 44:442-6.

6. Jacobs MJ, de Mol BA, Legemate DA, et al. Retrograde aortic and selective organ perfusion during thoracoabdominal aortic aneurysm repair. Eur J Vasc Endovasc Surg 1997; 14:360-6.

7. Coselli JS, LeMaire SA, Conklin LD, et al. Morbidity and mortality after extent II thoracoabdominal aortic aneurysm repair. Ann Thorac Surg 2002; 73:1107-15.

8. Rectenwald JE, Huber TS, Martin TD, et al. Functional outcome after thoracoabdominal aortic aneurysm repair. J Vasc Surg 2002; 35:640-7.

9. Kieffer E, Chiche L, Godet G, et al. Type IV thoracoabdominal aneurysm repair: predictors of postoperative mortality, spinal cord injury, and acute intestinal ischemia. Ann Vasc Surg 2008; 22:822-8.

10. Vermeer $H$, Teerenstra $S$, de Sevaux RG, et al. The effect of hemodilution during normothermic cardiac surgery on renal physiology and function: a review. Perfusion 2008; 23:329-38.

11. Fink MP. Thoracoabdominal aortic aneurysm repair: a human model of ischemia/reperfusioninduced cytokine-driven multiple organ dysfunction syndrome. Crit Care Med 2000; 28:3356-7.

12. Leijdekkers VJ, Wirds JW, Vahl AC, et al. The visceral perfusion system and distal bypass during thoracoabdominal aneurysm surgery: an alternative for physiological blood flow? Cardiovasc Surg 1999; 7:219-24.

13. Kuttila K, Niinikoski J, Haglund U. Visceral and peripheral tissue perfusion after cardiac surgery. Scand J Thorac Cardiovasc Surg 1991; 25:57-62.

14. Brooker RF, Brown WR, Moody DM, et al. Cardiotomy suction: a major source of brain lipid emboli during cardiopulmonary bypass. Ann Thorac Surg 1998; 65:1651-5.

15. Bronden B, Dencker M, Allers $M$, et al. Differential distribution of lipid microemboli after cardiac surgery. Ann Thorac Surg 2006; 81:643-8.

16. Hanssen SJ, Derikx JP, Vermeulen Windsant IC, et al. Visceral injury and systemic inflammation in patients undergoing extracorporeal circulation during aortic surgery. Ann Surg 2008; 248:117-25.

17. Rosner $\mathrm{MH}$, Okusa MD. Acute kidney injury associated with cardiac surgery. Clin J Am Soc Nephrol 2006; 1:19-32.

18. Huybregts RA, Morariu AM, Rakhorst G, et al. Attenuated renal and intestinal injury after use of a mini-cardiopulmonary bypass system. Ann Thorac Surg 2007; 83:1760-6.

19. Yamada T, Ochiai R, Takeda J, et al. Off-pump coronary artery bypass attenuates transient hepatocellular damage after myocardial revascularization. J Cardiothorac Vasc Anesth 2005; 19:603-7.

20. Nigwekar SU, Kandula P, Hix JK, Thakar CV. Off-pump coronary artery bypass surgery and acute kidney injury: a meta-analysis of randomized and observational studies. Am J Kidney Dis 2009; 54:413-23.

21. Kelly KJ, Molitoris BA. Acute renal failure in the new millennium: time to consider combination therapy. Semin Nephrol 2000; 20:4-19.

22. Fransen EJ, Ganushchak YM, Vijay V, et al. Evaluation of a new condensed extra-corporeal circuit for cardiac surgery: a prospective randomized clinical pilot study. Perfusion 2005; 20:91-9.

23. Vercaemst L. Hemolysis in cardiac surgery patients undergoing cardiopulmonary bypass: a review in search of a treatment algorithm. J Extra Corpor Technol 2008; 40:257-67. 
24. Reiter CD, Wang $X$, Tanus-Santos JE, et al. Cell-free hemoglobin limits nitric oxide bioavailability in sickle-cell disease. Nat Med 2002; 8:1383-9.

25. Minneci PC, Deans KJ, Zhi H, et al. Hemolysis-associated endothelial dysfunction mediated by accelerated NO inactivation by decompartmentalized oxyhemoglobin. J Clin Invest 2005; 115:3409-17.

26. Meyer $C$, Heiss $C$, Drexhage $C$, et al. Hemodialysis-induced release of hemoglobin limits nitric oxide bioavailability and impairs vascular function. J Am Coll Cardiol; 55:454-9.

27. Donadee CL, Gladwin MT. Hemodialysis hyperhemolysis. A novel mechanism of endothelial dysfunction and cardiovascular risk? J Am Coll Cardiol; 55:460-2.

28. Vermeulen Windsant IC, Snoeijs MG, Hanssen SJ, et al. Hemolysis is associated with acute kidney injury during major aortic surgery. Kidney Int 2010; 77:913-20.

29. Rother RP, Bell L, Hillmen P, Gladwin MT. The clinical sequelae of intravascular hemolysis and extracellular plasma hemoglobin: a novel mechanism of human disease. Jama 2005; 293:1653-62.

30. Tanaka K, Kanamori Y, Sato T, et al. Administration of haptoglobin during cardiopulmonary bypass surgery. ASAIO Trans 1991; 37:M482-3.

31. Maines MD. The heme oxygenase system: a regulator of second messenger gases. Annu Rev Pharmacol Toxicol 1997; 37:517-54.

32. Philippidis $P$, Mason JC, Evans BJ, et al. Hemoglobin scavenger receptor CD163 mediates interleukin10 release and heme oxygenase- 1 synthesis: antiinflammatory monocyte-macrophage responses in vitro, in resolving skin blisters in vivo, and after cardiopulmonary bypass surgery. Circ Res 2004; 94:119-26.

33. Belcher JD, Mahaseth $\mathrm{H}$, Welch TE, et al. Heme oxygenase-1 is a modulator of inflammation and vaso-occlusion in transgenic sickle mice. J Clin Invest 2006; 116:808-16.

34. Kristiansen $\mathrm{M}$, Graversen $\mathrm{JH}$, Jacobsen $\mathrm{C}$, et al. Identification of the haemoglobin scavenger receptor. Nature 2001; 409:198-201.

35. Liao JC, Hein TW, Vaughn MW, et al. Intravascular flow decreases erythrocyte consumption of nitric oxide. Proc Natl Acad Sci U S A 1999; 96:8757-61.

36. Vaughn MW, Huang KT, Kuo L, Liao JC. Erythrocytes possess an intrinsic barrier to nitric oxide consumption. J Biol Chem 2000; 275:2342-8.

37. Morris CR, Kato GJ, Poljakovic M, et al. Dysregulated arginine metabolism, hemolysis-associated pulmonary hypertension, and mortality in sickle cell disease. Jama 2005; 294:81-90.

38. van de Poll MC, Hanssen SJ, Berbee $M$, et al. Elevated plasma arginase-1 does not affect plasma arginine in patients undergoing liver resection. Clin Sci (Lond) 2008; 114:231-41.

39. Burck HC, Diekman MA, Sedlaczek T. Acute renal failure after the infusion of hemoglobin solutions with or without red cell ghosts in rabbits. Res Exp Med 1975; 166:79-84.

40. Zager RA, Gamelin LM. Pathogenetic mechanisms in experimental hemoglobinuric acute renal failure. Am J Physiol 1989; 256:F446-55.

41. Paller MS. Hemoglobin- and myoglobin-induced acute renal failure in rats: role of iron in nephrotoxicity. Am J Physiol 1988; 255:F539-44.

42. Davis $\mathrm{CL}$, Kausz AT, Zager RA, et al. Acute renal failure after cardiopulmonary bypass in related to decreased serum ferritin levels. J Am Soc Nephrol 1999; 10:2396-402.

43. Everse J, Hsia N. The toxicities of native and modified hemoglobins. Free Radic Biol Med 1997; 22:1075-99.

44. Natanson C, Kern SJ, Lurie P, et al. Cell-free hemoglobin-based blood substitutes and risk of myocardial infarction and death: a meta-analysis. Jama 2008; 299:2304-12.

45. Hanssen SJ, Lubbers $\mathrm{T}$, Hodin CM, et al. Hemolysis results in impaired intestinal microcirculation and intestinal epithelial cell injury. World J Gastroenterol 2011; 14:213-8.

46. Fabre O, Vincentelli A, Corseaux D, et al. Comparison of blood activation in the wound, active vent, and cardiopulmonary bypass circuit. Ann Thorac Surg 2008; 86:537-41.

47. Mulholland JW, Massey W, Shelton JC. Investigation and quantification of the blood trauma caused by the combined dynamic forces experienced during cardiopulmonary bypass. Perfusion 2000; 15:485-94. 
48. Cheung AT, Cruz-Shiavone GE, Meng QC, et al. Cardiopulmonary bypass, hemolysis, and nitroprusside-induced cyanide production. Anesth Analg 2007; 105:29-33.

49. Kameneva MV, Undar A, Antaki JF, et al. Decrease in red blood cell deformability caused by hypothermia, hemodilution, and mechanical stress: factors related to cardiopulmonary bypass. Asaio J 1999; 45:307-10.

50. Svenmarker S, Jansson E, Stenlund H, Engstrom KG. Red blood cell trauma during cardiopulmonary bypass: narrow pore filterability versus free haemoglobin. Perfusion 2000; 15:33-40.

51. Serrick CJ, Scholz M, Melo A, et al. Quality of red blood cells using autotransfusion devices: a comparative analysis. J Extra Corpor Technol 2003; 35:28-34.

52. Nishiyama T, Hanaoka K. Free hemoglobin concentrations in patients receiving massive blood transfusion during emergency surgery for trauma. Can J Anaesth 2000; 47:881-5.

53. Yazer $\mathrm{MH}$, Waters JH, Elkin KR, et al. A comparison of hemolysis and red cell mechanical fragility in blood collected with different cell salvage suction devices. Transfusion 2008; 48:1188-91.

54. Sakota D, Sakamoto R, Sobajima H, et al. Mechanical damage of red blood cells by rotary blood pumps: selective destruction of aged red blood cells and subhemolytic trauma. Artif Organs 2008; 32:785-91.

55. Koch CG, Li L, Sessler DI, et al. Duration of red-cell storage and complications after cardiac surgery. N Engl J Med 2008; 358:1229-39.

56. Koch CG, Li L, Duncan Al, et al. Morbidity and mortality risk associated with red blood cell and bloodcomponent transfusion in isolated coronary artery bypass grafting. Crit Care Med 2006; 34:1608-16.

57. Cruz-Landeira A, Bal MJ, Quintela O, Lopez-Rivadulla M. Determination of methemoglobin and total hemoglobin in toxicological studies by derivative spectrophotometry. J Anal Toxicol 2002; 26:67-72.

58. Gladwin MT, Kim-Shapiro DB. Storage lesion in banked blood due to hemolysis-dependent disruption of nitric oxide homeostasis. Curr Opin Hematol 2009; 16:515-23.

59. Reynolds JD, Ahearn GS, Angelo M, et al. S-nitrosohemoglobin deficiency: a mechanism for loss of physiological activity in banked blood. Proc Natl Acad Sci U S A 2007; 104:17058-62.

60. Kato GJ, Gladwin MT. Evolution of novel small-molecule therapeutics targeting sickle cell vasculopathy. Jama 2008; 300:2638-46.

61. Kelm M, Preik-Steinhoff H, Preik M, Strauer BE. Serum nitrite sensitively reflects endothelial NO formation in human forearm vasculature: evidence for biochemical assessment of the endothelial $\mathrm{L}$ arginine-NO pathway. Cardiovasc Res 1999; 41:765-72.

62. Lundberg JO, Weitzberg E, Gladwin MT. The nitrate-nitrite-nitric oxide pathway in physiology and therapeutics. Nat Rev Drug Discov 2008; 7:156-67.

63. Weiner DL, Hibberd PL, Betit P, et al. Preliminary assessment of inhaled nitric oxide for acute vasoocclusive crisis in pediatric patients with sickle cell disease. Jama 2003; 289:1136-42.

64. Chang WL, Corate LM, Sinclair JM, van der Heyde HC. Continuous inhaled nitric oxide therapy in a case of sickle cell disease with multiorgan involvement. J Investig Med 2008; 56:1023-7.

65. Lunn RJ. Inhaled nitric oxide therapy. Mayo Clin Proc 1995; 70:247-55.

66. Winterhalter M, Antoniou T, Loukanov T. Management of adult patients with perioperative pulmonary hypertension: technical aspects and therapeutic options. Cardiology 2010; 116:3-9.

67. Cannon RO, 3rd, Schechter AN, Panza JA, et al. Effects of inhaled nitric oxide on regional blood flow are consistent with intravascular nitric oxide delivery. J Clin Invest 2001; 108:279-87.

68. Fox-Robichaud A, Payne D, Hasan S, et al. Inhaled NO as a viable antiadhesive therapy for ischemia/reperfusion injury of distal microvascular beds. J Clin Invest. 1998, 101:2497-505.

69. Shiva S, Gladwin MT. Nitrite mediates cytoprotection after ischemia/reperfusion by modulating mitochondrial function. Basic Res Cardiol 2009; 104:113-9.

70. Raat NJ, Noguchi AC, Liu VB, et al. Dietary nitrate and nitrite modulate blood and organ nitrite and the cellular ischemic stress response. Free Radic Biol Med 2009; 47:510-7.

71. Piknova B, Keszler A, Hogg N, Schechter AN. The reaction of cell-free oxyhemoglobin with nitrite under physiologically relevant conditions: Implications for nitrite-based therapies. Nitric Oxide 2009; 20:88-94. 
72. Shiva S, Sack MN, Greer JJ, et al. Nitrite augments tolerance to ischemia/reperfusion injury via the modulation of mitochondrial electron transfer. J Exp Med 2007; 204:2089-102.

73. Dezfulian C, Raat N, Shiva S, Gladwin MT. Role of the anion nitrite in ischemia-reperfusion cytoprotection and therapeutics. Cardiovasc Res 2007; 75:327-38.

74. Zweier JL, Wang P, Samouilov A, Kuppusamy P. Enzyme-independent formation of nitric oxide in biological tissues. Nat Med 1995; 1:804-9.

75. Mack AK, McGowan li VR, Tremonti CK, et al. Sodium nitrite promotes regional blood flow in patients with sickle cell disease: a phase I/II study. Br J Haematol 2008; 142:971-8.

76. Minneci PC, Deans KJ, Shiva S, et al. Nitrite reductase activity of hemoglobin as a systemic nitric oxide generator mechanism to detoxify plasma hemoglobin produced during hemolysis. Am J Physiol Heart Circ Physiol 2008; 295:H743-54.

77. Lu P, Liu F, Yao Z, et al. Nitrite-derived nitric oxide by xanthine oxidoreductase protects the liver against ischemia-reperfusion injury. Hepatobiliary Pancreat Dis Int 2005; 4:350-5.

78. Duranski MR, Greer JJ, Dejam A, et al. Cytoprotective effects of nitrite during in vivo ischemiareperfusion of the heart and liver. J Clin Invest 2005; 115:1232-40.

79. Dimmeler S, Zeiher AM. Nitric oxide and apoptosis: another paradigm for the double-edged role of nitric oxide. Nitric Oxide 1997; 1:275-81.

80. Goldman DW, Breyer RJ, 3rd, Yeh D, et al. Acellular hemoglobin-mediated oxidative stress toward endothelium: a role for ferryl iron. Am J Physiol 1998; 275:H1046-53.

81. Lim YK, Jenner A, Ali AB, et al. Haptoglobin reduces renal oxidative DNA and tissue damage during phenylhydrazine-induced hemolysis. Kidney Int 2000; 58:1033-44.

82. Azarov I, He X, Jeffers A, et al. Rate of nitric oxide scavenging by hemoglobin bound to haptoglobin. Nitric Oxide 2008; 18:296-302.

83. Boretti FS, Buehler PW, D'Agnillo F, et al. Sequestration of extracellular hemoglobin within a haptoglobin complex decreases its hypertensive and oxidative effects in dogs and guinea pigs. J Clin Invest 2009; 119:2271-80.

84. Morariu AM, Loef BG, Aarts LP, et al. Dexamethasone: benefit and prejudice for patients undergoing on-pump coronary artery bypass grafting: a study on myocardial, pulmonary, renal, intestinal, and hepatic injury. Chest 2005; 128:2677-87.

85. Chaney MA. Corticosteroids and cardiopulmonary bypass : a review of clinical investigations. Chest 2002; 121:921-31.

86. Morris CR, Kuypers FA, Larkin S, et al. Arginine therapy: a novel strategy to induce nitric oxide production in sickle cell disease. Br J Haematol 2000;111:498-500.

87. Morris CR, Morris SM, Jr., Hagar W, et al. Arginine therapy: a new treatment for pulmonary hypertension in sickle cell disease? Am J Respir Crit Care Med 2003; 168:63-9.

88. Luiking YC, Poeze M, Ramsay G, Deutz NE. Reduced citrulline production in sepsis is related to diminished de novo arginine and nitric oxide production. Am J Clin Nutr 2009; 89:142-52.

89. Wolin MS, Davidson CA, Kaminski PM, et al. Oxidant--nitric oxide signalling mechanisms in vascular tissue. Biochemistry (Mosc) 1998; 63:810-6.

90. Sabaa N, de Franceschi L, Bonnin P, et al. Endothelin receptor antagonism prevents hypoxia-induced mortality and morbidity in a mouse model of sickle-cell disease. J Clin Invest 2008; 118:1924-33.

91. Nijboer JM, van der Horst IC, Hendriks HG, et al. Myth or reality: hematocrit and hemoglobin differ in trauma. J Trauma 2007; 62:1310-2.

92. Polaschegg HD. Red blood cell damage from extracorporeal circulation in hemodialysis. Semin Dial 2009; 22:524-31.

93. Bryan NS, Calvert JW, Elrod JW, et al. Dietary nitrite supplementation protects against myocardial ischemia-reperfusion injury. Proc Natl Acad Sci USA 2007; 104:19144-9.

94. Garg HK, Bryan NS. Dietary sources of nitrite as a modulator of ischemia/reperfusion injury. Kidney Int 2009; 75:1140-4. 
Chapter 5 Hemolysis Compromises NO-Dependent Vasodilatory Responses in Patients Undergoing Major Cardiovascular Surgery

Sebastiaan J. Hanssen, Marcel C. van de Poll, Alfons J. Houben, Iris C. Vermeulen Windsant, Maarten G. Snoeijs, Otto Bekers, Wim A. Buurman, Michael J. Jacobs

This chapter has been submitted for publication. 


\section{Abstract}

Introduction The use of extracorporeal circulation (ECC), transfusion of allogeneic blood, and autologous cell-salvage during cardiovascular surgery may result in hemolysis. In this study we evaluated the relevance of hemolysis to NO-dependent blood flow in patients undergoing major cardiovascular surgery. The hemolytic products cell-free oxyhemoglobin ( $\mathrm{FHb}$ ) and arginase-1 reduce nitric oxide (NO) bioavailability by scavenging of $\mathrm{NO}$ and by degrading the NO precursor arginine to ornithine, respectively.

Methods In patients undergoing major cardiovascular surgery, we measured plasma $\mathrm{FHb}$, arginase-1 and amino acid concentrations perioperatively. Forearm blood flow (FBF) responses to the NO-donor sodium nitroprusside (SNP) and the endotheliumdependent vasodilator acetylcholine (ACh) were measured by venous occlusion plethysmography after surgery.

Results Plasma FHb and arginase- 1 , mainly released by the ECC, increased over time reaching peak values at 2 hours after ECC. At this time, vascular dilation to SNP, but not $\mathrm{ACh}$, was significantly reduced compared to 1 day postoperatively, when $\mathrm{FHb}$ had returned to baseline levels. Interestingly, in the immediate postoperative period plasma $\mathrm{FHb}$ concentration was inversely correlated to FBF responses to SNP. In contrast, the increase in arginase- 1 was not biologically relevant since the ratio of plasma arginine to ornithine remained constant.

Conclusions We conclude that hemolysis with concomitant release of $\mathrm{FHb}$ during major cardiovascular surgery is associated with impaired NO-dependent forearm blood flow. We suggest this may contribute to organ injury after surgery and worse patient outcome. 


\section{Introduction}

Intravascular hemolysis is associated with disturbances in endothelial nitric oxide (NO) metabolism, the key system in regulating vascular tone and microcirculatory blood flow. ${ }^{1,2}$ First, oxyhemoglobin released from injured erythrocytes (FHb) reduces NO bioavailability by scavenging NO. ${ }^{1}$ Oxyhemoglobin in its ferrous form binds NO to generate ferric hemoglobin, also known as methemoglobin, and bioinactive nitrate $\left(\mathrm{HbFe}^{2+}-\mathrm{O}_{2}+\mathrm{NO} \rightarrow \mathrm{HbFe}^{3+}+\mathrm{NO}_{3}{ }^{-}\right)$. Second, arginase- 1 release from hemolytic erythrocytes has been suggested to decrease NO production by depletion of plasma arginine, the precursor for NO synthesis, with a concomitant increase of plasma ornithine, the product of arginase- 1 activity. ${ }^{3}$ Both $\mathrm{FHb}$ and arginase- 1 may impair NO bioavailability resulting in a compromised microcirculation. Evidence is mounting that hemolysis is an important factor in the pathogenesis of compromised microcirculation in chronic hereditary or acquired hemolytic diseases such as sickle cell disease and falciparum malaria infection. ${ }^{3-5}$

Hemolysis is unwanted but not uncommon in cardiovascular surgery. Extracorporeal circulation (ECC) is an inevitable part of open cardiac and thoracic- or thoracoabdominal aortic surgery and known to result in hemolysis. ${ }^{6,7}$ This type of surgery is also associated with considerable blood loss, leading to massive transfusion requirements. Hemolysis during storage of red blood cells intended for transfusion is associated with increased mortality rate in patients undergoing massive allogeneic transfusion. ${ }^{8}$ Furthermore, storage results in lower viability of erythrocytes intended for transfusion, which has been associated with clinical adverse events in the recipient such as postoperative infection, pulmonary and renal complications and multiple organ failure. ${ }^{9}$ Allogeneic transfusion requirements may be reduced by the application of cell-salvage devices during cardiovascular surgery. However, such devices lead to injury of red blood cells intended for autologous transfusion. ${ }^{10}$

Aim of the present study was first to investigate the extent of hemolysis and the concomitant release of $\mathrm{FHb}$ and arginase-1 in patients undergoing cardiovascular surgery with extracorporeal circulation and massive transfusion including cellsalvage. Next, forearm vascular smooth muscle responses to exogenous NO in the presence of plasma FHb were evaluated. Finally, the effect of elevated plasma arginase-1 on plasma arginine and ornithine levels was evaluated.

\section{Methods}

\section{Study subjects}

The local institutional review board approved the study and written informed consent was obtained from every patient $(N=19)$ prior to surgery. Patients, 18 years or 
older, undergoing open thoracic aortic aneurysm (TAA) or thoracoabdominal aortic aneurysm (TAAA) repair at the Maastricht University Medical Center (Maastricht, the Netherlands) were continuously included in the study. Exclusion criteria were pregnancy, morbid obesity (> $120 \mathrm{~kg}$ or $\mathrm{BMI}>35 \mathrm{~kg} / \mathrm{m} 2$ ), prolonged or high dose corticosteroid use, insulin-dependent diabetes mellitus, metastases, hematological malignancies or chemotherapy, pre-existent renal failure, liver cirrhosis, preexistent urea cycle disorders, or any other condition that, in the physician's judgment, would make the patient an unsuitable candidate for participation in this study. In the first consecutive series of 10 patients plasma $\mathrm{FHb}$, arginase-1 and amino acid levels were evaluated; then a consecutive series of 9 patients was included in the study to conduct forearm blood flow measurements as described below. This study design was chosen to eliminate possible confounding factors resulting from interference of the NO-donor sodium nitroprusside used in the forearm blood flow study on measurement of $\mathrm{FHb}$ levels and potentially $\mathrm{NO}$ metabolism, possibly affecting amino acid levels. In all cases ECC was applied using a centrifugal pump with oxygenation (Jostra Rotaflow with Jostra Quadrox, Maquet Cardiopulmonary AG, Hirrlingen, Germany) in combination with a cell-saver (CATS, Fresenius SE, Bad Homburg, Germany). Surgical procedures are extensively described elsewhere. $^{11,12}$

All patients had an indwelling radial artery catheter that was placed as part of standard anesthetic care. Postoperatively, all patients were transported to the Cardiothoracic Intensive Care Unit for postoperative monitoring and circulatory and ventilatory support. Patient characteristics and intraoperative data are reported in Table 5.1.

Table 5.1. Characteristics and intraoperative data of patients undergoing open TAA or TAAA repair

\begin{tabular}{lcc}
\hline & Initial study & FBF study \\
\hline Patients (N) & 10 & 9 \\
TAA & 0 & 2 \\
TAAA* & & 1 \\
TAAA I & 0 & 2 \\
TAAA II & 3 & 2 \\
TAAA III & 4 & 2 \\
TAAA IV & 3 & 5 \\
Male (N) & 7 & $63.7 \pm 2.0$ \\
Age (Years) & $68.0 \pm 2.2$ & 6 \\
(Ex-) Smoker with $>10$ pack-years (N) & 8 & 7 \\
Hypertension (N) & 8 & 4 \\
Dyslipidaemia (N) & 6 & - \\
NIDDM (N) & 1 & $100.6 \pm 28.4$ \\
ACC time (min) & $89.7 \pm 14.3$ & $139.9 \pm 35.5$ \\
ECC time (min) & $161.8 \pm 15.5$ & $2.8 \pm 0.6$ \\
Flow ECC (L/min) & $2.5 \pm 0.1$ &
\end{tabular}




\begin{tabular}{lcc}
\hline & Initial study & FBF study \\
\hline Patient hematocrit during ECC (L/L) & $0.27 \pm 0.01$ & $0.24 \pm 0.01$ \\
Estimated blood loss (L) & $16.6 \pm 2.6$ & $14.3 \pm 5.1$ \\
Infused fresh frozen plasma (L) & $2.9 \pm 0.5$ & $1.7 \pm 0.7$ \\
Infused crystalloids (L) & $6.5 \pm 0.9$ & $5.4 \pm 0.9$ \\
Infused colloids (L) & $5.1 \pm 1.0$ & $3.4 \pm 0.7$ \\
Transfused allogeneic blood (L) & $3.3 \pm 0.5$ & $3.3 \pm 1.0$ \\
Transfused autologous cell-salvage blood (L) & $5.9 \pm 1.1$ & $5.0 \pm 1.8$ \\
Total operation time (min) & $424.2 \pm 25.5$ & $400.4 \pm 44.8$ \\
\hline
\end{tabular}

TAA = thoracic aortic aneurysm; TAAA = thoracoabdominal aortic aneurysm; NIDDM = non-insulin dependent diabetes mellitus; $A C C=$ aorta cross clamp; $E C C$ = extracorporeal circulation. *TAAA classification is according to Crawford. ${ }^{37}$

Continues variables are expressed as mean \pm SEM.

\section{Blood sampling, sample processing and laboratory analysis}

Arterial blood was drawn preoperatively and at several points in time during and after surgery and collected in vacuum tubes containing EDTA (Becton Dickinson, Franklin Lakes, NJ). Whole blood was centrifuged (3500 x G, 4 ${ }^{\circ} \mathrm{C}, 15 \mathrm{~min}$ ), $100 \mu \mathrm{l}$ plasma was deproteinized with $8 \mathrm{mg}$ sulphosalicylic acid (SSA) and stored at $-80^{\circ} \mathrm{C}$, the remainder was stored untreated $\left(-80^{\circ} \mathrm{C}\right)$ for $\mathrm{FHb}$ and arginase- 1 analysis. $\mathrm{FHb}$ concentrations were measured by derivative spectrometry as described elsewhere. ${ }^{13}$ Arginase-1 concentrations were measured using Enzyme-Linked Immuno Sorbent Assay (ELISA) ${ }^{14}$ kindly provided by Hycult biotechnology, Uden, the Netherlands. The detection limits of the assays were $2 \mu \mathrm{mol} / \mathrm{l}$ (FHb) and $21 \mu \mathrm{g} / \mathrm{l}$ (arginase1). Amino acid levels were analyzed in SSA samples by high performance liquid chromatography as described before. ${ }^{15}$

\section{Hemolysis in extracorporeal circulation, transfusion bags, and cell-salvage device}

To determine the possible sources of $\mathrm{FHb}$ and arginase-1 release, we evaluated the contribution of ECC, transfusion bags and cell-salvage to elevated plasma FHb and arginase- 1 levels. In the first series of patients the inflow and outflow tubes of the ECC and the outflow tube of the cell-salvage device were sampled simultaneously at the end of the ECC procedure.

The contribution of the ECC to plasma FHb and plasma arginase-1 was calculated using the plasma $\mathrm{FHb}$ and arginase-1 concentration in outflow tube minus inflow tube ( $\mu \mathrm{mol} / \mathrm{l}$ and $\mu \mathrm{g} / \mathrm{l}$, respectively) multiplied by mean ECC flow $(\mathrm{l} / \mathrm{min})$ and corrected for hematocrit ( $\mathrm{Hct}$ ), which indicates the release of $\mathrm{FHb}$ and arginase- 1 by ECC ( $\mu \mathrm{mol} / \mathrm{min}$ and $\mu \mathrm{g} / \mathrm{min}$, respectively). Total contribution to the circulating volume was calculated using the release of $\mathrm{FHb}$ and arginase- 1 by the ECC device multiplied by the duration of ECC. 
A number of 20 randomly chosen red blood cell transfusion bags (Hct of $0.5-0.7 \mathrm{l} / \mathrm{l}$, Sanquin Blood Bank, Maastricht, the Netherlands), actually administered to the patients under study, were sampled to determine the amount of extracellular $\mathrm{FHb}$ and arginase-1. From each bag $(330 \mathrm{ml}), 1.5 \mathrm{ml}$ erythrocyte concentrate was collected, which was centrifuged at $3500 \times \mathrm{G}$ for 15 minutes $\left(4^{\circ} \mathrm{C}\right)$. The resulting supernatant was assayed for $\mathrm{FHb}$ and arginase-1 concentration. The mean volume of transfused allogeneic blood was used to appraise absolute contribution of $\mathrm{FHb}$ and arginase-1 to the patient's circulating volume.

$\mathrm{FHb}$ and arginase- 1 concentration in supernatant of the cell-salvage device was evaluated using the given Hct of $0.66 \mathrm{l} / \mathrm{I}^{10}$ to calculate $\mathrm{FHb}$ and arginase- 1 in the supernatant of processed blood product intended for autologous transfusion. Total processed volume was used to calculate absolute release of $\mathrm{FHb}$ and arginase-1.

\section{Forearm blood flow measurements and NO reactivity}

Forearm blood flow (FBF) served as a model for organ perfusion and was measured using venous occlusion plethysmography as described previously. ${ }^{16,}{ }^{17}$ FBF measurements in the non-dominant arm were conducted on the day of surgery immediately upon arrival at the Cardiothoracic Intensive Care Unit approximately 2 hours following cessation of ECC and massive transfusion including cell-salvage $(2 \mathrm{~h} R)$ and again 24 hours later (Day 1 ).

FBF was measured before and during infusion of vasoactive substances in the brachial artery of the study arm. Both an endothelium-independent vasodilator (NO-donor sodium nitroprusside (SNP), Spruyt Hillen BV, IJsselstein, the Netherlands), as well as an endothelium-dependent vasodilator (Acetylcholine (ACh), Clinalfa, Läufelfingen, Switzerland) was used. Both substances were infused in two accumulating dosages (SNP $1 \mu \mathrm{g} / \mathrm{min}$ and $10 \mu \mathrm{g} / \mathrm{min}$; ACh $3 \mu \mathrm{g} / \mathrm{min}$ and $30 \mu \mathrm{g} / \mathrm{min}$; $3 \mathrm{~min} /$ dosage). The order of SNP and ACh was randomly chosen with a washout period of 30 minutes between SNP and ACh infusion.

\section{Statistics}

Changes versus preoperative values in plasma $\mathrm{FHb}$, arginase- 1 and amino acid concentrations were analyzed using repeated-measures ANOVA with post hoc Dunnet's multiple comparison test using pre-operative values as control. Changes in FBF measurements were tested using Wilcoxon signed rank tests. Statistical calculations were made using Prism 4.0 for Windows (GraphPad Software Inc. San Diego, CA). Data are expressed as mean \pm SEM. Results were considered significant at $P<0.05$. 


\section{Results}

\section{Hemolysis during open TAA / TAAA repair}

Plasma levels of $\mathrm{FHb}$ and arginase-1, used as marker for hemolysis, were within normal ranges prior to surgery (Figure 5.1). After initiation of the ECC, FHb and arginase-1 levels increased and peak plasma levels were found at 2 hours in the reperfusion phase $(2 \mathrm{~h} R)$, indicating ongoing lysis of red blood cells after cessation of ECC. Spearman correlation analysis between area under the curve of each parameter for every individual patient revealed a significant association between $\mathrm{FHb}$ and arginase- 1 release $(r=0.83, P<0.01)$.

\section{Sources and causes of hemolysis}

The contributions of ECC, transfusion bags and cell-salvage to elevated plasma $\mathrm{FHb}$ and arginase-1 levels were evaluated. Differences in $\mathrm{FHb}$ and arginase-1 concentrations in the inflow and outflow tubes of the ECC device were measured and revealed significant release of FHb by the ECC device (FHb $2.9 \pm 0.8 \mu \mathrm{mol} / \mathrm{I}$ vs. $3.5 \pm$ $0.9 \mu \mathrm{mol} / \mathrm{l}, \mathrm{P}<0.05$; arginase-1 $30.3 \pm 10.5 \mu \mathrm{g} / \mathrm{l}$ vs. $33.1 \pm 10.6 \mu \mathrm{g} / \mathrm{l})$. Per patient the average contribution of ECC per minute and in total to circulating FHb and arginase1 was calculated and revealed release by the ECC of $1.4 \pm 0.3 \mu \mathrm{mol} / \mathrm{min} \mathrm{FHb}$ and $12.6 \pm 6.2 \mu \mathrm{g} / \mathrm{min}$ arginase -1 , with an absolute total release of $211.4 \pm 52.1 \mu \mathrm{mol}$ $\mathrm{FHb}$ and $2517 \pm 1552 \mu \mathrm{g}$ arginase- 1 .

The average $\mathrm{FHb}$ concentration in the supernatant of transfusion bags was 35.7 $\pm 2.4 \mu \mathrm{mol} / \mathrm{l}$, and the mean arginase- 1 concentration was $370.7 \pm 51.0 \mu \mathrm{g} / \mathrm{l}$, both indicating hemolysis in commonly used transfusion bags. Depending on the Hct of allogeneic donor blood bags, upper limit of $\mathrm{FHb}$ and arginase-1 per liter allogeneic transfused blood is $16.8 \pm 0.9 \mu \mathrm{mol} / \mathrm{I}$ and $185.4 \pm 25.5 \mu \mathrm{g} / \mathrm{l}$, respectively. Upper limit of the total contribution to the patient's circulating volume was also calculated (FHb $55.5 \pm 3.1 \mu \mathrm{mol}$, and arginase-1 $611.7 \pm 84.2 \mu \mathrm{g}$ ).

The measured concentration of $\mathrm{FHb}$ in the outflow of the cell-salvage device was $66.6 \pm 15.7 \mu \mathrm{mol} / \mathrm{l}$, the concentration of arginase-1590.1 $\pm 118.7 \mu \mathrm{g} / \mathrm{l}$, both representing infusion of hemolytic products in combination with the washed red blood cells. Total FHb and arginase-1 per liter autologous transfused blood was 22.6 $\pm 5.3 \mu \mathrm{mol} / \mathrm{l}$ and $200.6 \pm 40.3 \mu \mathrm{g} / \mathrm{l}$, respectively. Total release by the cell-saver during surgery was $152.8 \pm 47.4 \mu \mathrm{mol} F H \mathrm{~b}$ and $1305 \pm 394.0 \mu \mathrm{g}$ arginase- 1 . These data indicate that the ECC system is the main contributor to circulating $\mathrm{FHb}$ and arginase1 in patients undergoing cardiovascular surgery (Figure 5.2). 


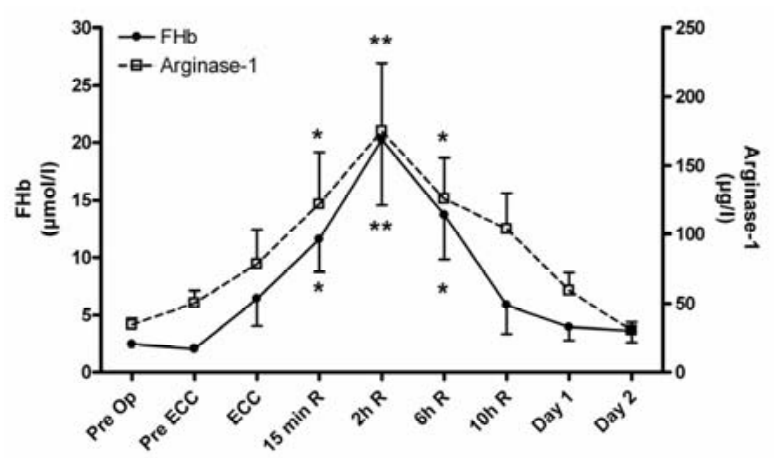

Figure 5.1. Markers of hemolysis in patients undergoing major cardiovascular surgery Circulating plasma $\mathrm{FHb}$ and arginase-1 during open thoracic - / thoracoabdominal aortic aneurysm repair reached peak values at 2 hours in the reperfusion phase $(2 \mathrm{~h} \mathrm{R})$. Both markers of hemolysis had returned to preoperative range at the first postoperative day. Spearman correlation analysis revealed a significant association between both variables $(r=0.83, P<0.01)$. Op, operation; ECC, extracorporeal circulation; $R$, reperfusion; $* \mathrm{P}<0.05 ; * * \mathrm{P}<0.01$

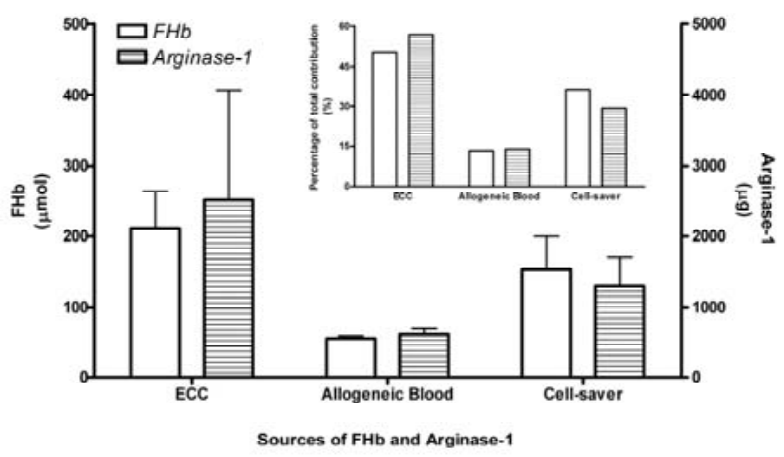

Figure 5.2. Sources of hemolysis during cardiovascular surgery with ECC and massive transfusion including cell-salvage. The individual contribution of the extracorporeal circulation (ECC), transfusion bags and cell-salvage to elevated plasma FHb and arginase-1 levels during ECC was measured and the relative contribution was calculated as well (inset). These data suggest that ECC is mainly responsible for elevated circulating plasma levels $\mathrm{FHb}$ and arginase- 1 . Data are expressed as mean $\pm \mathrm{SEM}$.

\section{Forearm vascular smooth muscle responses to exogenous NO}

Increased plasma concentrations of cell-free hemoglobin may limit NO-mediated vasodilatation. Therefore, we studied $\mathrm{FBF}$ in a series of nine consecutive patients undergoing TAAA repair (Figure 5.3). Plasma FHb levels were measured in these patients before FBF measurements began ( $2 \mathrm{~h} \mathrm{R:} 20.9 \pm 6.5 \mu \mathrm{mol} / \mathrm{l}$ vs. Day 1: $3.8 \pm$ $0.5 \mu \mathrm{mol} / \mathrm{l}, \mathrm{P}<0.05)$ and were comparable to those measured in the first series of patients (Figure 5.1). 

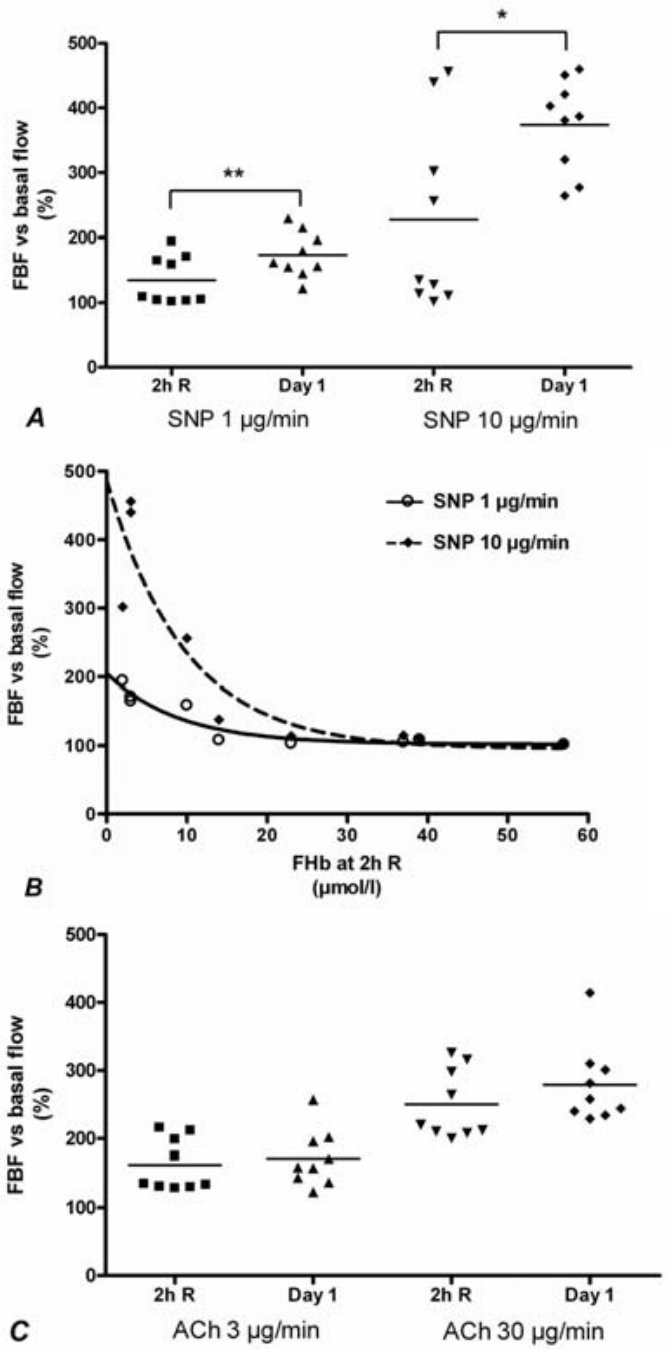

Figure 5.3. High levels of $\mathrm{FHb}$ correlate with an impaired NO-bioactivity in vivo (A) After infusion of the NO-donor sodium nitroprusside (SNP) forearm blood flow (FBF) measurements revealed reduced smooth muscle response at 2 hours reperfusion ( $2 \mathrm{~h} \mathrm{R}$ ), when FHb levels peaked (Figure 5.1). At the first postoperative day (Day 1) FBF was significantly higher after infusion of SNP, indicating smooth muscle relaxation to exogenous NO infusion was restored. (B) Single exponential decay curve-fit was evaluated by plotting individual FBF responses to SNP at $2 \mathrm{~h} \mathrm{R}$ against plasma $\mathrm{FHb}$ levels. Using Spearman correlation test, increasing levels of $\mathrm{FHb}$ appeared negatively correlated with FBF responses to SNP for both dosages (SNP $1 \mu \mathrm{g} / \mathrm{min} r=$ $0.89, \mathrm{P}<0.01$; SNP $10 \mu \mathrm{g} / \mathrm{min} \mathrm{r}=-0.93$, $P<0.001)$. Importantly, these findings reproduce data from Reiter et al., evaluating plasma $\mathrm{FHb}$ versus SNP responses in sickle-cell disease patients. ${ }^{28}$ (C) Infusion with Acetylcholine (ACh), which acts predominantly via hyperpolarization induced vasodilatation, at $2 \mathrm{~h} \mathrm{R}$ and Day 1 revealed a similar endothelial smooth muscle reaction to both dosages infused, indicating near equal vasodilatory capacity at the studied time points. Basal flow was set at $100 \%$ for every measurement. * $\mathrm{P}<0.05 ; * * \mathrm{P}<0.01$

Blood flow responses to SNP, an endothelium-independent NO-donor, were measured postoperatively ( $2 \mathrm{~h} \mathrm{R}$ ) and at day 1 postoperative (Day 1$)$. FBF responses to SNP were significantly reduced direct postoperatively when compared to the first postoperative day (SNP $1 \mu \mathrm{g} / \mathrm{min} 134.7 \pm 12.3 \%$ vs. $173.4 \pm 11.6 \%$, P < 0.01; SNP 10 $\mu \mathrm{g} / \mathrm{min}: 227.1 \pm 47.8 \%$ vs. $373.8 \pm 23.9 \%, \mathrm{P}<0.05$; Figure $5.3 \mathrm{~A})$. Interestingly, using Spearman correlation analysis at $2 \mathrm{~h} \mathrm{R}$, forearm blood flow was negatively correlated with plasma FHb for both dosages studied (SNP $1 \mu \mathrm{g} / \mathrm{min} \mathrm{r}=-0.89, \mathrm{P}<0.01$; SNP 10 $\mu \mathrm{g} / \mathrm{min} r=-0.93, \mathrm{P}<0.001$, Figure 5.3B).

To control for vasodilatory capacity the response to exogenous ACh, a vasodilator that induces hyperpolarization of the endothelial smooth muscle cells, was assessed at the same time points. The dose response reaction to ACh was not signifi- 
cantly different at $2 \mathrm{~h} R$ versus Day 1, indicating unchanged potent vasodilatory capacity (ACh $3 \mu \mathrm{g} / \mathrm{min}$ : $162.3 \pm 12.7 \%$ vs. $172.0 \pm 13.7 \%$; ACh $30 \mu \mathrm{g} / \mathrm{min}: 250.4 \pm$ $17.0 \%$ vs. $279.0 \pm 19.5 \%$, respectively; Figure $5.3 \mathrm{C}$ ).

Taken together, these data indicate a deleterious effect of hemolytic product $\mathrm{FHb}$ on NO-dependent blood flow responses, whereas NO-independent blood flow responses remained unchanged around cardiovascular surgery with ECC and massive transfusion including cell-salvage.

\section{In vivo indices of arginase-1 activity}

Plasma arginase-1 activity potentially leads to a decreased plasma arginine concentration with a concomitant elevated plasma ornithine concentration. To test for arginase-1 activity, we measured plasma levels of arginine and ornithine. Also, for each individual patient plasma arginine / ornithine ratio was calculated at every time-point (Figure 5.4).

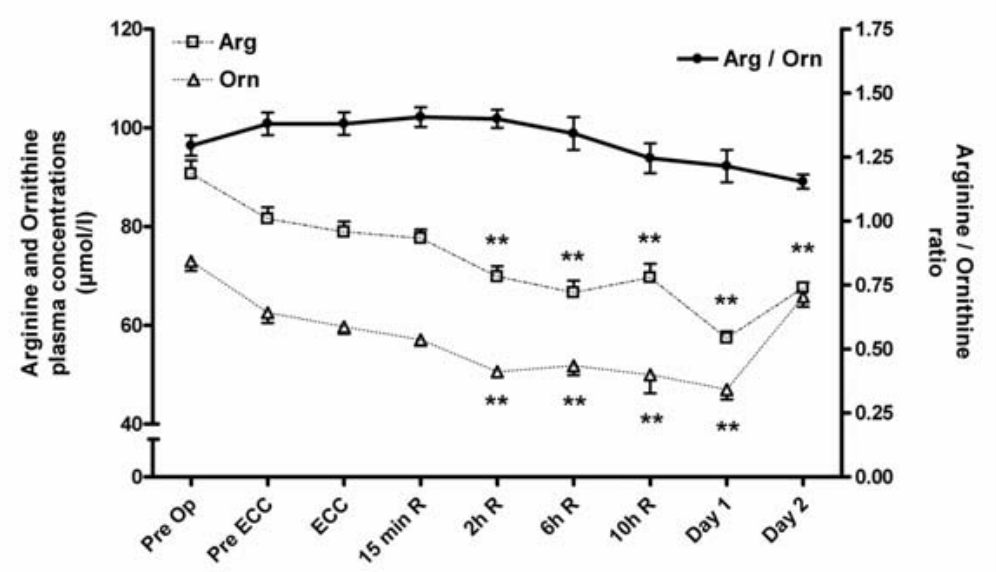

Figure 5.4. Plasma amino acid levels. To evaluate plasma arginase-1 activity the substrate plasma arginine (Arg) and product, plasma ornithine (Orn) levels were measured. Arginine / ornithine ratio (Arg / Orn) was calculated to appraise plasma arginase-1 activity. Arg / Orn ratio was not significantly altered during the study, indicating no increased plasma arginase- 1 activity. ${ }^{* *} \mathrm{P}<0.01$

Plasma arginine and ornithine levels decreased during and after the operation just as several other amino acids (data not shown). Despite increasing plasma levels of arginase-1 (Figure 5.1) no significant changes in plasma arginine / ornithine ratio were observed during the studied period.

Moreover, correlation analysis between the increase of plasma arginase- 1 and the decrease of plasma arginine levels for each individual patient revealed no association between both parameters (Spearman $r=0.55 ; P=0.105)$. These results do 
not support increased plasma arginase-1 activity in cardiovascular patients undergoing ECC with massive transfusion including cell-salvage.

\section{Discussion}

In this study hemolysis, represented by elevated plasma $\mathrm{FHb}$ and arginase-1 levels, was observed in cardiovascular patients who underwent ECC and massive transfusion including cell-salvage. NO is the central component in regulation of vasodilatation and maintaining adequate tissue oxygenation and function. ${ }^{18}$ Therefore, interference in NO metabolism, either by scavenging of NO via $\mathrm{FHb}$ or by depletion of the NO substrate arginine, may result in vasoconstriction, modulation of platelet activation, enhanced leukocyte adhesion and oxygen free-radical generation in the vascular compartment. ${ }^{2,19}$ These disturbances can lead to clinical symptoms such as systemic and pulmonary hypertension, intravascular thrombosis, ischemic cerebrovascular events, priapism, and paroxysmal nocturnal hemoglobinuria; all these phenomena are associated with hemolytic crisis in experimental, hereditary or acquired chronic hemolytic diseases. ${ }^{2-5}, 20-22$ This study is directed at investigating acute effects of hemolysis during and after surgery. We have now shown that hemolysis, in particular the release of $\mathrm{FHb}$, is associated with an acutely impaired NO-mediated vasodilatory capacity in cardiovascular patients undergoing ECC with massive transfusion and cell-salvage. Moreover, our data suggest that ECC is the main contributor to elevated plasma FHb levels.

Elevated plasma FHb in patients undergoing ECC has been described previously; furthermore, FHb is commonly used as a hemolytic marker when ECC is used. ${ }^{6}$ Massive allogeneic transfusion, to cope for considerable blood loss during surgery, contributes to increased levels of plasma $\mathrm{FHb}$, whereas red blood cell damage occurring in cell-salvage devices is also likely to increase levels of circulating plasma $\mathrm{FHb}^{10,23}$ Our data implicate that ECC is to a greater extent responsible for elevated circulating $\mathrm{FHb}$ and arginase-1 levels during cardiovascular surgery with ECC and massive transfusion including cell-salvage. Surprisingly, peak plasma FHb levels were found 2 hours after cessation of the ECC when patients arrived at the Cardiothoracic Intensive Care Unit. Transfusion requirements, both red blood cell and plasma, at that time were minimal and cell-saver blood product had been administered to the patients before transportation to the Cardiothoracic Intensive Care Unit. These data suggest that hemolysis is ongoing after ECC is terminated and the observed increase is a result of exhaustion of natural $\mathrm{FHb}$ scavengers such as haptoglobin and CD163. ${ }^{24,}{ }^{25}$ Also, the fact that arginase-1, which has a plasma half-life of $40 \mathrm{~min}$ utes $^{26}$ increased in this time-period, suggests that ongoing hemolysis explains the increase in $\mathrm{FHb}$. 
Plasma $\mathrm{FHb}$ is thought to extravasate into the surrounding extracellular compartment, increasing its potential to interfere with endogenously produced NO thereby further challenging the vasodilatory capacity of vascular smooth muscle cells. ${ }^{27}$ Hence, we evaluated whether levels of $\mathrm{FHb}$ were correlated with reduced vascular smooth muscle reaction to exogenous NO. The results of our study show that the responses to the NO-donor SNP were significantly lower when plasma FHb was elevated compared with measurements 24 hours later, when plasma $\mathrm{FHb}$ had returned to baseline levels. The observed decreased responses to exogenous NO were strongly correlated with plasma FHb levels in a way similar to what has been reported by Reiter et al. evaluating plasma $\mathrm{FHb}$ and SNP responses in patients with sickle cell disease. ${ }^{28}$ This indicates that across diseases, this process is reproducible. To test for endothelial dysfunction we evaluated responses to the vasodilator ACh, which acts predominantly via hyperpolarization of endothelial smooth muscle cells resulting in $\mathrm{Ca}^{2+}$ influx with a concomitant vasodilatory response, and to a lesser extent via induction of NO synthesis. ${ }^{29,30}$ Near equally potent endothelial vasodilatory capacities at both points in time were found after ACh infusion, representing viable endothelial function. In theory, ACh at a concentration of $3 \mu \mathrm{g} / \mathrm{min}$ might be too low to exert a significantly different vasodilatory response between both points in time, whereas ACh $30 \mu \mathrm{g} / \mathrm{min}$ could have been high enough to bypass a potential reduction in vasodilation directly postoperatively in the presence of circulating $\mathrm{FHb}$. Therefore, a potential effect of $\mathrm{FHb}$ on ACh induced vasodilation at e.g. $15 \mu \mathrm{g} / \mathrm{min}$ cannot be excluded. Taken together, these data show scavenging of exogenously infused NO (SNP) and support also the general hypothesis of endogenously produced NO-scavenging by $\mathrm{FHb}$.

Arginase-1 release can be the result of both hemolysis and hepatocyte injury. Since the kinetics of arginase- 1 release in the present study correlated significantly with the release of $\mathrm{FHb}$, hemolysis appears to be the primary cause of elevated plasma arginase-1. Furthermore, recent data from our group indicate that the activity of plasma arginase-1, at concentrations found in our patients is too low to exert a substantial and lasting effect on plasma arginine, the substrate for NO metabolism. ${ }^{26}$ Only plasma arginase-1 levels of $1500 \mu \mathrm{g} / \mathrm{l}$ or higher, as found after deceased donor liver transplantation, were able to reduce plasma arginine and increase plasma ornithine levels, potentially hampering NO metabolism. ${ }^{26}$ Plasma arginine levels in our patients decreased in parallel with ornithine and other amino acid concentrations as has been described previously after cardiovascular surgery with ECC. $^{31}$ In line, Arg / Orn ratio in the present study remained unchanged. Moreover, we found no association between elevated plasma arginase-1 levels and decreased plasma arginine levels. We conclude therefore, that NO-production in our patient population was not hampered by plasma arginase-1 activity.

Whereas the potential consequences of hemolysis are recently reported for chronic hemolytic diseases, such as sickle cell disease, here we show that hemolysis 
is likely to also have consequences for cardiovascular, cardiothoracic and trauma surgery. Data from our group show that cardiovascular surgery is associated with intestinal mucosal injury during the post-operative period. ${ }^{12}$ At this time, plasma $\mathrm{FHb}$ levels peak, potentially linking hemolysis and in particular $\mathrm{FHb}$ release, to a reduced visceral microcirculation by scavenging of NO. A reduced visceral microcirculation may induce visceral injury, which on its turn, mainly acute kidney injury, is strongly associated with inflammation and worse patient outcome. ${ }^{32}$ Recently, we have shown that the concentrations of plasma $\mathrm{FHb}$ levels and urine $\mathrm{N}$-acetyl glucosaminidase (NAG) levels, a marker for tubular epithelial cell injury, both increased during cardiovascular surgery. Interestingly, we found that the total release of plasma FHb was independently correlated with urine NAG, which in turn was independently associated with the postoperative increase in serum creatinine, used as marker for acute kidney injury. ${ }^{33}$ Further studies are underway to evaluate correlations between perioperative disturbances in vasoregulation and clinical outcome in cardiovascular surgical patients. Also, the potential effect of hemolysis on induction of vascular inflammation and oxidative stress during elevated levels of circulating $\mathrm{FHb}$ remains unclear and need to be addressed in future studies.

In conclusion, our data show diminished vascular smooth muscle reactivity to NO during hemolysis in cardiovascular surgical patients, compromising forearm blood flow, which we attribute to elevated levels of circulating FHb. Such acute disturbance in NO-dependent blood flow potentially contributes to organ injury after cardiovascular surgery. We therefore suggest that either hemolysis should be prevented by reducing in particular ECC time, or the deleterious effects of $\mathrm{FHb}$ should be counteracted in clinical practice to restore NO-dependent blood flow in cardiovascular patients undergoing ECC and massive transfusion including cellsalvage. Therapy options include FHb scavenging (haptoglobulin infusion), ${ }^{24}$ inactivating $\mathrm{FHb}$ (NO-inhalation) ${ }^{20}$ or enhancing the circulating NO-pool (NO-inhalation, parenteral or enteral nitrite suppletion). ${ }^{34-36}$ 


\section{Acknowledgements}

The authors wish to thank dr. Jan Serroyen (Department of Methodology and Statistics, Maastricht University Medical Center, the Netherlands) for critical revision of the statistical analyses used in this study. Prof. dr. Wim A. Buurman is shareholder of Hycult biotechnology (Uden, the Netherlands) who kindly provided the arginase-1 ELISA kits used in this study.

\section{References}

1. Rother RP, Bell L, Hillmen P, et al. The clinical sequelae of intravascular hemolysis and extracellular plasma hemoglobin: a novel mechanism of human disease. Jama 2005; 293:1653-62.

2. Villagra J, Shiva S, Hunter LA, et al. Platelet activation in patients with sickle disease, hemolysisassociated pulmonary hypertension, and nitric oxide scavenging by cell-free hemoglobin. Blood 2007; 110:2166-72.

3. Morris CR, Kato GJ, Poljakovic M, et al. Dysregulated arginine metabolism, hemolysis-associated pulmonary hypertension, and mortality in sickle cell disease. Jama 2005; 294:81-90.

4. Yeo TW, Lampah DA, Gitawati R, et al. Impaired nitric oxide bioavailability and L-arginine reversible endothelial dysfunction in adults with falciparum malaria. J Exp Med 2007; 204:2693-704.

5. Ataga $\mathrm{KI}$, Moore CG, Hillery CA, et al. Coagulation activation and inflammation in sickle cell diseaseassociated pulmonary hypertension. Haematologica 2008; 93:20-6.

6. Fransen EJ, Ganushchak YM, Vijay V, et al. Evaluation of a new condensed extra-corporeal circuit for cardiac surgery: a prospective randomized clinical pilot study. Perfusion 2005; 20:91-9.

7. Maruyama $\mathrm{O}$, Numata $\mathrm{Y}, \mathrm{Nishida} \mathrm{M}$, et al. Hemolysis caused by surface roughness under shear flow. J Artif Organs 2005; 8:228-36.

8. Karkouti K, Wijeysundera DN, Yau TM, et al. The independent association of massive blood loss with mortality in cardiac surgery. Transfusion 2004; 44:1453-62.

9. Koch CG, Li L, Sessler DI, et al. Duration of red-cell storage and complications after cardiac surgery. $\mathrm{N}$ Engl J Med 2008; 358:1229-39.

10. Serrick CJ, Scholz M, Melo A, et al. Quality of red blood cells using autotransfusion devices: a comparative analysis. J Extra Corpor Technol 2003; 35:28-34.

11. Jacobs MJ, Mommertz G, Koeppel TA, et al. Surgical repair of thoracoabdominal aortic aneurysms. J Cardiovasc Surg (Torino) 2007; 48:49-58.

12. Hanssen SJ, Derikx JP, Vermeulen Windsant IC, et al. Visceral injury and systemic inflammation in patients undergoing extracorporeal circulation during aortic surgery. Ann Surg 2008; 248:117-25.

13. Cruz-Landeira A, Bal MJ, Quintela, et al. Determination of methemoglobin and total hemoglobin in toxicological studies by derivative spectrophotometry. J Anal Toxicol 2002; 26:67-72.

14. Ikemoto $M$, Tsunekawa $S$, Awane $M$, et al. A useful ELISA system for human liver-type arginase, and its utility in diagnosis of liver diseases. Clin Biochem 2001; 34:455-61.

15. van Eijk HM, Rooyakkers DR, Deutz NE. Rapid routine determination of amino acids in plasma by high-performance liquid chromatography with a 2-3 microns Spherisorb ODS II column. J Chromatogr 1993; 620:143-8.

16. Houben AJ, Schaper NC, de Haan $\mathrm{CH}$, et al. Local 24-h hyperglycemia does not affect endotheliumdependent or -independent vasoreactivity in humans. Am J Physiol 1996; 270:H2014-20.

17. Kimura M, Ueda K, Goto C, et al. Repetition of ischemic preconditioning augments endotheliumdependent vasodilation in humans: role of endothelium-derived nitric oxide and endothelial progenitor cells. Arterioscler Thromb Vasc Biol 2007; 27:1403-10. 
18. Ince C. The microcirculation is the motor of sepsis. Crit Care 9 2004; Suppl 4:S13-9.

19. Taddei S, Virdis A, Ghiadoni L, et al. Which endothelium-derived factors are really important in humans? Biol Chem 2006; 387:151-7.

20. Minneci PC, Deans KJ, Zhi H, et al. Hemolysis-associated endothelial dysfunction mediated by accelerated NO inactivation by decompartmentalized oxyhemoglobin. J Clin Invest 2005; 115:3409-3417.

21. Kato GJ, Hsieh M, Machado R, et al. Cerebrovascular disease associated with sickle cell pulmonary hypertension. Am J Hematol 2006; 81:503-10.

22. Lewis DA, Nyska A, Potti A, et al. Hemostatic activation in a chemically induced rat model of severe hemolysis and thrombosis. Thromb Res 2006; 118:747-53.

23. Nishiyama T, Hanaoka K. Free hemoglobin concentrations in patients receiving massive blood transfusion during emergency surgery for trauma. Can J Anaesth 2000; 47:881-5.

24. Tanaka K, Kanamori $Y$, Sato $T$, et al. Administration of haptoglobin during cardiopulmonary bypass surgery. ASAIO Trans 1991; 37:M482-3.

25. Schaer DJ, Schaer CA, Buehler PW, et al. CD163 is the macrophage scavenger receptor for native and chemically modified hemoglobins in the absence of haptoglobin. Blood 2006; 107:373-80.

26. van de Poll MC, Hanssen SJ, Berbée M, et al. Elevated plasma arginase-1 does not affect plasma arginine in patients undergoing liver resection. Clin Sci (Lond) 2008; 114:231-41.

27. Schechter AN, Gladwin MT. Hemoglobin and the paracrine and endocrine functions of nitric oxide. $N$ Engl J Med 2003; 348:1483-5.

28. Cohen RA, Vanhoutte PM. Endothelium-dependent hyperpolarization. Beyond nitric oxide and cyclic GMP. Circulation 1995; 92:3337-49.

29. Takaki A, Morikawa K, Tsutsui M, et al. Crucial role of nitric oxide synthases system in endotheliumdependent hyperpolarization in mice. J Exp Med 2008; 205:2053-63.

30. Barr FE, Beverley $\mathrm{H}$, VanHook $\mathrm{K}$, et al. Effect of cardiopulmonary bypass on urea cycle intermediates and nitric oxide levels after congenital heart surgery. J Pediatr 2003; 142:26-30.

31. Welborn MB, Oldenburg HS, Hess PJ, et al. The relationship between visceral ischemia, proinflammatory cytokines, and organ injury in patients undergoing thoracoabdominal aortic aneurysm repair. Crit Care Med 2000; 28:3191-7.

32. Vermeulen Windsant IC, Snoeijs MG, Hanssen SJ, et al. Hemolysis is associated with acute kidney injury during major aortic surgery. Kidney Int. 2010; 77:913-20

33. Bloch KD, Ichinose F, Roberts JD Jr, et al. Inhaled NO as a therapeutic agent. Cardiovasc Res 2007; 75:339-48.

34. Kim-Shapiro DB, Schechter AN, Gladwin MT. Unraveling the reactions of nitric oxide, nitrite, and hemoglobin in physiology and therapeutics. Arterioscler Thromb Vasc Biol 2006; 26:697-705.

35. Dejam A, Hunter CJ, Tremonti C, et al. Nitrite infusion in humans and nonhuman primates: endocrine effects, pharmacokinetics, and tolerance formation. Circulation 2007; 116:1821-31.

36. Crawford ES. Thoraco-abdominal and abdominal aortic aneurysms involving renal, superior mesenteric, celiac arteries. Ann Surg 1974; 179:763-72. 
<smiles>C=C=C</smiles> 
Chapter 6

Circulating Free Hemoglobin Results in Impaired Intestinal Microcirculation and Epithelial Cell Injury

Sebastiaan J. Hanssen, Tim Lubbers, Caroline M. Hodin, Frits W. Prinzen, Wim A. Buurman, Michael J. Jacobs

World Journal of Gastroenterology, Volume 17, January 2011, Pages 213-218. 


\section{Abstract}

Aim To study the effect of circulating cell-free oxyhemoglobin (FHb) on intestinal microcirculation and intestinal epithelial injury in a rat model.

Methods To induce elevated intravascular circulating $\mathrm{FHb}$, male Sprague-Dawley rats received water or $\mathrm{FHb}$ infusions. Microcirculatory changes in jejunum, ileum and colon were evaluated using fluorescent microspheres. Intestinal injury was quantified as plasmatic release of ileal lipid binding protein (iLBP) and verified by histological analysis of the ileum.

Results Water and $\mathrm{FHb}$ infusion resulted, when compared with saline infusion, in reduced intestinal microcirculation (after $30 \mathrm{~min} . \mathrm{P}<0.05$, or better; after $60 \mathrm{~min}$. $\mathrm{FHb}$ infusion $\mathrm{P}<0.05$ for jejunum and colon). Circulating $\mathrm{FHb}$ levels correlated significantly with release of iLBP (Spearman $r=0.70, P=0.0017$ ). Epithelial cell injury of the villi was histologically observed after water and $\mathrm{FHb}$ infusion.

Conclusions This study shows that circulating $\mathrm{FHb}$ leads to a reduction in intestinal microcirculatory blood flow with marked injury to intestinal epithelial cells. These data support that circulating $\mathrm{FHb}$ contributes to the development of intestinal injury. 


\section{Introduction}

Gastrointestinal complications following cardiovascular surgery are feared as these complications are associated with high patient morbidity and mortality rates. ${ }^{1-4}$ The proposed pathophysiological mechanisms underlying intestinal complications include (i) ischemia/reperfusion and hypoperfusion injury as a result of redistribution of blood flow and increased oxygen demand, (ii) inflammatory mediated endothelial dysfunction and priming and (iii) increased mesenteric vascular resistance. ${ }^{5-7}$

It is widely accepted that cardiovascular surgery is associated with considerable injury to red blood cells resulting in hemolysis. The use of extracorporeal circulation, donor blood transfusion and cell salvage devices inevitably leads to increased circulating levels of the hemolytic product cell-free oxyhemoglobin (FHb). ${ }^{8-10}$ Such circulating $\mathrm{FHb}$ has been reported to scavenge endothelial nitric oxide (NO) in chronic hemolytic diseases, potentially perturbing microcirculatory blood flow which may result in organ injury and/or organ dysfunction. ${ }^{11,12}$ The effect of hemolysis on intestinal microcirculation and gut wall integrity remains unclear. We hypothesized that intravascular FHb compromises intestinal blood flow and consequently induces intestinal epithelial cell injury.

The present study aimed to evaluate intestinal blood flow and intestinal epithelial cell injury due to elevated circulating FHb levels. An animal model was developed with FHb plasma levels, similar to those found during cardiovascular surgery. The influence of circulating $\mathrm{FHb}$ on intestinal microcirculation was studied using fluorescent microspheres and intestinal injury was evaluated both biochemically and histopathologically.

\section{Methods}

\section{Animals}

The Animal Ethics Committee of the Maastricht University Medical Center, the Netherlands approved the study. Male Sprague-Dawley rats, $450-500$ g (Charles River Laboratories, Maastricht, the Netherlands) were housed under controlled conditions of temperature and humidity. Prior to the experiments, rats were fed standard rodent chow ad libitum and had free access to water.

\section{Generation and measurement of $\mathrm{FHb}$}

To generate $\mathrm{FHb}$ containing solution for infusion, heparinized blood was obtained from rats through aortic punction one day prior to intervention. Red blood cells were isolated by centrifugation $\left(2,750 \times \mathrm{G}, 15\right.$ minutes at $\left.4^{\circ} \mathrm{C}\right)$. Supernatant and 
buffy-coat were carefully discarded and the remaining red blood cells were washed trice in fresh sterile saline $(1: 3 \mathrm{v} / \mathrm{v})$. Hemolysis was induced by freeze-thaw cycles. To remove all red blood cell-membranes the solution was ultra-centrifuged $(20,000$ $x \mathrm{G}, 30$ minutes at $\left.4^{\circ} \mathrm{C}\right)$ and filtered $(0.2 \mu \mathrm{m}$, Schleicher \& Schuell, Dassel, Germany). Final $\mathrm{FHb}$ concentration was adjusted with sterile saline to $300 \mu \mathrm{M}$. FHb concentration for infusion as well as plasma values were measured by derivative spectrophotometry. $^{13}$

\section{Experimental design}

After induction with $4 \%$ isoflurane, anesthesia was maintained at $2 \%$ during the whole study protocol. To calculate mean arterial pressure (MAP) a cannule (polyethylene tubing, PE-10) was placed in the left femoral artery and connected to an external pressure transducer (Uniflow ; Baxter, Utrecht, the Netherlands). Microspheres were infused via a cannule $(P E-10,11 \mathrm{~cm})$ that was placed in the aortic arch via the right femoral artery. The left femoral vein was used to infuse saline, water or FHb.

Three groups ( $\mathrm{N}=6$ per group) were included in the study. To induce intravascular hemolysis and yield circulating $\mathrm{FHb}$, the first group received sterile pyrogenefree water infusion (prime $0.6 \mathrm{~mL} / 100 \mathrm{gr}$. BW, continuous infusion of $2 \mathrm{~mL} / 100 \mathrm{gr}$. $\mathrm{BW} /$ hour); the second group received $\mathrm{FHb}$ infusion (prime $0.65 \mathrm{~mL} / 100$ gr. BW, continuous infusion $1.3 \mathrm{~mL} / 100$ gr. BW / hour). The control group received saline infusion in the same volume as the water infusion group.

\section{Assessment of microcirculatory blood flow using microspheres}

To evaluate the intestinal microcirculatory blood flow pre-infusion, and after 15, 30, and 60 minutes, fluorescent microspheres with a different color were used (yellow, lemon, orange or persimmon; diameter $15 \mu \mathrm{m}, 1 \times 10^{6}$ microspheres/mL; Dye-Trak ${ }^{\circledR}$, Triton Technology, San Diego, CA). Infusion of microspheres $(0.25-0.3 \mathrm{~mL})$ and calculation of organ blood flow was performed as described previously. ${ }^{14}$

\section{Evaluation of intestinal injury}

To evaluate enterocyte damage, the release of intestinal ileal lipid binding protein (iLBP) was measured. For iLBP assessment, arterial blood samples $(600 \mu \mathrm{L})$ were collected after 15, 30, and 60 minutes of infusion and measured in plasma by an Enzyme Linked Immuno Sorbent Assay (ELISA, detection limit $1.28 \mathrm{ng} / \mathrm{mL}$ ) kindly provided by Hycult biotechnology (Hbt, Uden, the Netherlands).

After sacrifice, ileum, jejunum, and colon tissue samples were fixed in neutral buffered formaldehyde and embedded in paraffin wax. For morphological evalua- 
tion, deparaffinized $3 \mu \mathrm{m}$ sections were either stained with hematoxylin and eosin or anti-iLBP, using a polyclonal rabbit anti-mouse iLBP (cross-reactive with rat; Hbt, Uden, the Netherlands) and a biotinylated polyclonal antibody swine anti-rabbit, a streptavidin-biotin system (Dako, Glostrup, Denmark) and visualized by applying 3amino-9-ethylcarbazole (AEC, Sigma, St. Louis, MO). A Nikon eclipse E800 microscope with a Nikon digital camera DXM1200F was used to capture images.

\section{Statistics}

To test for differences in plasma levels of FHb and iLBP, 2-way ANOVA with Bonferroni post-tests was used. To test for differences between changes in microcirculatory blood flow, two-tailed unpaired t-test was used. To evaluate an association between plasma FHb and plasmatic iLBP release, Spearman correlation analysis for nonparametric data was used on area under the curve (AUC) between FHb and iLBP for each individual subject of every group.

\section{Results}

\section{Hemolysis, FHb and MAP}

Plasma levels of $\mathrm{FHb}$ before intervention were comparable between all groups (Figure 6.1). Water and $\mathrm{FHb}$ infusion resulted in significantly elevated plasma levels $\mathrm{FHb}$ (peak values 29.6 (8.9) $\mu \mathrm{mol} / \mathrm{L}$ and 32.6 (2.7) $\mu \mathrm{mol} / \mathrm{L}$, respectively; $\mathrm{P}<0.001$ ). These levels are comparable to those found in patients during cardiovascular surgery in our University Medical Center, whereas infusion of saline did not result in elevated plasma FHb levels. Infusion of either solution did not lead to changes in MAP.

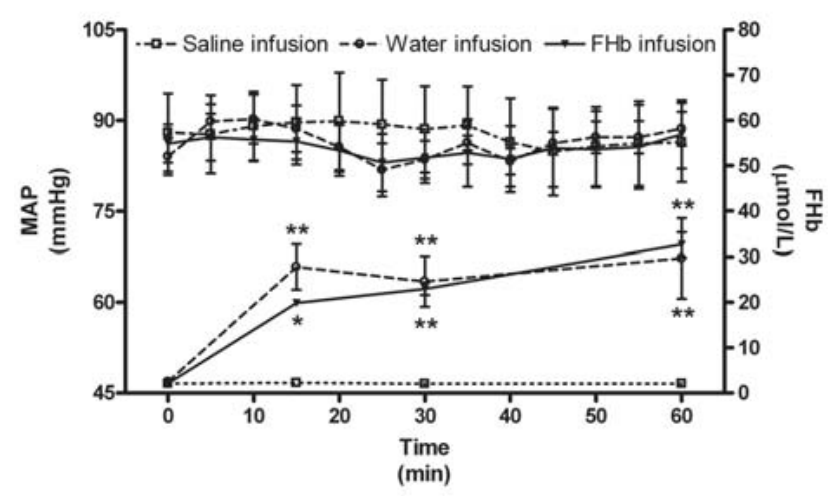

Figure 6.1. The effect of saline, water or $\mathrm{FHb}$ infusion on MAP and $\mathrm{FHb}$ levels. During the study period the MAP (left $Y$ axis) remained unchanged in all interventional groups. Plasma FHb levels (right $\mathrm{Y}$-axis) were significantly elevated in the group with water infusion and in the group with $\mathrm{FHb}$ infusion after 15 minutes and onwards. * $\mathrm{P}<0.01, * * \mathrm{P}<$ 0.001 


\section{Changes in intestinal microcirculation during hemolysis}

The microcirculation was evaluated in the jejunum, ileum and colon (Figure 6.2). Whereas after 15 minutes of infusion no differences in blood flow occurred, at 30 minutes a significant decrease in microcirculatory blood flow of the jejunum, ileum, and colon was seen, when compared to the saline group $(\mathrm{P}<0.05$ or better). After sixty minutes, the jejunal and colonic microcirculation was still significantly reduced in the $\mathrm{FHb}$ infusion group (jejunum and colon: $\mathrm{FHb}$ vs. saline infusion, $\mathrm{P}<0.05$ ). These data indicate a deleterious effect of $\mathrm{FHb}$ on intestinal microcirculatory blood flow.

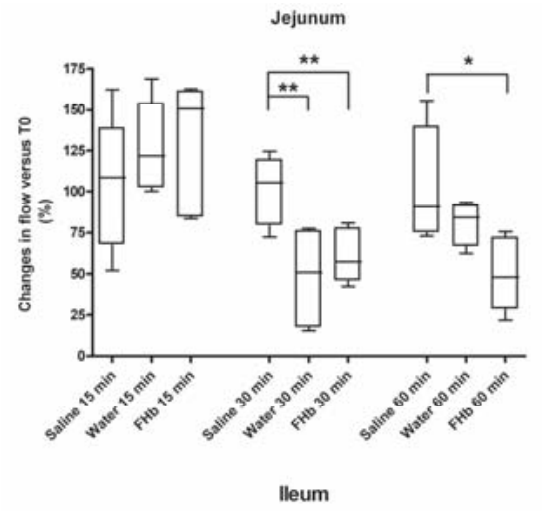

Figure 6.2. Decreased intestinal microcirculatory blood flow after water and $\mathrm{FHb}$ infusion. The gut was divided in three sections: jejunum, ileum and colon. Basal flow was set at $100 \%$ for all groups at T0. In both the water infusion group as well as in the $\mathrm{FHb}$ infusion group the microcirculation decreased. After infusion of saline, the microcirculatory blood flow remained around $100 \%$ in the saline group. Changes in time in microcirculatory blood flow are presented at T15, T30 and T60 and compared with the saline infusion group. ${ }^{*} \mathrm{P}<0.05 ; * * \mathrm{P}<0.01$
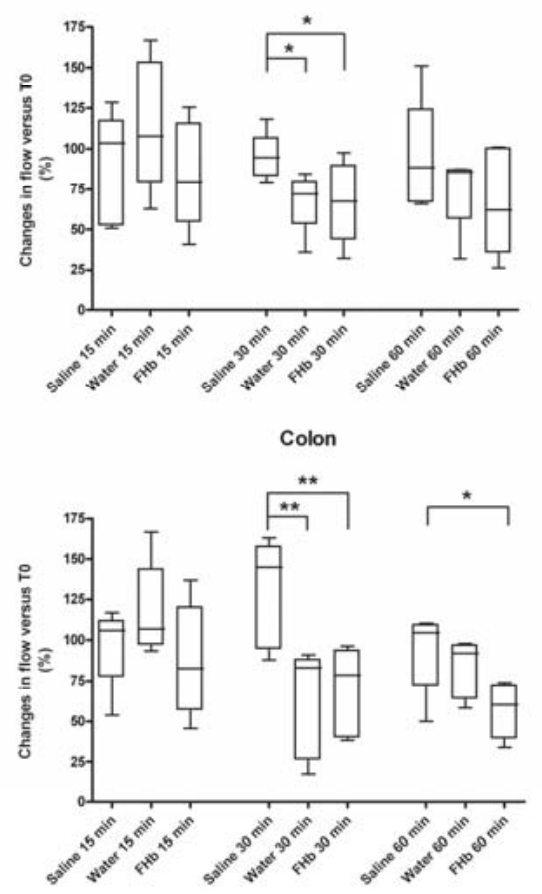


\section{Intestinal injury during elevated circulating FHb levels}

Release of iLBP: ILBP levels before infusion were comparable in all groups (Figure 6.3). Interestingly, at the time of reduced microcirculatory blood flow, at 30 and 60 minutes, plasma iLBP levels were significantly elevated in both the water and $\mathrm{FHb}$ infusion group (peak values 20.6 (4.4) ng/mL and 16.1 (2.5) ng/mL, respectively). Moreover, the AUC for plasma FHb levels correlated significantly with the AUC for iLBP release $(r=0.72, P=0.001)$, indicating a strong association between hemolysis and intestinal injury.

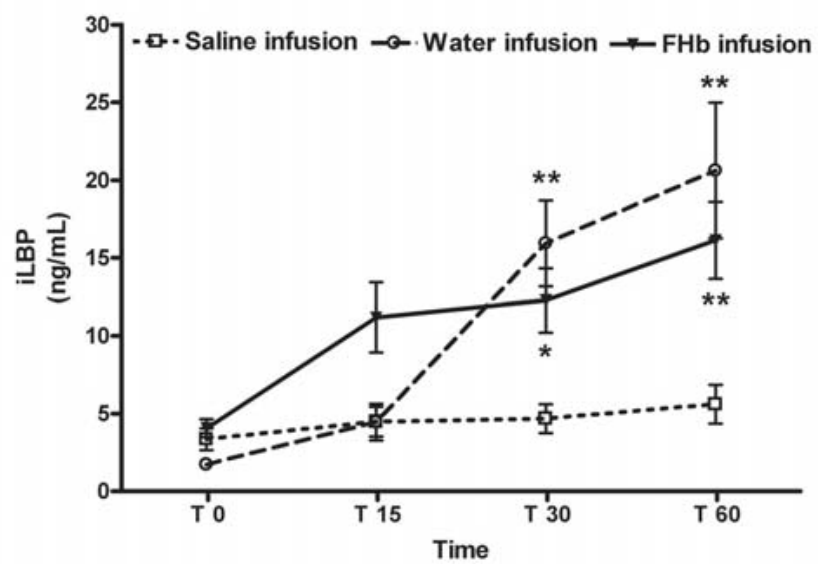

Figure 6.3. Hemolysis is associated with intestinal injury. The infusion of water and FHb led to a rapid and significant release of ileal lipid binding protein (iLBP), a cytosolic protein mainly present in the ileum and expressed in mature enterocytes. ${ }^{*} \mathrm{P}<0.05 ;{ }^{*} \mathrm{P}<0.001$

\section{Histological analysis for intestinal injury}

Histological analysis (Figure 6.4) showed subepithelial spaces and injury at the tip of the villi in both the water infusion and $\mathrm{FHb}$ infusion group, but not in the saline infusion group. Immunohistochemical staining of the ileum show subepithelial spaces positive for iLBP in both the water and FHb infusion group, indicating that iLBP had leaked from epithelial cells. These data show epithelial cell injury of the gut. No staining was observed in control sections (data not shown). 


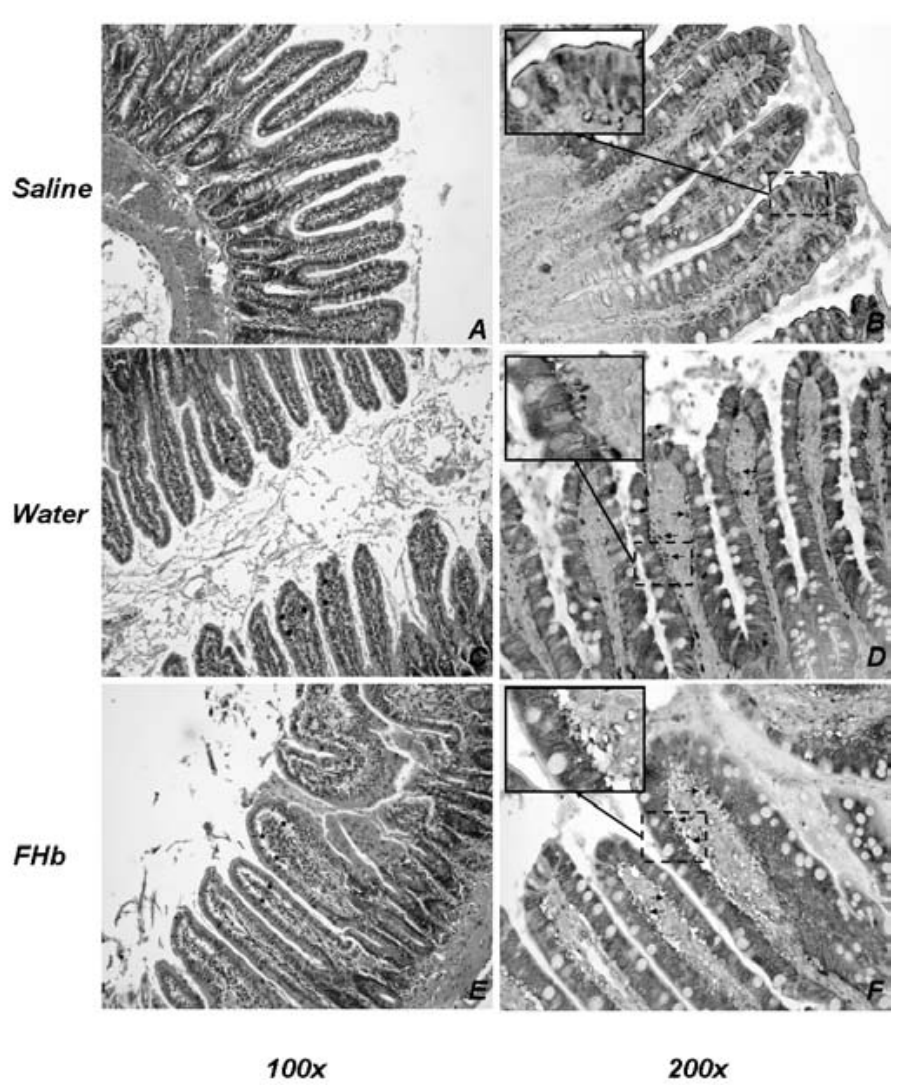

Figure 6.4. Histological and immunohistochemical evaluation of intestinal injury. Histological evaluation of the ileum was performed using $\mathrm{HE}$ staining $(\mathbf{A}, \mathbf{C}$, and $\mathbf{E})$. When compared to the saline group, water and $\mathrm{FHb}$ infusion led to the development of subepithelial spaces (see ${ }^{*}$ ) in the villi. In support of the findings of plasmatic release of iLBP, immunohistochemical analysis of the ileum shows cytosolic staining for iLBP in the epithelial cells of the upper part of the villi (B). Leaking of iLBP in the subepithelial spaces (see arrows), indicates intestinal epithelial cell injury after water or FHb infusion (D, F). Insets, show 400x magnification of selected areas where staining of iLBP can be seen outside the intestinal epithelial cellular membrane, indicating epithelial cellular injury (D, F). See page 169 for color figure.

\section{Discussion}

Taken together, these data show that elevated plasma levels of circulating FHb, as occurs during intravascular hemolysis, decrease intestinal microcirculation and result in intestinal injury, seen by the release of iLBP and confirmed immunohistochemically.

Our animal model was designed after a canine model of Minneci et al. to study the effects of water infusion induced intravascular hemolysis on NO-bioavailability and hemodynamic variables as model for chronic hemolysis as occurs in sickle-cell 
anemia. ${ }^{11}$ Our infusion protocol was adjusted to reach plasma FHb levels comparable to those found during cardiovascular surgery in our University Medical Center (Figure 6.1). ${ }^{8}$ The observed decreased microcirculatory blood flow at 30 minutes (Figure 6.2) suggests a rapid exhaustion of $\mathrm{FHb}$ scavenger proteins (haptoglobin, $\mathrm{CD}$ 163). ${ }^{15}$ The reduction in microcirculatory blood flow was less pronounced after sixty minutes in both the water and $\mathrm{FHb}$ infusion group. This might be explained by the gradual upregulation of heme catabolizing enzymes (HO-1, biliverdin reductase) ${ }^{16,17}$ or enhanced NO generating systems (NOS I, II and III), ${ }^{18,19}$ through either enhancing $\mathrm{FHb}$ clearance or counteracting the deleterious effects of $\mathrm{FHb}$, respectively.

Intestinal damage, assessed by intestinal fatty acid binding proteins such as iLBP (Figure 6.3), has been reported previously in cardiovascular surgical patients. ${ }^{2,5}$ To the authors' best knowledge, so far no studies have been performed to evaluate a possible correlation between $\mathrm{FHb}$ and gastrointestinal injury in clinical or experimental studies. Recently, we have shown that intestinal epithelial cell injury occurring during and after major cardiovascular is associated with a systemic inflammatory response. ${ }^{20}$ It is tempting to speculate that $\mathrm{FHb}$ plays a role in the development of intestinal and also renal injury in such patients, where levels of circulating $\mathrm{FHb}$ are found comparable or even higher than those reached in this study. ${ }^{20,}{ }^{21}$ Acute gastrointestinal complications after cardiovascular surgery are known to result in a complicated postoperative period and are associated with high mortality rates. In a current study, we show that the concentrations of plasma $\mathrm{FHb}$ and urine $\mathrm{N}$-acetyl glucosaminidase levels increased during extracorporeal bypass-assisted cardiovascular surgery, which indicates that hemolysis and tubular epithelial injury occurred. Interestingly, we found that the total release of plasma $\mathrm{FHb}$ was independently correlated with urine NAG, which in turn was independently associated with the postoperative increase in serum creatinine ${ }^{21}$ used as marker for acute kidney injury.

Taken together, our data suggest that circulating $\mathrm{FHb}$ is not only a health risk in chronic diseases such as sickle-cell anemia, thalassemia and malaria, but rather may be a cause for concern in patients subject to extracorporeal circulation, blood transfusion and cell salvage devices resulting in substantial acute hemolysis. Therefore, circulating $\mathrm{FHb}$ levels should be closely monitored in clinical practice when treating these patients, who are at risk at developing gastrointestinal complications. Future studies are needed to develop means to counteract the deleterious effects of circulating $\mathrm{FHb}$. 


\section{Acknowledgements}

The authors wish to thank Dian Kuipers (Department of Surgery, Maastricht University Medical Center, the Netherlands) for laboratory assistance and dr. Jan Serroyen (Department of Methodology and Statistics, Maastricht University Medical Center, the Netherlands) for critical revision of the statistical analyses used in this study.

\section{References}

1 Halm MA. Acute gastrointestinal complications after cardiac surgery. Am J Crit Care 1996; 5:109-118.

2 Welborn MB, Oldenburg HS, Hess PJ, et al. The relationship between visceral ischemia, proinflammatory cytokines, and organ injury in patients undergoing thoracoabdominal aortic aneurysm repair. Crit Care Med 2000; 28:3191-3197.

3 Achouh PE, Madsen K, Miller CC, 3rd, et al. Gastrointestinal complications after descending thoracic and thoracoabdominal aortic repairs: a 14-year experience. J Vasc Surg 2006; 44:442-446.

4 Filsoufi F, Rahmanian PB, Castillo JG, et al. Predictors and outcome of gastrointestinal complications in patients undergoing cardiac surgery. Ann Surg 2007; 246:323-329.

5 Morariu AM, Loef BG, Aarts LP, et al. Dexamethasone: benefit and prejudice for patients undergoing on-pump coronary artery bypass grafting: a study on myocardial, pulmonary, renal, intestinal, and hepatic injury. Chest 2005; 128:2677-2687.

6 Tao W, Zwischenberger JB, Nguyen TT, et al. Gut mucosal ischemia during normothermic cardiopulmonary bypass results from blood flow redistribution and increased oxygen demand. J Thorac Cardiovasc Surg 1995; 110:819-828.

7 Ohri SK, Velissaris T. Gastrointestinal dysfunction following cardiac surgery. Perfusion 2006; 21:215223.

8 Fransen EJ, Ganushchak YM, Vijay V, et al. Evaluation of a new condensed extra-corporeal circuit for cardiac surgery: a prospective randomized clinical pilot study. Perfusion 2005; 20:91-99.

9 Nishiyama T, Hanaoka K. Free hemoglobin concentrations in patients receiving massive blood transfusion during emergency surgery for trauma. Can J Anaesth 2000; 47:881-885.

10 Serrick CJ, Scholz M, Melo A, et al. Quality of red blood cells using autotransfusion devices: a comparative analysis. J Extra Corpor Technol 2003; 35:28-34.

11 Minneci PC, Deans KJ, Zhi H, et al. Hemolysis-associated endothelial dysfunction mediated by accelerated NO inactivation by decompartmentalized oxyhemoglobin. J Clin Invest 2005; 115:3409-3417.

12 Rother RP, Bell L, Hillmen P, Gladwin MT. The clinical sequelae of intravascular hemolysis and extracellular plasma hemoglobin: a novel mechanism of human disease. Jama 2005; 293:1653-1662.

13 Cruz-Landeira A, Bal MJ, Quintela, Lopez-Rivadulla M. Determination of methemoglobin and total hemoglobin in toxicological studies by derivative spectrophotometry. J Anal Toxicol 2002; 26:67-72.

14 Prinzen FW, Bassingthwaighte JB. Blood flow distributions by microsphere deposition methods. Cardiovasc Res 2000; 45:13-21.

15 Schaer DJ, Schaer CA, Buehler PW, et al. CD163 is the macrophage scavenger receptor for native and chemically modified hemoglobins in the absence of haptoglobin. Blood 2006; 107:373-380.

16 Yamazaki H, Ohta K, Tsukiji H, et al. Corticosteroid enhances heme oxygenase-1 production by circulating monocytes by up-regulating hemoglobin scavenger receptor and amplifying the receptormediated uptake of hemoglobin-haptoglobin complex. Biochem Biophys Res Commun 2007; 358:506-512.

17 Loboda A, Jazwa A, Grochot-Przeczek A, et al. Heme oxygenase-1 and the vascular bed: from molecular mechanisms to therapeutic opportunities. Antioxid Redox Signal 2008; 10:1767-1812. 
18 Dasgupta T, Hebbel RP, Kaul DK. Protective effect of arginine on oxidative stress in transgenic sickle mouse models. Free Radic Biol Med 2006; 41:1771-1780.

19 Hsu LL, Champion HC, Campbell-Lee SA, et al. Hemolysis in sickle cell mice causes pulmonary hypertension due to global impairment in nitric oxide bioavailability. Blood 2007; 109:3088-3098.

20 Hanssen SJ, Derikx JP, Vermeulen Windsant IC, et al. Visceral injury and systemic inflammation in patients undergoing extracorporeal circulation during aortic surgery. Ann Surg 2008; 248:117-125.

21 Vermeulen Windsant IC, Snoeijs MG, Hanssen SJ, et al. Hemolysis is associated with acute kidney injury during major aortic surgery. Kidney Int 2010; 77:913-920. 
<smiles>C=C=C</smiles> 
Chapter 7

\section{NO-Ventilation Attenuates the Deleterious Effects of Cell-Free Hemoglobin on Microcirculatory Blood Flow and Injury in the Kidney}

Sebastiaan J. Hanssen, Marlies Oostendorp, Tim Lubbers, Eduardo Villamor, Walter H. Backes, Carine J. Peutz-Kootstra, Wim A. Buurman, Michael J. Jacobs

This chapter has been submitted for publication. 


\section{Abstract}

Background and objectives Intravascular hemolysis during cardiovascular surgery leads to elevated levels of circulating cell-free hemoglobin (FHb). FHb has been shown to scavenge endothelial nitric oxide (NO), potentially reducing NObioavailability and compromising renal microcirculatory blood flow, triggering acute kidney injury (AKI). The potential role of $\mathrm{FHb}$ on renal microcirculation and inducing AKI was evaluated in an animal model enduring elevated circulating $\mathrm{FHb}$ levels similar to those found in the clinical setting of cardiovascular surgery, with and without $\mathrm{FHb}$-inactivating NO-inhalation.

Design, setting, animals, and measurements Changes in renal microcirculatory blood flow in response to elevated $\mathrm{FHb}$ levels with and without $\mathrm{FHb}$-inactivating NO-inhalation were assessed using fluorescent microspheres in rats. AKI was evaluated by measuring urinary $N$-acetyl glucosaminidase (NAG) and by histological evaluation of the kidneys. Hypoxemia of the kidneys during elevated circulating $\mathrm{FHb}$ levels was calculated using Blood Oxygen Level Dependent Magnetic Resonance Imaging (BOLD-MRI).

Results $\mathrm{FHb}$ reduced renal microcirculatory blood flow significantly, leading to renal hypoxemia. Increased urinary NAG depicted the development of AKI, at the level of proximal tubular epithelial cells, which was associated with circulating $\mathrm{FHb}$ levels ( $\mathrm{P}$ $=0.0026$ ). The histological findings confirmed the biochemical and BOLD-MRI results. Interestingly, the development of AKI was attenuated by FHb-inactivating NOinhalation.

Conclusions These data support a mechanism of AKI development in an FHbdependant way and reveal NO-inhalation to be a potential therapeutic option to reduce $\mathrm{AKI}$ during elevated circulating $\mathrm{FHb}$ levels. 


\section{Introduction}

Acute kidney injury (AKI) develops, depending on the specific definition used, in up to $30 \%$ of patients undergoing elective major cardiovascular surgery of which $1-5 \%$ requires (temporary) dialysis. ${ }^{1-5}$ AKI after cardiovascular surgery is feared as this is associated with high patient morbidity and mortality rates. ${ }^{6,7}$ Risk factors for developing AKI after cardiovascular surgery include age, female gender, reduced left ventricular function or the presence of congestive heart failure, diabetes mellitus, peripheral vascular disease, chronic obstructive pulmonary disease, decreased preoperative kidney function, the need for emergent surgery, the use of extracorporeal circulation, hemodilution and factors associated with cardiovascular surgery, such as aortic cross clamp time and duration of extracorporeal circulation. ${ }^{1-7}$ The proposed pathophysiological mechanism that underlies AKI is most likely acute tubular necrosis, which can be caused by several preoperative, intraoperative- and postoperative features; chronic kidney disease, renovascular disease, nephrotoxic drugs, decreased renal perfusion, embolic events, systemic inflammation and sepsis probably contribute, alone or in combination, to the pathophysiology of acute tubular necrosis. ${ }^{5}$

There is a body of evidence that cardiovascular surgery is associated with considerable injury to red blood cells resulting in hemolysis. The use of extracorporeal circulation, donor blood transfusion and/or cell salvage devices inevitably leads to increased circulating levels of cell-free hemoglobin (FHb). ${ }^{8-10} \mathrm{FHb}$ is known, due to its iron containing moieties, as a nephrotoxin ${ }^{11}$; More recently circulating $\mathrm{FHb}$ has been shown to be a scavenger of the vasodilator nitric oxide (NO), thereby perturbing microcirculatory blood flow, which might result in organ injury. ${ }^{12-16}$ In addition, endothelial NO deficiency can lead to vascular oxidative injury and proliferation, since NO is also an antioxidant and antiproliferative molecule. ${ }^{17,18}$ In a previous study we have shown that the concentrations of plasma $\mathrm{FHb}$ levels and urinary tubular epithelial cell injury marker $\mathrm{N}$-acetyl glucosaminidase (NAG) levels both increased during cardiovascular surgery. ${ }^{19}$ Interestingly, an independent correlation between the total release of plasma FHb and urinary NAG was found, which in turn was independently associated with the postoperative increase in serum creatinine, used as marker for AKI. Therefore, we hypothesized that intravascular FHb release compromises renal blood flow, resulting in hypoperfusion and hypoxia of the kidney, and consequently induces AKI.

Aim of the present study was to evaluate renal blood flow and renal tubular epithelial cell injury in rats exposed to elevated circulating FHb levels, with and without NO-inhalation. NO-inhalation was used to study the NO scavenging capacities of circulating $\mathrm{FHb}$. To this end, we developed an animal model that yields plasma levels of $\mathrm{FHb}$, similar to levels found during cardiovascular surgery. ${ }^{19}$ The potential influence of circulating $\mathrm{FHb}$ with or without NO-inhalation on renal micro- 
circulation was studied using fluorescent microspheres. Changes in renal oxygenation were evaluated using Blood Oxygen Level Dependent Magnetic Resonance Imaging (BOLD-MRI). Urinary NAG and histopathological parameters of renal tubular injury were assessed to depict the extent of AKI.

\section{Methods}

\section{Animal model}

The Animal Ethics Committee of the Maastricht University Medical Center, the Netherlands approved the study. The study was performed according to the guide for the care and use of laboratory animals at our institution. Male Sprague-Dawley (SD) rats, weighing 450 - 500 g were purchased from Charles River Laboratories (Maastricht, the Netherlands) and housed under controlled conditions of temperature and humidity. Prior to the experiments, rats had free access to water and standard rodent chow.

\section{Generation and Measurement of FHb}

To generate $\mathrm{FHb}$ for infusion, fresh whole blood samples were obtained from SD rats through aortic punction one day prior to intervention and processed as described previously. ${ }^{16}$ The final FHb stock concentration was adjusted with sterile saline to reach $300 \mu \mathrm{M} \mathrm{FHb}$ which was used for infusion. FHb concentrations for infusion, as well as plasma values, were measured by derivative spectrophotometry. $^{20}$

\section{Experimental Design}

Anesthesia was induced with $4 \%$ isoflurane and maintained at $2 \%$ during the studies. The left femoral vein was used to infuse either $\mathrm{FHb}$ or sterile saline.

First, two groups ( $N=6$ per group) were included to validate the infusion protocol. One group received $\mathrm{FHb}$ infusion (prime $0.65 \mathrm{~mL} / 100 \mathrm{~g}$. BW, continuous infusion $1.3 \mathrm{~mL} / 100 \mathrm{~g}$. BW / hour), whereas the control group received similarly saline infusion.

Next, we evaluated renal microcirculatory blood flow, renal tubular cell injury and oxygenation of the kidneys during $\mathrm{FHb}$ and saline infusion, with or without inhalation of NO. Therefore, another 4 groups ( $N=6$ per group) were included. After anesthesia induction animals were subjected to $\mathrm{FHb}$ infusion, $\mathrm{FHb}$ infusion with NO-inhalation, saline infusion or saline infusion with NO inhalation. Anesthesia and infusion protocols were the same as in the first study. 


\section{Assessment of Microcirculatory Blood Flow using Microspheres}

Infusion of fluorescent microspheres (colors: yellow, lemon, orange, and persimmon; diameter $15 \mu \mathrm{m}, 1 \times 10^{6}$ microspheres/mL (Dye-Trak ${ }^{\circledR}$, Triton Technology, San Diego, CA)) and calculation of organ blood flow for both kidneys was performed as described previously. ${ }^{21,22}$ For microspheres infusion purposes, the right femoral artery was cannulated with a cannule $(P E-10,11 \mathrm{~cm})$ that was placed in the aortic arch. The flow before the experimental protocol started (first microsphere infusion at T0) was set at $100 \%$ and the percentage renal flow change during the experiments was calculated for each individual subject after fifteen, thirty and sixty minutes (T15, T30, and T60, respectively).

\section{Nitric Oxide Inhalation}

NO gas (Linde Gas Benelux, Schiedam, the Netherlands) was introduced into the inspiratory limb of the ventilation circuit via a regulated flow meter to yield inspired concentrations of $40 \mathrm{ppm}$, which was continuously monitored with a CLD $700 \mathrm{AL}$ chemiluminescence analyzer (Eco Physics, Dürnten, Switserland). NO inhalation was performed in two out of four experimental groups i.e. during $\mathrm{FHb}$ infusion $(\mathrm{N}=6)$ or saline infusion $(\mathrm{N}=6)$.

\section{BOLD-MRI}

All animals underwent blood oxygen level dependent MR imaging (BOLD-MRI) during the experimental protocol. BOLD-MRI reflects changes in the apparent transverse relaxation rate $\left(R_{2}{ }^{*}\right)$. Due to the paramagnetic nature of deoxyhemoglobin, increased $R_{2}{ }^{*}$ values indicate a decreased tissue oxygenation. ${ }^{23}$ Experiments were performed on a dedicated 7.0 Tesla small animal imaging system (Bruker Biospec 70/30 USR, Bruker Biospin, Karlsruhe, Germany). BOLD measurements were performed using a multi-slice, multi-gradient echo sequence using the following parameters: $\mathrm{TR}=770 \mathrm{~ms}$, TE $=4.0,9.3,14.6,19.8,25.1,30.4,35.6,40.9,46.2$, and 51.5 $\mathrm{ms}, \mathrm{FA}=30$ - 4 signal averages, matrix 256x256, FOV $4 \times 4 \mathrm{~cm}^{2}$. On average, 191.0 $\mathrm{mm}$ thick axial slices were acquired covering both kidneys. Measurements were performed continuously throughout the experimental procedure. Signal intensity versus echo time curves were fitted with a non-linear Levenberg-Marquadt optimization algorithm in Matlab (Matlab version 7.04, The MathWorks, Natick, MA) to the gradient echo signal intensity function $S=S_{0} \exp \left(-T E R_{2}{ }^{*}\right)$ to generate $R_{2}{ }^{*}$ maps on a voxel-by-voxel basis. Three slices in the center of the kidney were selected to draw regions of interest (ROI) on the maps. Blood vessels were excluded from the ROIs and mean $R_{2}{ }^{*}$ (SEM) was calculated. ${ }^{24}$ BOLD-MRI measurements were performed continuously in each individual animal. 


\section{Evaluation of kidney injury}

To study kidney injury, urinary NAG was determined at the end of the experiments. NAG is a lysosomal brush border enzyme of proximal renal tubular epithelial cells. ${ }^{25}$ NAG concentrations were determined using a colorimetric assay according to manufacturer's instructions (HaemoScan, Groningen, the Netherlands) and corrected for urinary creatinine levels. After sacrifice, urine was collected via bladder puncture and tissue samples from the kidneys were fixed in formaldehyde and embedded in paraffin wax. For morphological evaluation, deparaffinized $3 \mu \mathrm{m}$ sections were stained PAS+ and evaluated for tubular dilatation and cast formation on a five-point scale according to Leemans et al. ${ }^{26}$ by a pathologist blinded for the study protocol. Since the time-frame between infusion and tissue sample processing was short $1<$ one hour and a half), tubular necrosis, brush-border loss and neutrophil influx were evaluated but not scored, as these manifestations of AKI are seen much later after ischemic kidney injury.

\section{Statistics}

Continuous variables are shown as mean ( \pm SEM) or box and whiskers showing the median, $25^{\text {th }}$ and $75^{\text {th }}$ percentiles, when appropriate. Two-way ANOVA with Bonferroni post-test correction was used to evaluate statistical differences in plasma $\mathrm{FHb}$ levels between the different groups. To test for differences between changes in microcirculatory blood flow, tubular dilation and cast formation, and changes in $\mathrm{R}_{2}{ }^{*}$, two-tailed unpaired T-test with Welch's correction was used. To assess a possible association between plasma FHb and urinary NAG release, Pearson correlation analysis between areas under the curve (AUC) of FHb and NAG was used.

\section{Results}

\section{Circulating FHb levels}

Oxygenated-FHb was infused in rats to generate a model of circulating $\mathrm{FHb}$ with levels ranging between $19.8(0.9) \mu \mathrm{M}$ and $32.6(2.8) \mu \mathrm{M}$. These levels are comparable to those found during and after cardiovascular surgery. ${ }^{8,19}$ Shortly after initiation of $\mathrm{FHb}$ infusion the $\mathrm{FHb}$ levels were significantly elevated compared to the saline infusion group (Figure 7.1; $\mathrm{P}<0.001$ between groups). 


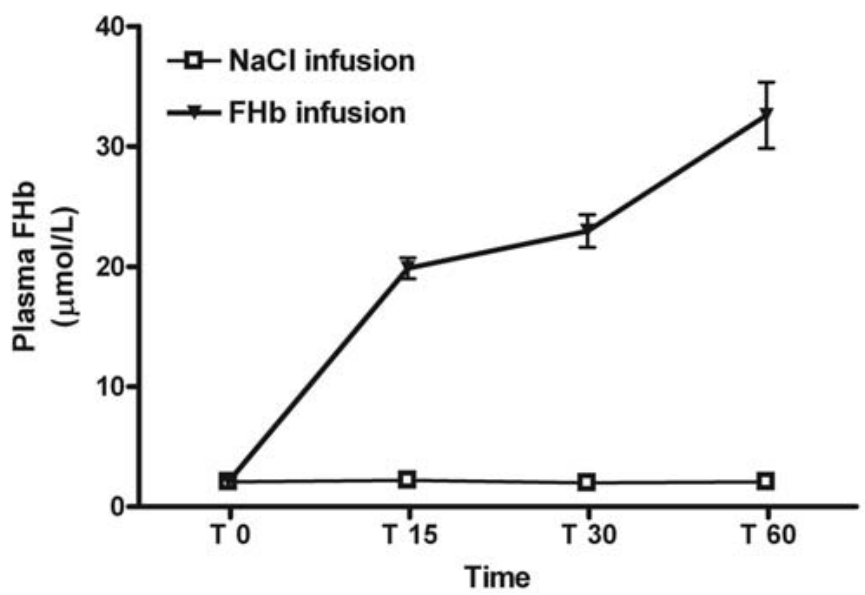

Figure 7.1. Circulating FHb levels during intravenous infusion of FHb or saline. To generate a model with elevated circulating $\mathrm{FHb}$ levels, either $\mathrm{FHb}$ or saline (control group) was infused into the left femoral vein. After infusion with $\mathrm{FHb}$, a rapid significant increase in circulating $\mathrm{FHb}$ levels was reached, comparable to levels found in patients during cardiovascular surgery with extracorporeal circulation at our university hospital. 2-way ANOVA revealed a statistically significant difference between both groups $(\mathrm{P}<0.001)$. Data represent mean (SEM).

\section{Renal microcirculatory blood flow}

To study changes in renal microcirculatory blood flow during elevated circulating $\mathrm{FHb}$ levels, fluorescent microspheres were infused at several time-points. The microcirculatory blood flow measured before infusion started was set at $100 \%$ (Figure 7.2). Interestingly, a significant reduction in mean (SEM) microcirculatory blood flow to $62(10) \%$ was observed after fifteen minutes FHb infusion, whereas microcirculatory blood flow in the saline infusion group remained $98(9) \%(P<0.05$ between groups). After thirty minutes of FHb infusion the microcirculatory blood flow had decreased considerably to 39 (4) \%, whereas the renal microcirculation in the saline infusion group remained stable at $99(8) \%(P<0.0001$ between groups). The effect of reduced renal microcirculatory blood flow was still observed after sixty minutes of FHb infusion (T60, FHb infusion 44 (4) \% vs. saline infusion 95 (6) \%; P $<0.001$ ).

NO-inhalation of the $\mathrm{FHb}$ infusion group resulted in significantly enhanced renal microcirculation when compared to FHb infusion alone (T30; 106 (9) \% vs. 39 (4) \%, respectively; $\mathrm{P}<0.001)$, showing improved renal microcirculation by inhalation of $\mathrm{NO}$ in the presence of circulating FHb. Inhalation of NO during FHb infusion still resulted in enhanced renal microcirculatory blood flow after sixty minutes whencompared to $\mathrm{FHb}$ infusion alone (T60; 101 (10) \% vs. 44 (4) \%, respectively; P < 0.01). Infusion of saline in combination with NO-inhalation resulted in an enhanced 


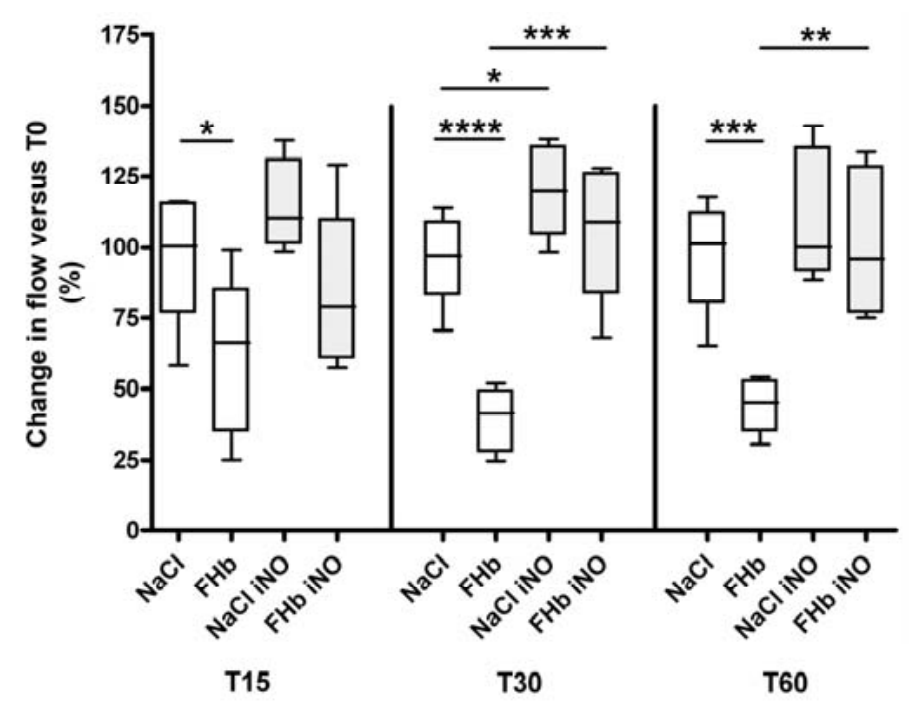

Figure 7.2. Changes in renal microcirculatory blood flow during elevated circulating FHb levels, with or without NO-inhalation. Intravascular FHb resulted in decreased renal microcirculatory blood flow, compared to the control group with saline infusion, where microcirculatory blood flow remained unaltered throughout infusion. The reduction in microcirculation during $\mathrm{FHb}$ infusion was eminent after 15 minutes and further decreased as the infusion continued. NO-inhalation was used to test NO-scavenging capacities of circulating $\mathrm{FHb}$. NO-inhalation during elevated levels of $\mathrm{FHb}$ resulted in a significantly enhanced microperfusion of the kidney after 30 minutes and onwards when compared to FHb infusion alone, indicating that $\mathrm{NO}$-inhalation attenuated the $\mathrm{FHb}$-induced reduction in renal microcirculatory blood flow. Infusion of saline in combination with NO-inhalation resulted in a temporarily enhanced microcirculation of the kidney after thirty minutes compared to saline infusion alone, though no difference in renal microcirculation could be detected between $\mathrm{FHb}$ and saline infusion with NO inhalation after thirty and sixty minutes.

Data are presented as median with box and whiskers. Mean (SEM) is given in the text (see Results section). ${ }^{*} \mathrm{P}<0.05 ; * * \mathrm{P}<0.01 ; * * * \mathrm{P}<0.001 ; * * * * \mathrm{P}<0.0001$

microcirculation of the kidney compared to saline infusion alone after thirty minutes (T30; 120 (6) \% vs. 96 (6) \%, respectively; P< 0.05). However, no difference in renal microcirculatory blood flow was seen between $\mathrm{FHb}$ and saline infusion when combined with NO inhalation, indicating equally adequate renal perfusion at T30 and T60.

Interestingly, these data indicate that elevated circulating levels of FHb lead to a significant and substantial reduction in renal microcirculatory blood flow, whereas inhalation of NO during elevated circulating FHb levels abrogates this effect and improves renal microcirculation.

\section{BOLD-MRI analysis of the kidney}

To study the oxygenation of the kidneys during elevated circulating FHb levels and reduced renal microcirculatory blood flow, the BOLD-MRI technique was used. 
BOLD-MRI data were processed to calculate mean (SEM) $R_{2}{ }^{*}$ values over both kidneys (Figure 7.3), which increased and revealed significant hypoxia of the kidney when $\mathrm{FHb}$ infusion was compared to $\mathrm{NaCl}$ infusion (53.0 (1.7) $\mathrm{s}^{-1}$ vs. 47.9 (0.8) $\mathrm{s}^{-1} ; \mathrm{P}<$ 0.01). These data, for the first time, show a decreased renal oxygenation due to elevated circulating FHb levels.

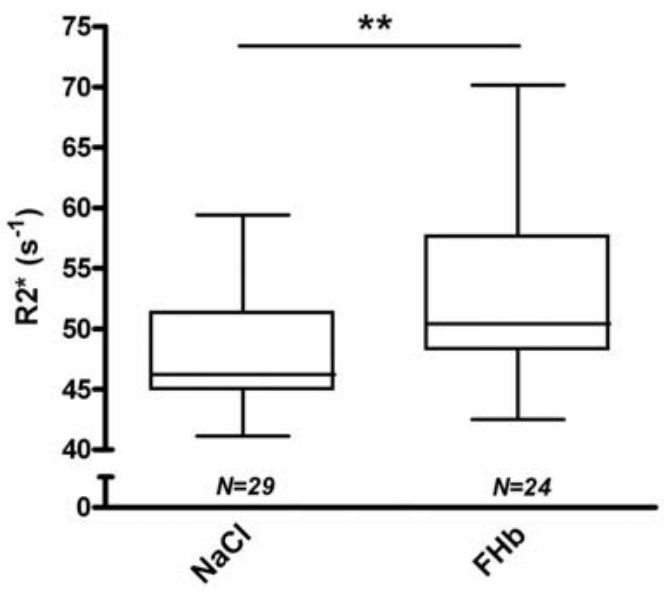

Figure 7.3. BOLD-MRI measurements reveal renal hypoxemia during $\mathrm{FHb}$ infusion. BOLD-MRI measurements were used to calculate $\mathrm{R}_{2}{ }^{*}$-values representing the degree of renal hypoxemia. $\mathrm{FHb}$ infusion led to a significant increase in renal hypoxemia, when compared to saline infusion.

Data are median, with box and whiskers. $* * \mathrm{P}<0.01$

\section{Hemolysis and kidney injury}

To evaluate kidney injury, urinary NAG (U/mmol Creat) was measured at the end of the infusion protocol (Figure 7.4A). Infusion of FHb led to a significant increase of urinary NAG release, indicating proximal renal tubular cell injury of the kidney $(P<$ 0.01). Pearson correlation analysis of area under the curve for FHb release and NAG between these groups revealed a significant association $(r=0.78, P=0.0026)$ between both parameters (data not shown). FHb inactivation through NO-inhalation significantly reduced urinary NAG release $(P<0.01)$. Although a significant reduction in urinary NAG release was seen, urinary NAG release during FHb infusion with inhalation of NO was still significant when compared to saline infusion with inhalation of NO, but not compared to saline infusion alone.

A pathologist blinded for the study protocol performed morphological evaluation of the kidney by scoring tubular dilatation and cast deposition in tissue samples (Figure 7.4B). No significant differences in tubular dilatation were seen between groups. Cast deposition was significantly increased in the group with $\mathrm{FHb}$ infusion when compared to the control group with $\mathrm{NaCl}$ infusion $(P<0.01)$. Moreover, cast formation was significantly reduced when $\mathrm{FHb}$ infusion was combined with inhalation of NO ( $P<0.05)$. The reduction in cast formation was significant, although cast formation in the group of $\mathrm{FHb}$ with inhalation of $\mathrm{NO}$ was still higher when compared to $\mathrm{NaCl}$ infusion with inhalation of $\mathrm{NO}(\mathrm{P}<0.01)$, but not compared to $\mathrm{NaCl}$ infusion 
alone. No tubular necrosis, brush-border loss or neutrophil influx was seen in the tissue samples (data not shown).

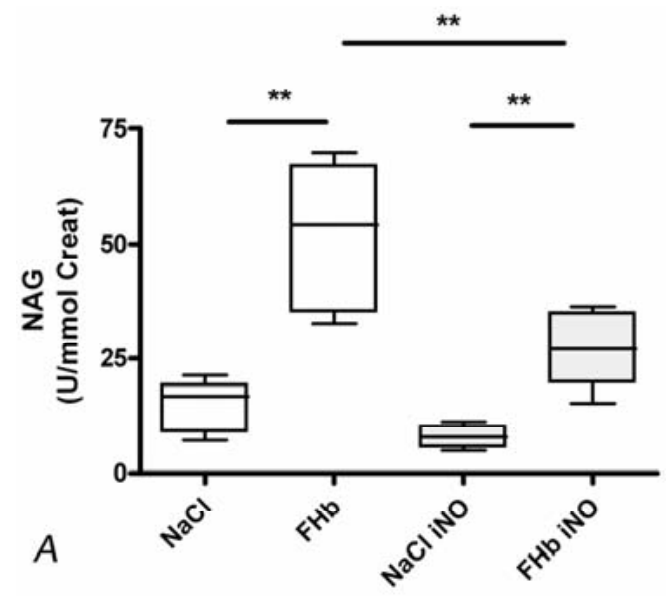

Figure 7.4. Kidney injury resulting from circulating $\mathrm{FHb}$ is attenuated by inhalation of NO. To assess potential acute kidney injury after elevated levels of circulating $\mathrm{FHb}$ with or without $\mathrm{FHb}$ inactivating NOinhalation, both urinary $\mathrm{N}$-acetyl glucosaminidase (NAG) and histological parameters of renal tubular injury were assessed. (A) Urinary NAG (U / mmol Creat) was significantly elevated after infusion of $\mathrm{FHb}$ when compared to saline infusion. A significant reduction was seen when $\mathrm{FHb}$ infusion was combined with $\mathrm{FHb}$ inactivating NO-inhalation. These results indicate that elevated circulating levels of $\mathrm{FHb}$ lead to AKI, which is reduced when $\mathrm{FHb}$ infusion is combined with inhalation of NO.

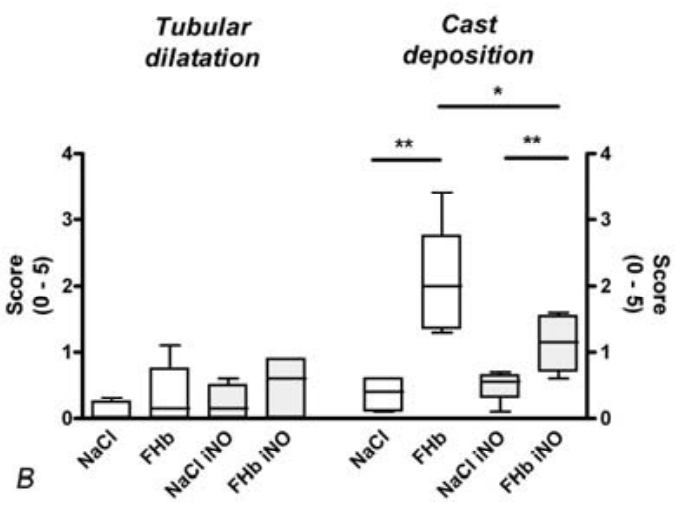

(B) Renal tubular cell injury was scored in PAS+ stained tissue samples from all animals. Ten areas on every tissue sample were evaluated for tubular dilatation and cast formation on a five-point scale according to Leemans et al. ${ }^{26}$ by a pathologist blinded for the study protocol. Tubular dilatation did not differ between groups. Significant cast formation was seen after $\mathrm{FHb}$ infusion and $\mathrm{FHb}$ infusion with NOinhalation when compared to saline infusion or saline infusion with inhalation of NO, respectively. Inhalation of NO significantly reduced cast formation after $\mathrm{FHb}$ inhalation compared to the cast formation after $\mathrm{FHb}$ infusion alone, indicating that NO-inhalation attenuated $\mathrm{FHb}$ induced acute renal tubular injury.

Data are expressed as mean (SEM). ${ }^{*} \mathrm{P}<$ $0.05 ; * * \mathrm{P}<0.01$

Microscopic photographs of the kidneys show cast deposition in the groups receiving $\mathrm{FHb}$ infusion (Figure 7.5). However, as described above and shown in Figure 7.4B, cast deposition was significantly less when NO-inhalation was applied.

Taken together, biochemical and histopathological evaluation revealed kidney injury after $\mathrm{FHb}$ infusion measured as urinary NAG release and morphological cast 
deposition, which were both attenuated by inactivation of circulating $\mathrm{FHb}$ using inhalation of NO.

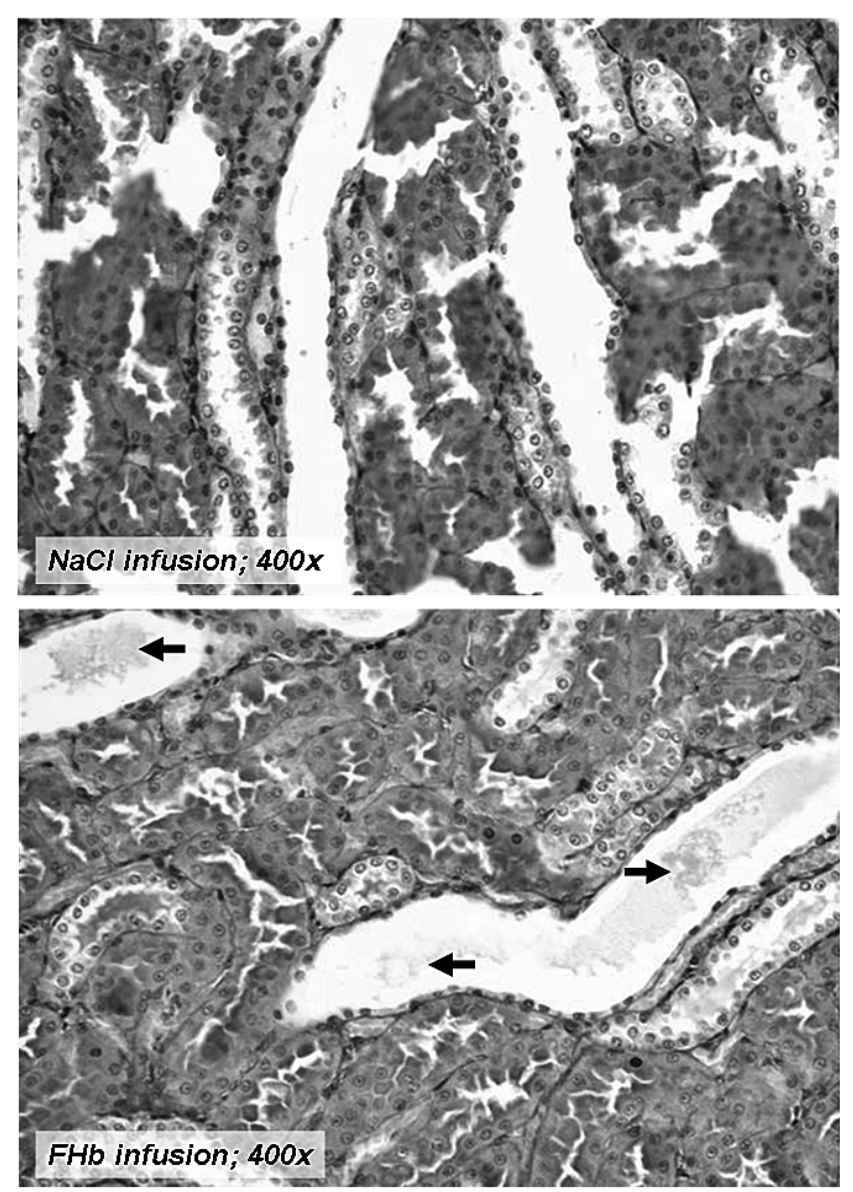

Figure 7.5. Kidney injury after elevated circulating FHb levels. Microscopic photographs to visualize kidney injury showed cast formation in renal tubules after $\mathrm{FHb}$ infusion (see arrows), but not after $\mathrm{NaCl}$ infusion. See page 170 for color figure.

\section{Discussion}

Our findings reveal a decreased renal microcirculatory blood flow due to elevated circulating levels of $\mathrm{FHb}$. This was accompanied by renal hypoxemia and resulted in kidney injury. Interestingly, the deleterious effects of FHb could be counteracted significantly by inhalation of FHb-inactivating $\mathrm{NO}$ gas in our animal model.

The infusion protocol used in this report was based on a previous study in dogs by Minecci et al., and adjusted to our rodent animal model, to achieve circulating 
$\mathrm{FHb}$ levels comparable to those found in the clinical setting of cardiovascular surgery with extracorporeal circulation. ${ }^{16,27}$ The $\mathrm{FHb}$-infusion protocol used rapidly resulted in significantly elevated levels of circulating $\mathrm{FHb}$ which are comparable to levels found during major aortic surgery. ${ }^{19}$

The increase in $\mathrm{FHb}$ levels resulted in a significantly and persisting reduced renal microcirculatory blood flow. Previous studies have shown a reduction in kidney function when elevated circulating levels of FHb are present, ${ }^{19,27-30}$ however, to the authors' best knowledge, this is the first time that $\mathrm{FHb}$ has been shown to reduce microcirculatory blood flow and oxygenation of the kidney. The microcirculatory blood flow of the kidney was evaluated with the microsphere technique, using the first microsphere infusion as basic organ flow. Dividing the kidney in medulla and cortex was technically not feasible in our rodent model, since the minimum amount of tissue needed to retrieve the microspheres was two grams or more, therefore no subdivision in different kidney regions was made. A larger animal model would make subdivision in medulla and cortex, and perhaps even inner- and outer parts of these regions possible. Voss et al. used fluorescent microsphere techniques to evaluate renal circulation during pulsatile and non-pulsatile extracorporeal perfusion for a period of aortic cross-clamping in pigs. ${ }^{31}$ The FHb levels measured were comparable to those used in this study, showing significant hemolysis in the pulsatile group. Interestingly, while aortic blood flow remained unchanged, renal blood flow was approximately $1.3-1.5$ fold lower during extracorporeal circulation and remained lower after cessation of extracorporeal circulation when compared to preextracorporeal circulation states. It is tempting to speculate that the extent of hemolysis would contribute to the observed reduction in renal blood flow during and after pulsatile extracorporeal circulation in that study as well. ${ }^{31}$ Hemolysis also results in release of the enzyme arginase-1, which converts L-arginine, the substrate for NO synthesis, to ornithine and polyamine production. ${ }^{32}$ This way, hemolysis causes not only scavenging of NO, but also theoretically prevents new NO formation. In practice, however, we showed that arginase-1 release during surgery with extracorporeal circulation does not affect the arginine-ornithine ratio (unpublished data). This implies that arginase levels during this type of surgery are not high enough to affect arginine levels and decrease NO-synthesis. ${ }^{33}$

NO-inhalation of $20 \mathrm{ppm}$ up to $80 \mathrm{ppm}$ is considered safe in patients with sickle cell disease. ${ }^{13,34}$ In this study, inhalation of NO 40 ppm was used to inactivate $\mathrm{FHb}$ in the pulmonary circulation and reduce its peripheral NO scavenging properties. First, we evaluated the effect of NO-inhalation on microcirculatory blood flow during saline infusion. Microcirculatory blood flow increased after thirty minutes, indicating enhanced renal blood flow. Next to oxidation of $\mathrm{FHb}$, inhalation of NO can result in the formation of relatively stable NO-species e.g. through S-nitrosylation of both cell-free deoxygenated-FHb and intracellular deoxyhemoglobin (SNO-Hb). ${ }^{35,}{ }^{36}$ Red blood cells containing SNO-Hb are believed to contribute to vasodilation through 
release of NO. SNO-Hb is rapidly depleted and the capacity of red blood cells to induce vasodilation significantly diminishes parallel to SNO-Hb depletion. ${ }^{36}$ A role for NO species such as SNO-Hb in our saline group is supported by the temporary increase in microcirculatory blood flow during saline infusion with NO-inhalation, suggesting the renal microperfusion is enhanced through extra-pulmonary effects of NO-inhalation. Also, Troncy et al. showed that inhaled NO increases porcine glomerular filtration rate in association with a modest increase in renal blood flow. ${ }^{37}$ NOinhalation during elevated circulating levels of $\mathrm{FHb}$ resulted in significantly enhanced renal microcirculatory blood flow when compared to FHb infusion alone. These experiments in which oxygenated circulating FHb reacts in the lung with NO, inactivating its peripheral NO scavenging properties support our hypothesis that reduced renal microcirculation is caused by NO scavenging through circulating $\mathrm{FHb}$; moreover, these data confirm previous reports on the $\mathrm{FHb}$-inactivating capacities of NO-donors such as NO-gas. ${ }^{15,27,38-44}$

The BOLD-MRI technique was used to objectify renal hypoxemia during the infusion protocols. BOLD-MRI measures the relative deoxygenation of red blood cells based on the paramagnetic properties of deoxyhemoglobin (ferrous hemoglobin, $\mathrm{HbFe}^{2+}$ ) as an indirect marker for tissue (de-)oxygenation. ${ }^{23}$ Higher $\mathrm{R}_{2}{ }^{*}$ levels were measured during the period of $\mathrm{FHb}$ infusion, indicating decreased renal oxygenation, when tissue injury was observed as well. Unfortunately, the BOLD-MRI technique is not useable following NO-inhalation due to the formation of intracellular methemoglobin (ferric hemoglobin, $\mathrm{HbFe}^{3+}$ ) and nitrate $\left(\mathrm{NO}_{3}{ }^{-}\right.$) from oxyhemoglobin (ferrous oxyhemoglobin, $\mathrm{HbFe}^{2+}-\mathrm{O}_{2}$ ) in the red blood cells. ${ }^{45}$ Red blood cells contain a physiologic redox potential in which methemoglobin is converted back into deoxyhemoglobin $\left(\mathrm{HbFe}^{2+}\right)$ by the $\mathrm{NADH}$-dependent cytochrome b5 reductase, ${ }^{46}$ which results in modulated $\mathrm{R}_{2}$ * values.

Interestingly, inhalation of NO in the experimental group with $\mathrm{FHb}$ infusion decreased kidney injury seen as a reduction in AKI markers NAG and tubular cast formation. Although the reduction in AKI was significant when compared to FHb infusion alone, there was still AKI present in the group receiving $\mathrm{FHb}$-infusion with NOinhalation. The application of inhaled NO as a therapeutic agent has been studied in neonates with hypoxemia and pulmonary hypertension and in patients with sickle cell disease, as was recently reviewed. ${ }^{43,47}$ So far, the effects of NO-inhalation on AKI in patients who endure elevated circulating $\mathrm{FHb}$ levels during cardiovascular surgery with extracorporeal circulation, remains to be established. Future patient studies are needed, although caution needs to be taken since prolonged inhalation of NO may promote tubular apoptosis. ${ }^{48}$ Furthermore, inhalation of NO is only one possibility of inactivating $\mathrm{FHb}$; haptoglobin infusion has been studied in the past, and efforts to enhance the NO donor pool are currently investigated. ${ }^{29,30,43,49}$

In conclusion, here we show a reduced renal microcirculatory blood flow accompanied by tissue hypoxemia and the induction of AKI in an FHb-dependent way. 
Furthermore, NO-inhalation has been shown to effectively reduce the deleterious effects of circulating $\mathrm{FHb}$ on peripheral NO scavenging, restoring renal microcirculatory blood flow and reducing the extent of AKI development. These data support a role for $\mathrm{FHb}$ in cardiovascular surgery with extracorporeal circulation, when elevated circulating levels of $\mathrm{FHb}$ with equal $\mathrm{NO}$ scavenging capacities can be expected. Unfortunately, AKI is still a major determinant of post-operative patient morbidity and mortality following cardiovascular surgery. 1, 5, 19, 50 Therefore, we propose that further studies are needed in man, to reduce circulating $\mathrm{FHb}$ or counteract its effects in this patient population.

\section{Acknowledgements}

This research was supported by the 'Profileringsfonds' Maastricht University Medical Center, the Netherlands and an AGIKO-stipendium 920-03-522 (to Tim Lubbers) from the Netherlands Organization for Health Research and Development.

The authors wish to thank Jos Slenter (Department of Radiology, Maastricht University Medical Center, the Netherlands) for expert assistance in and processing of the BOLD-MRI measurements. 


\section{References}

1. Conlon PJ, Stafford-Smith M, White WD, et al. Acute renal failure following cardiac surgery. Nephrol Dial Transplant 1999; 14:1158-1162.

2. Huynh TT, Miller CC, 3rd, Estrera AL, et al. Determinants of hospital length of stay after thoracoabdominal aortic aneurysm repair. J Vasc Surg 2002; 35:648-653.

3. Jacobs MJ, Eijsman L, Meylaerts SA, et al. Reduced renal failure following thoracoabdominal aortic aneurysm repair by selective perfusion. Eur J Cardiothorac Surg 1998; 14:201-205.

4. Rectenwald JE, Huber TS, Martin TD, et al. Functional outcome after thoracoabdominal aortic aneurysm repair. J Vasc Surg 2002; 35:640-647.

5. Rosner $\mathrm{MH}$, Portilla $\mathrm{D}$, Okusa MD. Cardiac surgery as a cause of acute kidney injury: pathogenesis and potential therapies. J Intensive Care Med 2008; 23:3-18.

6. Chertow GM, Levy EM, Hammermeister KE, et al. Independent association between acute renal failure and mortality following cardiac surgery. Am J Med 1998; 104:343-348.

7. Schepens MA, Kelder JC, Morshuis WJ, et al. Long-term follow-up after thoracoabdominal aortic aneurysm repair. Ann Thorac Surg 2007; 83:S851-855; discussion S890-852.

8. Fransen EJ, Ganushchak YM, Vijay V, et al. Evaluation of a new condensed extra-corporeal circuit for cardiac surgery: a prospective randomized clinical pilot study. Perfusion 2005; 20:91-99.

9. Nishiyama T, Hanaoka K. Free hemoglobin concentrations in patients receiving massive blood transfusion during emergency surgery for trauma. Can J Anaesth 2000; 47:881-885.

10. Serrick CJ, Scholz M, Melo A, et al. Quality of red blood cells using autotransfusion devices: a comparative analysis. J Extra Corpor Technol 2003; 35:28-34.

11. Bunn HF, Esham WT, Bull RW. The renal handling of hemoglobin. I. Glomerular filtration. J Exp Med 1969; 129:909-923.

12. Doherty DH, Doyle MP, Curry SR, et al. Rate of reaction with nitric oxide determines the hypertensive effect of cell-free hemoglobin. Nat Biotechnol 1998; 16:672-676.

13. Reiter CD, Wang $X$, Tanus-Santos JE, et al. Cell-free hemoglobin limits nitric oxide bioavailability in sickle-cell disease. Nat Med 2002; 8:1383-1389.

14. Alayash Al. Oxygen therapeutics: can we tame haemoglobin? Nat Rev Drug Discov 2004; 3:152-159.

15. Rother RP, Bell L, Hillmen P, Gladwin MT. The clinical sequelae of intravascular hemolysis and extracellular plasma hemoglobin: a novel mechanism of human disease. Jama 2005; 293:1653-1662.

16. Hanssen SJ, Lubbers T, Hodin CM, et al. Hemolysis results in impaired intestinal microcirculation and intestinal epithelial cell injury. World J Gastroenterol 2011; 17:213-8.

17. Tofovic SP, Jackson EK, Rafikova O. Adenosine deaminase-adenosine pathway in hemolysisassociated pulmonary hypertension. Med Hypotheses 2009; 72:713-719.

18. Forstermann U. Nitric oxide and oxidative stress in vascular disease. Pflugers Arch 2010; 459:923939.

19. Vermeulen Windsant IC, Snoeijs MG, Hanssen SJ, et al Hemolysis is associated with acute kidney injury during major aortic surgery. Kidney Int 2010; 77:913-920.

20. Cruz-Landeira A, Bal MJ, Quintela, Lopez-Rivadulla M. Determination of methemoglobin and total hemoglobin in toxicological studies by derivative spectrophotometry. J Anal Toxicol 2002; 26:67-72.

21. Prinzen FW, Bassingthwaighte JB. Blood flow distributions by microsphere deposition methods. Cardiovasc Res 2000; 45:13-21.

22. Raab S, Thein E, Harris AG, Messmer K. A new sample-processing unit for the fluorescent microsphere method. Am J Physiol 1999; 276:H1801-1806.

23. Prasad PV, Edelman RR, Epstein FH. Noninvasive evaluation of intrarenal oxygenation with BOLD MRI. Circulation 1996; 94:3271-3275.

24. Oostendorp $M$, de Vries $E$, Slenter J, et al. MRI of renal oxygenation and function after normothermic ischemia-reperfusion injury. NMR Biomed 2011; 24:194-200. 
25. Liangos O, Perianayagam MC, Vaidya VS, et al. Urinary N-acetyl-beta-(D)-glucosaminidase activity and kidney injury molecule-1 level are associated with adverse outcomes in acute renal failure. J Am Soc Nephrol 2007; 18:904-912.

26. Leemans JC, Stokman G, Claessen N, et al. Renal-associated TLR2 mediates ischemia/reperfusion injury in the kidney. J Clin Invest 2005; 115:2894-2903.

27. Minneci PC, Deans KJ, Zhi H, et al. Hemolysis-associated endothelial dysfunction mediated by accelerated NO inactivation by decompartmentalized oxyhemoglobin. J Clin Invest 2005; 115:3409-3417.

28. Tam SC, Wong JT. Impairment of renal function by stroma-free hemoglobin in rats. J Lab Clin Med 1988; 111:189-193.

29. Tanaka K, Kanamori Y, Sato T, et al. Administration of haptoglobin during cardiopulmonary bypass surgery. ASAIO transactions / American Society for Artificial Internal Organs 1991; 37:M482-483.

30. Gando S, Tedo I. The effects of massive transfusion and haptoglobin therapy on hemolysis in trauma patients. Surg Today 1994; 24:785-790.

31. Voss $B$, Krane $M$, Jung $C$, et al. Cardiopulmonary bypass with physiological flow and pressure curves: pulse is unnecessary! Eur J Cardiothorac Surg 2010; 37:223-232.

32. Morris CR, Kato GJ, Poljakovic M, et al. Dysregulated arginine metabolism, hemolysis-associated pulmonary hypertension, and mortality in sickle cell disease. Jama 2005; 294:81-90.

33. van de Poll MC, Hanssen SJ, Berbee M, et al. Elevated plasma arginase-1 does not affect plasma arginine in patients undergoing liver resection. Clin Sci (Lond) 2008; 114:231-241.

34. Weiner DL, Hibberd PL, Betit P, et al. Preliminary assessment of inhaled nitric oxide for acute vasoocclusive crisis in pediatric patients with sickle cell disease. Jama 2003; 289:1136-1142.

35. Cannon RO, 3rd, Schechter AN, Panza JA, et al. Effects of inhaled nitric oxide on regional blood flow are consistent with intravascular nitric oxide delivery. J Clin Invest 2001; 108:279-287.

36. Reynolds JD, Ahearn GS, Angelo M, et al. S-nitrosohemoglobin deficiency: a mechanism for loss of physiological activity in banked blood. Proc Natl Acad Sci USA 2007; 104:17058-17062.

37. Troncy E, Francoeur M, Salazkin I, et al. Extra-pulmonary effects of inhaled nitric oxide in swine with and without phenylephrine. Br J Anaesth 1997; 79:631-640.

38. Gladwin MT, Vichinsky E. Pulmonary complications of sickle cell disease. N Engl J Med 2008; 359:2254-2265.

39. Villagra J, Shiva S, Hunter LA, et al. Platelet activation in patients with sickle disease, hemolysisassociated pulmonary hypertension, and nitric oxide scavenging by cell-free hemoglobin. Blood 2007; 110:2166-2172.

40. Dejam A, Hunter CJ, Tremonti $C$, et al. Nitrite infusion in humans and nonhuman primates: endocrine effects, pharmacokinetics, and tolerance formation. Circulation 2007; 116:1821-1831.

41. Jeffers A, Gladwin MT, Kim-Shapiro DB. Computation of plasma hemoglobin nitric oxide scavenging in hemolytic anemias. Free Radic Biol Med 2006; 41:1557-1565.

42. Frei AC, Guo Y, Jones DW, et al. Vascular dysfunction in a murine model of severe hemolysis. Blood 2008; 112:398-405.

43. Kato GJ, Gladwin MT. Evolution of novel small-molecule therapeutics targeting sickle cell vasculopathy. Jama 2008; 300:2638-2646.

44. Yu B, Raher MJ, Volpato GP, et al. Inhaled nitric oxide enables artificial blood transfusion without hypertension. Circulation 2008; 117:1982-1990.

45. Kim-Shapiro DB, Schechter AN, Gladwin MT. Unraveling the reactions of nitric oxide, nitrite, and hemoglobin in physiology and therapeutics. Arterioscler Thromb Vasc Biol 2006; 26:697-705.

46. Prchal JT, Gregg XT. Red cell enzymes. Hematology Am Soc Hematol Educ Program 2005; $19-23$.

47. Bloch KD, Ichinose F, Roberts JD, Jr., Zapol WM. Inhaled NO as a therapeutic agent. Cardiovasc Res 2007; 75:339-348.

48. Gozdzik W, Albert J, Harbut P, et al. Prolonged exposure to inhaled nitric oxide transiently modifies tubular function in healthy piglets and promotes tubular apoptosis. Acta Physiol (Oxf) 2009; 195:495-502. 
49. Vermeulen Windsant IC, Hanssen SJ, Buurman WA, Jacobs MJ. Cardiovascular surgery and organ damage; time to reconsider the role of hemolysis. J Thorac Cardiovasc Surg 2011; 142:1-11.

50. Haase M, Bellomo R, Haase-Fielitz A. Novel biomarkers, oxidative stress, and the role of labile iron toxicity in cardiopulmonary bypass-associated acute kidney injury. J Am Coll Cardiol 2010; 55:20242033. 
<smiles>C=C=C</smiles> 
Chapter 8

\section{Summary and Discussion}




\section{Summary and Discussion}

This thesis is entitled 'Hemolysis, Microcirculatory Changes and Organ Injury Induced by Cardiovascular Surgery'. Recently, studies addressing the effect of hemolysis in chronic hereditary or acquired hemolytic diseases, such as sickle-cell disease or falciparum malaria infection, have started gaining extensive interest among scholars. These studies evaluate the effect of hemolysis, in particular the release of the enzyme arginase- 1 and the release of hemoglobin from the red blood cell in the circulation. The putative effect of both substances on vascular endothelial nitric oxide metabolism and consequently their effect on microcirculatory (organ) perfusion and induction of organ injury are described extensively. However, while these studies address chronic hemolytic disorders, little information is available about the effect of hemolysis in an acute setting such as cardiovascular surgery. The precise role of hemolysis in this patient population remained largely unknown. The major aim of the studies presented in this thesis was to evaluate whether hemolysis is merely an innocent bystander effect of cardiovascular surgery or exhibits a more important role in this patient population. The focus laid on alleged disturbances in microcirculatory perfusion and induction of visceral injury, since the development of visceral injury remains a major determinant of patient outcome, translated in morbidity and mortality rates compliant with this kind of surgery.

Open surgical repair of thoracic aortic aneurysms (TAA) and thoracoabdominal aortic aneurysms (TAAA) are extensive, complex cardiovascular surgical procedures that are associated with significant post-operative morbidity and mortality. ${ }^{1-3}$ Experimental studies of major surgery and trauma suggest that hypoperfusion of visceral organs leads to the initiation of a systemic pro-inflammatory response. ${ }^{4,5}$ Visceral protection during aortic surgery is thus warranted. ${ }^{6,7}$ The extracorporeal circulation (ECC) technique, also known as cardiopulmonary bypass (CPB) system, has been implemented to provide visceral arteries directly with blood in a retrograde or antegrade manner to preserve organ integrity and function during cardiovascular surgery. ${ }^{8,9}$ The first aim of this thesis was to evaluate to what extent visceral organ injury and inflammation occurred in patients undergoing open TAA or TAAA repair (Chapter 2). Fatty acid binding proteins (FABP), cytosolic proteins abundantly expressed in visceral tissue, have been used as sensitive plasma markers to detect early cellular injury. ${ }^{10}$ Two types of FABP, intestinal-type FABP (I-FABP) and livertype (L-FABP), are expressed at the tips of the villi of intestinal mucosal epithelial cells. ${ }^{11}$ The displayed data show intestinal mucosal cell injury in patients undergoing elective open TAA or TAAA repair. In addition, plasma levels of the cytokines IL-6 and IL-8 were assayed to determine the systemic inflammatory response following TAA or TAAA repair. These cytokines, commonly used as general inflammatory markers, are amongst others produced by stimulated monocytes and activated 
endothelium and are considered as key players in the development of systemic inflammatory response after major trauma and surgical stress. ${ }^{12-14}$ To investigate whether intestinal injury was related to the systemic inflammatory response, correlations of $A \cup C_{\mathrm{I}-\mathrm{FABP}}$ with $A \cup C_{\mathrm{IL}-6}$ and $A \cup C_{\mathrm{IL}-8}$ (Figure 2.5) were analyzed in all patients undergoing ECC. AUC $C_{1-F A B P}$ correlated significantly with both $A_{U C} C_{\mathrm{IL}-6}(r=0.64, P<$ $0.001)$ and $A U C_{\mathrm{IL}-8}(r=0.54, \mathrm{P}<0.01)$, indicating an association between the extent of intestinal organ injury and systemic inflammation.

Despite the intended protective effect of artificial visceral perfusion by means of ECC, development of intestinal injury was imminent. The arteriovenous concentration differences measured over the intestines demonstrated significant release of I-FABP and L-FABP. Interestingly, during reperfusion the systemic plasma concentration of both I-FABP and L-FABP initially continued to increased, suggesting either continued wash-out of these proteins from the injured gut mucosa or sustained hypoperfusion injury leading to continued enhanced release of both proteins. These data are in line with low flow states in patients with hypovolemic or cardiogenic shock and inherent blood flow redistribution towards the heart and central nervous system at the expense of visceral organs. However, this phenomenon might also represent another pathophysiologic process, as outlined hereafter. Red blood cell injury resulting in hemolysis is unwanted, but not uncommon in cardiovascular patients undergoing extracorporeal circulation as was recently reviewed by Vercaemst. ${ }^{15}$ Hemolysis is associated with disturbances in vascular endothelial nitric oxide (NO) metabolism, the key system in regulating vascular tone and microcirculatory blood flow. ${ }^{16-18}$ The hemolytic products arginase-1 and free oxyhemoglobin (FHb) might reduce NO bioavailability by degrading the NO precursor arginine to ornithine or by scavenging of NO respectively, thereby compromising microcirculatory (organ) blood flow and inducing organ injury. As stated before, development of visceral injury remains a major determinant of patient outcome after cardiovascular surgery.

To establish the putative relevance of plasma arginase- 1 release on arginine plasma levels, the substrate for NO metabolism, Chapter $\mathbf{3}$ describes the effects of arginase1 release on arginine metabolism, both in vivo as well as in vitro. Arginase-1 is, besides being expressed in mononuclear cells and red blood cells, largely present in the liver as an enzyme in the urea cycle. ${ }^{19-21}$ Therefore liver surgery patients, both resection and transplantation patients with anticipated elevated arginase-1 levels, were used as a model of intravascular arginase-1 release and to establish the potential significance of circulating arginase-1 for arginine metabolism. Arginase-1 was released from the liver into the plasma in patients undergoing liver resection. Since arginase-1 catalyzes the breakdown of arginine to ornithine and urea, it was expected that increasing levels of circulating arginase-1 would lead to decreased plasma arginine levels. 
Roth et al. were the first to show that liver transplantation leads to an immediate decrease of plasma arginine to virtually zero with a stoichiometric increase of plasma ornithine. ${ }^{22,23}$ In such patients we found arginase- 1 concentrations in plasma that were 100-fold higher than those in patients undergoing liver resection. Incubation of post-transplantation plasma samples confirmed that plasma arginase- 1 activity contributed to the in vivo changes in arginine and ornithine levels following liver transplantation and that these changes were not predominantly caused by other arginine regulating processes. From these studies it was concluded that in response to a liver transplantation arginase-1 activity in plasma may become clinically relevant.

However, we could find no effect of an 8-fold increase versus preoperative values of circulating arginase-1 concentration on plasma arginine and ornithine levels in patients undergoing liver resection. In agreement with these in vivo observations we found no significant ornithine formation and arginine consumption when plasma samples with a mean arginase-1 concentration of $185 \mathrm{ng} / \mathrm{mL}$, comparable to levels found during cardiovascular surgery (see Chapter 5 ), were incubated at $37^{\circ} \mathrm{C}$. To explore whether plasma arginase- 1 activity was dependent on factors that were present in whole blood but not in plasma, whole blood samples were incubated in a similar manner. Significant arginine consumption with stoichiometric ornithine production was observed in these samples, but actual arginase-1 activity was independent of the amount of extracellular arginase-1. From these experiments it is clear that arginase-1 plasma levels above $2,000 \mathrm{ng} / \mathrm{mL}$ were necessary to reduce plasma arginine. Moreover, the data show that increased arginase-1 activity in the circulation may be ascribed to increased arginase- 1 activity in the intact red blood cells rather than to circulating plasma arginase-1.

In conclusion, it was found that increased plasma levels of arginase-1, as seen in TAA and TAAA surgery, do not lead to arginine breakdown. The threshold beyond which the plasma level of arginase- 1 significantly affects plasma arginine concentration is probably rarely reached in clinical practice, with the exception of liver transplantation. Plasma levels arginase- 1 reached around cardiovascular surgery, as described and depicted in Chapter 5, remain far below this threshold.

Reiter et al. suggested hemolysis and concomitant release of $\mathrm{FHb}$ to be an important factor in the pathogenesis of compromised microcirculation in hereditary and acquired hemolytic disorders. ${ }^{24}$ They showed that plasma from patients with sicklecell disease contains cell-free oxyhemoglobin ( $\mathrm{FHb}$ ) which is capable of scavenging NO, seen by disturbances in forearm blood flow responses to nitric oxide donor infusions. Their insight, however indirect, was the first step into understanding the vascular complications shared by acute and chronic hemolytic disorders and triggered various research groups to study the deleterious effects of $\mathrm{FHb}$ in acute, chronic hereditary or acquired hemolytic disorders. ${ }^{17,18,25-29}$ Hemolysis during car- 
diovascular surgery is acknowledged, but the potential consequences of $\mathrm{FHb}$ in the light of the findings by Reiter and et al. are unknown, although elevated FHb levels can be anticipated. ${ }^{15}$ The sources of hemolysis, its possible effects and therapies in cardiovascular surgery are reviewed in Chapter 4.

Hemolysis can be attributed to three sources during cardiovascular surgery; (i) the ECC or $\mathrm{CPB},{ }^{15,30}$ (ii) the cell saver system ${ }^{31}$ and (iii) (massive) red blood cell transfusion. $^{32,33}$ The increase in plasma $\mathrm{FHb}$ may contribute to organ injury development through scavenging of NO, inducing perturbations in microcirculatory blood flow and subsequent hypoperfusion or even ischemic injury to organ systems. The reaction between $\mathrm{FHb}$ and $\mathrm{NO}$ is rapid and irreversible. By donating an electron and its oxygen molecule, $\mathrm{FHb}\left(\mathrm{HbFe}^{2+}-\mathrm{O}_{2}\right)$ is transformed into bioinactive methemoglobin $\left(\mathrm{HbFe}^{3+}\right)$ and NO to nitrate $\left(\mathrm{NO}_{3}{ }^{-}\right){ }^{16}$ Because of intravascular NO scavenging, which potentially impairs microcirculatory blood flow resulting in organ injury, we therefore consider $\mathrm{FHb}$ more than an innocent bystander effect of cardiopulmonary bypass assisted surgery, with or without cell salvage and red blood cell transfusion. Interventional studies using haptoglobin infusion or NO inhalation to inactivate $\mathrm{FHb}$, or using nitrite administration to increase NO bioavailability are suggested to establish the causal role between plasma $\mathrm{FHb}$, NO bioavailability, and organ injury in the cardiovascular surgical setting.

As described above, hemolysis is recognized to potentially decrease NO bioavailability leading to compromised microcirculatory blood flow. The relevance of hemolysis to the microcirculation in cardiovascular surgical patients remained largely unknown. The aim of the work presented in Chapter 5 was first to investigate the extent of hemolysis and the concomitant release of $\mathrm{FHb}$ and arginase- 1 in patients undergoing cardiovascular surgery with extracorporeal circulation and massive transfusion including cell-salvage. Next, forearm vascular smooth muscle responses to exogenous NO in the presence of plasma FHb were evaluated. Lastly, the effect of elevated plasma arginase-1 on plasma arginine and ornithine levels was evaluated.

Hemolysis, represented by elevated plasma $\mathrm{FHb}$ and arginase-1 levels, was observed in cardiovascular patients, revealing a significant association between $\mathrm{FHb}$ and arginase- 1 release (Spearman $r=0.83, P=0.005$ ). Since elevated plasma concentrations of $\mathrm{FHb}$ may limit NO-mediated vasodilatation, forearm blood flow was measured using venous occlusion plethysmography in patients undergoing open TAA or TAAA surgery. Forearm blood flow measurements were used as a model to study the effect of an intra-arterially infused NO-donor (sodium nitroprusside, accumulating dosages) during high levels and low levels of circulating FHb. Interestingly, forearm blood flow was negatively correlated with plasma FHb concentrations, indicating NO scavenging during high levels of circulating FHb. This suggests, however indirect, that elevated circulating levels of $\mathrm{FHb}$ during cardiovascular sur- 
gery might compromise organ perfusion as well and potentially induce organ injury. Despite increasing plasma levels of arginase-1 no significant changes in plasma arginine / ornithine ratio, as a surrogate marker for arginase-1 plasma activity, were observed during the studied period. This suggests arginase-1 release during cardiovascular surgery does not hamper arginine bioavailability, the surrogate for NO synthesis. Moreover, correlation analysis between the increase of plasma arginase-1 and the decrease of plasma arginine levels revealed no association between both parameters (Spearman $r=0.55 ; P=0.105$ ). These results do not support increased plasma arginase- 1 activity in cardiovascular patients as was anticipated based on the previous results in Chapter 3.

Next, we hypothesized that intravascular $\mathrm{FHb}$ release compromises intestinal blood flow and consequently induces intestinal injury. Gastrointestinal complications following cardiovascular surgery are feared as these complications are associated with high patient morbidity and mortality rates. 3, 74-37 Aim of the work presented in Chapter 6 was to evaluate intestinal blood flow and epithelial cell injury in an animal model enduring elevated circulating FHb levels. In order to do this, we developed an animal model that yields elevated plasma levels of $\mathrm{FHb}$, similar to levels found during cardiovascular surgery. Subsequently, the potential influence of circulating $\mathrm{FHb}$ on intestinal microcirculation was studied using fluorescent microspheres. Also, both biochemical and histological parameters of intestinal injury were evaluated.

Three groups were included in the study. To induce intravascular hemolysis and yield circulating $\mathrm{FHb}$ the first group received sterile pyrogene-free water infusion, as described previously in a canine model, ${ }^{17}$ adjusted after pilot experiments to our rodent model; the second group received $\mathrm{FHb}$ infusion, while the control group received saline infusion. Water and $\mathrm{FHb}$ infusion resulted, when compared to the saline infusion, in a reduced intestinal microcirculation. Interestingly, circulating $\mathrm{FHb}$ levels correlated significantly with plasmatic release of ileal lipid binding protein (iLBP), a protein solely present in mature epithelial cells of the gut (Spearman $r=$ $0.70, P=0.0017)$. The protein is a member of the fatty acid binding protein family, which can be used to measure early epithelial cell injury in plasma, as well as in urine samples, and visualize injury of the intestinal villi using immunohistochemistry. ${ }^{38}$ Epithelial cell injury of the villi was observed in response to the water and $\mathrm{FHb}$ infusion and verified by histological analysis of the ileum.

This work shows for the first time the deleterious effect of elevated circulating levels of $\mathrm{FHb}$ on intestinal mucosal integrity. We suggest that intravascular hemolysis could contribute to visceral injury during cardiovascular surgery. Intestinal damage, assessed by intestinal fatty acid binding proteins such as iLBP, has been reported in cardiovascular surgical patients. ${ }^{7,} 13$ Furthermore, Chapter 2 shows that intestinal epithelial cell injury occurring during and after major cardiovascular sur- 
gery is associated with a systemic inflammatory response. ${ }^{39}$ It is tempting to speculate that $\mathrm{FHb}$ plays a role in the development of intestinal injury in such patients. As stated above, acute gastrointestinal complications after cardiovascular surgery are known to result in a complicated postoperative period and are associated with high mortality rates.

Acute kidney injury (AKI) after cardiovascular surgery is the longest known and most feared complication as it is associated with high patient morbidity and mortality rates. ${ }^{40,41}$ We hypothesized that intravascular $\mathrm{FHb}$ release compromises renal blood flow and consequently induces AKI. The work presented in Chapter 7 aimed at evaluating renal blood flow, renal oxygenation and renal tubular epithelial cell injury in an animal model enduring elevated circulating $\mathrm{FHb}$ levels with or without inhalation of NO-gas. To this end, the animal model that yields plasma levels of $\mathrm{FHb}$, similar to levels found during cardiovascular surgery and discussed above (see Chapter 6) was used. The potential influence of circulating $\mathrm{FHb}$ on renal microcirculation was studied using fluorescent microspheres. $\mathrm{FHb}$-induced changes in renal oxygenation were evaluated using Blood Oxygen Level Dependent-Magnetic Resonance Imaging (BOLD-MRI). AKI was assessed by measuring urinary tubular epithelial cell injury marker N-acetyl glucosaminidase (NAG). Histological parameters of AKI were evaluated as well.

A significant reduction in renal microcirculatory blood flow was observed already after fifteen minutes of $\mathrm{FHb}$ infusion, while the microcirculatory blood flow in the control group (saline infusion) remained unaltered. The effect of reduced renal microcirculation could still be observed after thirty and sixty minutes of FHb infusion, indicating that elevated circulating levels of $\mathrm{FHb}$ lead to a reduction in renal microcirculatory blood flow. BOLD-MRI measurements showed a decrease in renal tissue oxygenation during FHb infusion. Furthermore, urinary NAG and histological evaluation showed the development of AKI, at the level of proximal tubular epithelial cells. Moreover, the development of AKI, as measured by NAG release, was associated with the levels of circulating $\mathrm{FHb}$ (Spearman $r=0.78, \mathrm{P}=0.0026$ ). In order to assess the NO scavenging capacities of $\mathrm{FHb}, \mathrm{NO}$-ventilation was used as therapeutic option to abrogate the deleterious effects of $\mathrm{FHb}$. Interestingly the reduction in microcirculation as well as the development of AKI were attenuated by $\mathrm{FHb}$ inactivating NO-ventilation. These data reveal a new mechanism of AKI development dependent on elevated circulating FHb levels, which are levels also seen during cardiovascular surgery, and provide a therapeutic option as well.

As a whole this thesis implicates that circulating $\mathrm{FHb}$ is not only a health risk in chronic diseases such as sickle-cell anemia and malaria, but may rather be a cause for concern in cardiovascular surgical patients subject to extracorporeal circulation, blood transfusion and cell salvage devices resulting in substantial hemolysis. FHb 
might induce organ injury during and after cardiovascular surgery. Therefore, circulating $\mathrm{FHb}$ levels should be closely monitored in clinical practice when operating on these patients. Future patient studies are needed to develop means to reduce hemolysis and to counteract the deleterious effects of circulating FHb around cardiovascular surgery. 


\section{References}

1. Rectenwald JE, Huber TS, Martin TD, et al. Functional outcome after thoracoabdominal aortic aneurysm repair. J Vasc Surg 2002; 35:640-7.

2. Gloviczki P. Surgical repair of thoracoabdominal aneurysms: patient selection, techniques and results. Cardiovasc Surg 2002; 10:434-41.

3. Achouh PE, Madsen K, Miller CC, 3rd, et al. Gastrointestinal complications after descending thoracic and thoracoabdominal aortic repairs: a 14-year experience. J Vasc Surg 2006; 44:442-6.

4. Fink MP. Gastrointestinal mucosal injury in experimental models of shock, trauma, and sepsis. Crit Care Med 1991; 19:627-41.

5. Moore FA. The role of the gastrointestinal tract in postinjury multiple organ failure. Am J Surg 1999; 178:449-53.

6. MacArthur RG, Carter SA, Coselli JS, LeMaire SA. Organ protection during thoracoabdominal aortic surgery: rationale for a multimodality approach. Semin Cardiothorac Vasc Anesth 2005; 9:143-9.

7. Welborn MB, Oldenburg HS, Hess PJ, et al. The relationship between visceral ischemia, proinflammatory cytokines, and organ injury in patients undergoing thoracoabdominal aortic aneurysm repair. Crit Care Med 2000; 28:3191-7.

8. Jacobs MJ, de Mol BA, Legemate DA, et al. Retrograde aortic and selective organ perfusion during thoracoabdominal aortic aneurysm repair. Eur J Vasc Endovasc Surg 1997; 14:360-6.

9. Jacobs MJ, Mommertz G, Koeppel TA, et al. Surgical repair of thoracoabdominal aortic aneurysms. J Cardiovasc Surg (Torino) 2007; 48:49-58.

10. Lieberman JM, Sacchettini J, Marks C, Marks WH. Human intestinal fatty acid binding protein: report of an assay with studies in normal volunteers and intestinal ischemia. Surgery 1997; 121:335-42.

11. Pelsers MM, Hermens WT, Glatz JF. Fatty acid-binding proteins as plasma markers of tissue injury. Clin Chim Acta 2005; 352:15-35.

12. Ytting $\mathrm{H}$, Christensen IJ, Basse $\mathrm{L}$, et al. Influence of major surgery on the mannan-binding lectin pathway of innate immunity. Clin Exp Immunol 2006; 144:239-46.

13. Morariu AM, Loef BG, Aarts LP, et al. Dexamethasone: benefit and prejudice for patients undergoing on-pump coronary artery bypass grafting: a study on myocardial, pulmonary, renal, intestinal, and hepatic injury. Chest 2005; 128:2677-87.

14. Fiane $A E$, Videm V, Lingaas PS, et al. Mechanism of complement activation and its role in the inflammatory response after thoracoabdominal aortic aneurysm repair. Circulation 2003; 108:849-56.

15. Vercaemst L. Hemolysis in cardiac surgery patients undergoing cardiopulmonary bypass: a review in search of a treatment algorithm. J Extra Corpor Technol 2008; 40:257-67.

16. Rother RP, Bell L, Hillmen P, Gladwin MT. The clinical sequelae of intravascular hemolysis and extracellular plasma hemoglobin: a novel mechanism of human disease. Jama 2005; 293:1653-62.

17. Minneci PC, Deans KJ, Zhi H, et al. Hemolysis-associated endothelial dysfunction mediated by accelerated NO inactivation by decompartmentalized oxyhemoglobin. J Clin Invest 2005; 115:3409-3417.

18. Villagra J, Shiva S, Hunter LA, et al. Platelet activation in patients with sickle disease, hemolysisassociated pulmonary hypertension, and nitric oxide scavenging by cell-free hemoglobin. Blood 2007; 110:2166-72.

19. Ochoa JB, Bernard AC, O'Brien WE, et al. Arginase I expression and activity in human mononuclear cells after injury. Ann Surg 2001; 233:393-9.

20. Prins HA, Houdijk AP, Nijveldt RJ, et al. Arginase release from red blood cells: possible link in transfusion induced immune suppression? Shock 2001; 16:113-5.

21. Meijer AJ, Lamers WH, Chamuleau RA. Nitrogen metabolism and ornithine cycle function. Physiol Rev 1990; 70:701-48.

22. Langle $F$, Steininger $R$, Roth $R$, et al. L-arginine deficiency and hemodynamic changes as a result of arginase efflux following orthotopic liver transplantation. Transplant Proc 1995; 27:2872-3.

23. Roth $E$, Steininger R, Winkler $S$, et al. L-arginine deficiency after liver transplantation as an effect of arginase efflux from the graft. Transplantation 1994; 57:665-9. 
24. Reiter CD, Wang X, Tanus-Santos JE, et al. Cell-free hemoglobin limits nitric oxide bioavailability in sickle-cell disease. Nat Med 2002; 8:1383-9.

25. Morris CR, Kato GJ, Poljakovic M, et al. Dysregulated arginine metabolism, hemolysis-associated pulmonary hypertension, and mortality in sickle cell disease. Jama 2005; 294:81-90.

26. Kato GJ, Hsieh M, Machado R, et al. Cerebrovascular disease associated with sickle cell pulmonary hypertension. Am J Hematol 2006; 81:503-10.

27. Ataga $\mathrm{KI}$, Moore CG, Hillery CA, et al. Coagulation activation and inflammation in sickle cell diseaseassociated pulmonary hypertension. Haematologica 2008; 93:20-6.

28. Lewis DA, Nyska A, Potti A, et al. Hemostatic activation in a chemically induced rat model of severe hemolysis and thrombosis. Thromb Res 2006; 118:747-53.

29. Yeo TW, Lampah DA, Gitawati R, et al. Impaired nitric oxide bioavailability and L-arginine reversible endothelial dysfunction in adults with falciparum malaria. J Exp Med 2007; 204:2693-704.

30. Fransen EJ, Ganushchak YM, Vijay V, et al. Evaluation of a new condensed extra-corporeal circuit for cardiac surgery: a prospective randomized clinical pilot study. Perfusion 2005; 20:91-9.

31. Serrick CJ, Scholz M, Melo A, et al. Quality of red blood cells using autotransfusion devices: a comparative analysis. J Extra Corpor Technol 2003; 35:28-34.

32. Karkouti K, Wijeysundera DN, Yau TM, et al. The independent association of massive blood loss with mortality in cardiac surgery. Transfusion 2004; 44:1453-62.

33. Koch CG, Li L, Sessler DI, et al. Duration of red-cell storage and complications after cardiac surgery. N Engl J Med 2008; 358:1229-39.

34. Halm MA. Acute gastrointestinal complications after cardiac surgery. Am J Crit Care 1996; 5:109-18; quiz 119-20.

35. Hessel EA, 2nd. Abdominal organ injury after cardiac surgery. Semin Cardiothorac Vasc Anesth 2004; 8:243-63.

36. Geissler HJ, Fischer UM, Grunert S, et al. Incidence and outcome of gastrointestinal complications after cardiopulmonary bypass. Interact Cardiovasc Thorac Surg 2006; 5:239-42.

37. Filsoufi F, Rahmanian PB, Castillo JG, et al. Predictors and outcome of gastrointestinal complications in patients undergoing cardiac surgery. Ann Surg 2007; 246:323-9.

38. Derikx JP, Matthijsen RA, de Bruine AP, et al. Rapid reversal of human intestinal ischemia-reperfusion induced damage by shedding of injured enterocytes and reepithelialisation. PLoS ONE 2008; 3:e3428.

39. Hanssen SJ, Derikx JP, Vermeulen Windsant IC, et al. Visceral injury and systemic inflammation in patients undergoing extracorporeal circulation during aortic surgery. Ann Surg 2008; 248:117-25.

40. Chertow GM, Levy EM, Hammermeister KE, et al. Independent association between acute renal failure and mortality following cardiac surgery. Am J Med 1998; 104:343-8.

41. Schepens MA, Heijmen RH, Ranschaert W, et al. Thoracoabdominal aortic aneurysm repair: results of conventional open surgery. Eur J Vasc Endovasc Surg 2009; 37:640-5. 
Samenvatting 


\section{Samenvatting}

Dit proefschrift is getiteld 'Hemolysis, Microcirculatory Changes and Organ Injury Induced by Cardiovascular Surgery', oftewel vertaald naar het Nederlands 'Hemolyse, veranderingen in de microcirculatie en orgaan schade geïnduceerd door cardiovasculaire chirurgie'. Hemolyse is het uit elkaar vallen van rode bloedcellen, wat dagelijks in kleine hoeveelheden gereguleerd gebeurd. Deze kapotte rode bloedcellen worden in de milt weggevangen en de inhoud wordt afgebroken in de lever; echter, hemolyse kan ook ongecontroleerd en ongewenst optreden waarbij de inhoud van de rode bloedcel in de bloedbaan vrijkomt.

In de afgelopen jaren zijn er studies verschenen waarin het effect van hemolyse bestudeerd werd in patiënten met chronische aangeboren of verworven hemolytische ziekten, zoals sikkelcel ziekte of malaria. Deze studies keken naar het effect van hemolyse, en in het bijzonder het vrijkomen van het enzym arginase-1 en de stof hemoglobine uit de rode bloedcel. De mogelijke effecten van beide stoffen op de doorbloeding van organen op het kleinste niveau (microcirculatie) en dientengevolge mogelijke orgaanschade, is uitgebreid beschreven.

Terwijl deze studies zich gericht hebben op patiënten met chronische hemolytische ziektebeelden, is het onduidelijk wat de effecten zijn van hemolyse in acute situaties zoals tijdens cardiovasculaire chirurgie. Het hoofddoel van de studies beschreven in dit proefschrift was derhalve het evalueren of hemolyse rondom cardiovasculaire chirurgie slechts een onschuldige bijkomstigheid is, of dat het een belangrijke rol speelt bij deze patiëntenpopulatie. De focus van de studies ligt op het onderzoeken van mogelijke verstoringen in de microcirculatie en het ontstaan van orgaanschade tijdens hemolyse. Het optreden van orgaanschade speelt een belangrijke rol in de postoperatieve fase; immers orgaanschade, met name darm- en nierschade na cardiovasculaire chirurgie, betekent een gecompliceerd postoperatief beloop en een langere herstelfase, met een verhoogde kans op overlijden van de patiënt. In dit hoofdstuk worden de resultaten van de studies uit dit proefschrift samengevat.

Aorta aneurysmas zijn verwijdingen van de grote lichaamsslagader (aorta) die zich in de borstholte, het zogeheten thoracaal aorta aneurysma (TAA), of zowel in de borstalsook in de buikholte bevinden, het thoraco-abdominaal aorta aneurysma (TAAA). Een herstel van deze aneurysmas is een grote, complexe cardiovasculaire procedure die gepaard gaat met een groot postoperatief risico op het ontstaan van complicaties en overlijden. ${ }^{1-3}$

Experimentele studies over grote chirurgische ingrepen en trauma patiënten hebben laten zien dat hypoperfusie (te weinig bloeddoorstroming) van de buikorganen leidt tot een algehele ontstekingsreactie (systemische inflammatoire reactie); ${ }^{4,5}$ daarom is het beschermen van de buikorganen die voor hun bloedvoorziening af- 
hankelijk zijn van de aorta, zoals het maag-, darm- en leverstelsel en beide nieren, tijdens cardiovasculaire chirurgie van groot belang. ${ }^{6,7}$ De extracoporeale circulatie (ECC), ook wel cardiopulmonale bypass of hart-longmachine genoemd, wordt tijdens grote cardiovasculaire chirurgie gebruikt om de buikorganen van zuurstofrijk bloed te voorzien en deze zo te beschermen. ${ }^{8,9}$

Het eerste doel beschreven in dit proefschrift was het evalueren van vroege schade aan de darm, lever en nieren alsook de ontstekingsreactie in kaart te brengen in patiënten die een open chirurgisch herstel van een TAA of TAAA ondergingen met behulp van een ECC (Hoofdstuk 2). Fatty acid binding proteinen (FABP), zijn kleine eiwitten die in de cellen van verscheidene organen voorkomen. Ze kunnen gebruikt worden als gevoelige marker in het bloed om snel cellulaire schade te ontdekken in verschillende organen. ${ }^{10}$ Twee types FABP, I-FABP en L-FABP, komen in de darm tot expressie. ${ }^{11}$ De resultaten van de studie laten zien dat er darmschade optreedt tijdens en vlak nadat patiënten een geplande open herstel van een TAA of TAAA ondergingen. Daarnaast werden ontstekingswaarden in het bloed van deze patiënten gemeten (IL-6 en IL-8) om de algehele ontstekingsreactie in kaart te brengen. Om te onderzoeken of darmschade geassocieerd is met de ontstekingsreactie werden bij alle patiënten correlatie analyses uitgevoerd tussen de $A \cup C_{1-F A B P}$ met $A U C_{\mathrm{IL}-6}$ and $A U C_{\mathrm{IL}-8}$ (Figuur 2.5). De $A \cup C_{\text {I-FABP }}$, de hoeveelheid darmschade die in de gemeten tijd is opgetreden, correleerde significant met de totale vrijgekomen ontstekingsparameters IL-6 ( $\left.\mathrm{AUC}_{\mathrm{IL}-6, \mathrm{r}}=0.64, \mathrm{P}<0.001\right)$ en IL-8 ( $\left.\mathrm{AUC}_{\mathrm{IL}-8,}, \mathrm{r}=0.54, \mathrm{P}<0.01\right)$, wat indicatief is voor een sterke associatie tussen de hoeveelheid darmschade en de daarop volgende systemische inflammatoire reactie.

Ondanks het vermeende beschermende effect van ECC was het ontstaan van darmschade overduidelijk. Er werden naast systemische metingen ook orgaanspecifieke metingen verricht die het vrijkomen van I-FABP en L-FABP uit de darm bevestigde. Als interessante bevinding werd gezien dat niet alleen tijdens ECC perfusie van de buikorganen darmschade optrad, maar ook na de ECC procedure, in de zogeheten reperfusie fase. Dit suggereert dat er nog steeds cellen van de darm kapot gaan, of dat er nog steeds sprake is van hypoperfusie met continuerende darmschade als gevolg. Deze bevindingen zijn in lijn met eerdere studies naar reperfusieeffecten in patiënten met hypovolemische- of cardiogene shock, waarbij bloed herverdeling optreedt en bloed bij voorkeur naar de vitale organen gaat (het hart en de hersenen) wat ten koste gaat van de buikorganen. Echter, dit fenomeen zou bij cardiovasculaire chirurgie ook een ander pathofysiologisch proces kunnen herbergen, zoals hieronder beschreven staat.

Rode bloedcel schade resulteert in hemolyse wat ongewenst, maar onvermijdelijk is in patiënten die cardiovasculaire chirurgie met behulp van ECC ondergaan. ${ }^{12}$ Hemolyse is geassocieerd met verstoringen in de stikstofmonoxide (NO) huishouding van de vaatwand; NO geproduceerd in de vaatwand is voor het merendeel 
verantwoordelijk voor de vaatweerstand en vaatdiameter van arteriën en zodoende verantwoordelijk voor de bloeddoorstroming van organen. ${ }^{13-15}$ Het enzym arginase1 en het molecuul vrij oxyhemoglobine (FHb) zijn stoffen die vrijkomen in de bloedbaan tijdens hemolyse. Beide kunnen de NO beschikbaarheid verminderen, enerzijds door het substraat voor NO arginine om te zetten in ornithine, of anderzijds door NO weg te vangen; hierdoor verstoren ze de microcirculatie van organen en induceren orgaanschade. Zoals reeds hierboven beschreven is orgaanschade een belangrijke determinant voor het herstel van patiënten na cardiovasculair chirurgie.

Teneinde de mogelijke relatie te bestuderen tussen het vrijkomen van arginase-1 en het substraat voor NO (arginine) in het plasma van het bloed, wordt in de studie beschreven in Hoofdstuk 3 het effect van arginase-1 op de beschikbaarheid van arginine onderzocht, zowel in vivo als in vitro. Arginase-1 wordt, naast rode bloedcellen en mononucleaire cellen, vooral in de lever tot expressie gebracht waar het een belangrijke rol speelt als enzym in de ureum-cyclus. ${ }^{16-18}$ Daarom werden in deze studie patiënten bestudeerd die leverchirurgie ondergingen, in de vorm van leverresectie of levertransplantatie; deze patiënten dienden als model voor intravasaal vrijkomen van arginase-1 waarbij het mogelijke effect van circulerend arginase-1 op het aminozuur arginine in het plasma van het bloed onderzocht werd. We vonden dat patiënten met leverresectie een significante stijging van circulerend arginase-1 lieten zien; omdat arginase-1 de afbraak van arginine naar ornithine en ureum katalyseert, werd verwacht dat toenemende arginase-1 concentraties in het bloed een daling van de arginine concentratie teweeg zou brengen, wat echter in vivo niet het geval bleek.

Roth et al. waren de eerste die lieten zien dat levertransplantatie tot een acute daling in de arginine concentratie leidt met een gelijktijdige toename in de ornithine concentratie. ${ }^{19}$ Bij patiënten na lever transplantatie vonden we een arginase-1 concentratie in het bloed dat gemiddeld 100x hoger ligt dan bij patiënten die leverresectie ondergaan. Incubatie in vitro van plasma monsters die na levertransplantatie afgenomen werden, bevestigden dat plasma arginase- 1 activiteit bijdraagt aan de in vivo veranderingen in arginine en ornithine concentraties die na levertransplantaties in onze patiënten gevonden werden.

Uit deze studies kon worden geconcludeerd dat arginase-1 activiteit in het plasma klinisch relevant kan zijn na levertransplantatie. We hebben echter geen effect van een achtvoudige toename (versus preoperatief) van circulerende arginase-1 concentraties op arginine en ornithine plasma concentraties gevonden in patienten die leverresectie ondergingen. In overeenstemming met deze in vivo data hebben we geen toename in ornithine formatie en arginine consumptie in vitro gevonden in monsters met een gemiddelde arginase-1 concentratie van $185 \mathrm{ng} / \mathrm{mL}$, welke vergelijkbaar zijn met plasma concentraties in patiënten die cardiovasculaire chirurgie ondergingen (zie Hoofdstuk 5). Daarnaast laten we in vitro zien dat argina- 
se-1 activiteit in volbloed onafhankelijk is van de extracellulaire arginase-1 concentratie, maar vooral door intracellulair arginase- 1 in de rode bloedcel bepaald wordt. Bovendien laten de in vivo en in vitro studies zien dat een arginase-1 plasma concentratie boven $2000 \mathrm{ng} / \mathrm{mL}$ nodig is om een significante daling in het plasma arginine te bewerkstelligen.

Concluderend, een toename in plasma arginase-1 concentratie zoals gevonden wordt in cardiovasculaire chirurgie zal niet tot een daling in de arginine plasma concentratie leiden. De drempel waarboven arginase-1 een significante invloed op arginine plasma concentraties zal hebben en mogelijk NO productie in de vaatwand zou kunnen beperken, wordt zelden in de klinische setting bereikt, met uitzondering van levertransplantatie. Arginase-1 plasma concentraties rondom cardiovasculaire chirurgie, zoals wordt beschreven in Hoofdstuk 5, blijven ver beneden deze drempel.

Reiter et al. suggereerden dat hemolyse en het daaropvolgend vrijkomen van zuurstofrijk hemoglobine ( $\mathrm{FHb}$ ) een belangrijke rol speelt in de pathogenese van verstoorde microcirculatie bij patiënten met een aangeboren of verkregen hemolytische ziekte. ${ }^{20}$ Zij lieten als eerste zien dat plasma van patiënten met sikkelcel ziekte dat FHb bevat, in staat is om NO weg te vangen; zij beschreven veranderingen in de bloeddoorstroming van de onderarm als reactie op NO-donor infusies in de arteriële bloedtoevoer. Dit inzicht, hoewel indirect, was de eerste stap in het begrijpen van vasculaire complicaties die zowel in acute als chronische hemolytische ziekten optreden. Hun bevinding stimuleerde tot het verder in kaart brengen van de schadelijke effecten van $\mathrm{FHb}$ in acute, chronische en verworven hemolytische stoornissen. ${ }^{14}$ 15, 21-25 Hemolyse tijdens cardiovasculaire chirurgie wordt weliswaar beschreven in de literatuur, echter de consequenties van $\mathrm{FHb}$ in het kader van de bevindingen van Reiter et al. zijn onbekend, terwijl verhoogde plasma $\mathrm{FHb}$ waarden rondom cardiovasculaire chirurgie wel verwacht mogen worden. ${ }^{12}$ De mogelijke bronnen van hemolyse tijdens cardiovasculaire chirurgie en de mogelijke effecten en therapieën worden in een literatuurstudie in dit proefschrift beschreven (Hoofdstuk 4).

Hemolyse tijdens cardiovasculaire chirurgie kan voortkomen uit drie bronnen; (i) de ECC, ${ }^{12,26}$ (ii) het cell-saver systeem, waarmee rode bloed cellen uit het operatiegebied opgevangen worden en aan de patiënt terug gegeven kunnen worden, ${ }^{27}$ en (iii) het gebruik van (massale) bloed transfusie. ${ }^{28,29}$ De toename van plasma $\mathrm{FHb}$ zou middels het wegvangen van NO tot orgaanschade kunnen leiden, dit door verstoringen in de microcirculatie en vervolgens hypoperfusie en ischemische schade aan organen te induceren. De reactie tussen $\mathrm{FHb}$ en $\mathrm{NO}$ is snel en onomkeerbaar. Doordat een elektron en het zuurstofmolecuul van $\mathrm{FHb}\left(\mathrm{HbFe}^{2+}-\mathrm{O}_{2}\right)$ aan $\mathrm{NO}$ gebonden worden, ontstaat het inactieve methemoglobine $\left(\mathrm{HbFe}^{3+}\right)$ en als bijproduct nitraat $\left(\mathrm{NO}_{3}{ }^{-}\right){ }^{13}$ Doordat $\mathrm{NO}$ door $\mathrm{FHb}$ in de bloedbaan weggevangen kan worden en zodoende de microcirculatie mogelijk beïnvloed wordt en orgaanschade op- 
treedt, beschouwen we $\mathrm{FHb}$ als meer dan een onschuldige bijkomstigheid tijdens cardiovasculaire chirurgie met ECC, met of zonder cell-saver systeem en (massale) bloed transfusie. We suggereren verder in deze literatuurstudie dat studies met haptoglobin infusie of inhalatie met NO nodig zijn, om FHb onschadelijk te maken of studies met nitriet infusies om de NO beschikbaarheid te vergroten nodig zijn, om een causaal verband tussen plasma $\mathrm{FHb}$, NO beschikbaarheid en orgaanschade binnen de cardiovasculaire chirurgie verder te bestuderen.

Zoals hierboven beschreven wordt is hemolyse een potentieel gevaar om de beschikbaarheid van NO te reduceren wat kan leiden tot een verminderde microcirculatie. De relevantie van hemolyse op de microcirculatie bij cardiovasculaire chirurgie is tot dusver onbekend. Het doel van de studie beschreven in Hoofdstuk $\mathbf{5}$ was allereerst om de mate van hemolyse te evalueren en de hoeveelheid vrijgekomen arginase-1 en $\mathrm{FHb}$ te kwantificeren bij patiënten die cardiovasculaire chirurgie met behulp van een ECC en bloedtransfusie, inclusief cell-saver systeem ondergingen. Vervolgens werd de doorbloeding van de onderarm van deze patiënten gemeten in reactie op een NO-donor, zowel tijdens hoge en lage plasma FHb waarden. Tevens werd het effect van plasma arginase-1 op de plasma concentraties van arginine en ornithine bestudeerd.

Hemolyse trad op en werd tijdens cardiovasculaire chirurgie gemeten middels toegenomen $\mathrm{FHb}$ en arginase-1 concentraties in het plasma waarbij beide parameters significant aan elkaar gecorreleerd waren (Spearman $r=0.83, P=0.005$ ). Daar verhoogde $\mathrm{FHb}$ plasma concentraties de NO-gemediëerde vasodilatatie zou kunnen beperken, werd de NO-afhankelijke onderarm doorbloeding gemeten bij patiënten die een herstel van een TAA of TAAA ondergingen. Daarnaast werd als positieve controle voor het functioneren van de vaatwand NO-onafhankelijke vasodilatatie gemeten. Metingen van de onderarm doorbloeding werden gebruikt als model om de effecten van een intra-arterieel toegediende NO-donor (natrium nitroprusside, in toenemende dosering) te bestuderen tijdens zowel hoge als lage circulerende concentraties $\mathrm{FHb}$. Als belangrijke bevinding bleek de doorbloeding van de onderarm negatief gecorreleerd met de plasma FHb waarden, wat inhoudt dat er NO weggevangen werd tijdens hoge concentraties circulerend FHb. Dit suggereert, hoewel indirect, dat verhoogde concentraties circulerend $\mathrm{FHb}$ gedurende cardiovasculaire chirurgie de orgaanperfusie eveneens kan compromitteren en mogelijk orgaanschade kan induceren. Ondanks toename in de arginase-1 plasma concentratie, werd er geen verandering in de plasma arginine / ornithine ratio, welke gebruikt werd als surrogaat marker voor arginase-1 activiteit, gevonden tijdens de bestudeerde periode. Dit suggereert dat het vrijkomen van arginase-1 gedurende cardiovasculaire chirurgie de beschikbaarheid van arginine, het substraat voor NO synthese, niet beperkt. Daarnaast liet de correlatie analyse tussen het vrijkomen van arginase- 1 in het plasma en de daling van de arginine plasma concentratie geen associatie zien 
tussen beide parameters (Spearman $r=0.55 ; P=0.105$ ). Deze resultaten ondersteunen een toegenomen arginase-1 activiteit in het plasma niet, wat naar aanleiding van de studie in Hoofdstuk 3 beschreven ook niet te verwachten viel.

Onze volgende hypothese was dat intravasaal vrijgekomen FHb de microcirculatie van de darm kan verminderen en vervolgens tot darmschade zal leiden. Gastrointestinale complicaties na cardiovasculaire chirurgie worden gevreesd, omdat deze complicaties gepaard gaan met hoge morbiditeit en mortaliteit cijfers in deze patientenpopulatie. 3, 7, 30, 31 Doel van het werk beschreven in Hoofdstuk 6 was het evalueren van de darmdoorbloeding en darmschade in een diermodel met toegenomen circulerende $\mathrm{FHb}$ plasma concentraties. Om dit te bewerkstelligen hebben we een diermodel ontwikkeld waarbij plasma $\mathrm{FHb}$ waarden bereikt werden die vergelijkbaar zijn aan de waarden die we in de kliniek bij patiënten tijdens cardiovasculaire chirurgie gevonden hebben. Vervolgens werd de invloed van circulerend $\mathrm{FHb}$ op de microcirculatie van de darm bestudeerd door gebruik te maken van fluorescerende microsferen. Daarnaast werden biochemische en histologische parameters van darmschade geëvalueerd.

Drie groepen werden in de studie geïncludeerd. Om intravasale hemolyse en verhoogde circulerend $\mathrm{FHb}$ concentraties te bewerkstelligen kreeg de eerste groep steriel pyrogeen-vrij water geïnfundeerd, op een manier zoals eerder in een honden proefdiermodel beschreven is, ${ }^{14}$ aangepast aan ons ratten proefdiermodel; de tweede groep onderging $\mathrm{FHb}$ infusie, en de controle groep onderging infusie met een fysiologische zoutoplossing. Zowel water als FHb infusie leidde in vergelijking met de controle groep tot een verminderde microcirculatie van de darm. Bovendien correleerden circulerende $\mathrm{FHb}$ waarden significant met plasma ileal lipid binding protein (iLBP) waarden, een eiwit dat alleen in mature epitheliale darmcellen voorkomt (Spearman $r=0.70, P=0.0017$ ). Het eiwit iLBP is een lid van de FABP familie en is een snelle sensitieve marker waarmee intestinale epitheliale darmschade in plasma en urine gemeten kan worden en tevens epitheliale schade op het niveau van de villus, middels immunohistochemie, gevisualiseerd kan worden. ${ }^{32}$ Epitheliale cel schade aan de villus van de darm werd gemeten na water infusie en FHb infusie en middels histologische analyse van de darm bevestigd.

Deze studie laat voor het eerst de schadelijke effecten van verhoogde circulerende $\mathrm{FHb}$ concentratie op de microcirculatie en weefselintegriteit van de darm zien. We suggereren hieruit dat intravasale hemolyse en toegenomen circulerende $\mathrm{FHb}$ waarden tijdens cardiovasculaire chirurgie kan bijdragen aan orgaanschade. Darmschade, gemeten middels FABP eiwitten zoals iLBP, is in de literatuur beschreven rondom cardiovasculaire chirurgie. ${ }^{7,} 33$ Bovendien, Hoofdstuk 2 laat zien dat epitheliale darmschade die optreedt rondom cardiovasculaire chirurgie geassocieerd is met een systemische inflammatoire reactie. ${ }^{34}$ Het is verleidelijk om te speculeren dat $\mathrm{FHb}$ een rol speelt in het ontstaan van darmschade binnen deze patiën- 
tenpopulatie. Zoals hierboven aangegeven is bekend dat acute gastrointestinale complicaties na cardiovasculaire chirurgie een groot risico op een gecompliceerd postoperatief verloop met hoge mortaliteitcijfers als gevolg hebben.

Acute nierschade (acute kidney injury, AKI) is de meest voorkomende en meest gevreesde complicatie na cardiovasculaire chirurgie, daar het geassocieerd is met hoge morbiditeit en mortaliteit cijfers. ${ }^{35,36}$ Naar aanleiding van deze gegevens hebben we de hypothese gesteld dat intravasaal vrijgekomen $\mathrm{FHb}$ de nierdoorbloeding vermindert en AKI veroorzaakt. De studie die in Hoofdstuk 7 gepresenteerd wordt had als doel om de nierdoorbloeding en renale tubulaire epitheelcel schade te evalueren in een proefdiermodel dat verhoogde circulerende $\mathrm{FHb}$ waarden onderging. Hiertoe werd hetzelfde proefdiermodel gebruikt als gepresenteerd in Hoofdstuk 6, dat FHb waarden bereikte die vergelijkbaar zijn aan de waarden die we bij patiënten rondom cardiovasculaire chirurgie gevonden hebben. In de studie beschreven in Hoofdstuk 7 werden de mogelijke effecten van circulerend FHb, met en zonder inhalatie van NO-gas als $\mathrm{FHb}$-inactiverende therapie, op de renale microcirculatie middels fluorescente microsferen bepaald. Daarnaast werd de tubulaire epitheelcel schademarker $\mathrm{N}$-acetyl glucosaminidase (NAG) in de urine bepaald, alsmede werden histologische parameters van AKI bestudeerd.

Teneinde het $\mathrm{FHb}$ onschadelijk te maken, werd ventilatie met NO-gas gebruikt als therapie om de schadelijke effecten van $\mathrm{FHb}$ tegen te gaan. De door FHb-infusie geïnduceerde veranderingen in het zuurstofgehalte van de nieren werd gemeten middels 'Blood Oxygen Level Dependent Magnetic Resonance Imaging' (BOLD-MRI). Een significante reductie in de microcirculatie van de nier werd gevonden na 15 minuten $\mathrm{FHb}$ infusie, vergeleken met de controle groep die alleen een infusie met fysiologisch zout onderging; het effect van gereduceerde microcirculatie van de nier werd na 60 minuten nog steeds gezien, indicatief voor een door verhoogde circulerende $\mathrm{FHb}$ concentratie veroorzaakte daling in de microcirculatie van de nieren. Daarnaast toonden urine NAG en histologische evaluatie van de nier de ontwikkeling van AKI aan, op het niveau van de proximale tubulaire epitheelcel van de nier. Tevens was de ontwikkeling van AKI, gemeten naar NAG concentratie in de urine, geassocieerd met de circulerende $\mathrm{FHb}$ waarden (Spearman $\mathrm{r}=0.78, \mathrm{P}=0.0026$ ). Opmerkelijk is dat de microcirculatie van de nieren verbeterde en de ontwikkeling van AKI teruggedrongen werd door het FHb-inactiverende NO-gas. BOLD-MRI data toonden een afname van het zuurstofgehalte van de nieren tijdens de periode van $\mathrm{FHb}$ infusie. Deze data onthullen een nieuw mechanisme van AKI ontwikkeling afhankelijk van verhoogde circulerende $\mathrm{FHb}$ concentraties, zoals die ook tijdens cardiovasculaire chirurgie voorkomen, en bieden tevens een therapeutische optie om het $\mathrm{FHb}$ onschadelijk te maken. 
Concluderend laat dit proefschrift zien dat verhoogde circulerende $\mathrm{FHb}$ waarden niet alleen een gezondheidsrisico vormen in chronische ziekten zoals sikkelcel ziekte of malaria. Verhoogde FHb waarden zijn wel degelijk een reden voor aandacht bij patiënten die cardiovasculaire chirurgie ondergaan, met behulp van extracorporale circulatie, bloed transfusies en een cell-saver systeem; deze patiënten zijn onderhevig aan substantiële hemolyse. FHb kan orgaanschade induceren gedurende en na cardiovasculaire chirurgie, waarbij inhalatie van NO-gas een mogelijkheid biedt het circulerende $\mathrm{FHb}$ onschadelijk te maken. Daarom dienen circulerende $\mathrm{FHb}$ waarden in de kliniek nauwlettend in de gaten gehouden te worden wanneer deze patiënten geopereerd worden. Er zullen in de toekomst meer studies gedaan moeten worden met patiënten om interventies te ontwikkelen teneinde hemolyse te reduceren en de schadelijke effecten van $\mathrm{FHb}$ rondom cardiovasculaire chirurgie tegen te gaan.

Voor referenties zie pagina 148. 
<smiles>C=C=C</smiles> 


\section{Zusammenfassung}




\section{Zusammenfassung}

Der Titel dieser Dissertation lautet „Hemolysis, Microcirculatory Changes and Organ Injury Induced by Cardiovascular Surgery", ins Deutsche übersetzt „Hämolyse, Veränderungen der Mikrozirkulation und Organschäden induziert durch kardiovaskuläre Chirurgie". Hämolyse ist der Zerfall von roten Blutkörperchen, das täglich in kleinen Mengen kontrolliert stattfindet. Die beschädigten roten Blutkörperchen werden in der Milz abgefangen, und ihr Inhalt wird in der Leber abgebaut. Hämolyse kann jedoch auch in unkontrollierter Form stattfinden, wobei der Inhalt der roten Blutkörperchen in den Blutkreislauf freigesetzt wird.

In den letzten Jahren wurden Studien veröffentlicht, in denen die Wirkung der Hämolyse bei Patienten mit angeborenen oder erworbenen chronischen hämolytische Erkrankungen wie Sichelzellanämie und Malaria erforscht wurden. In diesen Studien werden insbesondere die Freisetzung von Hämoglobin und dem Enzym Arginase- 1 aus den roten Blutkörperchen unter die Lupe genommen. Die möglichen Auswirkungen der beiden Substanzen auf den Blutfluss auf der kleinsten Ebene (die sogenannte Mikrozirkulation) und somit mögliche Organschäden werden im Detail beschrieben. Während sich diese Studien auf Patienten mit chronischen hämolytischen Krankheiten konzentrieren, sind die Auswirkungen der Hämolyse in akuten Situationen wie bei kardiovaskulären Operationen unklar.

Das Hauptziel der Studien, die in dieser Dissertation beschrieben werden, war daher die Erforschung von Hämolyse während kardiovaskulärer Eingriffe. Bewertet werden sollte, ob Hämolyse bei den betroffenen Patienten nur ein harmloser Nebeneffekt ist oder ob sie eine wichtige Rolle während und nach der Operation spielt. Der Schwerpunkt der Studien lag darin, mögliche Störungen in der Mikrozirkulation und die Entwicklung von Organschäden aufgrund von Hämolyse zu untersuchen. Das Auftreten von Organschäden spielt besonders in der postoperativen Phase eine extrem wichtige Rolle. Nach kardiovaskulären Operationen führen insbesondere intestinale Schäden und Nierenschäden zu einem komplizierten postoperativen Verlauf, einer längeren Erholungsphase und einer erhöhten Sterberate bei den Patienten. Im folgenden Kapitel werden die Ergebnisse der Studien zusammengefasst.

Aortenaneurysmen sind Erweiterungen der Hauptschlagader (Aorta), deren genauere Bezeichnung abhängig ist von der anatomischen Lokalisation des Aneurysmas. Ein in der Brusthöhle gelegenes Aneurysma wird als thorakales Aortenaneurysma (TAA) bezeichnet. Befindet sich ein Aneurysma in der Brust- und Bauchhöhle, so spricht man von einem thorako-abdominalen Aortenaneurysma (TAAA). Die Operation eines Aneurysmas ist ein sehr komplexer kardiovaskulärer Eingriff, der mit hohen postoperativen Risiken für Komplikationen und Mortalität einhergeht. ${ }^{1-3}$ Experimentelle Studien während großer Operationen und bei Traumapatienten haben gezeigt, dass Hypoperfusion (verminderter Blutfluss) der Bauchorgane zu einer 
ganzheitlichen entzündlichen Reaktion (systemische inflammatorische Reaktion) führt. ${ }^{4,5}$ Der Schutz der Bauchorgane wie Magen, Darm, Leber und Nieren, die in ihrer Blutversorgung abhängig sind von der Aorta, ist daher während großer kardiovaskulärer Eingriffe sehr wichtig. ${ }^{6,7}$ Die extrakorporale Zirkulation (EKZ), auch HerzLungen-Maschine genannt, versorgt die Bauchorgane während großer kardiovaskulärer Operationen zu ihrem Schutz mit sauerstoffreichem Blut., ${ }^{8,9}$

Das erste Ziel der vorliegenden Dissertation war es, früh auftretende Schäden an Darm, Leber und Nieren und entzündliche Reaktionen bei Patienten mit offenen TAA- und offenen TAAA-Operationen zu vergleichen. Alle Operationen wurden unter Einsatz einer EKZ durchgeführt (Kapitel 2). Fettsäurebindende Proteine (FABP) sind kleine Eiweiße, die in den Zellen verschiedener Organe vorkommen. Diese Proteine können als sensibler Marker im Blut genutzt werden, um Zellschäden früh zu erkennen und den verschiedenen Organen zuzuordnen. ${ }^{10}$ I-FABP und L-FABP sind zwei Arten von FABP, die im menschlichen Darm häufig vorhanden sind. ${ }^{11}$ Die Ergebnisse der vorliegenden Studie zeigen, dass Darmverletzungen bei Patienten entweder während oder unmittelbar nach einer offenen TAA- oder TAAA-Opertaion auftreten. Zur Bewertung der allgemeinen Entzündungsreaktion wurden die Entzündungsparameter (IL-6 und IL-8) im Blut dieser Patienten gemessen. Um bei allen Patienten den Zusammenhang zwischen Darmschädigungen und der entzündlichen Reaktion zu untersuchen, wurden Korrelationsanalysen zwischen $\mathrm{AUC}_{\mathrm{I-FABP}}$ mit $A U \mathrm{C}_{\mathrm{IL}}$ 6 und $A \cup C_{\mathrm{IL}-8}$ durchgeführt (Abbildung 2.5). $A \cup C_{\text {I-FABP }}$ steht für das Ausmaß der Darmschädigung in der gemessenen Zeit. Da diese statistisch signifikant mit den freigegeben Entzündungsmarkern IL-6 $\left(\mathrm{AUC}_{\mathrm{IL}-6}, \mathrm{r}=0,64, \mathrm{P}<0,001\right)$ und IL-8 $\left(A \cup \mathrm{C}_{\mathrm{IL}-8}\right.$, $r=0,54, P<0,01)$ korreliert, deutet dies auf eine starke Assoziation zwischen der Höhe der Darmschädigung und der anschließenden systemischen, inflammatorischen Reaktion hin. Trotz der vermeintlichen Schutzwirkung der EKZ ist die Entstehung von Darmverletzungen offensichtlich. Zusätzlich zu den systemischen Untersuchungen wurden organspezifische Messungen durchgeführt, welche die Freisetzung von I-FABP und L-FABP im Darm bestätigten. Erstaunlicherweise kam es nicht nur während der Durchblutung der Bauchorgane mit Hilfe der EKZ, sondern auch in der sogenannten Reperfusionsphase, nachdem das EKZ-Verfahren beendet war, zu Darmverletzungen. Dies legt nahe, dass entweder weiterhin Darmzellen beschädigt werden oder die Hypoperfusion, mit Darmschäden als Folge, fortbesteht. Diese Befunde bestätigen die Ergebnisse von früheren Studien, in denen der Reperfusionseffekt bei Patienten mit Hypovolämie oder kardiogenem Schock untersucht wurde. In diesen Fällen kommt es zu einer Umverteilung des Blutes, wobei lebenswichtige Organe (z.B. Herz und Hirn) zulasten der Bauchorgane bevorzugt versorgt werden. Dieses Phänomen könnte allerdings, wie im folgenden Abschnitt beschrieben wird, in der kardiovaskulären Chirurgie auch durch einen anderen pathophysiologischen Prozess erklärt werden. 
Bei Patienten mit kardiovaskulären Operationen unter Einsatz einer EKZ führen Schäden an roten Blutkörperchen zur unerwünschten, aber unvermeidlichen Hämolyse. $^{12}$ Hämolyse wiederum führt zu Störungen des Stickstoffmonoxid (NO)Stoffwechsels in der Gefäßwand. NO, das in der Gefäßwand produziert wird, spielt eine große Rolle bei der Regulierung des Widerstandes und des Durchmessers der Arterien und ist somit hauptsächlich für den Blutfluss in den Organen zuständig. ${ }^{13-15}$ Das Enzym Arginase-1 und das Molekül freies oxygeniertes Hämoglobin (FHb) sind Stoffe, die während der Hämolyse in die Blutbahn freigesetzt werden. Beide können die Verfügbarkeit von NO vermindern: einerseits indem Arginase-1 das Substrat für NO, Arginin, in Ornithin umwandelt, und andererseits indem FHb NO abfängt und somit die NO-Verfügbarkeit reduziert. Hierdurch wird die Mikrozirkulation in den Organen gestört, was wiederum Organschäden zur Folge hat. Wie bereits oben beschrieben, sind die Organschäden ein wichtiger Faktor für die Rehabilitation von Patienten nach kardiovaskulären Operationen.

Um den möglichen Zusammenhang zwischen der Freisetzung von Arginase-1 und dem Substrat für NO (Arginin) im Blutplasma zu erforschen, wird wie in Kapitel 3 beschrieben, die Wirkung von Arginase-1 auf die Verfügbarkeit von Arginin sowohl in vivo als auch in vitro getestet. Arginase- 1 ist außer in roten Blutkörperchen und in mononukleären Zellen vor allem in der Leber vorhanden, wo es als Enzym eine wichtige Rolle im Harnstoffzyklus spielt. ${ }^{16-18}$ Aus diesem Grund nahmen an dieser Studie Patienten mit leberchirurgischen Operationen in Form einer Leberresektion oder Lebertransplantation teil. Diese Patienten dienten als Modell für die intravaskuläre Freisetzung von Arginase-1, wobei die potenziellen Auswirkungen der zirkulierenden Arginase-1 auf die Aminosäure Arginin im Plasma des Blutes untersucht wurden. Wir stellten fest, dass diese Patienten eine deutliche Zunahme von zirkulierender Arginase-1 aufwiesen. Da Arginase-1 den Abbau von Arginin zu Ornithin und Harnstoff katalysiert, wurde erwartet, dass ein erhöhter Arginase-1Spiegel im Blut eine Abnahme der Arginin-Konzentration verursacht, was in vivo nicht der Fall zu sein schien.

Roth et al. zeigten erstmals im Jahr 1994, dass eine Lebertransplantation zu einer akuten Abnahme von Arginin und einem gleichzeitigen Anstieg der OrnithinKonzentration führt. ${ }^{19}$ Wir fanden heraus, dass bei Patienten nach Lebertransplantationen die Arginase-1-Konzentration im Blut durchschnittlich 100x höher war als bei Patienten, die einer Leberresektion unterzogen wurden. In vitro Inkubation von Plasma-Proben, die Patienten nach Lebertransplantationen entnommen wurden, bestätigten, dass die Arginase-1-Plasma-Aktivität zu in vivo Veränderungen in Arginin und Ornithin-Konzentrationen beiträgt, welche nach Lebertransplantationen bei unseren Patienten gefunden wurden.

Diese Studien zeigen, dass die Arginase-1-Aktivität im Plasma nach Lebertransplantationen klinisch relevant sein kann. Wir haben jedoch keinen Einfluss der (im 
Vergleich zu präoperativ) achtfach erhöhten zirkulierenden Arginase-1Konzentration auf die Arginin und Ornithin-Konzentrationen im Plasma bei Patienten von Leberresektionen festgestellt. In Einklang mit diesen in vivo Daten haben wir in vitro bei Proben mit einer durchschnittlichen Arginase-1-Konzentration von $185 \mathrm{ng} / \mathrm{ml}$, welche vergleichbar ist mit Plasmakonzentrationen von Patienten mit kardiovaskulären Eingriffen (siehe Kapitel 5), keine Zunahme in der Bildung von Ornithin oder dem Verbrauch von Arginin gefunden. Darüber hinaus zeigten wir in vitro, dass die Aktivität von Arginase-1 im Vollblut unabhängig ist von der Konzentration von extrazellulärem Arginase- 1 und vor allem durch intrazelluläre Arginase-1 in den roten Blutkörperchen bestimmt wird. Zusätzlich beweisen die in vivo und in vitro Studien, dass eine Arginase-1-Plasmakonzentration über dem Schwellenwert von $2000 \mathrm{ng} / \mathrm{ml}$ nötig ist, um eine signifikante Abnahme von Plasma-Arginin zu induzieren.

Abschließend zeigt die Studie, dass eine Zunahme der Arginase-1Plasmakonzentration, so wie sie in der kardiovaskulären Chirurgie gefunden wird, nicht zu einer Abnahme der Arginin-Plasmakonzentration führt. Der Schwellenwert, ab dem Arginase-1 einen erheblichen Einfluss auf die Arginin-Plasmakonzentration hat und möglicherweise die NO-Produktion in der Gefäßwand eingeschränkt wird, wird außer bei Lebertransplantationen, selten erreicht. Arginase-1-Plasmakonzentrationen bei kardiovaskulären Eingriffen, wie in Kapitel 5 beschrieben, bleiben weit unter diesem Schwellenwert.

Reiter et al. suggerierten, dass Hämolyse und die anschließende Freisetzung des oxygenierten Hämoglobins (FHb) eine wichtige Rolle in der Pathogenese der Mikrozirkulation bei Patienten mit angeborenen oder erworbenen hämolytischen Erkrankungen spielt. ${ }^{20}$ Sie zeigten erstmals, dass das Plasma von Patienten mit Sichelzellanämie, welches $\mathrm{FHb}$ beinhaltet, in der Lage ist, NO aufzunehmen. Sie beschrieben Veränderungen des Blutflusses in den Unterarmen als Reaktion auf NO-DonorInfusionen in die arterielle Blutbahn. Diese Ergebnisse stimulierten, wenn auch indirekt, die weitere Erforschung der schädlichen Auswirkungen von FHb bei akuten, chronischen und erworbenen hämolytischen Erkrankungen. ${ }^{14,15,21-25}$ Obwohl erhöhte FHb-Werte während kardiovaskulärer Eingriffe durchaus zu erwarten sind und Hämolyse während dieser Operationen in der Literatur beschrieben wird, sind die Konsequenzen von $\mathrm{FHb}$ unter Berücksichtigung der Erkenntnisse von Reiter et al. weiterhin unbekannt. ${ }^{12}$ Die möglichen Quellen von Hämolyse während kardiovaskulärer Chirurgie, sowie die möglichen Auswirkungen und Therapien werden in dieser Dissertation in Form einer Literaturstudie beschrieben (Kapitel 4).

Es gibt drei Faktoren, die Hämolyse während kardiovaskulärer Operationen verursachen können: i) die EKZ ${ }^{12,26}$, ii) das Zell-Bewahrungs-System, mit dem rote Blutkörperchen aus dem Operationsgebiet gesammelt und an den Patienten zurückgegeben werden können ${ }^{27}$ und iii) die Verwendung von (Massen-) Bluttransfu- 
sionen. $^{28,29}$ Der Anstieg von FHb im Plasma kann durch das Abfangen von NO die Mikrozirkulation stören, was wiederum zu einer Hypoperfusion und schlussendlich zu ischämischen Schäden an den Organen führen kann. Die Reaktion zwischen NO und $\mathrm{FHb}$ ist schnell und irreversibel. Durch die Bindung eines Elektrons und des Sauerstoff-Moleküls von $\mathrm{FHb}\left(\mathrm{HbFe}^{2+}-\mathrm{O}_{2}\right)$ an $\mathrm{NO}$, entsteht das inaktive Methämoglobin $\left(\mathrm{HbFe}^{3+}\right)$ und als Nebenprodukt Nitrat $\left(\mathrm{NO}_{3}{ }^{-}\right) .{ }^{13} \mathrm{Da} \mathrm{NO}$ durch $\mathrm{FHb}$ in der Blutbahn abgefangen werden kann, somit die Mikrozirkulation beeinflusst wird und Organschäden entstehen, betrachten wir FHb nicht nur als einen harmlosen Nebeneffekt während kardiovaskulärer Operationen mit EKZ, mit oder ohne ZellBewahrungs-System und (Massen-)Bluttransfusion. In unserer Literaturstudie suggerieren wir, dass Studien notwendig sind, in denen mit Haptoglobin-Infusion oder Inhalation von NO das $\mathrm{FHb}$ unschädlich gemacht oder mit Nitrit-Infusion die NO Verfügbarkeit erhöht wird. Nur so kann ein kausaler Zusammenhang zwischen Plasma-FHb, NO-Verfügbarkeit und Organschäden während kardiovaskulärer Operationen verstanden werden.

Wie bereits oben beschrieben, ist die Hämolyse eine potenzielle Gefahr, welche die Verfügbarkeit von NO reduzieren und somit zu einer Mikrozirkulationsstörung führen kann. Die Relevanz der Hämolyse bei der Mikrozirkulation in der kardiovaskulären Chirurgie ist bisher unbekannt. Das Ziel der in Kapitel 5 beschriebenen Studie war zunächst, den Grad der Hämolyse und die Menge von freigekommenen Arginase-1 und $\mathrm{FHb}$ bei Patienten mit kardiovaskulären Operationen unter Einsatz einer EKZ einschließlich Zell-Bewahrungs-System und Bluttransfusion zu quantifizieren. Im Anschluss daran wurde der Blutfluss in den Unterarmen der Patienten als Reaktion auf eine NO-Donor-Infusion, sowohl bei hohen, als auch bei niedrigen FHbPlasmakonzentrationen gemessen. Außerdem wurde die Wirkung von Arginase-1 im Plasma auf die Plasmakonzentrationen von Arginin und Ornithin untersucht.

Hämolyse trat auf und wurde während kardiovaskulärer Operationen mittels einer erhöhten FHb- und Arginase-1-Plasmakonzentration gemessen, wobei beide Parameter signifikant miteinander korrelierten (Spearman $r=0,83, P=0,005$ ). Da eine erhöhte $\mathrm{FHb}$-Plasmakonzentration die durch NO verursachte Gefäßerweiterung einschränken könnte, wurde der NO-abhängige Unterarmblutfluss bei Patienten mit einer TAA- oder TAAA-Operation gemessen. Darüber hinaus wurde als positive Kontrolle für die Funktionstüchtigkeit der Gefäßwand, die NO-unabhängige Gefäßerweiterung gemessen. Messungen des Blutflusses am Unterarm wurden als Modell angewandt, um die Auswirkungen intraarteriell verabreichter NO-Donor (Nitroprussidnatrium in zunehmender Dosierung) bei sowohl hohen als auch niedrigen FHbKonzentrationen zu untersuchen. Als wesentliches Ergebnis stellte sich heraus, dass die Durchblutung des Unterarms negativ mit den FHb-Plasmawerten korrelierte, was darauf hinweist, dass NO bei hoher Konzentration von zirkulierendem $\mathrm{FHb}$ abgefangen wurde. Dies zeigt, wenn auch indirekt, dass die Konzentration von zirku- 
lierendem FHb während kardiovaskulärer Chirurgie die Organperfusion einschränkt und somit unter Umständen Organschäden verursachen kann. Trotz der Zunahme der Arginase-1-Plasmakonzentration wurde keine Veränderung im Plasma Arginin / Ornithin-Verhältnis, welches als Surrogat-Marker für Arginase-1-Aktivität verwendet wurde, festgestellt. Dies deutet darauf hin, dass die Freisetzung von Arginase-1 während kardiovaskulärer Eingriffe die Verfügbarkeit von Arginin, das Substrat für die NO-Synthese, nicht einschränkt. Darüber hinaus zeigte die Korrelationsanalyse zwischen der Freisetzung von Arginase-1 im Plasma und der Abnahme der PlasmaArginin-Konzentration keinen Zusammenhang zwischen beiden Parametern (Spearman $r=0,55, P=0,105)$. Diese Ergebnisse bestätigen die Studie in Kapitel 3, wobei eine erhöhte Arginase-1-Aktivität im Plasma nicht erwartet wurde.

Unsere folgende Hypothese war, dass intravasal freigesetztes $\mathrm{FHb}$ die intestinale Mikrozirkulation beeinflusst und infolgedessen zu Darmschäden führen kann. Gastrointestinale Komplikationen werden nach kardiovaskulären Operationen gefürchtet, da sie mit einer hohen Morbidität und Mortalitätsrate einhergehen., 3, 30, 31 Ziel der Studie in Kapitel 6 war es, die Darmdurchblutung und Darmschäden in einem Tiermodell mit erhöhter Konzentration von zirkulierendem FHb im Plasma zu bewerten. Zu diesem Zweck haben wir ein Tiermodell entwickelt, in dem erhöhte $\mathrm{FHb}$-Plasmakonzentrationen hervorgerufen wurden, die mit denen von Patienten vergleichbar waren, die sich kardiovaskulären Operationen unterziehen. Mit Hilfe von fluoreszierenden Mikrobeads wurde anschließend der Einfluss von zirkulierendem FHb auf die Mikrozirkulation des Darms untersucht. Darüber hinaus wurden biochemische und histologische Parameter, die Darmschäden signalisieren, ausgewertet.

Drei Gruppen wurden in die Studie einbezogen. Um intravaskuläre Hämolyse und eine Erhöhung der Konzentration von zirkulierendem $\mathrm{FHb}$ zu erreichen, wurde bei der ersten Gruppe unseres Ratten-Versuchsmodells steriles pyrogenfreies Wasser injiziert, so wie es in früheren Studien mit Hunde-Versuchsmodellen beschrieben wurde. Bei der zweiten Gruppe wurden FHb-Infusionen und bei der Kontrollgruppe Infusionen mit Kochsalzlösung verwendet. Sowohl die Wasser- als auch die FHbInfusionen führten im Vergleich zu der Infusion bei der Kontrollgruppe zu einer verminderten Mikrozirkulation. Außerdem kam es zu einer signifikanten Korrelation zwischen den Werten des zirkulierenden FHb und dem Ileum-lipid-binding-protein (ILBP) - Werten im Plasma, ein Eiweiß, das nur in reifen intestinalen Epithelzellen vorkommt (Spearman $r=0,70, P=0,0017$ ). Das Eiweiß ILBP gehört zu der Familie der FABP und ist ein schneller und sensibler Marker, der das Messen von Darmschäden in Plasma und Urin ermöglicht und epitheliale Schäden auf der Ebene der Zotten, immunhistochemisch sichtbar macht. ${ }^{32}$ Epitheliale Zellschäden der Zotten des Darmes wurden nach der Infusion mit Wasser und FHb gemessen und durch histologische Analysen des Darms bestätigt. 
Diese Studie weist erstmalig die schädliche Auswirkung einer erhöhten Konzentration von zirkulierendem FHb auf die Mikrozirkulation und Gewebeintegrität des Darmes nach. Wir suggerieren daher, dass intravasale Hämolyse und somit erhöhte Mengen von zirkulierendem FHb während kardiovaskulärer Eingriffe zu Organschäden führen können. In der Literatur über kardiovaskuläre Chirurgie werden Darmschäden, die anhand von FABP-Eiweißen wie zum Beispiel ILPB gemessen werden können, beschrieben." ${ }^{73}$ In Kapitel 2 wird außerdem beschrieben, dass Darmepithelzellschäden, die während kardiovaskulärer Operationen entstehen, mit systemischen inflammatorischen Reaktionen einhergehen. ${ }^{34}$ An dieser Stelle ist es verlockend zu spekulieren, dass $\mathrm{FHb}$ in dieser Patientenpopulation bei der Entstehung von Darmschäden eine Rolle spielt. Wie bereits beschrieben, ist bekannt, dass akute gastrointestinale Komplikationen nach kardiovaskulären Operationen mit einem hohen Risiko auf einen komplizierten postoperativen Verlauf mit hoher Mortalitätsrate einhergehen.

Akutes Nierenversagen (acute kidney injury, AKI) ist die häufigste und gefürchtetste Komplikation nach kardiovaskulären Eingriffen, da es mit einer hohen Morbidität und Mortalitätsrate assoziiert wird. ${ }^{35,36}$ Aufgrund dieser Assoziation stellten wir die Hypothese auf, dass intravasal freigegebenes FHb die Nierendurchblutung vermindert und AKI verursachen kann. Das Ziel der Studie in Kapitel 7 war es in einem Tiermodell mit erhöhten Werten von zirkulierendem $\mathrm{FHb}$, die Nierendurchblutung und renale tubuläre Epithelzellschäden zu bewerten. Zu diesem Zweck haben wir das gleiche Ratten-Modell, das in Kapitel 6 beschrieben wurde, verwendet, da dieses $\mathrm{FHb}$-Werte erreichte, die vergleichbar waren mit denen von Patienten mit kardiovaskulären Eingriffen. In Kapitel 7 werden die möglichen Auswirkungen von zirkulierendem $\mathrm{FHb}$ sowohl mit als auch ohne Inhalation von NO-Gas als FHbinaktivierende Therapie auf die renale Mikrozirkulation unter Verwendung von fluoreszierenden Mikrobeads bestimmt. Darüber hinaus wurde der Marker für Schäden an der tubulären Epithelzelle, N-Acetyl Glucosaminidase (NAG), im Urin bestimmt und histologische Parameter von AKI untersucht. Die durch FHbInfusionen verursachten Veränderungen im Sauerstoffgehalt der Nieren wurden mit "Blood Oxygen Level Dependent Magnetic Resonance Imaging" (BOLD-MRI) untersucht.

Im Gegensatz zu der Kontrollgruppe, die lediglich eine Infusion mit Kochsalzlösung bekam, trat 15 Minuten nach Beginn der FHb-Infusion eine signifikante Abnahme in der Mikrozirkulation der Nieren ein. Da nach 60 Minuten noch immer eine Verringerung in der Mikrozirkulation der Nieren sichtbar war, lässt dies darauf schließen, dass eine erhöhte Konzentration von zirkulierendem $\mathrm{FHb}$ grundsätzlich eine Abnahme der Mikrozirkulation in den Nieren zur Folge hat. Zusätzlich wies NAG im Urin und die histologische Untersuchung der Nieren auf die Entwicklung von AKI auf der Ebene der proximalen Epithelzellen der Nieren hin. Außerdem war die Ent- 
wicklung von AKI, gemessen anhand der NAG-Konzentration im Urin, mit den zirkulierenden FHb-Werten assoziiert (Spearman $r=0,78, P=0,0026$ ). Bemerkenswert ist, dass sich durch das Inhalieren von FHb-inaktivierendem NO-Gas die Mikrozirkulation der Nieren verbesserte und die Entwicklung von AKI abnahm. Während der FHb-Infusionen wiesen BOLD-MRI-Daten eine Abnahme des Sauerstoffgehaltes in den Nieren auf. Diese Daten offenbaren einen neuen Mechanismus für die Entstehung von AKI, welcher abhängig ist von einer erhöhten Konzentration von zirkulierendem $\mathrm{FHb}$, wie sie bei kardiovaskulären Eingriffen vorkommt und bietet außerdem eine therapeutische Möglichkeit FHb unschädlich zu machen.

Auf Basis dieser Dissertation lässt sich schlussfolgernd sagen, dass erhöhte Werte zirkulierenden FHbs nicht nur ein gesundheitliches Risiko bei chronischen Krankheiten wie Sichelzellanämie und Malaria darstellen. Auch bei Patienten mit kardiovaskulären Eingriffen, mit EKZ, Zellbewahrungs-Systemen und Bluttransfusionen muss durchaus auf erhöhte Werte FHb-Werte geachtet werden. FHb kann Organschäden während und nach kardiovaskulären Eingriffen verursachen, wobei die Inhalation von NO-Gas eine Möglichkeit bietet, das zirkulierende FHb unschädlich zu machen. Daher müssen die Werte von zirkulierendem $\mathrm{FHb}$ bei Patienten, die sich dieser Operationen unterziehen müssen, gut überwacht werden. In der Zukunft sind weitere Studien bei Patienten mit kardiovaskulären Eingriffen nötig, um Methoden zu entwickeln, die helfen, Hämolyse bei diesen Patienten zu reduzieren und dem schädlichen Einfluss von FHb entgegenzuwirken. 


\section{Referenties / Literaturverzeichnis}

1. Rectenwald JE, Huber TS, Martin TD, et al. Functional outcome after thoracoabdominal aortic aneurysm repair. J Vasc Surg 2002; 35:640-7.

2. Gloviczki P. Surgical repair of thoracoabdominal aneurysms: patient selection, techniques and results. Cardiovasc Surg 2002; 10:434-41.

3. Achouh PE, Madsen K, Miller CC, 3rd, et al. Gastrointestinal complications after descending thoracic and thoracoabdominal aortic repairs: a 14-year experience. J Vasc Surg 2006; 44:442-6.

4. Fink MP. Gastrointestinal mucosal injury in experimental models of shock, trauma, and sepsis. Crit Care Med 1991; 19:627-41.

5. Moore FA. The role of the gastrointestinal tract in postinjury multiple organ failure. Am J Surg 1999; 178:449-53.

6. MacArthur RG, Carter SA, Coselli JS, LeMaire SA. Organ protection during thoracoabdominal aortic surgery: rationale for a multimodality approach. Semin Cardiothorac Vasc Anesth 2005; 9:143-9.

7. Welborn MB, Oldenburg HS, Hess PJ, et al. The relationship between visceral ischemia, proinflammatory cytokines, and organ injury in patients undergoing thoracoabdominal aortic aneurysm repair. Crit Care Med 2000; 28:3191-7.

8. Jacobs MJ, de Mol BA, Legemate DA, et al. Retrograde aortic and selective organ perfusion during thoracoabdominal aortic aneurysm repair. Eur J Vasc Endovasc Surg 1997; 14:360-6.

9. Jacobs MJ, Mommertz G, Koeppel TA, et al. Surgical repair of thoracoabdominal aortic aneurysms. J Cardiovasc Surg (Torino) 2007; 48:49-58.

10. Lieberman JM, Sacchettini J, Marks C, Marks WH. Human intestinal fatty acid binding protein: report of an assay with studies in normal volunteers and intestinal ischemia. Surgery 1997; 121:335-42.

11. Pelsers MM, Hermens WT, Glatz JF. Fatty acid-binding proteins as plasma markers of tissue injury. Clin Chim Acta 2005; 352:15-35.

12. Vercaemst L. Hemolysis in cardiac surgery patients undergoing cardiopulmonary bypass: a review in search of a treatment algorithm. J Extra Corpor Technol 2008; 40:257-67.

13. Rother RP, Bell L, Hillmen P, Gladwin MT. The clinical sequelae of intravascular hemolysis and extracellular plasma hemoglobin: a novel mechanism of human disease. Jama 2005; 293:1653-62.

14. Minneci PC, Deans KJ, Zhi H, et al. Hemolysis-associated endothelial dysfunction mediated by accelerated NO inactivation by decompartmentalized oxyhemoglobin. J Clin Invest 2005; 115:3409-3417.

15. Villagra J, Shiva S, Hunter LA, et al. Platelet activation in patients with sickle disease, hemolysisassociated pulmonary hypertension, and nitric oxide scavenging by cell-free hemoglobin. Blood 2007; 110:2166-72.

16. Ochoa JB, Bernard AC, O’Brien WE, et al. Arginase I expression and activity in human mononuclear cells after injury. Ann Surg 2001; 233:393-9.

17. Prins HA, Houdijk AP, Nijveldt RJ, et al. Arginase release from red blood cells: possible link in transfusion induced immune suppression? Shock 2001; 16:113-5.

18. Meijer AJ, Lamers WH, Chamuleau RA. Nitrogen metabolism and ornithine cycle function. Physiol Rev 1990; 70:701-48.

19. Roth E, Steininger R, Winkler S, et al. L-arginine deficiency after liver transplantation as an effect of arginase efflux from the graft. Transplantation 1994; 57:665-9.

20. Reiter CD, Wang $X$, Tanus-Santos JE, et al. Cell-free hemoglobin limits nitric oxide bioavailability in sickle-cell disease. Nat Med 2002; 8:1383-9.

21. Morris CR, Kato GJ, Poljakovic M, et al. Dysregulated arginine metabolism, hemolysis-associated pulmonary hypertension, and mortality in sickle cell disease. Jama 2005; 294:81-90.

22. Kato GJ, Hsieh M, Machado R, et al. Cerebrovascular disease associated with sickle cell pulmonary hypertension. Am J Hematol 2006; 81:503-10.

23. Ataga $\mathrm{KI}$, Moore CG, Hillery CA, et al. Coagulation activation and inflammation in sickle cell diseaseassociated pulmonary hypertension. Haematologica 2008; 93:20-6. 
24. Lewis DA, Nyska A, Potti A, et al. Hemostatic activation in a chemically induced rat model of severe hemolysis and thrombosis. Thromb Res 2006; 118:747-53.

25. Yeo TW, Lampah DA, Gitawati R, et al. Impaired nitric oxide bioavailability and L-arginine reversible endothelial dysfunction in adults with falciparum malaria. J Exp Med 2007; 204:2693-704.

26. Fransen EJ, Ganushchak YM, Vijay V, et al. Evaluation of a new condensed extra-corporeal circuit for cardiac surgery: a prospective randomized clinical pilot study. Perfusion 2005; 20:91-9.

27. Serrick CJ, Scholz M, Melo A, et al. Quality of red blood cells using autotransfusion devices: a comparative analysis. J Extra Corpor Technol 2003; 35:28-34.

28. Karkouti K, Wijeysundera DN, Yau TM, et al. The independent association of massive blood loss with mortality in cardiac surgery. Transfusion 2004; 44:1453-62.

29. Koch CG, Li L, Sessler DI, et al. Duration of red-cell storage and complications after cardiac surgery. N Engl J Med 2008; 358:1229-39.

30. Halm MA. Acute gastrointestinal complications after cardiac surgery. Am J Crit Care 1996; 5:109-18; quiz 119-20.

31. Filsoufi F, Rahmanian PB, Castillo JG, et al. Predictors and outcome of gastrointestinal complications in patients undergoing cardiac surgery. Ann Surg 2007; 246:323-9.

32. Derikx JP, Matthijsen RA, de Bruine AP, et al. Rapid reversal of human intestinal ischemia-reperfusion induced damage by shedding of injured enterocytes and reepithelialisation. PLoS ONE 2008; 3:e3428.

33. Morariu AM, Loef BG, Aarts LP, et al. Dexamethasone: benefit and prejudice for patients undergoing on-pump coronary artery bypass grafting: a study on myocardial, pulmonary, renal, intestinal, and hepatic injury. Chest 2005; 128:2677-87.

34. Hanssen SJ, Derikx JP, Vermeulen Windsant IC, et al. Visceral injury and systemic inflammation in patients undergoing extracorporeal circulation during aortic surgery. Ann Surg 2008; 248:117-25.

35. Chertow GM, Levy EM, Hammermeister KE, et al. Independent association between acute renal failure and mortality following cardiac surgery. Am J Med 1998; 104:343-8.

36. Schepens MA, Heijmen RH, Ranschaert W, et al. Thoracoabdominal aortic aneurysm repair: results of conventional open surgery. Eur J Vasc Endovasc Surg 2009; 37:640-5. 
<smiles>C=C=C</smiles> 


\section{Dankwoord / Danksagung}




\section{Dankwoord / Danksagung}

In dit laatste deel van het proefschrift is er plaats voor een persoonlijke noot, waarin ik iedereen die een bijdrage aan dit boekje heeft geleverd wil bedanken.

Mijn promotores Professor Michael Jacobs en Professor Wim Buurman wil ik van harte danken voor de mij geboden kans om onderzoek te verrichten binnen de afdeling Algemene Heelkunde. Professor Jacobs, vanaf de eerste dag bent $u$ de link geweest tussen de kliniek en het basaal wetenschappelijk deel van dit promotieonderzoek. U hebt de voortgang nauwlettend gevolgd en mij immer gesteund. Doordat $u$ het onderzoek tevens alle ruimte in Aken gegeven hebt, heeft u er persoonlijk voor gezorgd dat het een multi-center, internationaal tintje gekregen heeft, met als gevolg een mooie samenwerking met de Duitse collega's. Bedankt dat de deur altijd op een kier stond. Professor Buurman, beste Wim, je bent onmisbaar geweest om de link tussen de kliniek en het onderzoek te vertalen. Je enthousiasme werkte aanstekelijk en je gaf me de ruimte eigen ideeën te ontwikkelen en uit te voeren, waarvoor dank. Je spoorde mij aan altijd net dat beetje extra te geven. Je positieve kritische blik en analytisch vermogen zijn zeer belangrijk geweest voor de totstandkoming van dit boekje. Dank voor de leerzame periode op het lab en de vele uurtjes discussiëren en filosoferen, ook in Eijsden.

Professor Jos Maessen, dank dat u voorzitter van de beoordelingscommissie wilde zijn. De overige leden van de commissie wil ik danken voor hun beoordeling, Professor J. Waltenberger, Professor C. Stehouwer en Professor M. Daemen, sowie Professor R. Autschbach, vielen Dank für die Beurteilung meiner Dissertation.

Zonder de onbaatzuchtige medewerking van patiënten was de totstandkoming van dit promotieboekje nooit mogelijk geweest; ik ben hen dan ook veel dank verschuldigd.

Iris Vermeulen Windsant, van WESP-studente naar collega op het lab. Je werd een volwaardig lid van het TAAA-onderzoeksteam en zodoende hebben we veel met elkaar samengewerkt. Dank je voor de vele gezellige tripjes naar Aken, (altijd lachen na 10 uur samplen) en de gezamenlijke inspanningen om als (co-)auteur aan een aantal mooie artikelen te werken.

De collega's uit het Maastrichtse, zowel uit het ziekenhuis als van de universiteit wil ik graag bedanken voor hun bijdrage aan de verschillende studies. Professor Geert Willem Schurink, de mogelijkheid om tijdens TAA(A)-operaties te kunnen samplen was onmisbaar. Professor Kees Dejong en Dr. Martijn Poeze, bedankt voor jullie inzicht en samenwerking. Dr. John Heijmans, je was altijd zeer geïnteresseerd in de 
studies en bent daarnaast ook zeer behulpzaam geweest met raad en daad. Dr. Boy Houben, dank voor je hulp bij het implementeren van de FBF-metingen bij de TAAA patiënten. Dr. Otto Bekers, voor het mede op touw zetten van de vrij hemoglobine bepaling in ons lab. Professor Frits Prinzen, voor het leveren en de techniek van de microsferen. Dr. Eduardo Villamor, voor het implementeren van het NO ventilatie systeem. Dr. Carine Peutz-Kootstra, voor de hulp bij het beoordelen en scoren van de niercoupes. Dr. Walter Backes, Dr. Marlies Oostendorp en Jos Slenter, voor de BOLD-MRI studie. Dr. Jan Serroyen, voor de statistische ondersteuning. Daarnaast zijn er enkele buitenlandse collega's betrokken geweest bij dit promotieonderzoek; Professor Jacques Pirenne, UZ Leuven, voor de (vaak nachtelijke) mogelijkheid bij levertransplantatie patiënten onderzoek te doen. Dem ganzen Team der Gefäßchirurgie UK Aachen, insbesondere Professor Thomas Koeppel (aktuell UK München) und Dr. Johannes Kalder, vielen Dank für die nette und früchtetragende Zusammenarbeit.

Alle collega's van het onderzoekslab Algemene Heelkunde en mijn kamergenoten in het bijzonder (kamer 5.344 en later 5.340, met airco!), wil ik danken voor de leuke en leerzame tijd tijdens mijn promotieonderzoek; Maaike Berbée (roomie en tijdelijk lid van het TAAA-team), Annemarie van Bijnen (roomie), Johanne Bloemen, Bas Boonen (roomie), Maartje van den Broek, Simon Dello (roomie), Mick Deutz, Joep Derikx (voor je hulp op het lab en vooral met het TAAA stuk), Hans van Eijk, Irma Geenen, Joep Grootjans, Jacco de Haan (voor je medewerking aan de ratjes), Mo'hammed Hadfoune (voor van alles en nog wat in en rond het lab), Femke Hellenthal, Caroline Hodin (voor je hulp bij de IHC), Nicole Hoebers, Kirsten Huntjens, Dennis Japink, Trudy Jeun'homme (voor de eerste stapjes op het lab), Dian Kuijpers (roomie, je extraverte karakter zorgde voor veel sfeer op de kamer), Kaatje Lenaerts (roomie, Belgisch, rustig en altijd geïnteresseerd), Tim Lubbers (na de VLAG-dagen ook vaste kamergenoot op de chirurgendagen, dank voor je gezelligheid en je medewerking aan een aantal studies), Yvette Luiking, Robert Matthijsen, Jeroen Nijhuis (roomie van het eerste uur), Marcel van de Poll (dank voor je intensieve samenwerking, met fraaie publicaties als gevolg, je stelde je op als mentor op de werkvloer, waar ik dankbaar gebruik van heb gemaakt), Sander Rensen (roomie), Sedigheh Roostra (roomie), Martien Schellart, Marc Schreinemacher (roomie), Yanti Slaats (roomie, dank voor je gezelligheid), Maarten Snoeijs (voor je kritische blik en fijne samenwerking), Geertje Thuijls (roomie), Froukje Verdam, Ruben Visschers, Eva de Vries, Kim van Wijck, Nina Wijnands (roomie van het laatste uur) en Tim Wolfs (mastermind achter de meeste 'practical jokes' op het lab en de perfecte dj op mijn huwelijksfeest en mogelijk ook promotiefeest). Voor alle duidelijkheid: al deze 'roomies' in een verloop van 4 jaar tijd, verdeeld over 2 verschillende kamers... 
Medewerkers en studenten die ik wil danken voor alle bewezen hand en span diensten: Kim Augustin, Willemieke Balkema, Juliane van Driel, Sandra Hex, Paula Keschenau, Dennis Kusters, Claire Meertens, Heike Meier, en Tom Seijkens.

Professor Martin Westhofen, liebe Kolleginnen und Kollegen der HNO-Klinik Aachen, vielen Dank das Sie mir den Einstieg in das schönste Fachgebiet der Medizin so einfach und angenehm gemacht haben und auch dazu beitragen, dass ich mich täglich in meiner Entscheidung bestätigt fühle.

Eric, tuup, we kennen elkaar al vanaf dat je geboren bent. Ik zou nóg een boekje kunnen schrijven over voetbal, gamen, vakanties, school, eerste vriendinnetjes, feesten en alles wat we samen meegemaakt hebben. Ik ben er trots op dat je niet alleen naast me staat als beste vriend, maar ook de rol van 'Paranimf' op je hebt genomen. Liebe Julia, zwar kenne ich Dich 'erst' seit 2003, aber Du hast seitdem mit Deiner offenen Art, Deinem Humor, Hasi und Deiner 'Aandacht!' viel Eindruck auf mich gemacht. Danke für Deine Unterstützung, vor allem in der letzten Phase. Ich bin froh, dass Du als meine 'Paranimfe' dabei bist und freue mich auf noch viele gemeinsame Parties und Urlaube.

Omdat er naast promoveren ook een leven is, wil ik mijn familie en vrienden bedanken voor de oprecht getoonde interesse in mijn onderzoek en het verschaffen van de broodnodige ontspanning daarbuiten. Martijn, Björn, Bart \& Carla, Paolo \& Berry, Tjeu, bedankt voor vele gezellige uren en jullie vriendschap - ik hoop dat deze nog lang mag voortduren. Ein riesen Dankeschön für das aufrechte Interesse an meiner wissenschaftlichen Arbeit und Dissertation gilt auch meiner Familie und meinen Freunden in Deutschland. Im Besonderen möchte ich Euch, Daniela \& Matthias, Julia \& Florian, Jan \& Steffie, Daniel \& Sonja, Berenike \& Gregor, Sabina \& Florian, danken: Ihr habt immer dafür gesorgt, dass ich mich neben meiner Arbeit richtig entspannen konnte. Es ist toll Euch an meiner Seite zu haben und ich bin mir sicher dass unsere Freundschaft sich in der Zukunft nur noch verstärkt.

Mijn ouders, Wim \& Carla, pap en mam jullie zijn altijd van dichtbij op de hoogte geweest van wat er speelde, eindelijk is het dan zover en kunnen we een mooi hoofdstuk afsluiten. Hartelijk dank voor jullie onvoorwaardelijke steun en liefde, en jullie onvergetelijke bijdrage aan de totstandkoming van dit boekje, ik hou van jullie. Oma, Kim, Anke \& Maarten, ook van harte dank voor jullie interesse en gezelligheid, ik kan me geen betere familie wensen.

Meine Schwiegereltern, Sigrid \& Klaus, Ihr habt Euer Haus für mich zu einem weiteren Zuhause gemacht. Viele Stunden habe ich am Schreibtisch bei Euch gesessen und jetzt ist das Endergebnis endlich da. Herzlichen dank für Eure Liebe, Euer Interesse und Eure Unterstützung in jeglicher Hinsicht. Carsten \& Bettina (und mein 
Patenkind Anna Lisa, die nächste Ärztin in der Familie), Ihr habt es für mich einfach gemacht mich neben meiner Arbeit auch den angenehmen Dingen des Lebens zu widmen. Es ist schön, dass es Euch gibt.

Lieve Carolin, eindelijk is het dan zover, het boekje is af. Je hebt er altijd vertrouwen in gehouden dat ik ook deze uitdaging tot een goed einde zou brengen. Je geeft me zoveel steun en liefde en maakt me iedere dag aan het lachen. Inmiddels promoveer je zelf en ik hoop dat ik voor jou hetzelfde mag betekenen. Dank je wel! Je doorzettingsvermogen, vooral tijdens de moeilijke periode dat je ziek was, en je niet aflatende zorgzaamheid maken je uniek, maar bovenal ben je de liefde van mijn leven. Ik ben zo blij dat ik je tegenkwam op die mooie zomeravond en ik verheug me ontzettend op de rest van ons leven samen.

"Even if you cannot hear my voice

I'll be right beside you dear"

Ik hou van je. 
<smiles>C=C=C</smiles> 


\section{Curriculum Vitae}




\section{Curriculum Vitae}

Bas Hanssen was born in Heerlen, the Netherlands on December $9^{\text {th }}$ in 1977. After he finished high-school at the 'Katholiek Gymnasium Rolduc' in 1996 in Kerkrade, he started studying Biology at the University of Utrecht. In 1997 he was admitted to the study of Medicine at Maastricht University from which he graduated in January 2004. As a medical student he performed clinical internships in Brazil (2000) and Mexico (2001), and a student clerkship at the GROW School for Oncology \& Developmental Biology, Maastricht University Medical Center (2003, Professor Louis L.H. Peeters).

After his graduation from university, Bas worked at the Atrium Medical Center in Heerlen as emergency physician until February 2005. From March 2005 until February 2009 he conducted his PhD-research under the supervision of Professor Wim A. Buurman and Professor Michael J.H.M. Jacobs. He presented his work at several national and international conferences. From March until November 2009 he worked as a surgical resident at the Department of Surgery, Maastricht University Medical Center. In January 2010 Bas started his residency at the Department of Otorhinolaryngology, Plastic Head and Neck Surgery, University hospital Aachen, Germany (Professor dr. Martin Westhofen) where he works to this date. 
<smiles>C=C=C</smiles> 
Scientific Publications 


\section{Scientific Publications}

van de Poll MC, Hanssen SJ, Berbée M, Deutz NE, Monbaliu D, Buurman WA, Dejong $\mathrm{CH}$. Elevated plasma arginase-1 does not affect plasma arginine in patients undergoing liver resection. Clin Sci (Lond). 2008; 114:231-241. [IF: 3.9]

Hanssen SJ, Derikx JP, Vermeulen Windsant IC, Heijmans JH, Koeppel TA, Schurink GW, Buurman WA, Jacobs MJ. Visceral injury and systemic inflammation in patients undergoing extracorporeal circulation during aortic surgery. Ann Surg 2008; 248:117-125. [IF: 7.9]

Vermeulen Windsant IC, Snoeijs MG, Hanssen SJ, Altintas S, Heijmans JH, Koeppel TA, Schurink GW, Buurman WA, Jacobs MJ. Hemolysis is associated with acute kidney injury during major aortic surgery. Kidney Int. 2010; 77:913-920. [IF: 6.1]

Hanssen SJ, Lubbers T, Hodin CM, Prinzen FW, Buurman WA, Jacobs MJ. Hemolysis results in impaired intestinal microcirculation and intestinal epithelial cell injury. World J Gastroenterol. 2011; 17:213-218. [IF: 2.0]

Hanssen SJ, Vermeulen Windsant IC, Buurman WA, Jacobs MJ. Cardiovascular Surgery and Organ Damage; Time to Reconsider the Role of Hemolysis. J Thorac Cardiovasc Surg. 2011 Jul; 142:1-11. [IF: 3.0] 
<smiles>C=C=C</smiles> 
Color Figures 


\section{Chapter 1}

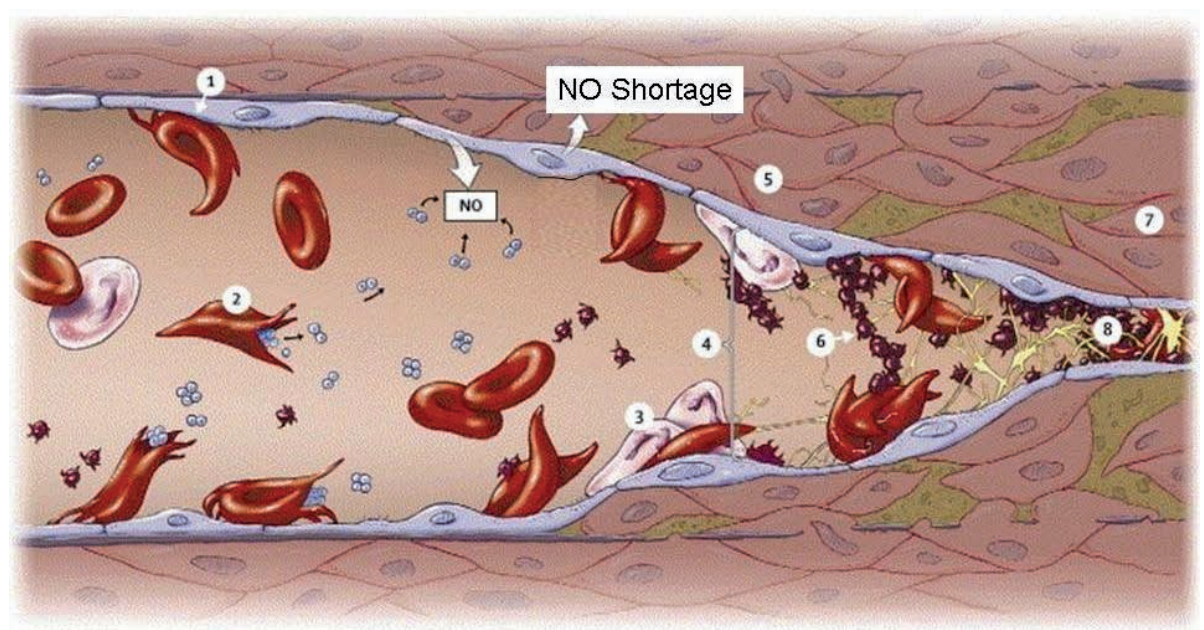

Figure 1.1 The damaged erythrocyte is pre-eminent in the development of disturbed tissue microcirculation as a result of abnormal adherence to the vascular endothelium (1) and hemolysis (2). These factors result in a proinflammatory state manifested, in part, by leucocyte adhesion (3) and platelet aggregation (6). As soon as scavenging of $\mathrm{NO}$ by $\mathrm{FHb}$ leads to increased vasomotor tone (4) luminal narrowing occurs (5) and results in disturbed tissue perfusion (8) with concomitant tissue injury (7). (Modified after Switzer et al. ${ }^{33}$ ). 


\section{Chapter 4}

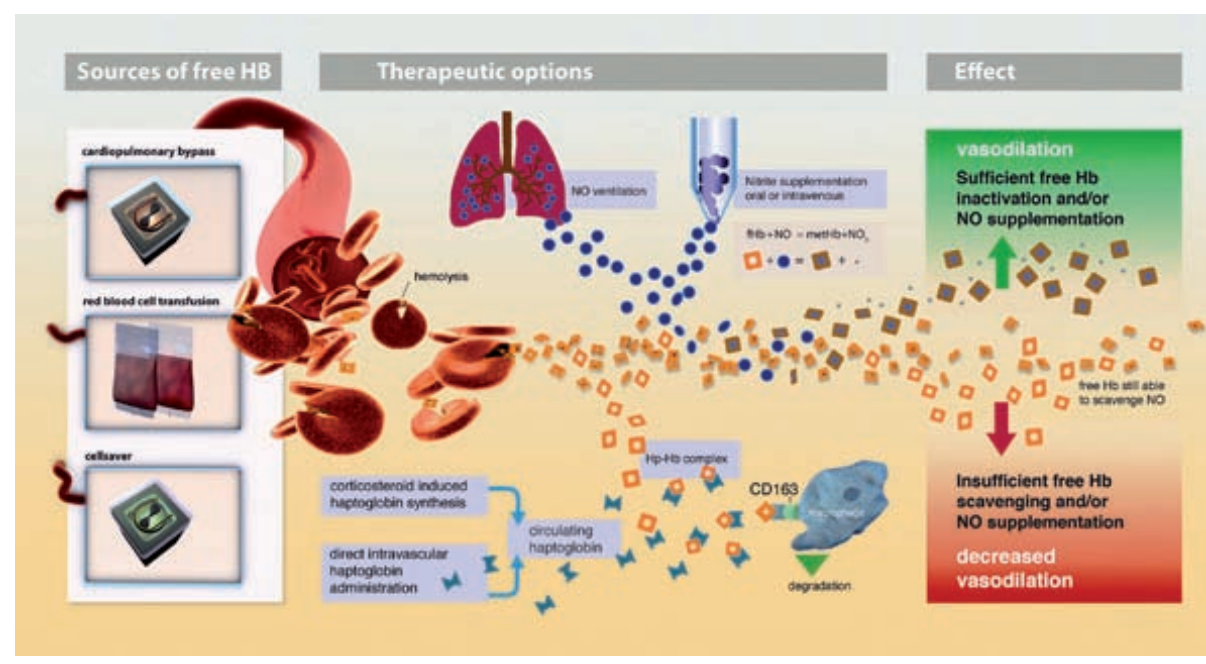

Figure 4.4. Potential sources and effects of plasma free hemoglobin during cardiovascular surgery with cardiopulmonary bypass, and therapeutic options to attenuate hemolysis-induced organ damage.

Intravascular hemolysis during cardiovascular surgery can be attributed to the cardiopulmonary bypass, transfusion of red blood cells, and cell-saver use (left). Lysis of red blood cells results in increased circulating plasma free hemoglobin ( $\mathrm{FHb}$ ) levels (orange squares). Under physiological circumstances, $\mathrm{FHb}$ is rapidly cleared by the $\mathrm{FHb}$ scavenger haptoglobin. Haptoglobin-hemoglobin complexes bind to CD-163 expressed by monocytes and macrophages, initiating endocytosis and degradation (middle, bottom). Haptoglobin is not recycled so excessive hemolysis depletes haptoglobin storages rapidly. Non-scavenged $\mathrm{FHb}$ potently binds circulating nitric oxide (NO), thereby limiting its bioavailability. This way, high $\mathrm{FHb}$ levels increase the NO-scavenging capacity of blood, causing impaired vasodilation due to vascular NOshortage. Decreased vasodilation contributes to impaired tissue perfusion and development of organ damage and organ dysfunction (right, bottom).

The adverse effects of $\mathrm{FHb}$ may be counteracted by either increasing haptoglobin levels to support $\mathrm{FHb}$ scavenging, or enhancing the NO(-donor) pool to increase NO-bioavailability. Haptoglobin can be administered intravenously or haptoglobin synthesis may be up-regulated through corticosteroid administration (center, bottom). The NO(-donor) pool could be increased by oral or intravenous nitrite administration which is oxidized to NO under low oxygen tension and/or low $\mathrm{pH}$. NO-inhalation inactivates $\mathrm{FHb}$ in the pulmonary circulation (or oxygenator in the cardiopulmonary bypass circuit) by transforming $\mathrm{FHb}$ to bioinactive methemoglobin (center, top). This way, scavenging and inactivation of FHb, and supplementation of NO prevents the adverse effects of plasma FHb during cardiovascular surgery (right, top).

$\mathrm{Hp}-\mathrm{Hb}$-complex, haptoglobin-hemoglobin complex; FHb, free hemoglobin; NO, nitric oxide; metHb, methemoglobin 


\section{Chapter 6}

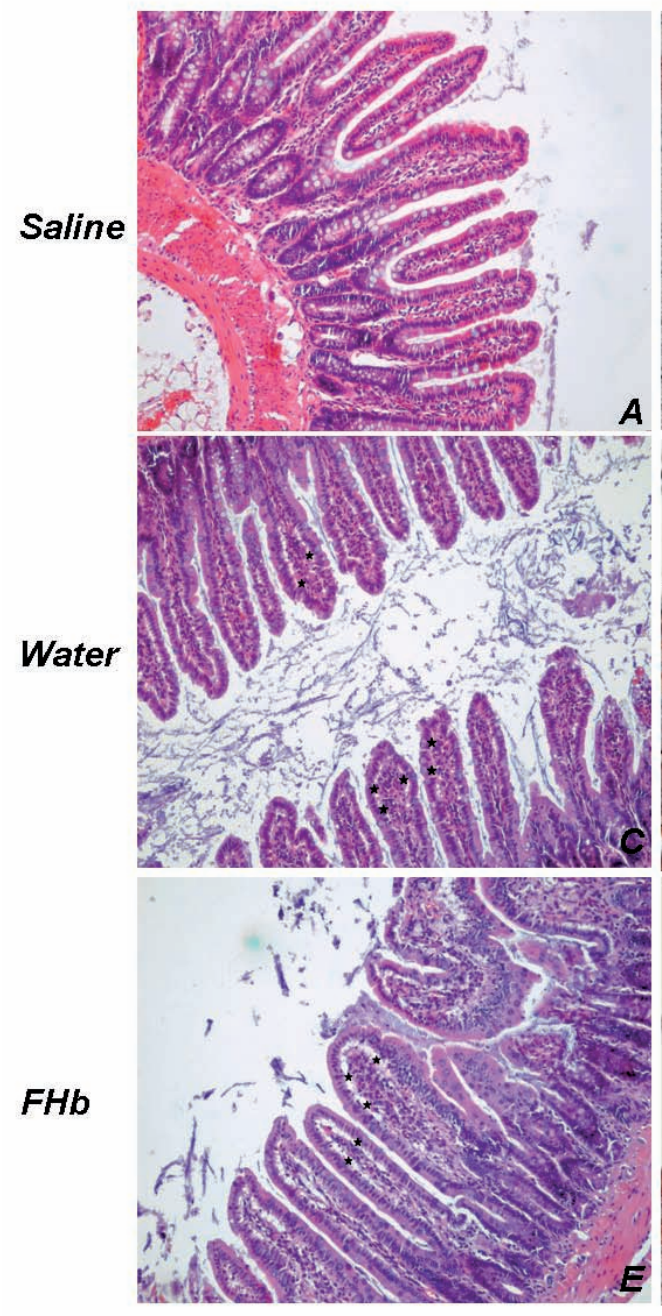

$100 x$
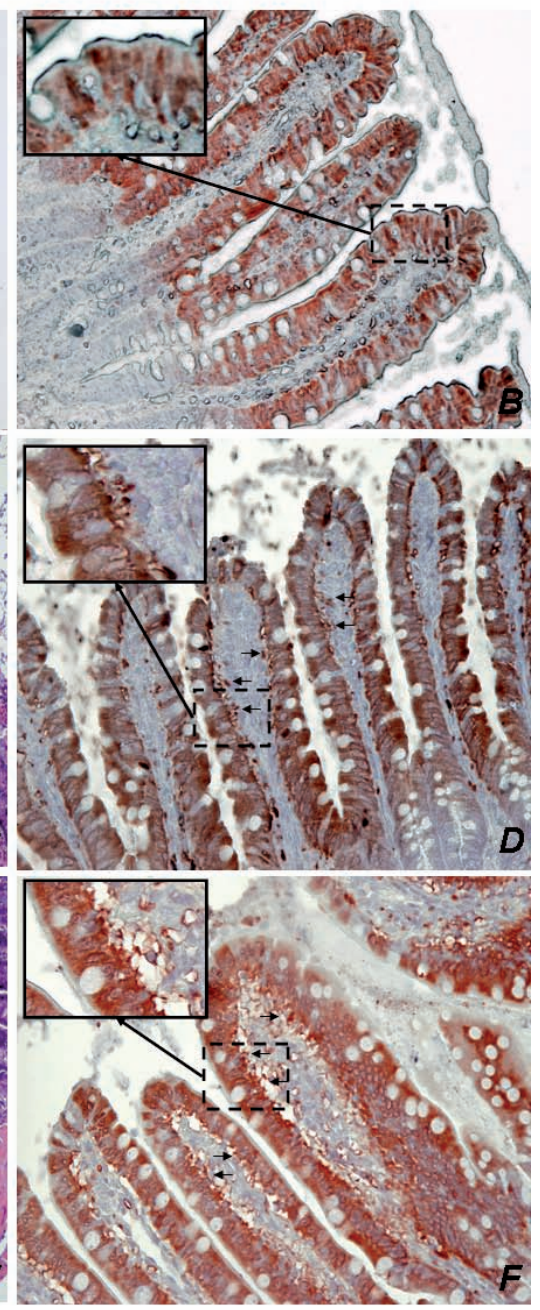

$200 x$

Figure 6.4. Histological and immunohistochemical evaluation of intestinal injury. Histological evaluation of the ileum was performed using HE staining ( $A, C$, and E). When compared to the saline group, water and $\mathrm{FHb}$ infusion led to the development of subepithelial spaces (see ${ }^{*}$ ) in the villi. In support of the findings of plasmatic release of iLBP, immunohistochemical analysis of the ileum shows cytosolic staining for iLBP in the epithelial cells of the upper part of the villi (B). Leaking of iLBP in the subepithelial spaces (see arrows), indicates intestinal epithelial cell injury after water or FHb infusion (D, F). Insets, show 400x magnification of selected areas where staining of iLBP can be seen outside the intestinal epithelial cellular membrane, indicating epithelial cellular injury (D, F). 


\section{Chapter 7}
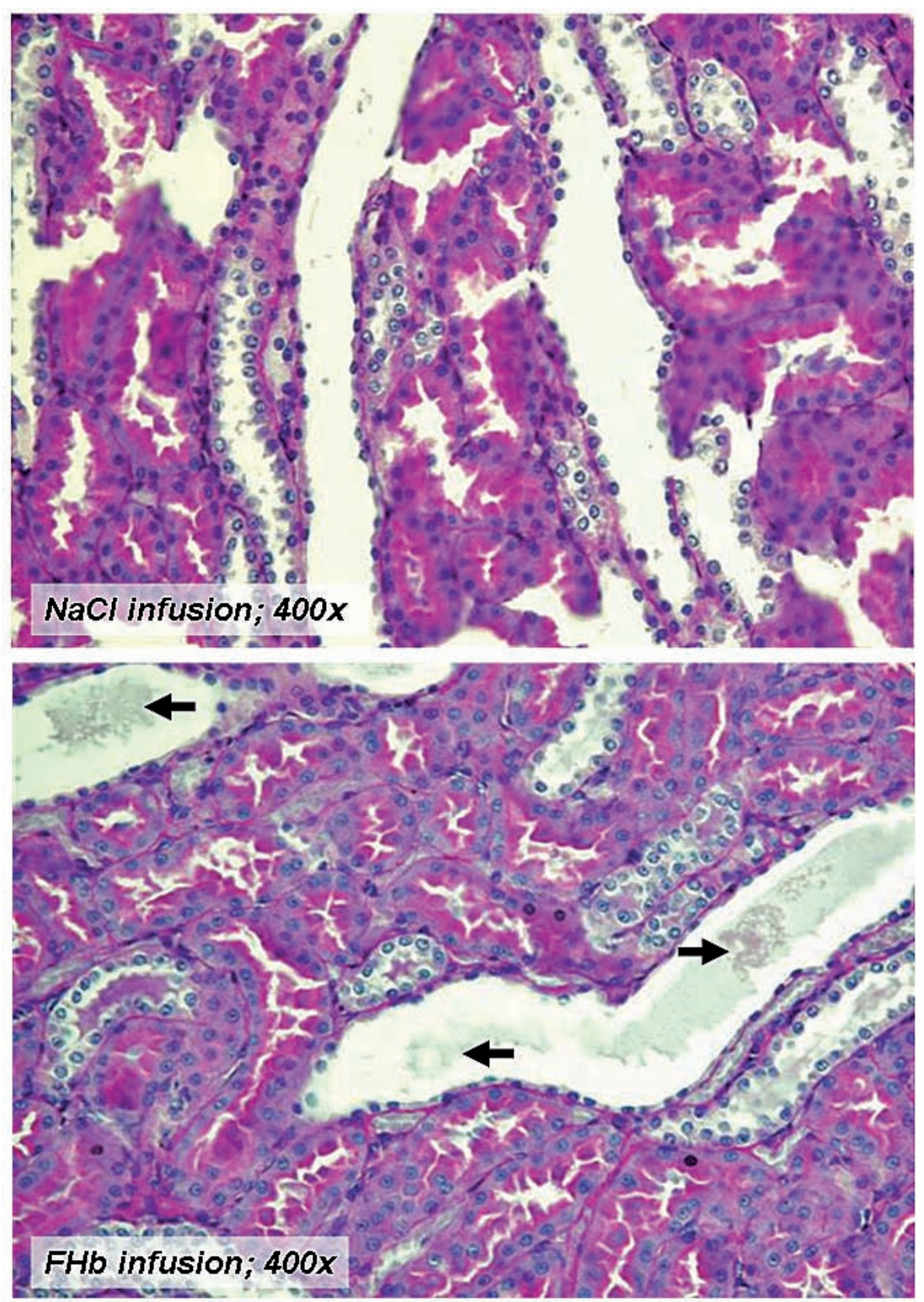

Figure 7.5. Kidney injury after elevated circulating FHb levels. Microscopic photographs to visualize kidney injury showed cast formation in renal tubules after $\mathrm{FHb}$ infusion (see arrows), but not after $\mathrm{NaCl}$ infusion. 